Tamara Machado Matos

Composição química das ceras cuticulares em espécies de Bryophyta (musgos) e Marchantiophyta (hepáticas)
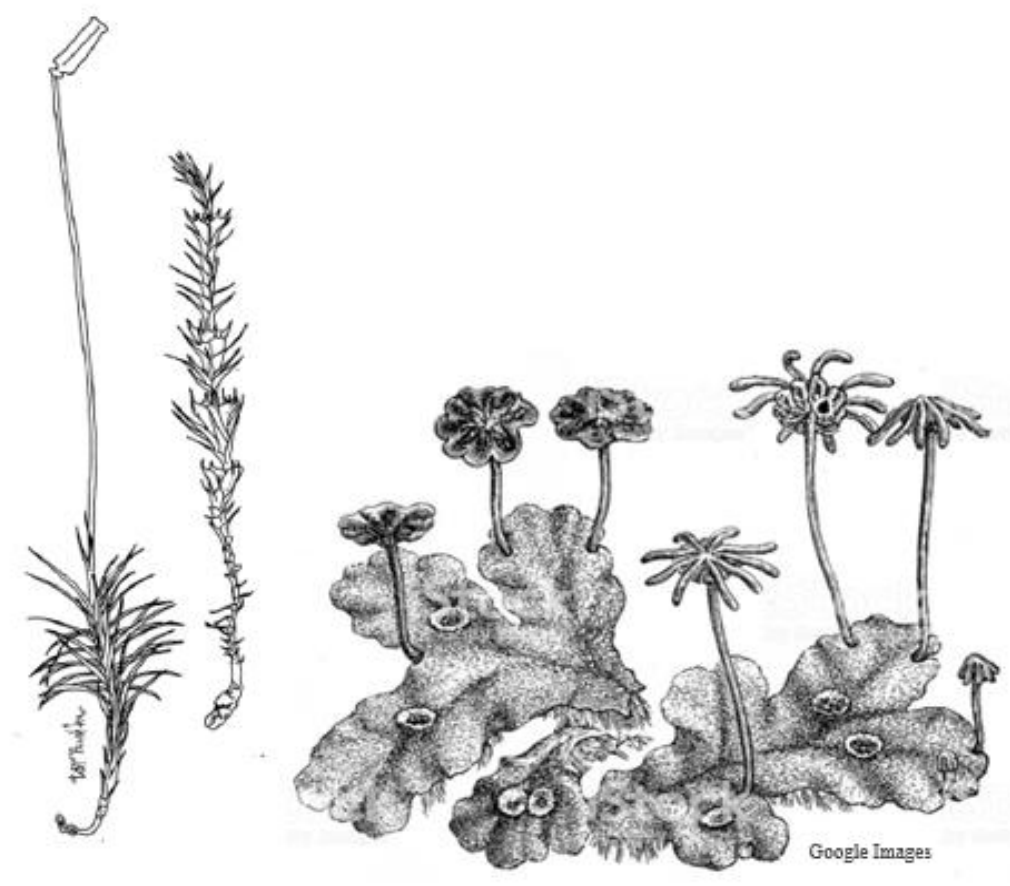

Chemical composition of cuticular waxes in species of Bryophyta (mosses) and Marchantiophyta (liverworts) 


\section{Composição química das ceras cuticulares em espécies de Bryophyta (musgos) e Marchantiophyta (hepáticas)}

\section{Chemical composition of cuticular waxes in species of Bryophyta (mosses) and Marchantiophyta (liverworts)}

Versão corrigida. A versão original dessa dissertação encontra-se disponível no Instituto de Biociências da USP.

Dissertação apresentada ao Instituto de Biociências da Universidade de São Paulo, para a obtenção de Título de Mestre em Ciências, na Área de Botânica.

Orientadora: Profa Dra Déborah Yara Alves Cursino dos Santos

Colaboradores: Prof Dr Denilson Fernandes Peralta (Instituto de Botânica - IBt/SP) Profa Dra Gladys Flávia de Albuquerque Melo de Pinna (Laboratório de Anatomia Vegetal - IB/USP)

São Paulo 


\section{FICHA CATALOGRÁFICA}

Matos, Tamara Machado

Composição química das ceras cuticulares em espécies de Bryophyta (musgos) e Marchantiophyta (hepáticas)

152 páginas

Dissertação (Mestrado) - Instituto de Biociências da Universidade de São Paulo, Departamento de Botânica.

1. Briófitas. 2. Cutícula vegetal. 3. Ceras cuticulares.

Instituto de Biociências. Departamento de Botânica.

\section{COMISSÃO JULGADORA:}

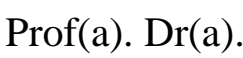

$\operatorname{Prof}(\mathrm{a}) . \operatorname{Dr}(\mathrm{a})$.

Profa Dra Déborah Y. A. C. dos Santos

Orientadora 


\section{Dedicatória}

À minha família, ao meu companheiro Guilherme, aos meus amigos de "fé" e que conquistei durante esta jornada, a minha orientadora, e aos colaboradores deste trabalho pelo apoio e dedicação de sempre. 
“...o caminho só existe quando você passa..."

Skank (Acima do sol) 


\section{Agradecimentos}

Primeiramente gostaria de agradecer às forças divinas por ter iluminado e guiado meu caminho até aqui. À minha família pelos ensinamentos que contribuíram para minha formação pessoal e profissional, pelo amor, carinho e apoio em todos os momentos da minha vida, vocês são a minha base. Ao meu companheiro Guilherme, pelo amor, força, paciência e pelas palavras de suporte sobretudo durante esta importante etapa da minha carreira. Você sempre acreditou mais em mim que eu mesma, e se hoje cheguei até onde estou devo especialmente ao seu constante incentivo. Também à sua família por todo carinho e apoio, obrigada por sempre estarem ao meu lado!!.

À minha orientadora de iniciação científica a Profa Dra. Nilvane T. G. Müller, a qual teve grande influência na minha escolha de seguir na área acadêmica fazendo com que eu me apaixonasse pela Botânica. Obrigada pela confiança, incentivo e amizade construída ao longo destes anos!!.

Agradeço imensamente a minha orientadora Profa Dra Déborah Y. A. C. dos Santos pela oportunidade e confiança em desenvolver este trabalho, pelos valiosos ensinamentos, pelo empenho, dedicação e paciência durante estes anos. Obrigada pelas palavras e conselhos nos momentos de aflição. Também aos colaboradores deste trabalho: o professor e pesquisador Dr Denilson F. Peralta do Instituto de Botânica - IBt/SP e a professora Dra Gladys Flávia A. M. de Pinna do laboratório de Anatomia Vegetal IB/USP, os quais eu tive o privilégio de trabalhar e aprender muito durante este período. Obrigada por serem sempre tão prestativos e dispostos em contribuir no desenvolvimento deste estudo. Aos professores(as) do Departamento de Botânica e principalmente do Laboratório de Fitoquímica pela contribuição no meu aprendizado em algum momento do mestrado.

Às técnicas do Laboratório de Fitoquímica: Mourisa e Aline pelo comprometimento e ajuda diária na bancada, e as técnicas do Laboratório de Anatomia Vegetal: Gisele e Tássia pelo auxílio e empenho indescritível nas análises anatômicas. Também agradeço aos funcionários Irwandro e Valdir por serem atenciosos e pacientes na obtenção das imagens do MEV e do MET, respectivamente. A concretização deste trabalho só foi possível com a ajuda constante de todos vocês!.

Aos colegas da sala 144 e demais colegas do Laboratório de Fitoquímica, especialmente ao Eli e ao Wilton, pela ajuda na bancada e fora dela, pelos conselhos e 
conversas, mas também pelos momentos de descontração principalmente na pausa para o almoço e café. Sem dúvida o apoio e a amizade de vocês foi essencial nesta etapa!. Também gostaria de agradecer especialmente ao colega doutorando Lucas pela ajuda nas identificações e pelas dicas durante a realização deste trabalho, sempre solícito em ajudar eu e os demais colegas de sala e do laboratório. À Carol, aluna de iniciação científica, que me ajudou a agilizar muito o trabalho de bancada. Também o meu muito obrigada às alunas da Anatomia: a doutoranda Leyde, e pós-doutorandas Priscila e Renata pelas dicas e ajuda nos protocolos e realização das análises anatômicas. Todos vocês tiveram uma participação fundamental nesta trajetória!!.

E por fim e não menos importante, obrigada à CAPES pelo auxílio financeiro conferido durante o mestrado. 


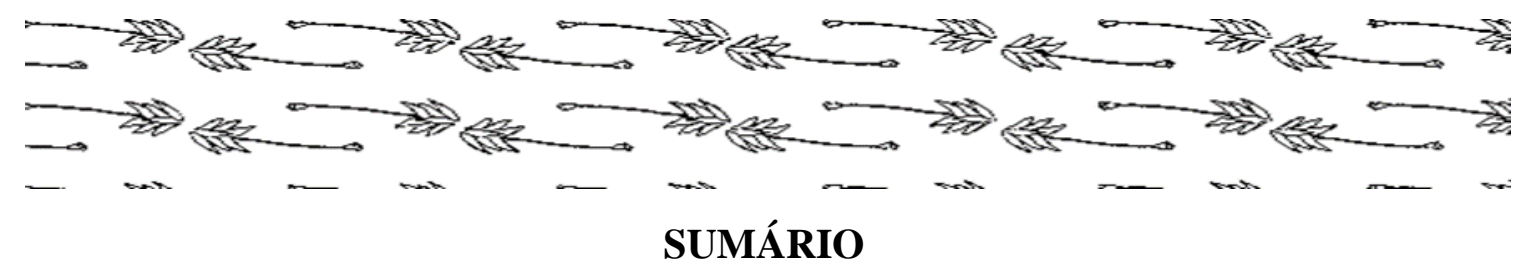

INTRODUÇÃO GERAL

RESUMO .1

ABSTRACT 2

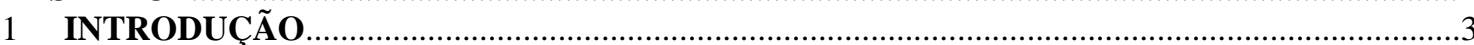

1.1 Evolução das embriófitas: conquista do ambiente terrestre ..........................................................

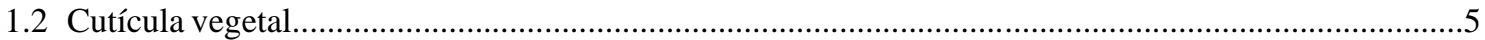

1.3 Caracterização e composição química da cutina e ceras cuticulares......................................................8

1.4 Caracterização morfológica das ceras epicuticulares.....................................................................10

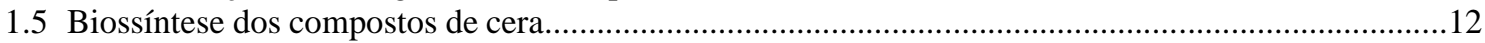

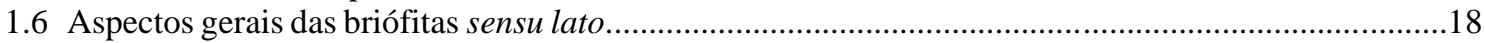

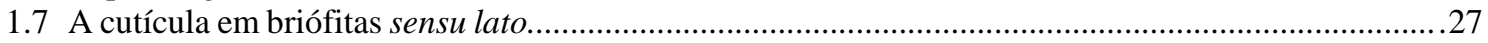

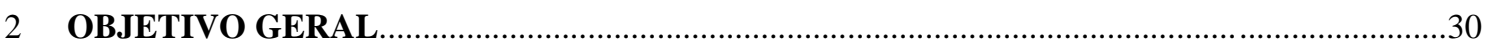

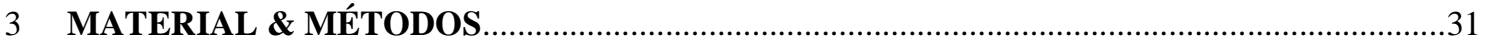

3.1 Definição dos grupos Bryophyta e Marchantiophyta para as análises................................................31

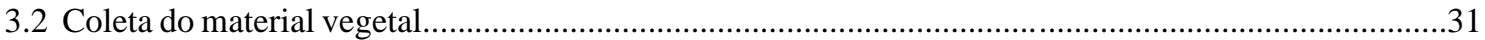

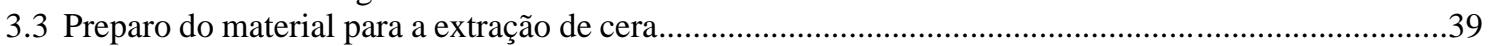

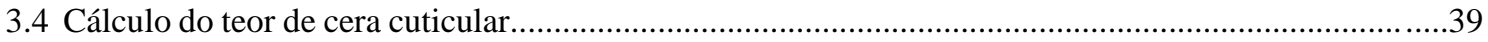

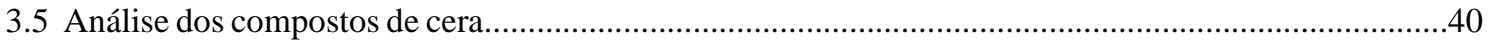

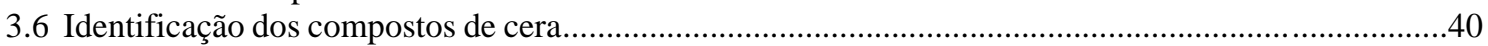

3.7 Análise por microscopia eletrônica de varredura (MEV) …........................................................42

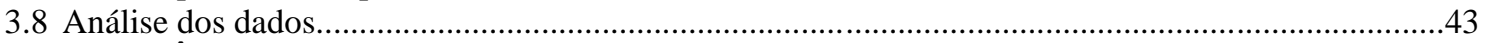

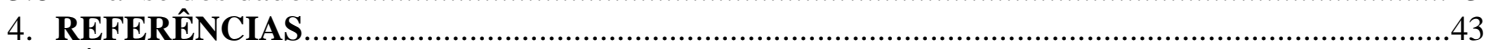

CAPÍTULO 1: Caracterização geral da morfologia e da composição química das ceras cuticulares em espécies brasileiras de Bryophyta e Marchanthiophyta.........................................................53

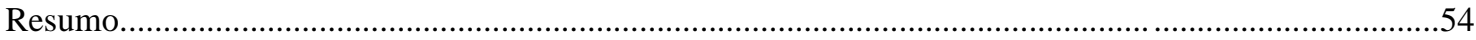

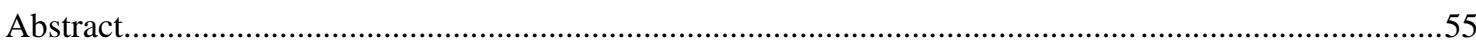

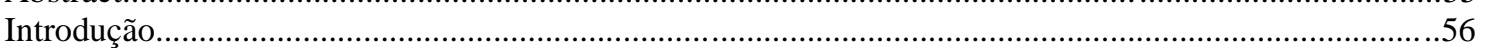

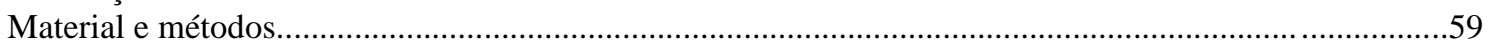

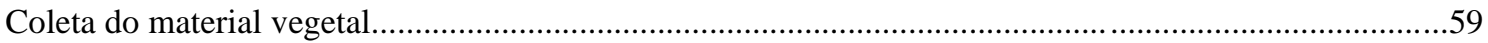

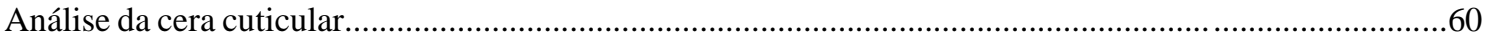

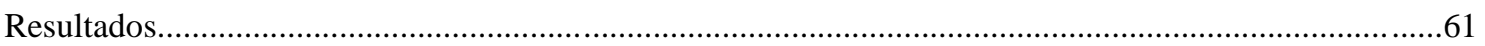

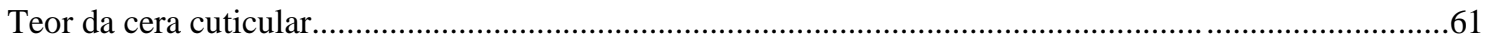

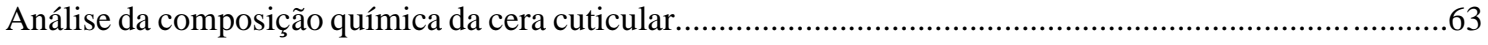

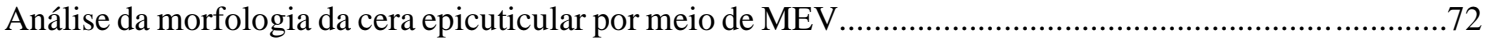

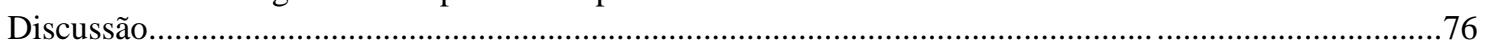

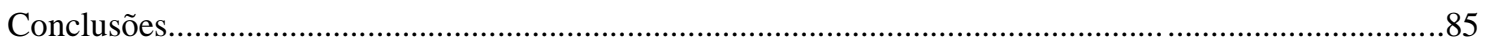

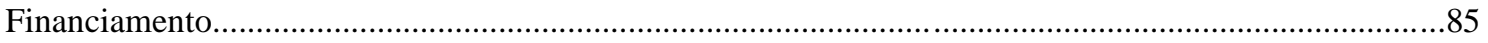

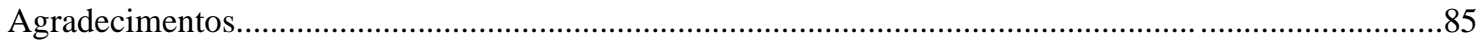

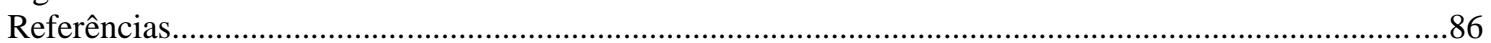

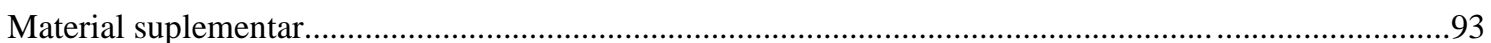

CAPÍTULO 2: Análise comparativa das ceras cuticulares do gametófito e do esporófito de espécies

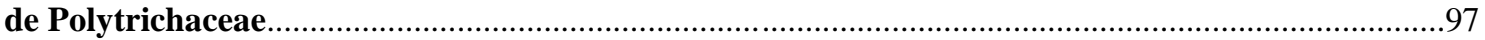

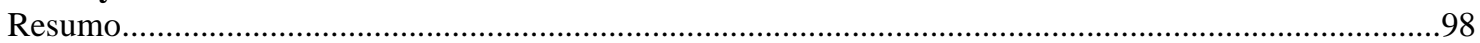

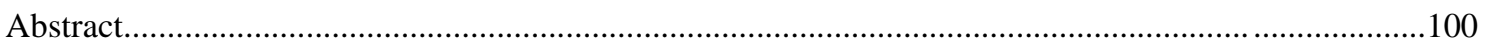

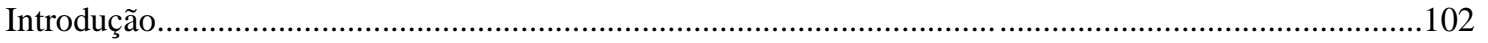

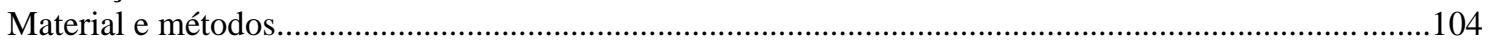

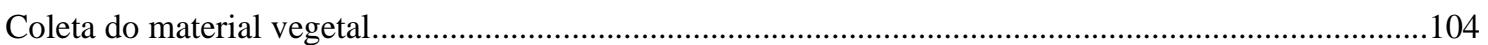

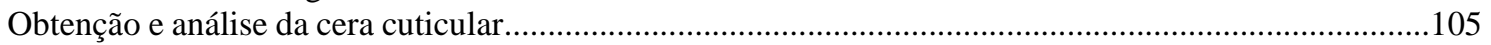

Análise por microscopia eletrônica de varredura (MEV) ...............................................................105

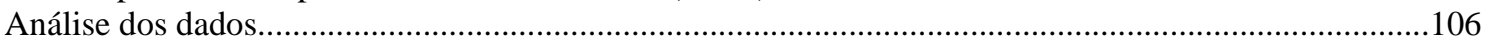

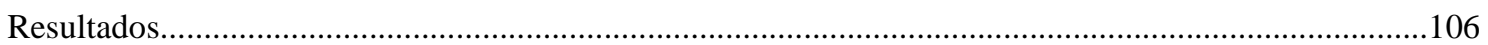

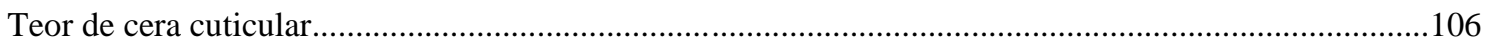

Análise da composição química da cera cuticular.............................................................................107 
Análise por microscopia eletrônica de varredura (MEV) .............................................................112

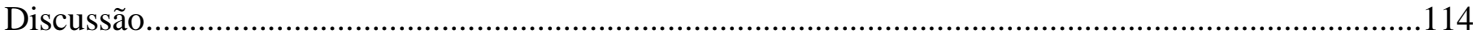

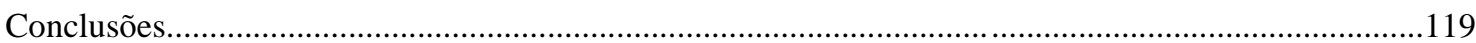

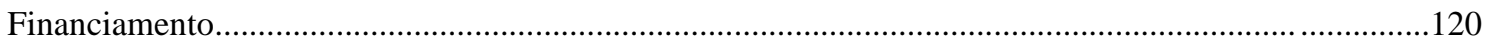

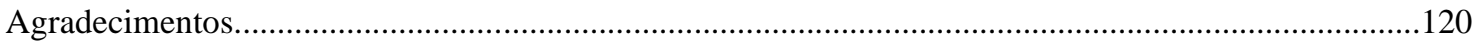

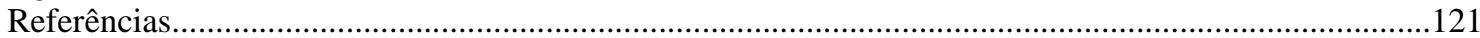

CAPÍTULO 3: Variação intraespecífica da composição química das ceras cuticulares em Lejeunea

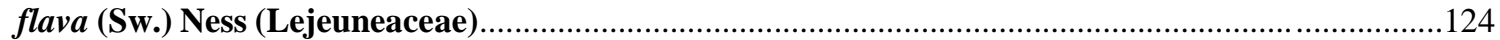

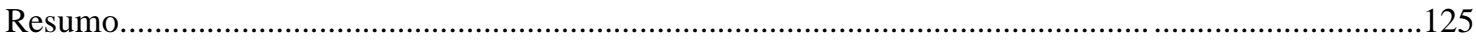

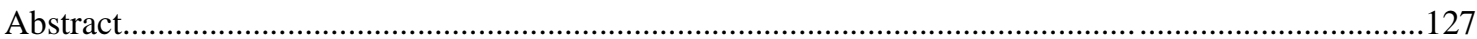

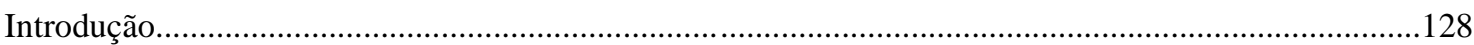

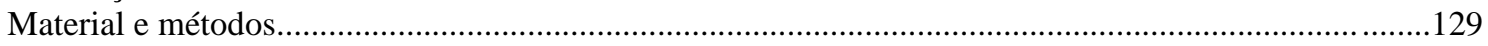

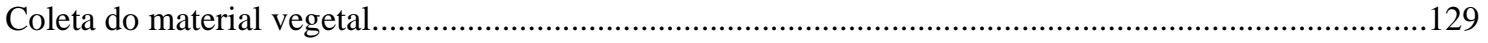

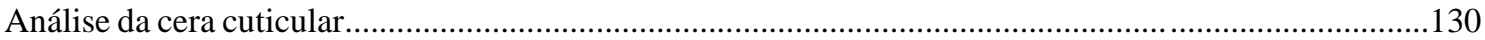

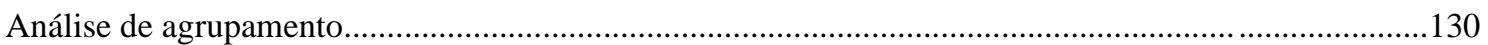

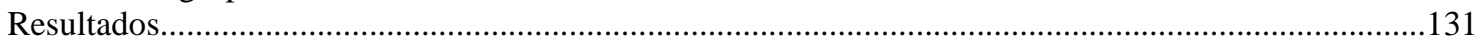

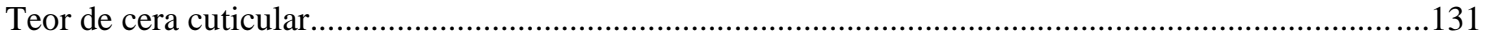

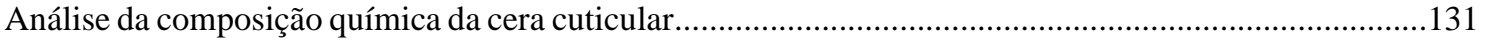

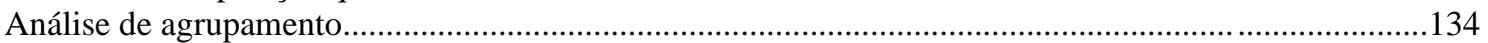

Análise por microscopia eletrônica de varredura (MEV) ................................................................136

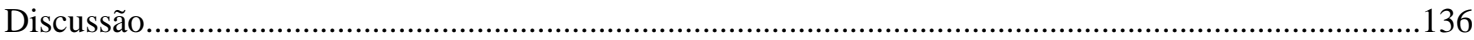

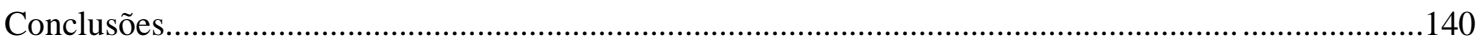

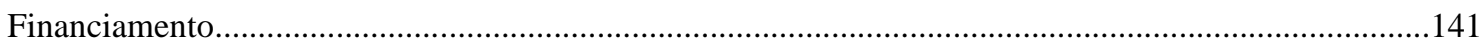

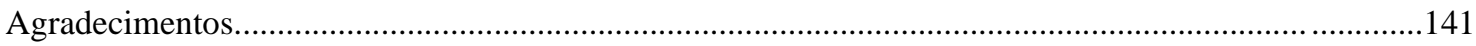

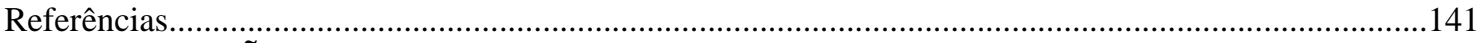

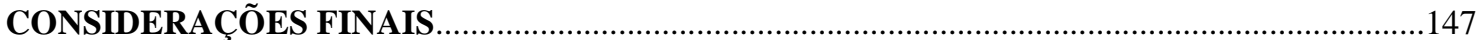

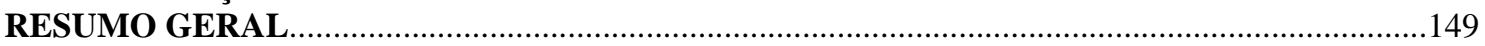

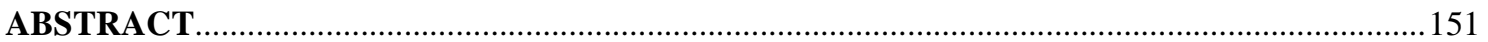




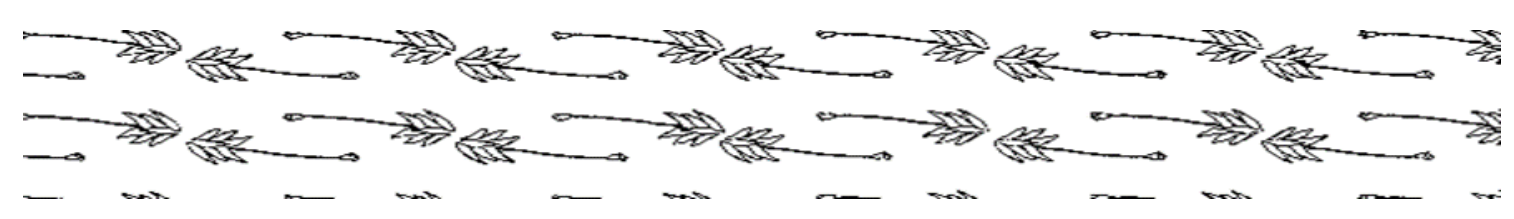

\section{INTRODUÇÃO GERAL}

\section{RESUMO}

A transição das primeiras plantas para o ambiente terrestre ocorreu aproximadamente há 450 milhões de anos. $\mathrm{O}$ aparecimento de importantes sinapomorfias foi essencial para a conquista desse ambiente pelas embriófitas, garantindo a relativa independência do habitat aquático. Entre essas novidades evolutivas, o surgimento de uma camada extracelular lipofílica contínua recobrindo as partes aéreas das plantas, a cutícula vegetal, foi crucial para o sucesso evolutivo desse grupo. A cutícula é composta pela cutina a qual é envolvida pelas ceras cuticulares e desempenha um papel multifuncional nas plantas, sobretudo reduzindo a perda de água não estomática e, portanto, evitando a dessecação. As ceras são formadas por diversos compostos hidrofóbicos acíclicos de cadeia longa tais como, os aldeídos, álcoois primários e secundários, alcanos, cetonas e ésteres. Também são encontrados compostos cíclicos como triterpenos e esteroides. Na superfície externa da camada cuticular, as ceras epicuticulares podem formar diferentes tipos de ornamentos, variando desde amorfas a cristaloides. O termo "briófitas" é utilizado para designar três divisões distintas: Marchantiophyta (hepáticas), Bryophyta (musgos) e Anthocerotophyta (antóceros). Essas plantas são consideradas as pioneiras na transição do ambiente aquático para o terrestre. São avasculares, criptógamas e possuem um ciclo de vida com a geração gametofítica dominante. Essas plantas podem tolerar condições ambientais extremas e por isso estão amplamente distribuídas no mundo, ocorrendo desde o Ártico até as florestas tropicais. Elas compõem o segundo maior grupo de plantas terrestres. No mundo, são conhecidas aproximadamente 20.000 espécies e, no Brasil, cerca de 1.524, ocorrendo em todas as regiões e biomas brasileiros, inclusive na Caatinga, sendo a Mata Atlântica do Sudeste o centro de diversidade dessas plantas. Embora muitos trabalhos já tenham sido publicados desde os anos de 1940, ainda há controversas sobre a presença de uma camada cuticular nessas plantas. Neste trabalho, estudamos um total de 34 espécies pertencentes às divisões Marchantiophyta e Bryophyta descrevendo a morfologia da cera epicuticular e a composição total da cera cuticular para os gametófitos, alguns esporófitos e também para a caliptra, quando disponíveis.

Palavras-chave: briófitas, cutícula vegetal, evolução, lipídios de superfície. 


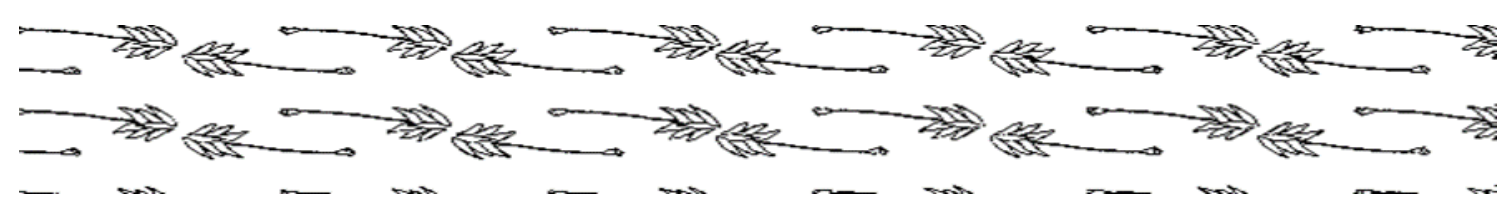

GENERAL INTRODUCTION

\section{ABSTRACT}

The transition of plants to the land environment took place approximately 450 million years ago. Several important synapomorphies were essential for the embryophytes to conquer the new environment, ensuring a relative independence from the aquatic habitat. Among these evolutionary novelties, the appearence of a continuous lipophilic extracellular layer covering the aerial parts of plants, the plant cuticle, was crucial for the evolutionary success of this group. The cuticle is made up of the cutin which is surrounded by cuticle waxes and plays a multifunctional role in plants, particularly reducing non-stomatal water lost and thus avoiding desiccation. Waxes are composed by long chain acyclic hydrophobic compounds such as aldehydes, primary and secondary alcohols, alkanes, ketones and esters. Cyclic compounds such as triterpenes and steroids are also found. The cuticle outermost part, the epicuticular waxes, can present different types of ornaments, ranging from amorphous to crystalloids. The term "bryophytes" is used to define three distinct linages: Marchantiophyta (liverworts), Bryophyta (mosses) and Anthocerotophyta (hornworts). These plants are considered the pioneers in the transition from aquatic to land environment. These plants are avascular, cryptogams and have a life cycle with the gametophytic generation dominant. They can tolerate extreme environmental conditions and are therefore widely distributed throughout the world, from the Arctic to the rainforests. Bryophytes constitute the second largest group of land plants. Approximately 20,000 species are known worldwide, and in the Brazil 1,524, distributed in all Brazilian regions and biomes, including Caatinga. The southeast Atlantic Forest is the Brazilian center of diversity for these plants. Although many papers have already been published since the 1940's, there still have some controversy concerning the presence of a cuticular layer in these plants. In this work, we studied a total of 34 species belonging to the Marchantiophyta and Bryophyta divisions describing the morphology of the epicuticular wax and the total wax composition, for the gametophytes, some sporophytes as well as for the calyptra when available.

Keywords: bryophytes, cuticle, evolution, surface lipids. 


\section{INTRODUÇÃ̃o}

\subsection{Evolução das embriófitas: conquista do ambiente terrestre}

Análises filogenéticas morfológicas, químicas e moleculares confirmam que as $\operatorname{algas}^{1}$ tradicionalmente chamadas de "algas verdes" (Chlorophyta e Charophyta) estão relacionadas com as plantas terrestres ${ }^{2}$ (Embryophyta) e juntas formam um clado conhecido como plantas verdes ou viridófitas (Viridiplantae). Este clado encontra-se dividido em duas linhagens: as clorófitas (Chlorophyta) e as estreptófitas (Streptophyta) (figura 1). As clorófitas (Chlorophyta) incluem uma grande diversidade de algas (ex. Chlorophyceae, Ulvophyceae, Trebouxiophyceae), enquanto as estreptófitas (Streptophyta) compreendem algumas algas da divisão das carófitas (Charophyta) tais como, Charales, Coleochaetales, Zygnematales etc, e as embriófitas (Embryophyta) (figura 1), incluindo as mais basais como as briófitas sensu lato (Judd et al., 2008; Leliaert et al., 2012).

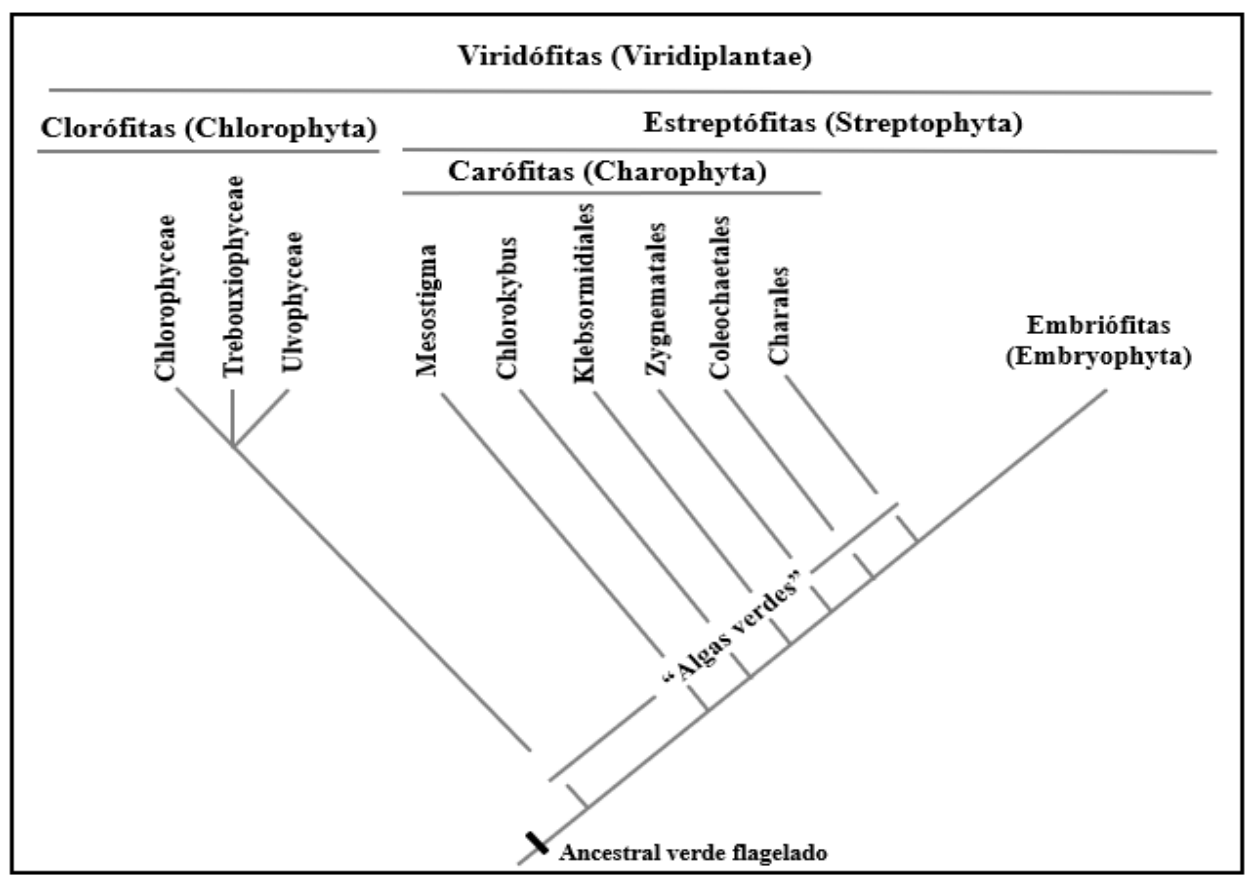

Figura 1. Filogenia das Viridófitas (Viridiplantae). Adaptado de Judd et al. (2008).

\footnotetext{
${ }^{1} \mathrm{O}$ termo "algas" é aplicado a uma ampla variedade de organismos aquáticos fotossintetizantes pertencentes a diversas linhagens não diretamente relacionadas umas com as outras, e, portanto, não formam um grupo monofilético (Judd et al., 2008).

${ }^{2}$ Embora o termo "plantas terrestres" seja utilizado muitas vezes como sinônimo de embriófitas, deve-se lembrar que diversas linhagens de algas (ex. Trebouxiophyceae) colonizaram independentemente o ambiente terrestre (Judd et al., 2008). Neste trabalho, a utilização de "plantas terrestres" não inclui essas linhagens de algas.
} 
As plantas verdes incluem mais de 300 mil espécies, ou seja, aproximadamente um sexto das espécies da terra (Judd et al., 2008), as quais se diversificaram a partir de um ancestral comum flagelado. A teoria mais aceita e fundamentada descreve que, por meio de um evento de endossimbiose primária, no qual uma célula hospedeira eucariótica heterotrófica capturou uma cianobactéria, a qual não foi digerida, tiveram origem os cloroplastos e o surgimento dos primeiros eucariotos fotossintéticos (Ambrose \& Purugganan, 2013).

O surgimento de clorofila $b$ em adição a clorofila $a$, a perda das ficobilinas como pigmentos fotossintéticos acessórios, a formação de membranas tilacoides (grana) e o armazenamento de amido nos cloroplastos foram algumas das modificações mais notáveis que são compartilhadas pelo grupo das plantas verdes (Leliaert et al., 2012; Ambrose \& Purugganan, 2013). Adicionalmente, análises moleculares (sequenciamento de DNA nuclear e de cloroplastos) dão suporte para monofilia do grupo das viridófitas (Leliaert et al., 2012).

Segundo Judd et al. (2008), algas Coleochaetales e Charales, pertencentes a divisão das carófitas (Charophyta), possuem algumas características funcionais importantes que são compartilhadas apenas com as embriófitas, como por exemplo, a presença de flavonoides e dos precursores químicos de cutícula. Essa divisão de algas é formada por organismos que vivem em ambientes de água doce e não marinho. A transição da água doce para o ambiente terrestre seria um processo menos radical do ponto de vista fisiológico. Assim, a adaptação à água doce pode ter sido uma vantagem adaptativa dessas algas que teria facilitado a conquista do ambiente terrestre (Ambrose \& Purugganan, 2013).

Estima-se que a transição das primeiras plantas para o ambiente terrestre ocorreu aproximadamente há 450 milhões de anos durante a Era Paleozoica, especificamente nos períodos Ordoviciano e Siluriano (Gerrienne \& Gonez, 2010; Leliaert et al., 2012; Bowman et al., 2017). Registros fósseis atribuídos a hepáticas (Marchantiophyta) (Ordoviciano-Siluriano) indicam que as primeiras plantas colonizadoras de habitats terrestres possuíam atributos muito próximos a esse grupo, sendo as hepáticas, portanto, consideradas as mais antigas do registro fóssil entre as briófitas sensu lato (Bowman et al., 2017). 
O início da diversificação do ecossistema terrestre foi um evento marcante na história evolutiva da Terra. Entretanto, para que as primeiras embriófitas conseguissem colonizar e se estabelecer com sucesso nesse novo ambiente foi necessário superar uma série de adversidades, como por exemplo, dificuldades de suporte estrutural e de trocas gasosas, temperaturas elevadas e níveis altos de radiação ultravioleta, sobretudo do tipo UV-B, além da escassez de água e risco de dessecação (Gerrienne \& Gonez, 2010; Ambrose \& Purugganan, 2013). Nesse sentido, o surgimento e a seleção de diversas inovações morfológicas e fisiológicas foram essenciais durante o processo evolutivo das embriófitas, garantindo a conquista do ambiente terrestre e a relativa independência do habitat aquático (Gerrienne \& Gonez, 2010).

Segundo Judd e colaboradores (2008), entre as principais sinapomorfias das embriófitas estão (a) o ciclo haplodiplobionte, ou seja, a alternância entre as gerações gametofíticas (haploide), originando gametas por meio de mitose, e esporofíticas (diploide) que, através de meiose, formará esporos com paredes espessadas, (b) a retenção do embrião dentro do arquegônio, permitindo que o esporófito jovem permanecesse associado ao gametófito, (c) o desenvolvimento de rizoides, contribuindo para a fixação das plantas ao substrato e (d) surgimento dos estômatos com células-guarda que podem abrir ou fechar de acordo com as condições do ambiente e, dessa forma, regular a perda de água. Contudo, sem dúvida o aparecimento de uma camada extracelular lipofílica contínua recobrindo as partes aéreas das plantas, a cutícula, foi crucial para o sucesso evolutivo das embriófitas.

\subsection{Cutícula vegetal}

Durante o estabelecimento das primeiras plantas no ambiente terrestre, a dessecação foi um dos principais desafios a ser superado por estes organismos. Um revestimento fundamental na prevenção contra a perda de água é denominado de cutícula (Raven et al., 2014).

A cutícula está presente desde os grupos mais basais das embriófitas, como nas briófitas sensu lato, até os grupos mais recentes, tais como as poliesporangiófitas (Bargel et al., 2006; Raven et al., 2014). Nas embriófitas recentes, a cutícula é encontrada revestindo a epiderme das partes aéreas dos órgãos com crescimento primário, tais como folhas (em ambas as superfícies), flores, frutos e caules (Taiz \& Zeiger, 2009; Bernard \& Joubés, 2013). Apenas a epiderme da raiz e alguns tecidos associados ao crescimento secundário das plantas, como a madeira e a casca, não são cobertos por cutícula (Koch et 
al., 2009a). Nas embriófitas basais, por exemplo hepáticas e musgos, esse revestimento é descrito no esporófito (p. ex. cápsula), no gametófito e, inclusive, na caliptra (uma estrutura protetora do esporófito de origem gametofítica) (Budke et al., 2011; 2012; 2013; Raven et al., 2014; Busta et al., 2016a; 2016b).

A cutícula é sintetizada pelas células da epiderme e a sua capacidade de proteção é baseada em propriedades bioquímicas de seus dois principais componentes altamente hidrofóbicos: (a) a cutina, que compreende uma matriz de poliésteres (compõe em torno de 40 a $80 \%$ da massa cuticular) e (b) as ceras cuticulares, que são formadas por uma variedade de lipídeos solúveis e que também podem conter uma série de metabólitos secundários (Kunst \& Samuels, 2003; 2009; Báez-Sañudo et al., 2013; Bernard \& Joubés, 2013).

A cutina e as ceras cuticulares se combinam de diferentes modos formando uma camada cuticular estrutural (figura 2) (Koch et al., 2009a). Esta estrutura é estratificada, dividida genericamente em três partes: a parte mais externa à epiderme, denominada de cera epicuticular, é formada apenas por ceras; abaixo da cobertura de cera epicuticular encontra-se uma camada espessa intermediária, formada por cutina embebida em cera (intracuticular), chamada de cutícula propriamente dita; por fim, há outra camada que fica mais próxima à parede celular e a camada de pectina, formada por cutina e ceras associadas à compostos da parede celular, denominada de cutícula secundária (Jeffree, 2006; Taiz \& Zeiger, 2009).

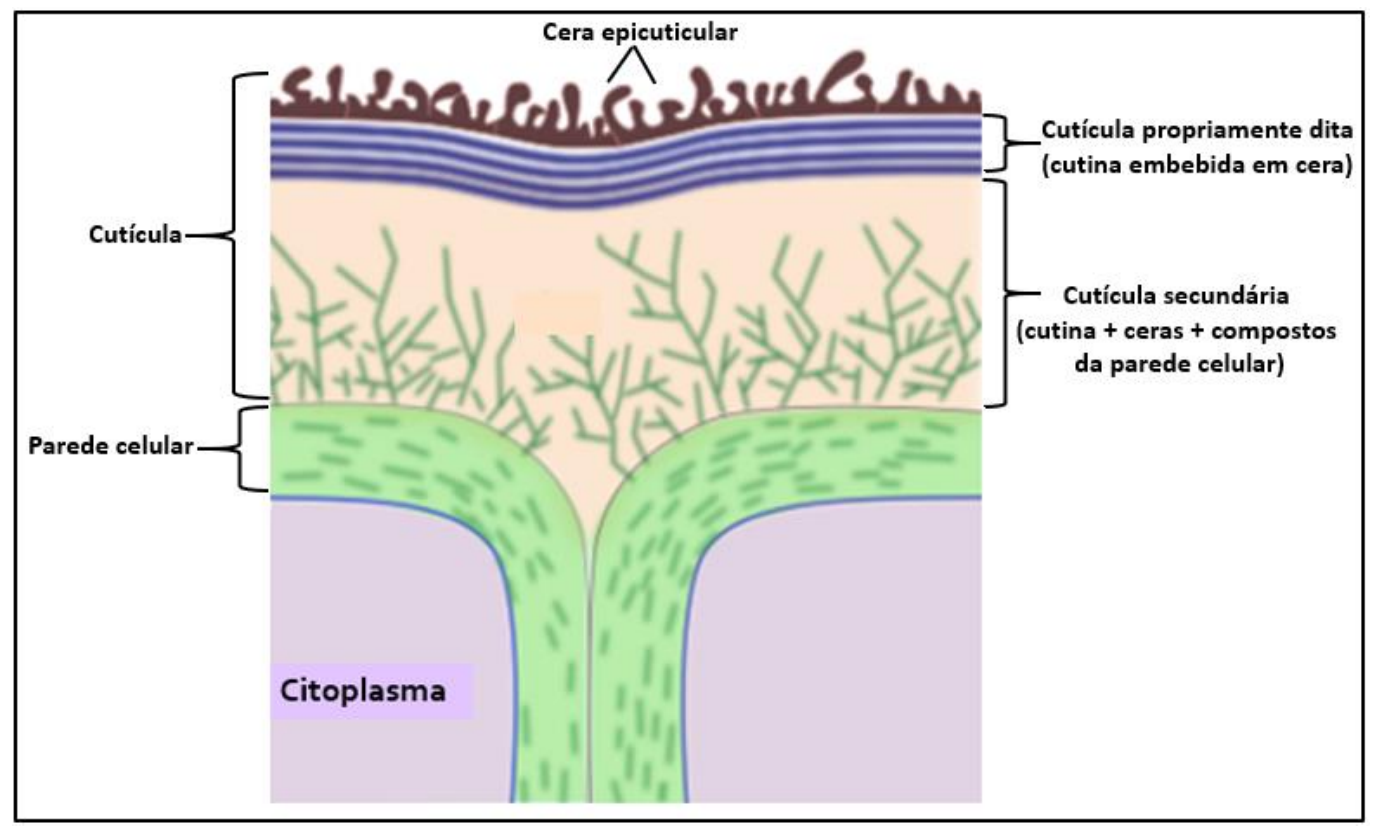

Figura 2. Esquema da estrutura da cutícula. Modificado de Taiz \& Zeiger (2009). 
Os componentes da cutícula formam uma camada protetora contínua depositados nas paredes periclinais externas dos vegetais que, além de constituir uma barreira reduzindo a perda de água e a difusão de gases através da transpiração cuticular, sobretudo quando os estômatos encontram-se fechados (figura 3A), desempenha outras funções importantes devido às suas propriedades marcantes como: prevenir a formação de filmes de água na superfície foliar, dificultando a proliferação de microrganismos (figura 3B); mediar a interação planta-inseto, através de suas propriedades antiadesivas, influenciando na capacidade de adesão de insetos e consequentemente de herbivoria e oviposição (figura 3C); prevenir a penetração de fitopatógenos (fungos parasitários e bactérias), a partir de tradução de sinais, ativando genes específicos (figura 3D); desempenhar um papel de termorreguladora, auxiliando nas mudanças de temperatura, reduzindo os danos causados pela incidência solar em excesso, além de proteger contra a radiação ultravioleta (figura 3E); conferir resistência contra o estresse mecânico, contribuindo com a estabilização e a manutenção da integridade fisiológica da planta (figura 3F) (Koch et al., 2009a; BáezSañudo et al., 2013; Bernard \& Joubés, 2013).

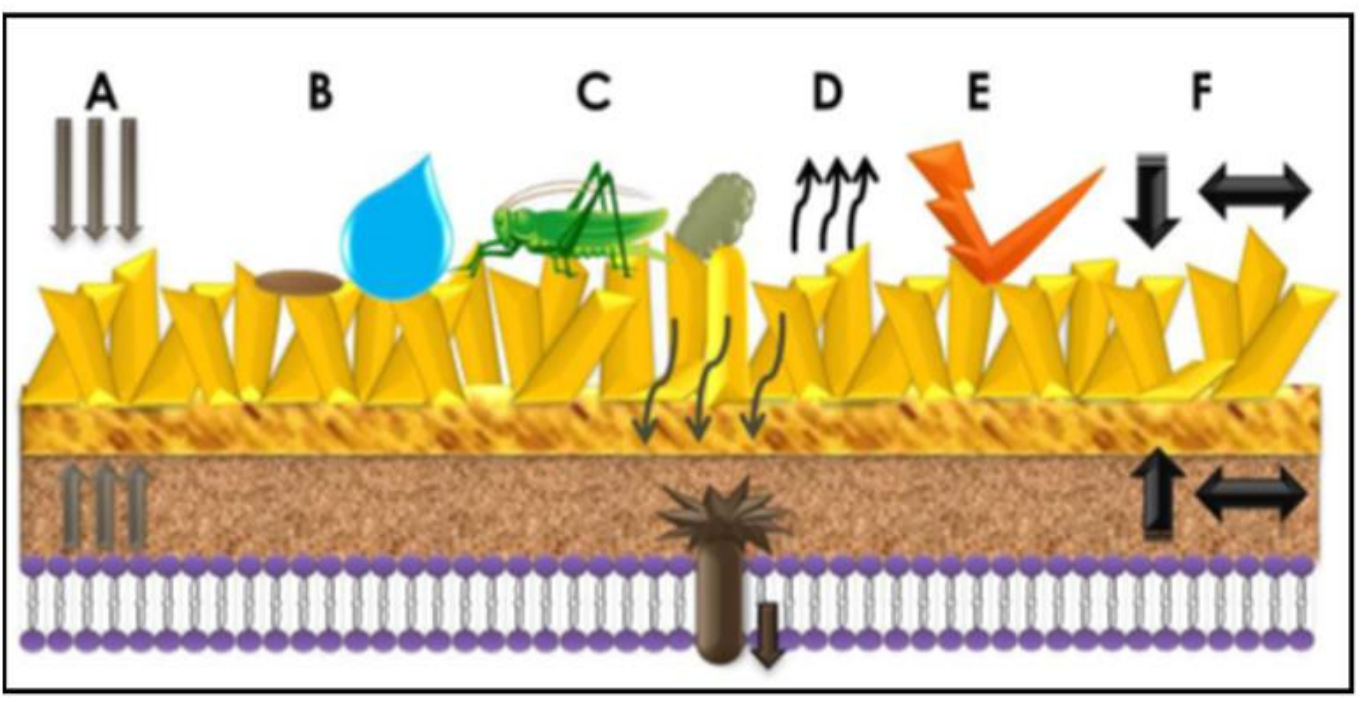

Figura 3. Esquema das principais funções da cutícula vegetal nas plantas. (A): Reduzir a perda de água e difusão de gases. (B): Evitar a acumulação de água e propiciar autolimpeza da superfície foliar. (C): Mediar a interação planta-inseto. (D): Prevenir a penetração de patógenos via sinalização. (E): Auxiliar na termorregulação e proteger contra os raios UV. (F): Promover suporte mecânico. Retirado de Báez-Sañudo et al. (2013). 
As ceras cuticulares são as principais responsáveis pela prevenção da perda de água na transpiração cuticular (Bargel et al., 2006; Koch et al., 2009a; Bernard \& Joubés, 2013; Xue et al., 2017). Os primeiros estudos a fim de demonstrar o papel da cutícula como uma barreira impermeável estabeleceram uma correlação positiva entre a espessura da camada da cutícula e a redução da transpiração não estomática (Bernard \& Joubés, 2013). Todavia, novos experimentos com diferentes espécies, constataram que espessuras semelhantes de camada cuticular apresentaram diferentes permeabilidades à água (Riederer \& Schreiber, 2001).

\subsection{Caracterização e composição química da cutina e ceras cuticulares}

A cutina é um polímero composto, predominantemente, por uma variedade de monômeros de ácidos graxos com 16 ou 18 átomos de carbono hidroxilados e epóxihidroxilados (figura 4A), originados do ácido palmítico (16:0) e do ácido oleico (18:1). Também pode conter uma proporção, ainda que relativamente menor, de fenilpropanoides, como o ácido ferúlico e o ácido $p$-cumárico, de glicerol e de ácidos dicarboxílicos (figura 4B) (Fich et al., 2016). Estes monômeros graxos encontram-se esterificados entre si e com as demais substâncias formando uma matriz de poliésteres que, através de ligações do tipo éster ou éter, unem-se a parede celular por meio de polissacarídeos da camada de pectina (figura 4C) (Yeats \& Rose, 2013; Fich et al., 2016).

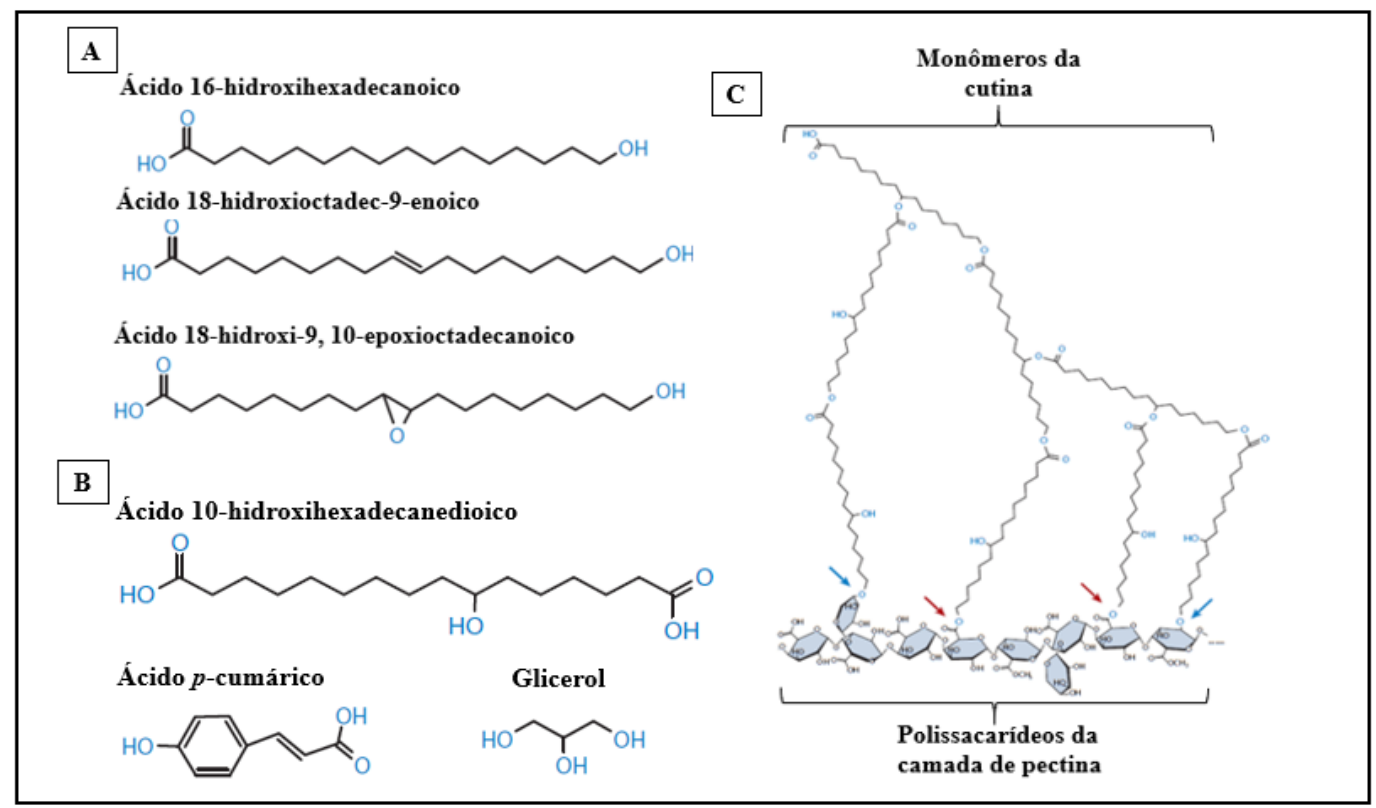

Figura 4. Diferentes constituintes da cutina e modelo proposto para a sua estrutura. A: monômeros derivados de ácidos graxos de 16 e 18 átomos de carbono. B: exemplos de outras substâncias que podem estar presentes na cutina, como ácidos dicarboxílicos, 
fenilpropanoides e glicerol. C: modelo sugerido para o arranjo da matriz de poliésteres da cutina. As setas mostram as possíveis ligações entre os monômeros de cutina e os polissacarídeos da camada de pectina: ligações éster (seta vermelha) e ligações éter (seta azul). Modificado de Fich et al. (2016).

As ceras cuticulares são formadas por diversas substâncias hidrofóbicas (constituindo de $20 \%$ a $60 \%$ da massa da cutícula) que correspondem a fração solúvel da cutícula, que pode ser extraída em breves imersões com solventes orgânicos não-polares como hexano, clorofórmio e diclorometano, por exemplo (Barthlott et al.,1998; Heredia, 2003; Kunst \& Samuels, 2003; 2009). Essas substâncias compreendem diferentes classes de compostos acíclicos de cadeia longa que são originadas a partir de moléculas de ácidos graxos livres e seus derivados, sendo as classes mais comuns os aldeídos, álcoois primários e secundários, alcanos, cetonas e ésteres (figura 5A) (Kunst \& Samuels, 2003; 2009; Reina-Pinto \& Yephremov, 2009; Báez-Sañudo et al., 2013). Nas ceras cuticulares também podem ser encontradas algumas classes de compostos cíclicos sintetizadas através de diferentes vias do metabolismo secundário. Entre estas principais classes estão os terpenos, tais como os triterpenos e fitoesteroides (figura 5B), além de compostos fenólicos, como os flavonoides e fenilpropanoides (figura 5C) (Koch et al., 2009a; BáezSañudo et al., 2013; Bernard \& Joubés, 2013).

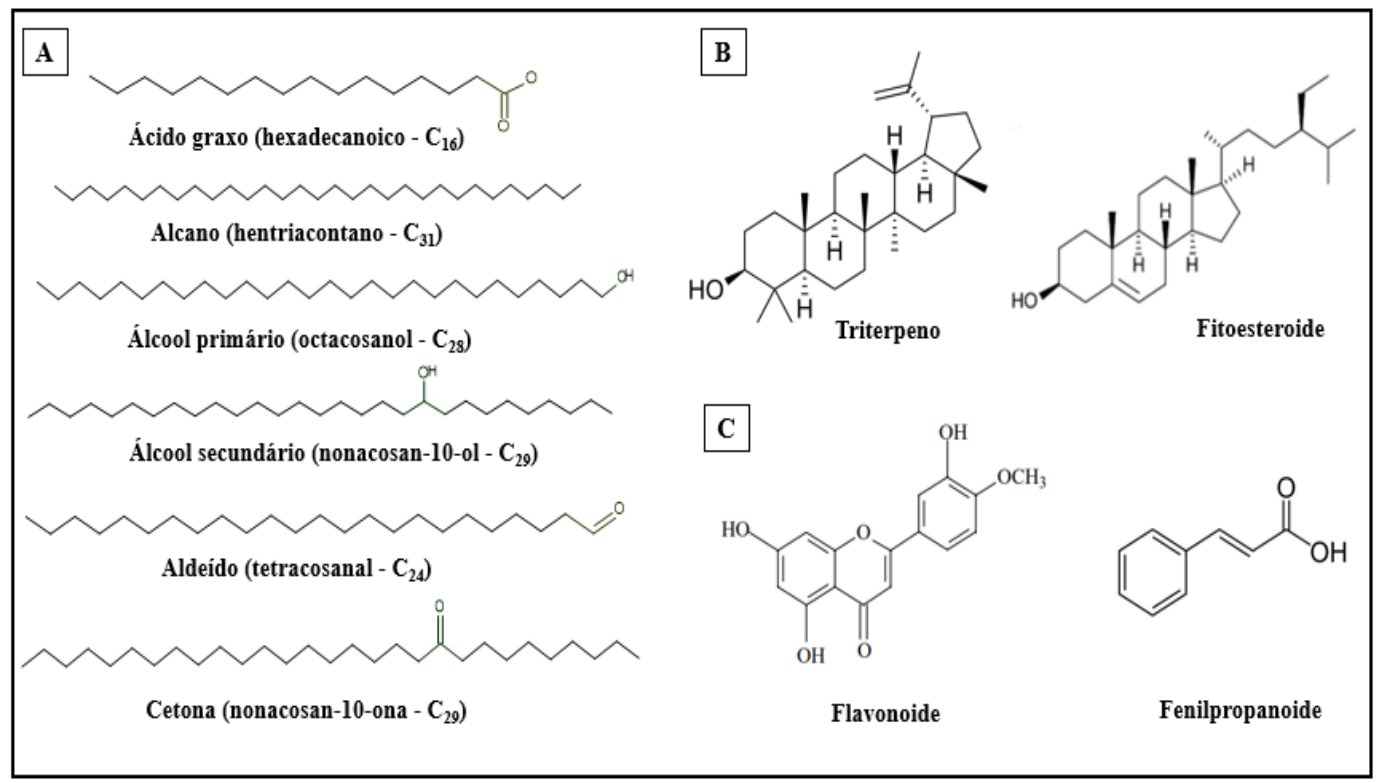

Figura 5. Principais classes de compostos encontrados na cera cuticular. A: exemplos de compostos acíclicos. B-C: exemplos de compostos cíclicos. B: terpenos. C: compostos fenólicos. 
A composição química e a proporção destas classes de compostos acíclicos e cíclicos podem variar nas ceras vegetais conforme a espécie, nos diferentes órgãos vegetais e durante a ontogenia desses órgãos, bem como sob diferentes condições ambientais (Bargel et al., 2006; Koch et al., 2009a; Reina-Pinto \& Yephremov, 2009; Barthlott et al., 2017).

Além disso, segundo Oliveira et al. (2003), as classes de substâncias de cera encontrados na camada cuticular possuem menor ou maior eficiência em reter a água. Segundo esses autores, os alcanos apresentam menor permeabilidade a água em relação ao triterpeno ácido ursólico, por exemplo. Nesse sentido, acredita-se que a organização e a conformação espacial das moléculas dos componentes da cera presentes na cutícula sejam cruciais na determinação de maior ou menor eficiência dessa cutícula em reter a água (Kerstiens, 2006; Bernard \& Joubés, 2013; Barthlott et al., 2017). As moléculas de alcano, por apresentarem estrutura química plana e linear, possuem mais facilidade em aproximar as suas cadeias carbônicas umas das outras, formando regiões na camada cuticular mais eficientes no bloqueio à passagem de moléculas de água (Oliveira et al., 2003; Kerstiens, 2006; Bush \& McInerney, 2013).

\subsection{Caracterização morfológica das ceras epicuticulares}

A partir da introdução da microscopia eletrônica de varredura (MEV) na década de 1970 e com a investigação de diversas espécies vegetais, uma ampla diversidade de morfologias tem sido descrita associadas as ceras epicuticulares (Barthlott et al., 1998).

As ceras epicuticulares podem formar diferentes tipos de ornamentos na superfície externa da camada cuticular (figura 6) (Koch et al., 2009a). Estas ornamentações podem ser divididas em dois principais tipos: amorfas e cristaloides. As ceras do tipo amorfas revestem a camada epicuticular e são subdivididas em: filmes, que são coberturas muito finas, contínuas, sem fissuras e camadas sobrepostas (figura 6A); camadas, que compreendem uma cobertura com aspecto de "craquelado" ou de "rachaduras", podendo ser denominadas de camadas fissuradas (figura 6B); e crostas, as quais formam camadas espessas com superfícies proeminentes (figura 6C). Já as ceras com ornamentações do tipo cristaloides são responsáveis pela formação de diferentes estruturas tridimensionais podendo estar depositadas formando padrões aleatórios ou ordenados sobre a cutícula. Os principais tipos de cristaloides são: as plaquetas (figura 6D); os túbulos (figura 6E); as lâminas (figura 6F); os grânulos (figura 6G) e os bastonetes (figura 6H). Também, é possível ocorrer a combinação de mais de um tipo de morfologia cristaloide na mesma 
camada epicuticular, característica chamada de sintopismo (figura 6I) (Barthlott et al., 1998; Jeffree, 2006; Koch et al., 2009a; Barthlott et al., 2017).

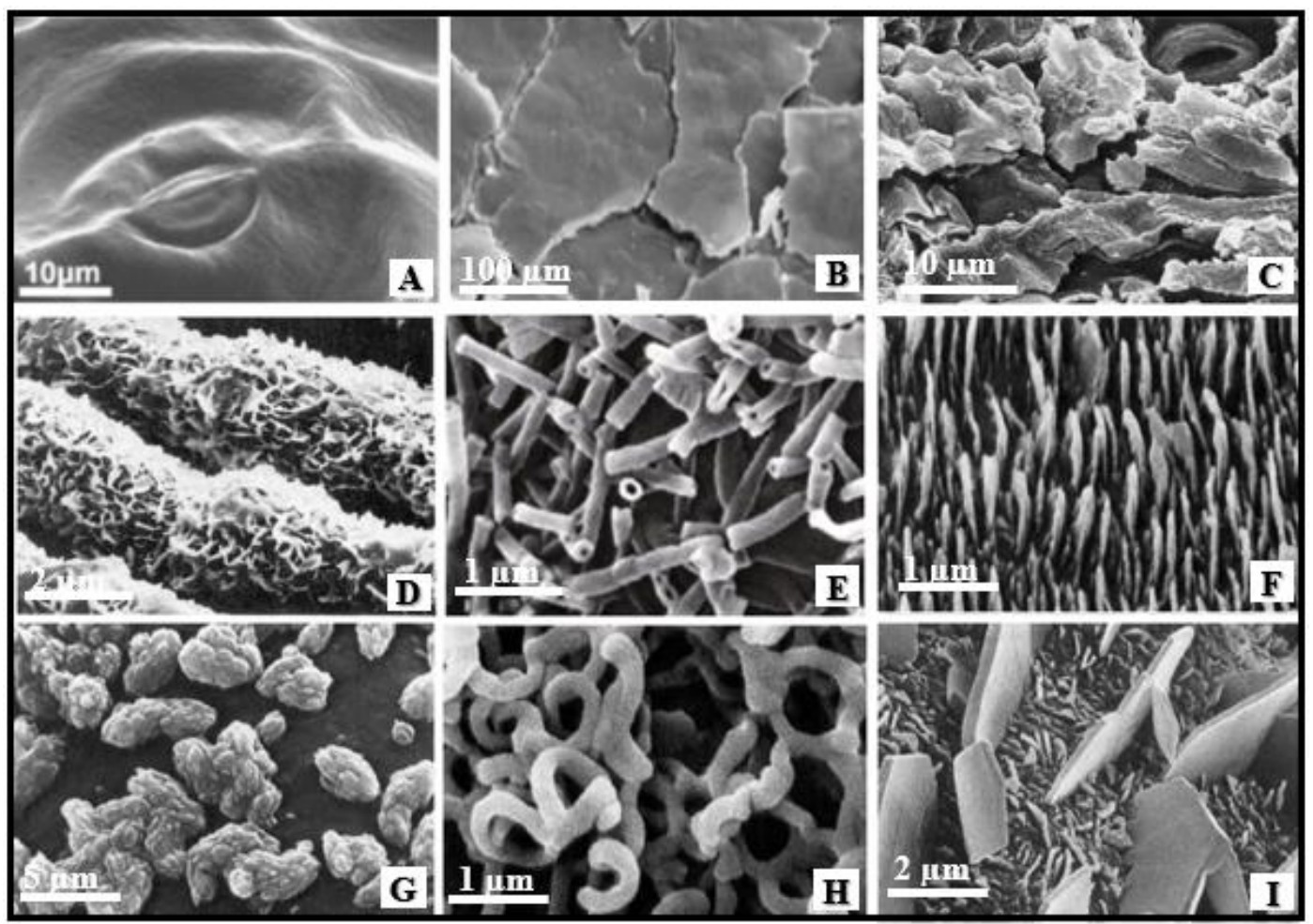

Figura 6. Diferentes morfologias das ceras epicuticulares obtidas por microscopia eletrônica de varredura (MEV). Morfologias amorfas (A-C). A: morfologia do tipo filme em Hydrocotyle bonariensis Lam. (Apiaceae). B: morfologia do tipo camadas fissuradas em Crassula ovata (Mill.) Druce (Crassulaceae). C: morfologia do tipo crosta em Cynanchum sarcostemma Lillo (Asclepiadaceae). Morfologias cristaloides (D-I). D: morfologia do tipo plaquetas no musgo Polytrichadelphus magellanicus (Hedw.) Mitt. (Polytrichaceae). E: morfologia do tipo túbulos de nonacosan-10-ol em Nelumbo nucifera Gaertn. (Nelumbonaceae). F: morfologia do tipo lâminas ordenadas em paralelo em Convallaria majalis L. (Convallariaceae). G: morfologia do tipo grânulos em Aegiceras corniculatum (L.) Blanco (Aegicerataceae). H: morfologia do tipo bastonetes enrolados em Buxus sempervirens L. (Buxaceae). I: sintopismo de plaquetas e lâminas em Benthamia alyxifolia (F. Muell. Ex Benth.) Tiegh. (Loranthaceae). Imagens retiradas e modificadas de Clayton-Greene et al. (1985), Barthlott et al. (1998; 2017) e Koch et al. (2009a).

Por meio dos estudos com recristalização de ceras, nos quais essas são removidas da cutícula e transferidas para um substrato artificial para investigações microscópicas, verificou-se uma forte correlação entre a morfologia detectada e sua composição química, 
visto que as estruturas cristalinas naturais e artificiais, na maioria das vezes, não diferiram entre si (Jeffree et al., 1975; Barthlott et al., 1998; Koch \& Ensikat, 2008). Essa forte correlação pode ser melhor compreendida quando a morfologia observada refere-se a presença de apenas um composto majoritário na cera, como no caso dos túbulos de nonacosan-10-ol encontrados nas folhas de lótus (Nelumbo nucifera) (figura 6E) (Jeffree, 2006; Koch et al., 2009a; Barthlott et al., 2017). Entretanto, em algumas plantas, também pode-se observar a correlação entre uma determinada morfologia com componentes minoritários (Barthlott et al., 2017).

A morfologia e a composição química das ceras epicuticulares têm papel importante em auxiliar a reflexão dos raios de luz da superfície foliar e/ou na atração de polinizadores (Koch \& Ensikat, 2008; Koch et al., 2009a; Barthlott et al., 2017). Em algumas plantas específicas, tais como as espécies de Nepenthes sp. (Nephenthaceae), a morfologia ordenada em combinação com a propriedade hiperhidrofóbica das ceras epicuticulares presentes nas suas folhas modificadas, também chamadas de jarros, garantem que os insetos quando atraídos para o seu interior, permaneçam aderidos na superfície interna, impossibilitando sua saída e facilitando a digestão (Reidel et al., 2003; Barthlott et al., 2017).

Desse modo, hoje há um grande número de trabalhos de caracterização dessas estruturas superficiais em diversas plantas terrestres disponíveis em bancos de dados informatizados (Koch et al., 2009a). Tal fato indica a relevância desses estudos a fim de ampliar a compreensão das funcionalidades das ceras epicuticulares e da sua importância ecológica para os vegetais.

\subsection{Biossíntese dos compostos de cera}

Nas plantas, o metabolismo primário do carbono, por meio de diversas reações e ciclos, é responsável pelos processos de fotossíntese, respiração, diferenciação ou síntese de carboidratos, proteínas e lipídeos etc., sendo estes vitais para todos os vegetais. Entretanto, através do metabolismo especial ou metabolismo secundário do carbono, as plantas também sintetizam uma grande variedade de substâncias chamadas de metabólitos especiais ou secundários, que desempenham importantes funções ecológicas nos vegetais (Dewick, 2009). Os produtos originados das vias de síntese do metabolismo primário do carbono são utilizados como blocos construtores para o metabolismo secundário do carbono (figura 7) (Taiz \& Zeiger, 2009). Os metabólitos especiais podem ser específicos 
a uma espécie vegetal ou a algum grupo de espécies relacionadas e são classificados em quatro grandes grupos de substâncias quimicamente distintas, os terpenos, os compostos fenólicos, os compostos nitrogenados e os compostos de cera (figura 7) (Taiz \& Zeiger, 2009).

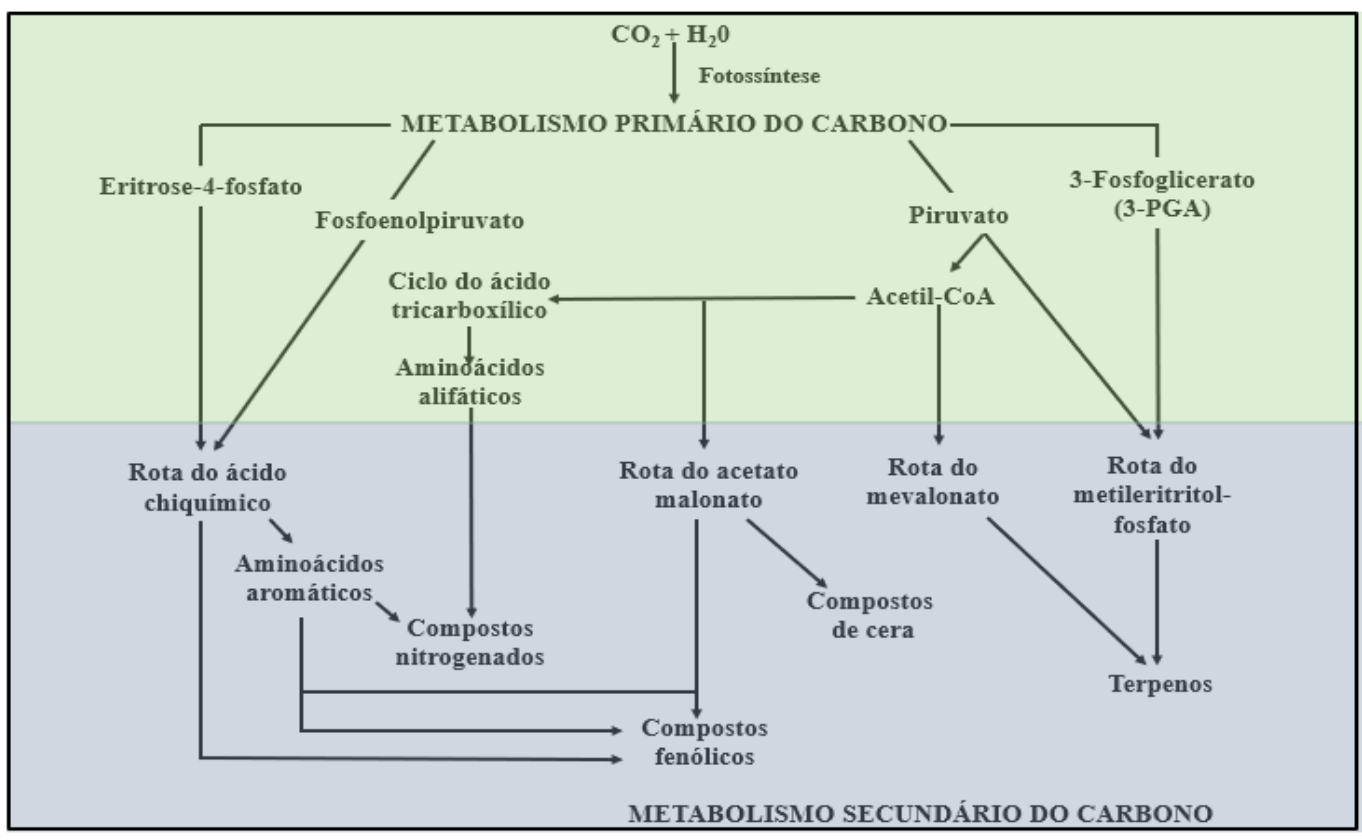

Figura 7. Interrelações entre o metabolismo primário e secundário do carbono. Modificado de Taiz \& Zeiger (2009).

Nas células epidérmicas, especificamente no estroma dos plastídios, os ácidos graxos de cadeia curta $\mathrm{C}_{16}$ e $\mathrm{C}_{18}$ são sintetizados por um processo denominado de síntese de novo dos ácidos graxos através de um complexo enzimático chamado de ácido graxo sintase do tipo II (FAS II, fatty acid synthase type II) (Kunst \& Samuels, 2003; 2009).

A síntese de novo tem como unidade inicial, uma molécula de acetil-CoA (um dos produtos oriundos da rota da glicólise) que se une a uma molécula de dióxido de carbono formando uma molécula de malonil-CoA. As moléculas de acetil-CoA e malonil-CoA formam compostos tioésteres ligados a enzimas. Em seguida, o grupo malonil é transferido do cofator CoA para o cofator ACP. A partir da formação do malonil-ACP (unidade extensora) ocorre uma série de reações cíclicas catalisadas pelo complexo enzimático FAS II, nas quais inicialmente há a condensação de uma molécula de acetilCoA (com dois átomos de carbonos) a uma molécula de malonil-ACP, reação conhecida como Claisen, levando a formação de um $\beta$-cetoéster. Esse composto formado é reduzido à um álcool, que sofre uma reação de desidratação, originando um éster conjugado com 
redução da dupla ligação, levando a formação de uma molécula (acil-ACP) com dois átomos de carbono a mais que a molécula inicial de acetil-CoA. Essa molécula formada, novamente via malonil-ACP, passa por essa série de reações (redução-desidrataçãoredução), formando uma nova molécula com dois átomos de carbono a mais que a molécula inicial deste ciclo. Esses ciclos se repetem sucessivamente, resultando em subprodutos com a adição de uma unidade $\mathrm{C}_{2}$ a mais que os iniciais. A formação de moléculas acil-ACP de cadeias curtas com 16 e 18 átomos de carbonos refletem o fim da síntese de novo. Um grupamento cetônico é reduzido após cada etapa de condensação e antes da próxima etapa de extensão (adição de malonil-ACP) (Shepherd \& Griffiths, 2006; Samuels et al., 2008; Dewick, 2009; Pimentel, 2014; Roma, 2018).

Moléculas com três átomos de carbono também podem atuar como unidades iniciais durante a síntese de novo, mesmo que de forma menos expressiva. Neste caso, originarão moléculas de acil-ACP ímpares com até 17 e 19 átomos de carbonos, considerando que são adicionadas unidades de $\mathrm{C}_{2}$ a cada ciclo (Shepherd \& Griffiths, 2006).

As moléculas de acil-ACP com 16 e 18 átomos de carbono biossintetizadas pela síntese de novo podem passar por outras reações (remoção do grupo $\mathrm{ACP}$ ) e seguir diversos caminhos na célula, resultando, por exemplo, na formação de ácidos graxos livres (Shepherd \& Griffiths, 2006). Essas moléculas também podem originar, através de processos de diferenciação (hidroxilação e epoxilação), os monômeros da cutina ( $\omega$ hidroxiácidos, polihidroxiácidos e ácidos $\alpha, \omega$-dicarboxílicos), ou elas podem passar por um processo de alongamento para a formação de ácidos graxos de cadeia longa, que posteriormente, por meio de diferenciações, originarão os diferentes compostos de ceras. Tanto a síntese de novo quanto o alongamento dos ácidos graxos fazem parte da rota do acetato malonato (Kunst \& Samuels, 2003; 2009).

Para que ocorram essas próximas etapas de síntese e diferenciação é necessário que essas moléculas de acil-ACP $\left(\mathrm{C}_{16}\right.$ e $\left.\mathrm{C}_{18}\right)$ sejam exportadas do plastídio para o retículo endoplasmático. Para tanto, enzimas denominadas de LACS (long chain acyl-CoA synthase) substituem o grupo ACP pelo grupo CoA, para que seja possível o transporte desses acil-graxos até o retículo endoplasmático, atravessando o citoplasma (Kunst \& Samuels, 2009). O mecanismo do transporte dos acil-CoA ainda não é bem esclarecido, mas uma das propostas sugeridas seria através de proteínas transportadoras ACBPs (acylCoA binding proteins) (Bernard \& Joubés, 2013). 
No retículo endoplasmático, essas moléculas de acil-CoA de cadeias curtas, passam por um processo de alongamento mediado por um complexo multienzimático de alongases FAE (fatty acid elongase). Durante esse processo, análogo a síntese de novo, ocorrem reações cíclicas com a adição de um par de carbonos às moléculas iniciais de cada ciclo, resultando em moléculas de acil-CoA de cadeia longa, com aproximadamente, 24 a 36 átomos de carbono em suas cadeias (Kunst \& Samuels, 2003; Samuels et al., 2008; Kunst \& Samuels, 2009).

As moléculas de acil-CoA de cadeia longa sintetizadas são as precursoras dos diferentes compostos de ceras que são formados por duas vias biossintéticas: a via da redução do grupo acil, que dá origem, a priori, aos compostos com números pares de átomos de carbono nas suas cadeias, como os aldeídos, álcoois primários e ésteres; e a via da descarbonilação, que leva a formação dos compostos com predominância de homólogos com números ímpares de átomos de carbono, tais como os alcanos, álcoois secundários e cetonas (figura 8) (Buchanan et al., 2000; Kunst \& Samuels, 2003; Shepherd \& Griffiths, 2006; Kunst \& Samuels, 2009; Bernard \& Joubés, 2013; Yeats \& Rose, 2013).

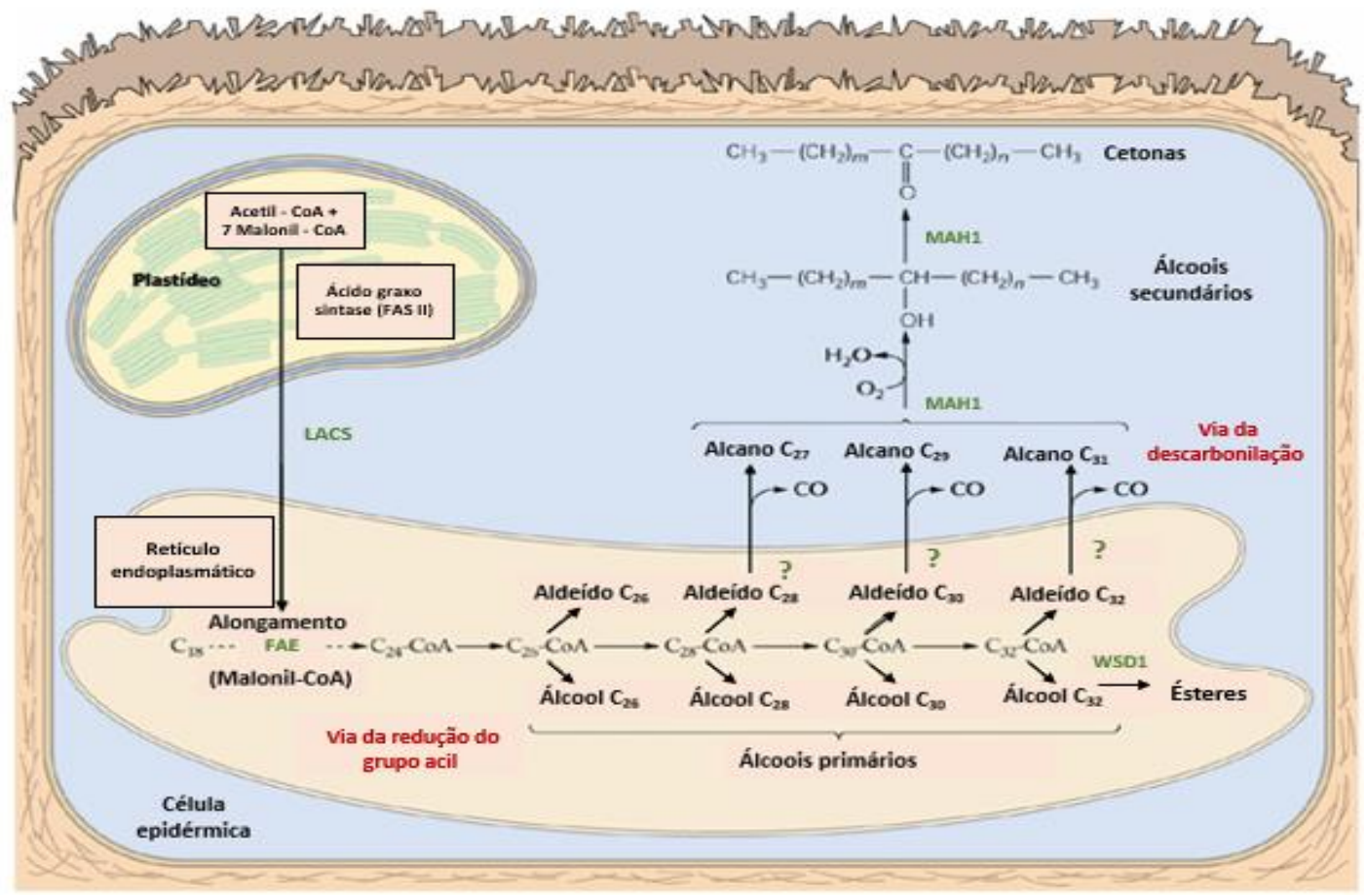

Figura 8. Síntese dos diferentes compostos acíclicos de ceras. As siglas destacadas em verde referem-se as principais enzimas envolvidas no processo de transporte LACS (long chain acyl-CoA synthase), alongamento FAE (fatty acid elongase) e de síntese WSD1 
(fatty acyl-CoA: fatty alcohol acyltransferase), MAH1 (midchain alkane hydroxylase). Modificado de Buchanan et al. (2000).

Na via da redução do grupo acil, os acil graxos de cadeia longa, através de enzimas redutases, são reduzidos a álcoois primários por meio de duas reações consecutivas, originando um aldeído intermediário que não é liberado em sua forma livre. Os ésteres são formados a partir da combinação de um álcool primário com um acil-graxo, (originado através da síntese de novo ou do processo de alongamento) pela ação da enzima fatty acyl-CoA: fatty alcohol acyltransferase WSDl (figura 8) (Vioque \& Kolattukudy, 1997; Kunst \& Samuels, 2003; 2009; Yeats \& Rose, 2013).

Na via da descarbonilação, ainda não se sabe quais são as enzimas envolvidas e como ocorre a formação dos alcanos através dos acil-graxos de cadeia longa. Uma alternativa seria a redução dos acil-graxos de cadeia longa a aldeídos que podem ser liberados na forma livre, catalisada por uma enzima redutase (envolvida no processo semelhante da via da redução do grupo acil). Em seguida, estes aldeídos formados podem ser descarbonilados, perda de um grupo CO, originando os alcanos. Sugere-se que a enzima envolvida nessa possível descarbonilação seja uma descarbonilase voltada para o aldeído. A partir dos alcanos, podem ser originados os álcoois secundários, através de um processo de hidroxilação, e a partir dos álcoois secundários, por meio de um processo de oxidação, são formadas as cetonas. Ambas as reações são catalisadas pela enzima MAH1 (midchain alkane hydroxylase) (figura 8) (Kunst \& Samuels, 2003; 2009; Rowland \& Domergue, 2012; Bernard \& Joubés, 2013).

Os triterpenoides também são importantes compostos presentes nas ceras cuticulares, os quais são sintetizados pela via do acetato-mevalonato (no citoplasma) (Dewick, 2009; Taiz \& Zeiger, 2009). Os triterpenoides podem ser divididos em dois principais grupos: os compostos pentacíclicos de cinco anéis (triterpenos) e os tetracíclicos de quatro anéis (esteroides) (Vickery \& Vickery, 1981).

Os triterpenos são biossintetizados a partir da via do acetato-mevalonato na qual ocorre a formação do ácido mevalônico através de duas reações de redução da 3-hidroxi3-metilglutaril-CoA (HMG-CoA), proveniente da condensação de 3 moléculas de acetilCoA mediada pela enzima $H M G-C o A$ reductase. Em seguida o ácido mevalônico passa por processos de pirofosforilação e de descarboxilação levando a formação de moléculas de isopentenil difosfato (IPP), as quais sofrem isomerização para formar o dimetilalil 
difosfato (DMAPP) através da enzima isopentenyl diphosphate. As moléculas de IPP e DMAPP são as unidades pentacarbonadas básicas para a formação das cadeias terpênicas (Dewick, 2009; Taiz \& Zeiger, 2009; Vranová et al., 2013).

A formação das cadeias terpênicas inicia-se com a condensação de uma molécula de IPP com uma de DMAPP pela ação da enzima geranyl diphosphate synthase para originar o geranil difosfato (GPP), molécula com 10 átomos de carbono precursora de quase todos os monoterpenos. A condensação de uma nova molécula de IPP à GPP, catalizada pela enzima farnesyl diphosphate synthase, formará o farnesil difosfato (FPP), molécula com 15 átomos de carbono precursora da maioria dos sesquiterpenos (Dewick, 2009; Taiz \& Zeiger, 2009; Vranová et al., 2013).

A condensação de duas moléculas de FPP, através da enzima squalene synthase, dará origem ao esqualeno, composto com 30 átomos de carbono e precursor dos triterpenoides penta e tetracíclicos. Inicialmente o esqualeno passa por um processo de ciclização (dobramento), através da epoxidação de uma das extremidades de sua cadeia, por ação da enzima squalene epoxidase, formando o 2,3-epóxi-esqualeno que não apresenta mais conformação linear plana. Após o processo de ciclização, são formados dois cátions intermediários instáveis estereoisômeros, o protosteril cátion ou o damarenil cátion, a partir dos quais outros cátions derivados podem ser formados e serão os precursores dos triterpenos tais como o lupeol, ácido ursólico, $\alpha$-amirina e $\beta$-amirina (Piironen et al., 2000; Dewick, 2009; Thimmappa et al., 2014).

Após a biossíntese, os diferentes compostos de ceras precisam ser exportados do interior da célula para a camada cuticular, processo esse ainda não completamente conhecido. Três principais hipóteses são utilizadas a fim de tentar explicar como ocorre esse transporte. A primeira alternativa seria com o auxílio de proteínas FABP (fatty acid binding protein) até o citoplasma e depois com a ligação a proteínas do tipo ABC (ATP binding cassette) através da membrana plasmática (Kunst \& Samuels, 2003; 2009; Bernard \& Joubés, 2013). De acordo com Samuels et al. (2008), foi identificado no mutante cer5 de Arabidopsis thaliana uma proteína transportadora do tipo ABC que parece estar associada ao transporte dessas substâncias das ceras para o exterior da célula. A segunda hipótese sugere o transporte desses compostos para o complexo de Golgi, onde poderiam ser envolvidos por vesículas lipídicas e atravessariam o citoplasma até a membrana plasmática unindo-se a ela. Já a terceira hipótese propõe que esses compostos de ceras seriam exportados através da parede celular por meio de proteínas chamadas de 
LTP (lipid transfer protein) para a camada cuticular (Kunst \& Samuels, 2003; 2009; Bernard \& Joubés, 2013; Yeats \& Rose, 2013). Proteínas do tipo ABC e LTP já foram identificadas em embriófitas mais basais como musgos e hepáticas, por exemplo (Buda et al., 2013; Edstam et al., 2014; Salminen et al., 2018).

\subsection{Aspectos gerais das briófitas sensu lato}

O termo "briófitas" compreende as hepáticas, os musgos e os antóceros. Desde os anos de 1980, estudos considerando caracteres bioquímicos e morfológicos indicaram que as "briófitas" são parafiléticas, correspondendo a três diferentes linhagens (Mishler \& Churchill, 1984; Crandall-Stotler, 1986). Entretanto, análises incluindo aspectos ultraestruturais da gametogênese sugeriam a monofilia do grupo, compartilhando um único ancestral comum (Garbary et al., 1993).

Filogenias baseadas em caracteres moleculares combinados a dados morfológicos e anatômicos reforçam que as três linhagens incluídas nas "briófitas" não formam um grupo monofilético, sendo os antóceros e os musgos mais relacionados com as plantas vasculares do que as hepáticas (figura 9) (Crandall-Stotler et al., 2009; Goffinet, 2000). Recentemente, Puttick et al. (2018) estudando dados de transcriptoma de algas e embriófitas, voltaram a sugerir uma origem comum as "briófitas", apresentando o grupo como monofilético. Entretanto, a hipótese de três linhagens independentes parece mais amplamente aceita.

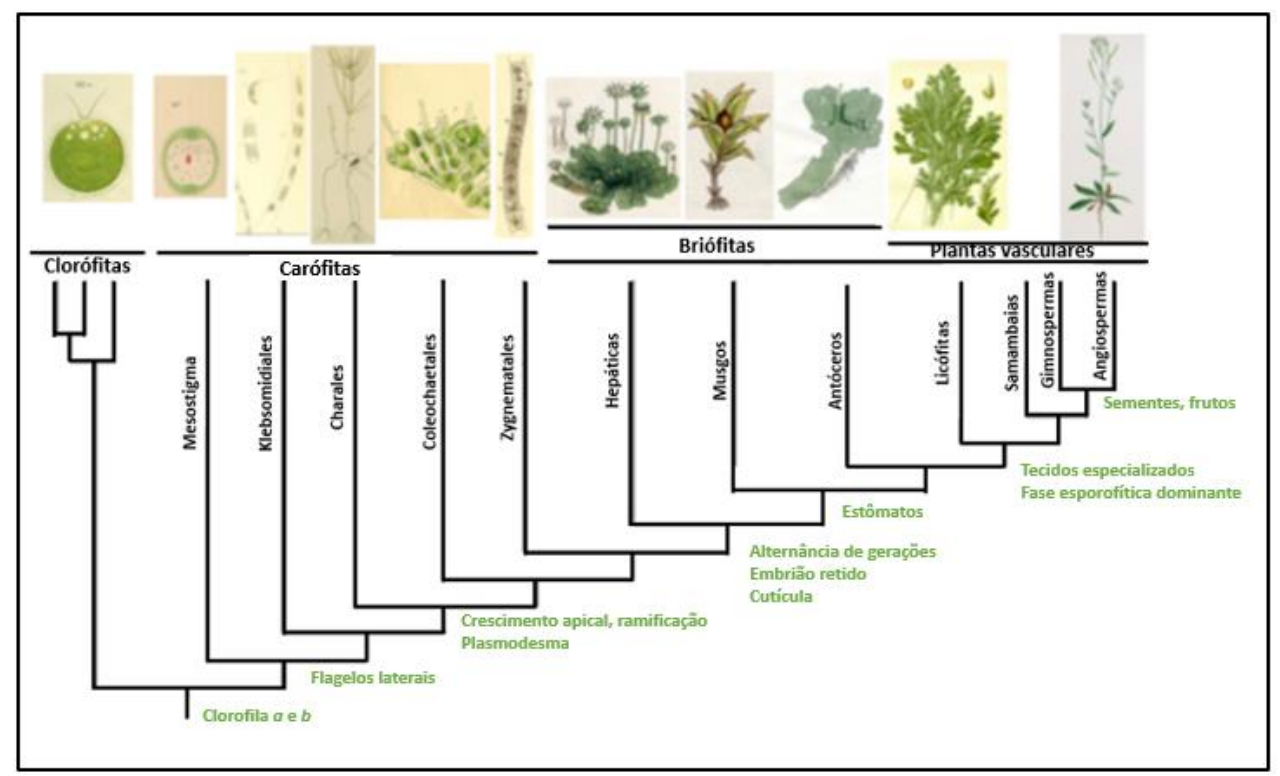

Figura 9. Relações filogenéticas das briófitas sensu lato. Modificado de Bowman et al. (2017). 
Dessa forma, neste trabalho, o termo "briófitas" é utilizado para designar três linhagens evolutivas distintas de plantas terrestres que correspondem as seguintes divisões: Marchantiophyta (hepáticas), Bryophyta sensu stricto (musgos) e Anthocerotophyta (antóceros) (Goffinet et al., 2009). Sua origem remonta o Ordoviciano há cerca de 400 milhões de anos (Gradstein et al., 2001; Magallón \& Hilu, 2009).

As briófitas compartilham vários caracteres, alguns dos quais foram retidos por todas as outras plantas terrestres, como o embrião protegido no início do desenvolvimento, e outros que são únicos dentre as plantas atuais, como esporófito não ramificado (Vanderpoorten \& Goffinet, 2009). Essas plantas são caracterizadas por serem criptógamas e avasculares, geralmente são pequenas, possuem clorofilas $a$ e $b$, carotenos, xantofilas, amido, gorduras, celulose e hemicelulose (Delgadillo \& Cárdenas, 1990; Costa \& Luizi-Ponzo, 2010).

As briófitas apresentam um ciclo de vida com alternância de gerações heteromórficas, marcado pela geração gametofítica haploide (n) que corresponde a fase dominante, enquanto a geração esporofítica diploide (2n) é dependente da primeira e efêmera (Vanderpoorten \& Goffinet, 2009). O esporófito produz esporos (haploides), que quando dispersos e em locais adequados, podem germinar e dar origem a um protonema (filamentos de células). O protonema inicial, pode então originar outros gametófitos. Os gametófitos produzem os gametângios, órgãos responsáveis pela produção dos gametas, chamados de anterídio (masculino) e arquegônio (feminino). Na porção ventral do arquegônio encontra-se a oosfera (gameta feminino), e na porção apical dos gametófitos, dentro dos anterídios estão os anterozoides (gametas masculinos). Na reprodução sexuada, os anterozoides, que são flagelados, dependem da água para chegar até a oosfera, ocorrendo a fertilização e a formação de um embrião. Esse embrião, através de várias divisões originará o esporófito, que produzirá esporos, iniciando o ciclo novamente (figura 10) (Goffinet, 2000; Vanderpoorten \& Goffinet, 2009). As briófitas também podem se reproduzir assexuadamente por meio de gemas, propágulos e fragmentos do gametófito (Goffinet, 2000; Schofield, 2001; Bordin, 2009; Vanderpoorten \& Goffinet, 2009). 


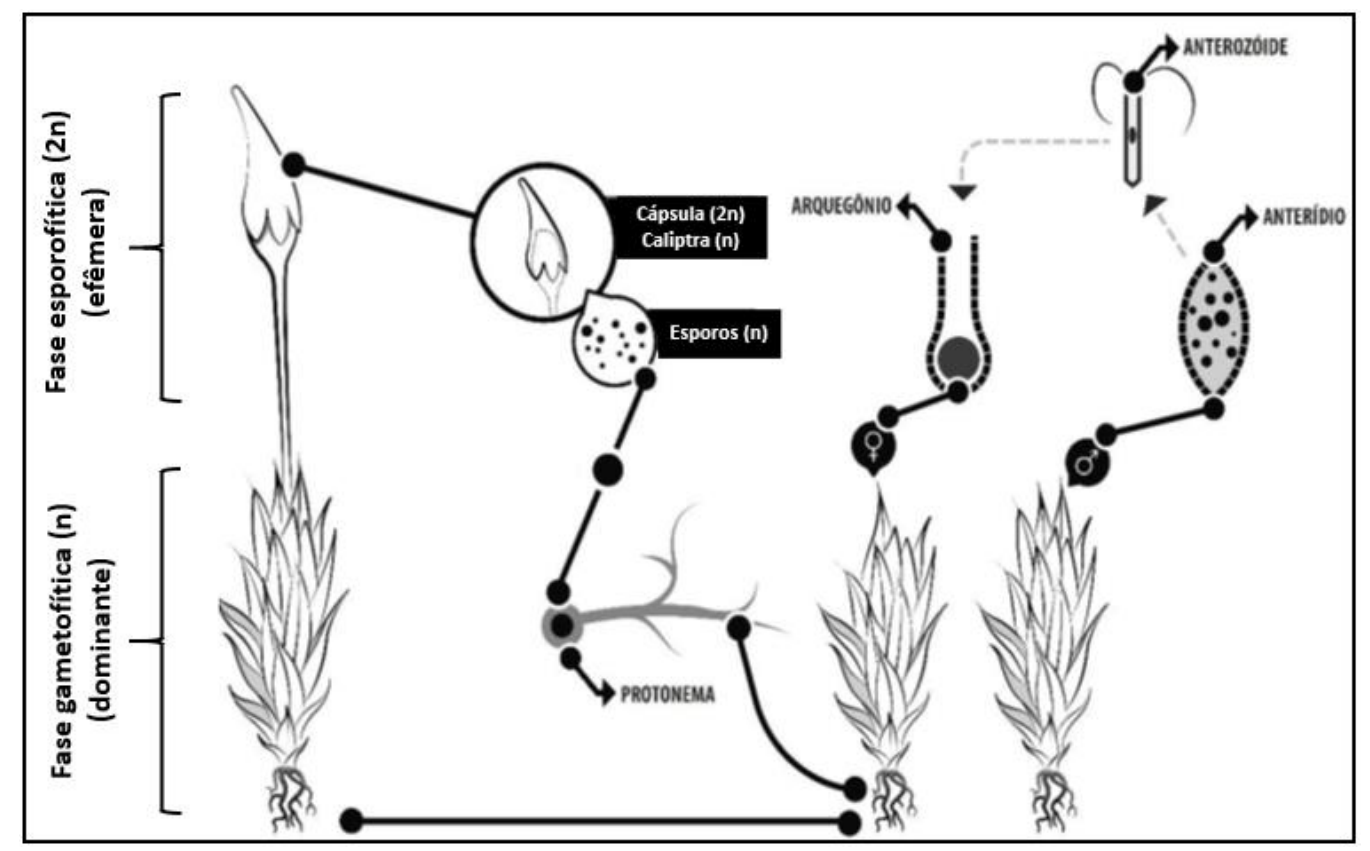

Figura 10. Ciclo de vida das briófitas. Modificado de Santos \& Della (2018).

De modo geral, musgos, hepáticas e antóceros são formados por estruturas básicas comuns, com algumas modificações para cada grupo (figura 11). O gametófito pode ser folhoso ou taloso, sempre fotossintetizante. Musgos e hepáticas podem apresentar gametófito folhoso (figura 11). Os filídios do gametófito folhoso encontram-se aderidos ao caulídio que é o eixo de sustentação desse gametófito. O gametófito taloso ocorre nos antóceros e algumas hepáticas talosas, sendo formado por um talo mais ou menos achatado, não diferenciado em caulídio e filídios (figura11). O talo dos antóceros é multilobado e possui células com apenas um cloroplasto e, geralmente, um pirenoide. Os rizoides ocorrem em todos os grupos e são estruturas filamentosas que possuem a função de absorção de nutrientes e fixação ao substrato (figura 11). Nos antóceros, os rizoides são unicelulares com paredes lisas (Goffinet, 2000; Bordin, 2009; Vanderpoorten \& Goffinet, 2009).

O esporófito é formado por pé, seta e cápsula, com diferenciações em cada grupo (figura 11). O pé está presente em musgos, hepáticas e antóceros. A seta ocorre em musgos e hepáticas, e é a porção alongada do esporófito (figura 11). A cápsula está presente nas três divisões, sendo, em musgos e hepáticas, protegida pela caliptra (estrutura de origem gametofítica) em seus estágios iniciais de desenvolvimento (figura 11). Nos antóceros, a cápsula é alongada e possui crescimento indeterminado devido a presença de um tecido meristemático na sua base. Nesse grupo, praticamente todo o esporófito é representado pela cápsula (figura 11) e a liberação dos esporos é gradual com auxílio de 
estruturas denominadas de pseudoelatérios (encontradas no interior dos esporângios) (Goffinet, 2000; Bordin, 2009; Vanderpoorten \& Goffinet, 2009). Essas características morfológicas e suas diferenciações são de grande importância, visto que também são utilizadas como critérios na identificação dos grupos de briófitas.

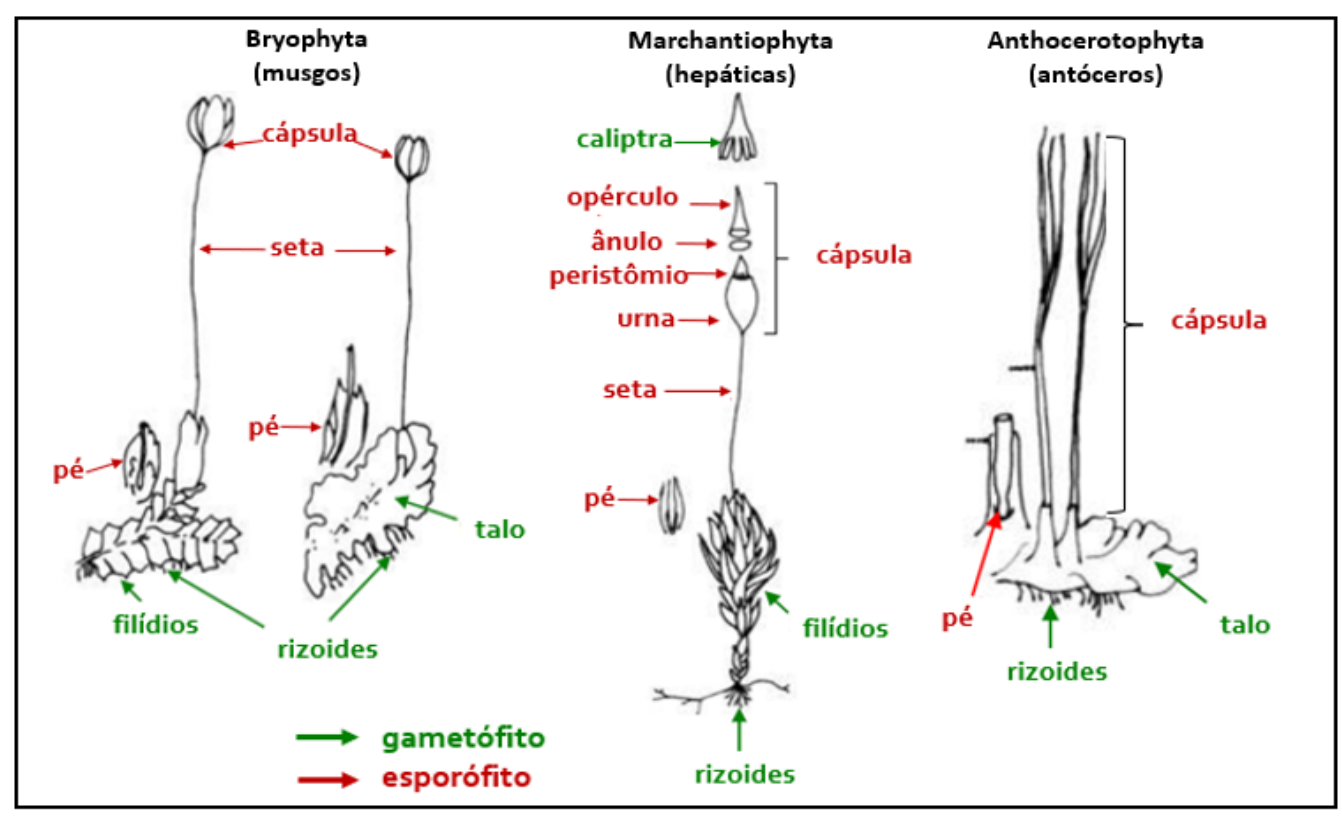

Figura 11. Estruturas morfológicas básicas das briófitas. Os nomes das estruturas destacados em verde correspondem ao gametófito e os destacados em vermelho pertencem ao esporófito. Modificado de Bordin (2009).

A divisão Bryophyta (musgos), devido a sua ampla diversidade, possui as estruturas mais variáveis entre as briófitas. Genericamente, os musgos são divididos em pleurocárpicos e acrocárpicos (figura 12). Os musgos pleurocárpicos apresentam os arquegônios nas laterais e nunca na extremidade apical dos caulídios, geralmente com uma filotaxia pinada e formam os "tapetes" que recobrem os substratos (figura 12A). Já os musgos acrocárpicos originam os "tufos" de musgos e possuem os arquegônios apenas na extremidade distal do eixo principal do caulídio com esporófito geralmente terminal, conferindo-lhes um aspecto ereto (figura 12B e 12C) (Goffinet, 2000; Vanderpoorten \& Goffinet, 2009; Costa \& Almeida, 2010). 


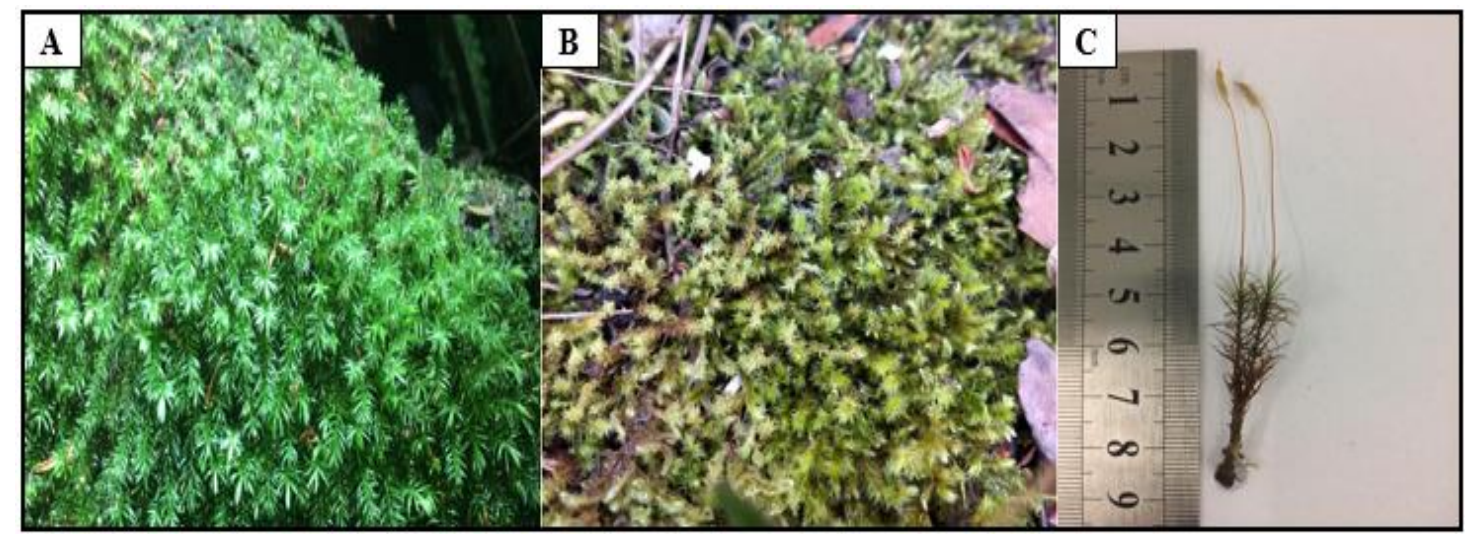

Figura 12. Exemplos de musgos pleurocárpicos (A) e acrocárpicos (B-C). A: "tapete" do musgo pleurocárpico Pyrrhobryum spiniforme (Hook.) T. J. Kop. (Mniaceae), cobrindo um tronco de árvore. B: "tufos" de musgos acrocárpicos no solo. C: detalhe do esporófito na extremidade distal do gametófito do musgo acrocárpico Polytrichum juniperinum Willd. ex Hedw. (Polytrichaceae). Fotos: Tamara Matos (2019).

O gametófito folhoso dos musgos pode variar na forma, no tamanho e na estrutura. Normalmente são verdes, podendo variar em diversos tons (figura 13A). Os filídios do gametófito folhoso são formados por uma lâmina, geralmente uniestratificada com ou sem uma costa multiestratificada, a qual pode ser única ou bifurcada (figura 13B). No interior do caulídio de algumas espécies são encontradas células especializadas na condução de água e nutrientes, chamados de hidroides e leptoides, respectivamente (figura 13C). Os rizoides são pluricelulares e septados (Bordin, 2009; Peralta, 2009; Vanderpoorten \& Goffinet, 2009).

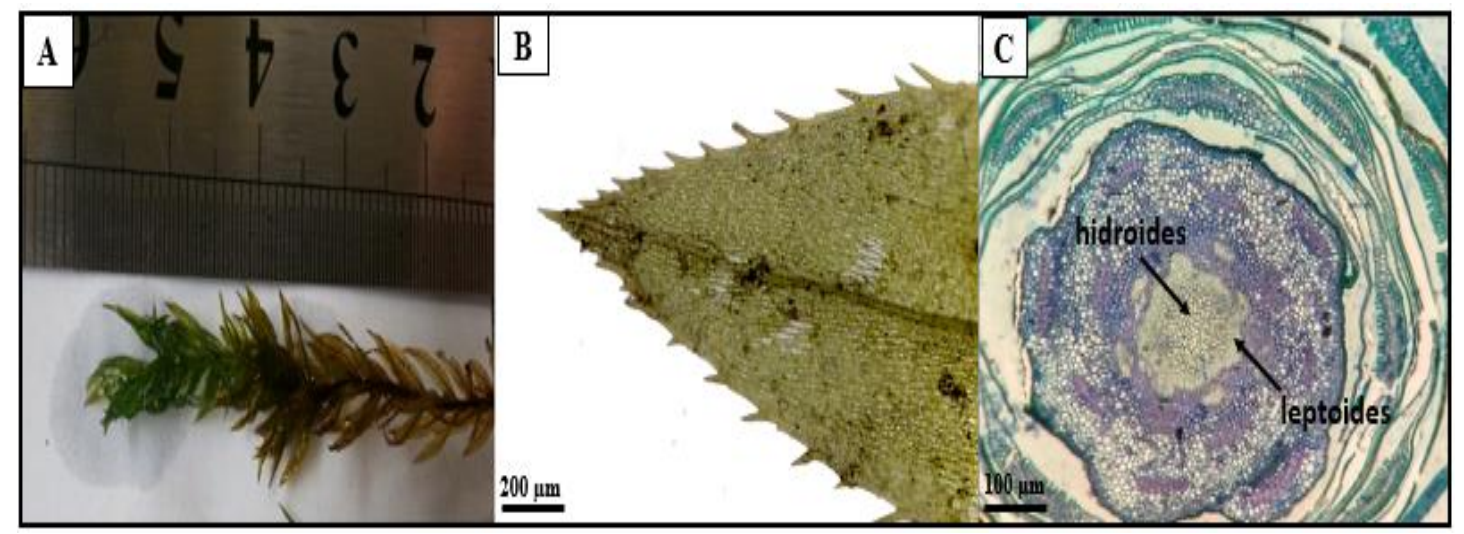

Figura 13. Principais características do gametófito folhoso dos musgos. A: estrutura do gametófito folhoso e detalhe do filídio com costa única (B) do musgo Atrichum androgynum (Müll. Hal.) A. Jaeger (Polytrichaceae). C: corte transversal de um caulídio 
de Polytrichum sp. (Polytrichaceae) com hidroides e leptoides localizados na região central do eixo. Fotos: Tamara Matos (2019).

Nos musgos, o esporófito é formado por estruturas mais complexas (figura 14). Na epiderme da cápsula do esporófito, encontram-se os estômatos (figura 14A). A cápsula é formada por urna, peristômio, ânulo e opérculo (figura 14B-C). O peristômio é formado por dentes arranjados em um ou dois anéis (figura 14C-D), os quais também são utilizados como critério na divisão genérica do grupo. A urna é a região produtora de esporos, o ânulo e o opérculo, juntamente com o peristômio, são responsáveis pela abertura da cápsula e liberação dos esporos. A caliptra, estrutura formada por parte do gametófito que aparece como um capuz acima da cápsula, é bem desenvolvida e visível nos musgos (figura 14E), mas também pode estar presente em hepáticas (Goffinet, 2000; Bordin, 2009; Vanderpoorten \& Goffinet, 2009).

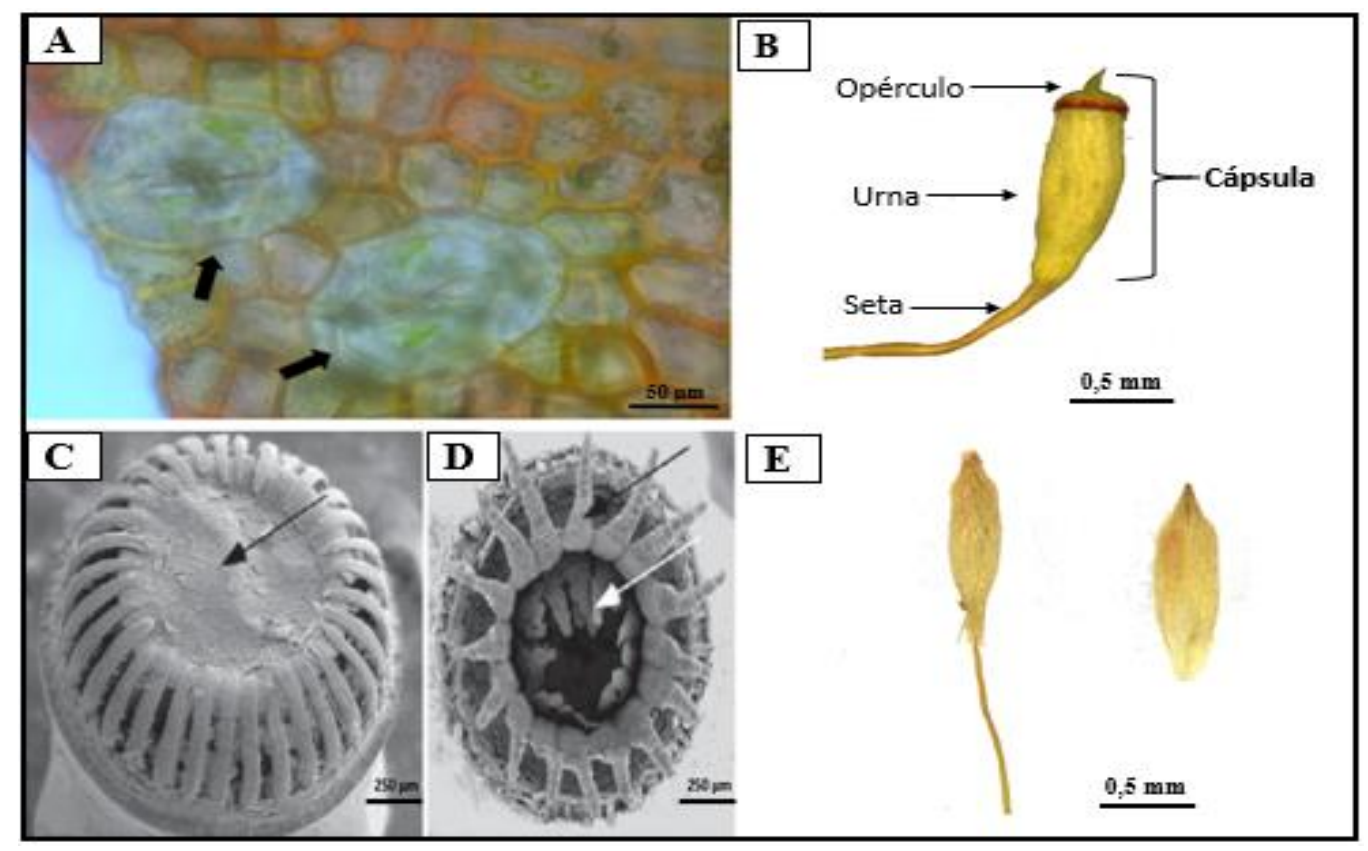

Figura 14. Estruturas características do esporófito dos musgos. A: estômatos localizados na epiderme da cápsula do musgo Polytrichadelphus pseudopolytrichum (Raddi) G.L. M. (Polytrichaceae). B-C: estruturas que compõem a cápsula. B: detalhe do opérculo e da urna em Pogonatum pensilvanicum (W. Bartram ex Hedw.) P. Beauv. (Polytrichaceae). C-D: detalhe do peristômio. Peristômio do musgo Atrichum undulatum (Hedw.) P. Beauv (Polytrichaceae) com um anel de dentes. Seta preta indica o ânulo. D: exemplo de peristômio com dois anéis de dentes (setas preta e branca). E: detalhe da caliptra do musgo Pogonatum pensilvanicum (Polytrichaceae). Fotos A, B, E: Tamara Matos (2019); C-D: 
microscopia eletrônica de varredura do peristômio composto por dentes, modificado de Vanderpoorten \& Goffinet (2009).

Marchantiophyta compõem uma divisão diversificada de plantas micro e macroscópicas, considerada o grupo de embriófitas mais basais. As hepáticas pertencentes a esta divisão podem ser subdivididas em dois grupos morfológicos principais, as folhosas e as talosas (figura 15). As hepáticas folhosas são caracterizadas pela ausência da costa (espessamento de células no centro do talo) (figura 15A), pela presença ou ausência de anfigastros (encontrados na posição ventral dos ramos) (figura 15B), e pelos lóbulos, que podem ter tamanho variável ou estar ausentes. Nas hepáticas talosas não há diferenciação de filí́dios e a costa pode estar presente ou ausente no talo (figura 15A). As células do gametófito possuem estruturas chamadas de "oleocorpos" ou "corpos de óleo" (figura 15C) que podem conter mono, sesqui ou diterpernos. A cápsula apresenta um formato mais arredondado e se abre por valvas, sendo os esporos dispersos com auxílio de elatérios. Os rizoides são unicelulares e podem apresentar escamas (Goffinet, 2000; Bordin, 2009; Vanderpoorten \& Goffinet, 2009; Asakawa et al., 2013; Santos, 2016).

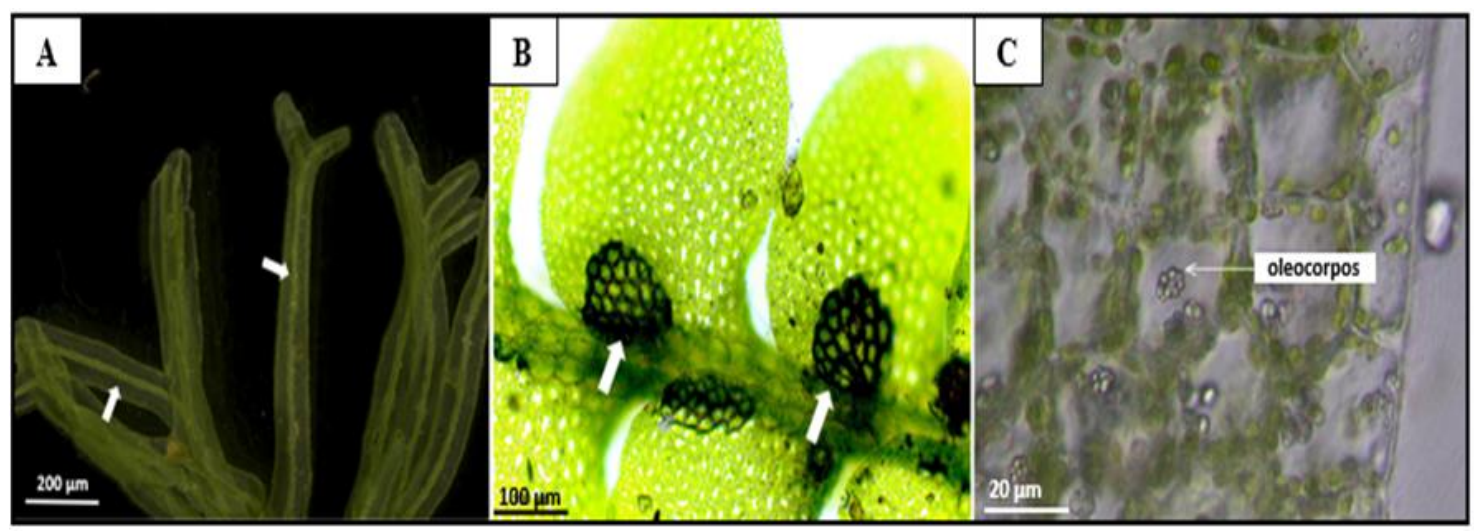

Figura 15. Hepáticas talosas e folhosas. A: presença de costa (setas) na hepática talosa Metzgeria albinea Spruce (Metzgeriaceae). B: anfigastros (setas) na hepática folhosa Lejeunea flava (Sw.) Nees (Lejeuneaceae). C: células do gametófito com “oleocorpos". Fotos A-B: Tamara Matos (2019); C: Google Images.

O gênero mais conhecido das hepáticas é Marchantia. As espécies pertencentes a esse gênero apresentam características únicas e são facilmente reconhecidas. O gametófito taloso dessas plantas possui na superfície dorsal poros aeríferos com células que, diferentes dos estômatos, não se fecham, originando uma abertura central para as 
trocas gasosas (figura 16A). Na região dorsal do talo há estruturas em forma de taça denominadas de conceptáculo, nas quais as gemas na reprodução assexuada são formadas e dispersas por meio da água para a formação de um novo indivíduo (figura 16B) (Goffinet, 2000; Bordin, 2009; Vanderpoorten \& Goffinet, 2009).

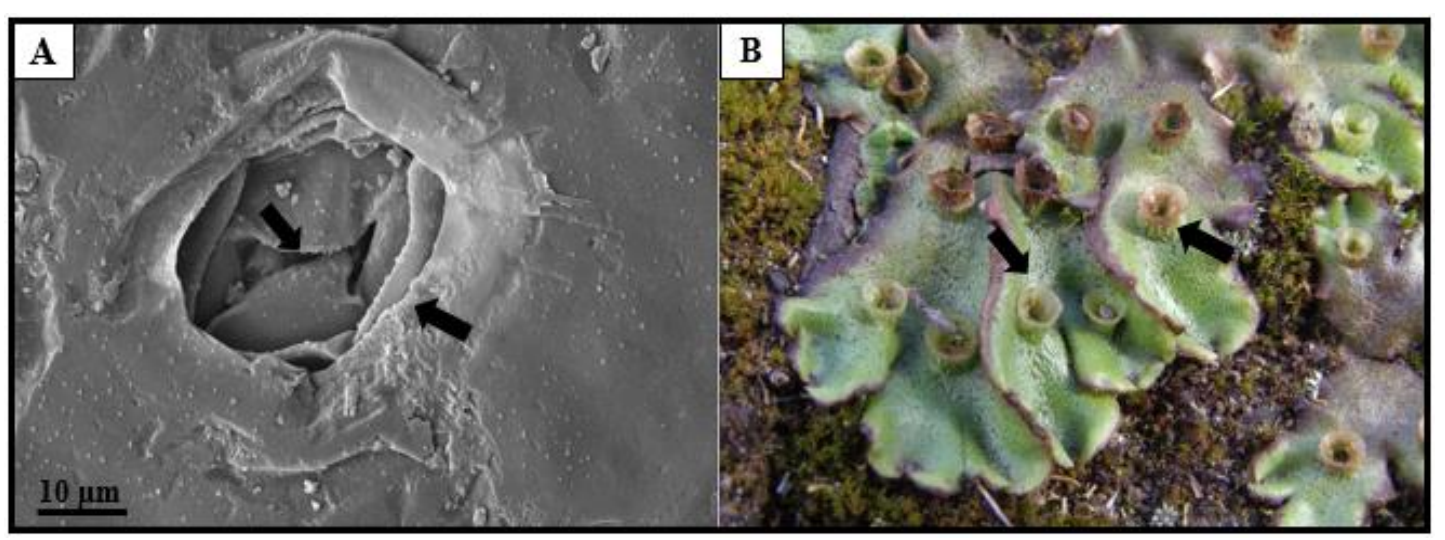

Figura 16. A: microscopia eletrônica de varredura da superfície do gametófito taloso de Marchantia papillata Raddi (Marchantiaceae). As setas indicam o poro e a abertura central para as trocas gasosas. B: conceptáculos (setas) na região dorsal do gametófito taloso da hepática Marchantia sp. Fotos A: Tamara Matos (2019); B: Déborah Santos (2013).

Entretanto, essas plantas também podem se reproduzir sexuadamente, com gametângios que são originados em estruturas especializadas denominadas gametóforos (unissexuados) (figura 17). Os gametófitos femininos e masculinos são identificados por seus gametóforos bem distintos. Os anterídios originam-se em gametofóros com a parte superior em forma de disco, chamado de anteridióforo (figura 17A), enquanto os arquegônios originam-se em gametóforos com a região superior em forma semelhante a um "guarda-chuva", o arquegonióforo (figura 17B-C) (Goffinet, 2000; Vanderpoorten \& Goffinet, 2009). 


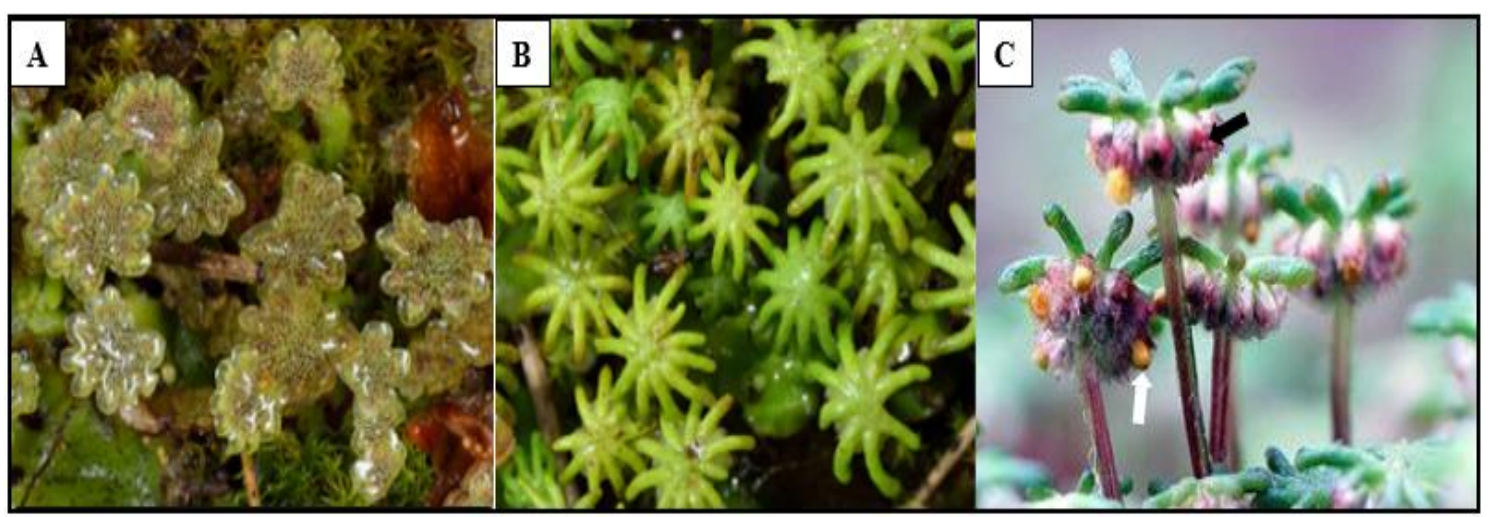

Figura 17. Gametófitos de Marchantia. A: detalhe da forma do gametófito masculino em forma de disco. B-C: gametófito feminino em forma de "guarda-chuva". C: detalhe do gametófito feminino com os esporófitos (seta preta) e cápsulas (seta branca). Imagens: Google Images.

As briófitas podem viver sobre os mais variados tipos de substrato, como troncos e ramos de árvores (corticícolas), folhas (epífilas), troncos em decomposição (epíxilas), solo (terrícolas) ou rochas (rupícolas), geralmente em locais úmidos pois necessitam de água para possibilitar a mobilidade dos gametas masculinos (Goffinet, 2000; Vanderpoorten \& Goffinet, 2009; Costa \& Luizi-Ponzo, 2010).

Essas plantas podem tolerar condições ambientais extremas e por isso estão amplamente distribuídas no mundo, sendo encontradas desde o Ártico até as florestas tropicais e em desertos, mas nunca no ambiente marinho (Delgadillo \& Cárdenas, 1990; Schofield, 2001). No Brasil, ocorrem em todos os biomas, inclusive na caatinga, sendo a região Sudeste a mais diversa com 1.228 táxons e também com maior endemismo, 219 espécies (Costa \& Peralta, 2015). Podem ser indicadoras de depósitos minerais, como por exemplo os "musgos de cobre" que estão associados a solos ou rochas com grande concentração deste mineral. Pioneiras na colonização de ambientes perturbados, auxiliam no combate à erosão do solo e na manutenção da umidade dos ecossistemas por reterem a água da chuva (Schofield, 2001).

Quanto a sua aplicabilidade, as espécies de briófitas comumente utilizadas para fins comerciais são as pertencentes ao gênero Sphagnum L. Essas plantas são empregadas como meio de cultivo de outras plantas, são utilizadas na fabricação de papel, como isolante térmico, em enchimento de camas e travesseiros, como combustível natural (turfeiras), para a filtração de água e para a ação antisséptica (Ando \& Matsuo, 1984; Delgadillo \& Cárdenas, 1990; Glime, 2007). Fernández \& Serrano (2009) descreveram 
algumas atividades biológicas relacionadas a espécies de briófitas, tais como: citotóxica, antioxidante, anti-inflamatória, carcinogênica, inibição enzimática, cardiotônica (aumento do fluxo sanguíneo coronário), antimicrobianas (antifúngica, antibacteriana, antiviral), alelopática (inibem o crescimento de raízes e folhas em plantas de arroz, por exemplo, ou promovem a germinação de sementes de trigo) e também podem apresentar toxicidade diante de moluscos e peixes.

Segundo Shaw \& Goffinet (2000) e Gradstein et al. (2001), as briófitas são o segundo maior grupo de plantas terrestres depois das angiospermas. De acordo com o The Plant List (2018), 20.000 espécies são reconhecidas no mundo. Estima-se que a maior diversidade do grupo encontra-se na região neotropical onde ocorrem aproximadamente 4.000 espécies (Pócs, 1982; Gradstein et al., 2001). O primeiro checklist da diversidade de briófitas brasileiras foi publicado por Costa \& Luizi-Ponzo (2010), no qual foram listadas 1.521 espécies pertencentes as três divisões. Pouco depois, Costa \& Peralta (2015) reavaliaram essa diversidade, com acréscimos de algumas espécies (1.524), das quais 11 são antóceros, 633 correspondem as hepáticas e 880 são musgos, distribuídas em 413 gêneros e 117 famílias.

\subsection{A cutícula em briófitas sensu lato}

Informações relativas à cutícula em briófitas sensu lato são escassas. Um levantamento de trabalhos científicos de caracterização da cutícula e das ceras cuticulares em briófitas sensu lato foi realizado através dos bancos de dados da Web of Science e do Google Scholar. Na primeira plataforma foram utilizadas as combinações cuticle e bryophytes, wax e moss e wax e liverworts, sendo encontrados 18 artigos. Pela ferramenta de busca do Google Scholar, com as palavras surface wax e bryophytes foram encontrados mais oito artigos (tabela 1). Desses 26 artigos, a maioria trata da morfologia da cutícula através de microscopia eletrônica de transmissão (MET) e/ou MEV. A análise da composição química das ceras e da cutina, bem como a análise combinada também aparece em outros artigos. Além disso, a partir desses artigos outras três referências incluindo livros e artigos da caracterização da cutícula nesse grupo de plantas foram encontradas. 
Tabela 1. Lista das referências de trabalhos científicos relacionados a análise da cutícula em briófitas sensu lato.

\section{Tópicos}

Composição química da cera

Composição química da cutina

MEV

MET

Composição química da cera + MEV

Composição química da cutina + MET

MEV + MET

\section{Referências*}

Benešová et al. (1972) ${ }^{\mathrm{a}}$

Haas (1982) ${ }^{b}$

Bush \& McInerney (2013) ${ }^{\mathrm{a}}$

Busta et al. (2016a) ${ }^{\mathrm{a}}$

Busta et al. (2016b) ${ }^{\mathrm{a}}$

Resemann et al. (2019) a

Caldicott \& Eglinton (1976) ${ }^{\mathrm{b}}$

Green \& Clayton-Greene (1977) ${ }^{\mathrm{b}}$

Proctor (1979) ${ }^{\mathrm{c}}$

Clayton-Greene et al. $(1985)^{\mathrm{b}}$ Pócs (2005) ${ }^{\mathrm{b}}$

Koch et al. (2009) ${ }^{\text {a }}$

Heinrichs \& Reiner-Drehwald (2012) ${ }^{\mathrm{c}}$

Pressel (2011) ${ }^{\mathrm{b}}$

Budke et al. (2012) ${ }^{\mathrm{a}}$

Budke et al. (2013) ${ }^{\mathrm{a}}$

Budke \& Goffinet (2016) ${ }^{\text {a }}$

Neinhuis \& Jetter (1995) ${ }^{\mathrm{b}}$

Heinrichs et al. (2000) ${ }^{\mathrm{c}}$

Heinrichs \& Rycroft (2001) ${ }^{\mathrm{a}}$

$\mathrm{Xu}$ et al. $(2009)^{\mathrm{c}}$

Renault et al. (2017) ${ }^{\mathrm{a}}$

Cook \& Graham (1998) ${ }^{\mathrm{c}}$

Budke et al. (2011) ${ }^{\mathrm{a}}$

Buda et al. (2013) ${ }^{\mathrm{a}}$

Salminem et al. (2018) ${ }^{\mathrm{b}}$

Proteínas de transferência lipídica

* a Artigos encontrados na base de dados Web of Science; ${ }^{b}$ Artigos encontrados na base de dados Google Scholar; ${ }^{\text {c }}$ Artigos encontrados nas duas bases de dados.

Além das análises histoquímicas nas quais a cutícula podia ser vista como uma fina camada acima da superfície da parede celular (Buch, 1945), as técnicas de MEV e MET permitiram a descrição dessa camada em diversos grupos de briófitas (Schonherr \& Ziegler, 1975; Buda et al., 2013; Budke \& Goffinet, 2016). Através de MET, por exemplo, foi demonstrada a presença da cutícula em torno dos poros aeríferos na epiderme dorsal dos gametófitos talosos de várias espécies de Marchantia (Schonherr \& Ziegler, 1975). 
Já por MEV, foram detectadas ceras com morfologias variando de amorfas a densas plaquetas e grânulos em musgos pertencentes à Polytrichaceae (Green \& Clayton-Greene, 1977; Clayton-Greene et al., 1985). Projeções de cristais de cera também foram detectados em muitas outras espécies de briófitas (Proctor, 1979; Neinhuis \& Jetter, 1995; Heinrichs et al., 2000). Ceras epicuticulares do tipo plaquetas já foram visualizadas em espécies de hepáticas de Plagiochilaceae e Lejeuneaceae, além de ceras do tipo filme em Lepidoziaceae (Heinrichs \& Reiner-Drehwald, 2012).

As análises de composição química das ceras cuticulares também auxiliaram na compreensão da cutícula nesse grupo de plantas. A composição das ceras de briófitas é semelhante à das plantas vasculares, sendo o principal componente o ácido hexadecanoico (Caldicott \& Eglinton, 1976), composto comumente encontrado em plantas vasculares (Haas, 1982; Neinhuis \& Jetter, 1995).

Em musgos, as ceras presentes nos gametófitos de Pogonatum urnigerum (Hedw.) P. Beauv. (Polytrichaceae) são formadas principalmente por aldeídos, enquanto aquelas dos gametófitos de Pogonatum aloides (Hedw.) P. Beauv. (Polytrichaceae) e Andreaea rupestris Hedw. (Andreaeaceae) possuem principalmente ácidos graxos, álcoois primários e ésteres (Haas, 1982). Os gametófitos de Syntrichia caninervis Mitt. (Pottiaceae) apresentam ceras compostas por ácidos graxos, álcoois primários e alcanos (Xu et al., 2009), sendo esses últimos majoritariamente encontrados em espécies de Sphagnum sp. (Sphagnaceae) (Caldicott \& Eglinton, 1976; Bush et al., 2013), enquanto em Physcomitrella patens (Hedw.) Bruch \& Schimp. (Funariaceae), os álcoois são os componentes principais (Buda et al., 2013). Em hepáticas pertencentes a Calypogeiaceae e Scapaniaceae, o ácido hexadecanoico foi encontrado como componente principal (Pócs, 2005; Pressel et al., 2011). Heinrichs et al. (2000) constataram a ocorrência de ceras em seis espécies de Plagiochilaceae, as quais apresentaram, predominantemente, os ácidos graxos. Em Anthelia julacea (L.) Dumort. (Antheliaceae), o diterpeno kaureno foi o principal constituinte das ceras (Huneck \& Vevle, 1970). Já em hepáticas de Anastrophyllaceae, Calypogeiaceae, Jungermanniaceae, Myliaceae e Pelliaceae, os alcanos e ésteres foram os constituintes principais das ceras (Benešová et al., 1972).

A presença das ceras cuticulares também já foi descrita na cápsula do esporófito e na caliptra (Koch et al., 2009b; Budke et al., 2011; 2012; 2013; Busta et al., 2016a). As cápsulas dos esporófitos de espécies de Polytrichales apresentam composição majoritária de álcool secundário nas ceras, e morfologia em túbulos e plaquetas (Neinhuis \& Jetter, 
1995). Plaquetas e grânulos de ceras foram encontrados nas cápsulas do esporófito do musgo Buxbaumia viridis (DC.) Moug. \& Nestl (Buxbaumiaceae) (Koch et. al, 2009b).

Recentemente, trabalhos com a análise da cutícula do musgo Funaria hygrometrica Hedw. (Funariaceae) demonstraram que esta camada protetora difere quanto ao teor e composição das ceras quando analisado o gametófito, a cápsula do esporófito e a caliptra, com alguns compostos específicos compartilhados somente entre o gametófito e a caliptra. Entretanto, a morfologia do tipo amorfa foi detectada na superfície de todas essas estruturas (Budke et al., 2011; 2012; 2013; Busta et al., 2016a; 2016b).

Além disso, a composição química da cutina também já foi descrita em espécies de Sphagnum (musgo) e Marchantia (hepática). Em Sphagnum, foram identificados diversos ácidos di-hidroxi-hexadecanoicos, enquanto nas hepáticas o ácido 15-hidroxihexadecanoico foi o componente principal, o qual é relatado como composto típico da cutina em plantas vasculares (Caldicott \& Eglinton, 1976). No musgo Physcomitrella patens (Funariaceae), além dos ácidos di-hidroxi-hexadecanoicos, o ácido 5-hidroxitetradecano e os ácidos p-cumárico e cafeico são os principais monômeros que compõem a cutina (Buda et al., 2013; Renault et al., 2017).

A presença destas classes de compostos de ceras comuns sugere que a biossíntese destes metabólitos em briófitas pode ser semelhante à das plantas vasculares (Kolattukudy, 2001; Busta et al., 2016a). Segundo Jetter et al. (2006), os compostos que formam a cera cuticular em musgos e hepáticas são idênticos aos das gimnospermas e angiospermas, sugerindo que as vias de síntese envolvidas na produção desses componentes da cutícula tenham surgido nos estágios iniciais da história evolutiva das plantas terrestres. Determinar as semelhanças entre as ceras de linhagens de plantas distantes, tais como as briófitas e plantas vasculares, é o primeiro passo para a visão da cutícula em termos evolutivos (Busta et al., 2016a).

\section{OBJETIVO GERAL}

Analisar a composição química e caracterizar a morfologia das ceras cuticulares do gametófito em diferentes espécies de Bryophyta (musgos) e Marchantiophyta (hepáticas) e do esporófito quando disponíveis em espécies de Polytrichaceae, a fim de ampliar nosso entendimento sobre esse grupo de plantas e sobre essa importante novidade evolutiva das embriófitas. 


\section{MATERIAL \& MÉTODOS}

\subsection{Definição dos grupos Bryophyta e Marchantiophyta para as análises}

Para a escolha dos grupos de briófitas a serem analisados e a posterior coleta do material botânico, alguns critérios foram adotados em conjunto com o Dr. Denilson Fernandes Peralta do Instituto de Botânica - IBt/SP. Primeiramente, foi realizado um levantamento a respeito da diversidade das três divisões no estado de São Paulo - Brasil, sendo definidas as divisões Bryophyta (musgos) e Marchantiophyta (hepáticas), considerando a maior diversidade. Em seguida, o mesmo procedimento foi utilizado para verificar quais eram as famílias e os gêneros de maior ocorrência. Também foram priorizados os grupos taxonomicamente bem resolvidos e que pudessem ser representativos das duas divisões. Finalmente, localidades próximas a cidade de São Paulo e de fácil acesso também foram critérios para a escolha do material vegetal.

\subsection{Coleta do material vegetal}

As amostras são formadas por um pool de indivíduos coletados aleatoriamente no local de ocorrência das populações. Foram coletadas 22 espécies de musgos e 12 espécies de hepáticas, totalizando 34 espécies de briófitas pertencentes a diferentes famílias e gêneros, provenientes de diferentes municípios e fitofisionomias do estado de São Paulo (tabela 2) (figuras 18 e 19), entre os anos de 2018 e 2019. O material foi identificado pelo Dr. Denilson F. Peralta e exemplares testemunhos foram depositados no Herbário de São Paulo - SP. 


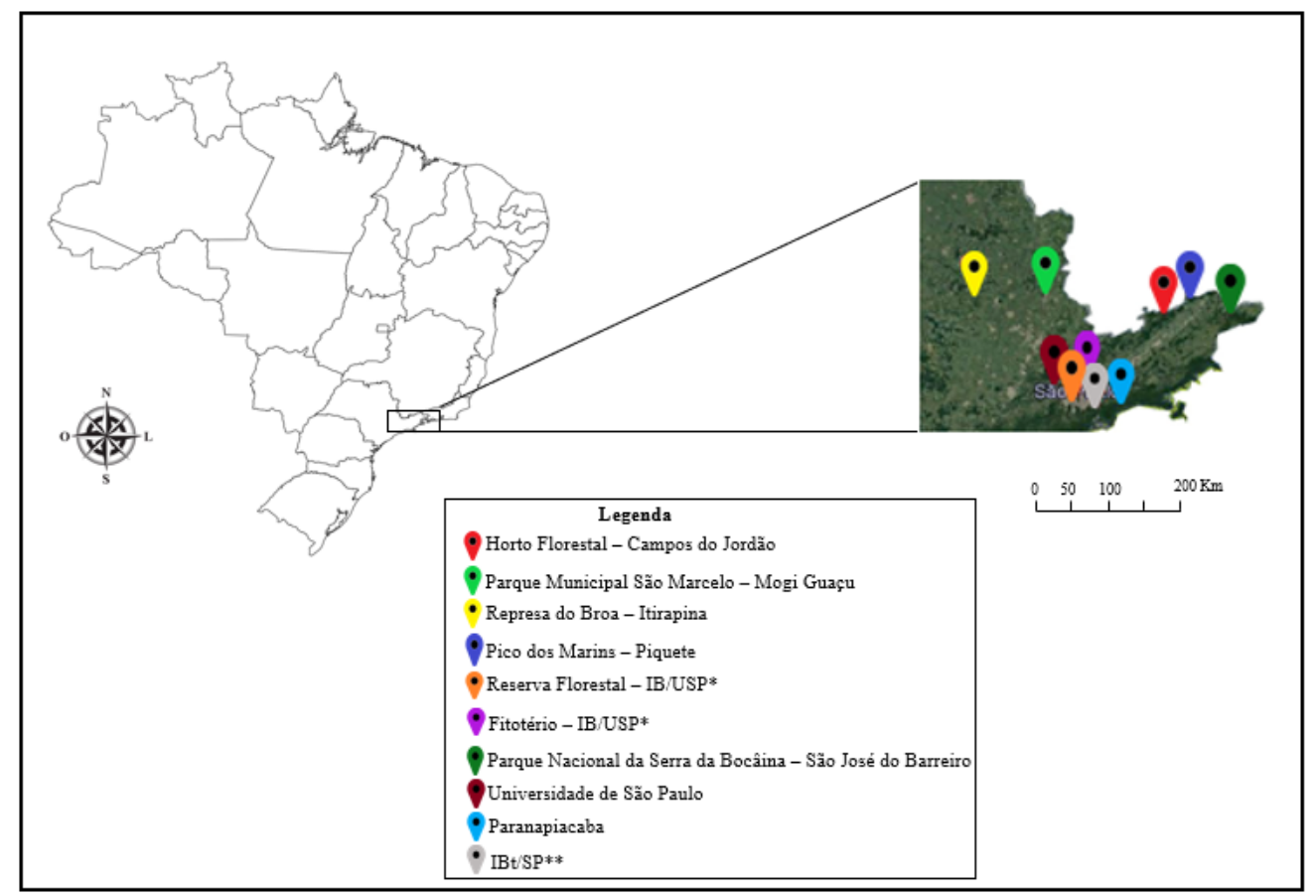

Figura 18. Localização dos pontos de coleta das amostras de musgos e hepáticas analisadas. Os mapas foram desenvolvidos pelo programa QuantumGis $2.18^{\circledR}$ e os pontos de coleta georreferenciados de acordo com suas respectivas coordenas (descritas na tabela 2) através do programa Google Earth Pro ${ }^{\circledR}$. *IB/USP - Instituto de Biociências da Universidade de São Paulo. **IBt/SP - Instituto de Botânica. 
Tabela 2. Informações das espécies de musgos (Bryophyta) e hepáticas (Machantiophyta) coletadas no estado de São Paulo, Brasil.

\begin{tabular}{|c|c|c|c|c|c|}
\hline \multicolumn{6}{|c|}{ Musgos (Bryophyta) } \\
\hline Família & Nome da espécie & Voucher & Local coletado & Coordenada geográfica & Fitofisionomia \\
\hline Bryaceae & 1- Rosulabryum densifolium (Brid.) Ochyra & 505379 & $\begin{array}{l}\text { Horto Florestal - Campos do } \\
\text { Jordão }\end{array}$ & $22^{\circ} 43^{\prime} 0^{\prime \prime} \mathrm{S}, 45^{\circ} 27^{\prime} 41^{\prime \prime} \mathrm{O}$ & $\begin{array}{c}\text { Floresta ombrófila mista com } \\
\text { araucária }\end{array}$ \\
\hline Calymperaceae & 2- Octoblepharum albidum Hedw. & 485282 & $\begin{array}{c}\text { Parque Municipal São Marcelo } \\
\text { - Mogi Guaçu }\end{array}$ & $22^{\circ} 21^{\prime} 48^{\prime \prime} \mathrm{S}, 46^{\circ} 58^{\prime} 34^{\prime \prime} \mathrm{O}$ & $\begin{array}{c}\text { Área de reflorestamento com } \\
\text { espécies nativas }\end{array}$ \\
\hline \multirow{5}{*}{ Dicranaceae } & 3- Campylopus arctocarpus (Hornsch.) Mitt. & 486358 & $\begin{array}{l}\text { Horto Florestal - Campos do } \\
\text { Jordão }\end{array}$ & $22^{\circ} 42^{\prime} 27^{\prime \prime} \mathrm{N}, 45^{\circ} 28^{\prime} 05^{\prime \prime} \mathrm{O}$ & $\begin{array}{c}\text { Floresta ombrófila mista com } \\
\text { araucária }\end{array}$ \\
\hline & 4- Campylopus filifolius (Hornsch.) Mitt. & 486352 & $\begin{array}{l}\text { Horto Florestal - Campos do } \\
\text { Jordão }\end{array}$ & $22^{\circ} 42^{\prime} 27^{\prime \prime} \mathrm{N}, 45^{\circ} 28^{\prime} 05^{\prime \prime} \mathrm{O}$ & $\begin{array}{c}\text { Floresta ombrófila mista com } \\
\text { araucária }\end{array}$ \\
\hline & 5- Campylopus gemmatus (Müll. Hal.) Paris & 505373 & Represa do Broa - Itirapina & $22^{\circ} 10^{\prime} 37^{\prime \prime} \mathrm{S}, 47^{\circ} 54^{\prime} 39^{\prime \prime} \mathrm{O}$ & Vegetação de savana \\
\hline & 6- Campylopus pilifer Brid. & 505384 & Pico dos Marins - Piquete & $22^{\circ} 30^{\prime} 57^{\prime \prime} \mathrm{S}, 45^{\circ} 09^{\prime} 02^{\prime \prime} \mathrm{O}$ & Floresta com araucária \\
\hline & 7- Pilopogon laevis (Taylor) Thér. & 505374 & Represa do Broa - Itirapina & $22^{\circ} 10^{\prime} 37^{\prime \prime} \mathrm{S}, 47^{\circ} 54^{\prime} 39^{\prime \prime} \mathrm{O}$ & Vegetação de savana \\
\hline Hypnaceae & 8- Calliergonella cuspidata (Hedw.) Loeske & 505377 & $\begin{array}{l}\text { Horto Florestal - Campos do } \\
\text { Jordão }\end{array}$ & $22^{\circ} 42^{\prime} 27^{\prime \prime} \mathrm{N}, 45^{\circ} 28^{\prime} 05^{\prime \prime} \mathrm{O}$ & $\begin{array}{c}\text { Floresta ombrófila mista com } \\
\text { araucária }\end{array}$ \\
\hline Lembophyllaceae & $\begin{array}{l}\text { 9- Porotrichodendron superbum (Taylor) } \\
\text { Broth. }\end{array}$ & 505381 & Pico dos Marins - Piquete & $22^{\circ} 30^{\prime} 57^{\prime \prime} \mathrm{S}, 45^{\circ} 09^{\prime} 02^{\prime \prime} \mathrm{O}$ & Floresta com araucária \\
\hline Leucobryaceae & 10- Leucobryum giganteum Müll. Hal. & 486355 & $\begin{array}{l}\text { Horto Florestal - Campos do } \\
\text { Jordão }\end{array}$ & $22^{\circ} 42^{\prime} 27^{\prime \prime} \mathrm{N}, 45^{\circ} 28^{\prime} 05^{\prime \prime} \mathrm{O}$ & $\begin{array}{c}\text { Floresta ombrófila mista com } \\
\text { araucária }\end{array}$ \\
\hline \multirow{2}{*}{ Mniaceae } & $\begin{array}{l}\text { 11- Plagiomnium rhynchophorum (Harv.) T.J. } \\
\text { kop. }\end{array}$ & 505380 & Pico dos Marins - Piquete & $22^{\circ} 30^{\prime} 57^{\prime \prime} \mathrm{S}, 45^{\circ} 09^{\prime} 02^{\prime \prime} \mathrm{O}$ & Floresta com araucária \\
\hline & 12- Pyrrhobryum spiniforme (Hedw.) Mitt. & 505389 & Reserva Florestal - IB/USP* & $23^{\circ} 33^{\prime} 59^{\prime \prime} \mathrm{S}, 46^{\circ} 43^{\prime} 45^{\prime \prime} \mathrm{O}$ & $\begin{array}{l}\text { Floresta com interferência } \\
\text { humana }\end{array}$ \\
\hline \multirow{4}{*}{ Polytrichaceae } & $\begin{array}{l}\text { 13- Atrichum androgynum (Müll. Hal.) A. } \\
\text { Jaeger }\end{array}$ & 493688 & Fitotério - IB/USP* & $23^{\circ} 33^{\prime} 55^{\prime \prime} \mathrm{S}, 46^{\circ} 43^{\prime} 51^{\prime \prime} \mathrm{O}$ & $\begin{array}{l}\text { Área com simulação de } \\
\text { ecossistemas naturais }\end{array}$ \\
\hline & $\begin{array}{c}\text { 14- Pogonatum pensilvanicum (W. Bartram } \\
\text { ex Hedw.) P. Beauv. }\end{array}$ & 505385 & Pico dos Marins - Piquete & $22^{\circ} 30^{\prime} 57^{\prime \prime} \mathrm{S}, 45^{\circ} 09^{\prime} 02^{\prime \prime} \mathrm{O}$ & Floresta com araucária \\
\hline & $\begin{array}{l}\text { 15- Polytrichadelphus pseudopolytrichum } \\
\text { (Raddi) G.L. Sm. }\end{array}$ & 493690 & $\begin{array}{l}\text { Horto Florestal - Campos do } \\
\text { Jordão }\end{array}$ & $22^{\circ} 42^{\prime} 27^{\prime \prime} \mathrm{N}, 45^{\circ} 28^{\prime} 05^{\prime \prime} \mathrm{O}$ & $\begin{array}{c}\text { Floresta ombrófila mista com } \\
\text { araucária }\end{array}$ \\
\hline & 16- Polytrichum angustifolium Mitt. & 502251 & $\begin{array}{l}\text { Parque Nacional da Serra da } \\
\text { Bocâina - São José do Barreiro }\end{array}$ & $22^{\circ} 45^{\prime} 34^{\prime \prime} \mathrm{S}, 44^{\circ} 36^{\prime} 46^{\prime \prime} \mathrm{O}$ & Mata ombrófila mista \\
\hline
\end{tabular}




\section{7- Polytrichum commune Hedw.}

18- Polytrichum juniperinum Willd. ex Hedw.

19- Sphagnum gracilescens Hampe ex Müll. Hal.

\section{Sphagnaceae}

20- Sphagnum recurvum P. Beauv.

21- Sphagnum subsecundum Nees

22- Thuidium delicatulum (Hedw.) Schimp.
505376

505386

505375

501994

501994

486354
Horto Florestal - Campos do

$$
\text { Jordão }
$$

Pico dos Marins - Piquete

Horto Florestal - Campos do Jordão

Parque Nacional da Serra da Bocâina - São José do Barreiro

Parque Nacional da Serra da

Bocâina - São José do Barreiro Horto Florestal - Campos do Jordão $22^{\circ} 42^{\prime} 27^{\prime \prime} \mathrm{N}, 45^{\circ} 28^{\prime} 05^{\prime \prime} \mathrm{O}$

$22^{\circ} 30 ' 57^{\prime \prime} \mathrm{S}, 45^{\circ} 09^{\prime} 02^{\prime \prime} \mathrm{O}$

$22^{\circ} 42^{\prime} 27^{\prime \prime} \mathrm{N}, 45^{\circ} 28^{\prime} 05^{\prime \prime} \mathrm{O}$

$22^{\circ} 45^{\prime} 34^{\prime \prime} \mathrm{S}, 44^{\circ} 36^{\prime} 46^{\prime \prime} \mathrm{O}$

$22^{\circ} 45^{\prime} 34^{\prime \prime} \mathrm{S}, 44^{\circ} 36^{\prime} 46^{\prime \prime} \mathrm{O}$

$22^{\circ} 42^{\prime} 27^{\prime \prime} \mathrm{N}, 45^{\circ} 28^{\prime} 05^{\prime \prime} \mathrm{O}$
Floresta ombrófila mista com araucária

Floresta com araucária

Floresta ombrófila mista com araucária

Mata ombrófila mista

Mata ombrófila mista

Floresta ombrófila mista com araucária

\begin{tabular}{|c|c|c|c|c|c|}
\hline \multicolumn{6}{|c|}{ Hepáticas (Marchantiaceae) } \\
\hline Família & Nome da espécie & Voucher & Local coletado & Coordenada geográfica & Fitofisionomia \\
\hline \multirow{6}{*}{ Lejeuneaceae } & $\begin{array}{c}\text { 23- Cheilolejeunea filiformis (Sw.) W. Ye, } \\
\text { R.L. Zhu \& Gradst. }\end{array}$ & 505383 & Pico dos Marins - Piquete & $22^{\circ} 30^{\prime} 57^{\prime \prime} \mathrm{S}, 45^{\circ} 09^{\prime} 02^{\prime \prime} \mathrm{O}$ & Floresta com araucária \\
\hline & 24- Lejeunea isocalycina (Nees) Steph. & 486357 & $\begin{array}{l}\text { Horto Florestal - Campos } \\
\text { do Jordão }\end{array}$ & $22^{\circ} 42^{\prime} 27^{\prime \prime} \mathrm{N}, 45^{\circ} 28^{\prime} 05^{\prime \prime} \mathrm{O}$ & $\begin{array}{c}\text { Floresta ombrófila Mista com } \\
\text { araucária }\end{array}$ \\
\hline & 25-Lejeunea flava (Sw.) Nees & 485279 & $\begin{array}{l}\text { Parque Municipal São } \\
\text { Marcelo - Mogi Guaçu }\end{array}$ & $22^{\circ} 21^{\prime} 48^{\prime \prime} \mathrm{S}, 46^{\circ} 58^{\prime} 34^{\prime \prime} \mathrm{O}$ & $\begin{array}{c}\text { Área de reflorestamento com } \\
\text { espécies nativas }\end{array}$ \\
\hline & 25a- Lejeunea flava (Sw.) Nees & 505372 & Represa do Broa - Itirapina & $22^{\circ} 10^{\prime} 01^{\prime \prime} \mathrm{S}, 47^{\circ} 54^{\prime} 49^{\prime \prime} \mathrm{O}$ & $\begin{array}{l}\text { Área com formação florestal } \\
\text { característica do cerrado }\end{array}$ \\
\hline & 25b-Lejeunea flava (Sw.) Nees & 493689 & Universidade de São Paulo & $23^{\circ} 33^{\prime} 60^{\prime \prime} \mathrm{S}, 46^{\circ} 43^{\prime} 45^{\prime \prime} \mathrm{O}$ & $\begin{array}{c}\text { Área com cobertura arbórea da } \\
\text { cidade de São Paulo }\end{array}$ \\
\hline & 26- Lejeunea laetevirens Ness \& Mont. & 505415 & Paranapiacaba & $23^{\circ} 46^{\prime} 09^{\prime \prime} \mathrm{S}, 46^{\circ} 22^{\prime} 52^{\prime \prime} \mathrm{O}$ & $\begin{array}{l}\text { Floresta pluvial montana com } \\
\text { interferência humana }\end{array}$ \\
\hline \multirow[t]{2}{*}{ Lepidoziaceae } & $\begin{array}{c}\text { 27- Bazzania gracilis (Hampe \& Gottsche) } \\
\text { Stephani }\end{array}$ & 502003 & $\begin{array}{c}\text { Parque Nacional da Serra da } \\
\text { Bocâina - São José do } \\
\text { Barreiro }\end{array}$ & $22^{\circ} 45^{\prime} 34^{\prime \prime} \mathrm{S}, 44^{\circ} 36^{\prime} 46^{\prime \prime} \mathrm{O}$ & Mata ombrófila mista \\
\hline & 28- Bazzania hookeri (Lindenb.) Trevis. & 486351 & $\begin{array}{l}\text { Horto Florestal - Campos } \\
\text { do Jordão }\end{array}$ & $22^{\circ} 42^{\prime} 27^{\prime \prime} \mathrm{N}, 45^{\circ} 28^{\prime} 05^{\prime \prime} \mathrm{O}$ & $\begin{array}{c}\text { Floresta ombrófila mista com } \\
\text { araucária }\end{array}$ \\
\hline Marchantiaceae & 29- Marchantia papillata Raddi & 486356 & $\begin{array}{l}\text { Horto Florestal - Campos } \\
\text { do Jordão }\end{array}$ & $22^{\circ} 42^{\prime} 27^{\prime \prime} \mathrm{N}, 45^{\circ} 28^{\prime} 05^{\prime \prime} \mathrm{O}$ & $\begin{array}{c}\text { Floresta ombrófila mista com } \\
\text { araucária }\end{array}$ \\
\hline
\end{tabular}




\section{Metzgeriaceae}

30- Metzgeria albinea Spruce

31- Metzgeria conjugata Lindb.

32- Metzgeria furcata (L.) Dumort.

Plagiochilaceae
505397

505371

505370

505388

505382
Pico dos Marins - Piquete

Universidade de São Paulo

$\mathrm{IBt} / \mathrm{SP} *$

Reserva Florestal - IB/USP**

Pico dos Marins - Piquete $22^{\circ} 30^{\prime} 57^{\prime \prime} \mathrm{S}, 45^{\circ} 09^{\prime} 02^{\prime \prime} \mathrm{O}$

$23^{\circ} 33^{\prime} 60^{\prime \prime} \mathrm{S}, 45^{\circ} 43^{\prime} 45^{\prime \prime} \mathrm{O}$

$23^{\circ} 38^{\prime} 33^{\prime \prime} \mathrm{S}, 46^{\circ} 37^{\prime} 17^{\prime \prime} \mathrm{O}$

$23^{\circ} 33^{\prime} 59^{\prime \prime} \mathrm{S}, 46^{\circ} 43^{\prime} 45^{\prime \prime} \mathrm{O}$

$22^{\circ} 30^{\prime} 57^{\prime \prime} \mathrm{S}, 45^{\circ} 09^{\prime} 02^{\prime \prime} \mathrm{O}$
Floresta com araucária Área com cobertura arbórea da cidade de São Paulo

Área com cobertura arbórea da cidade de São Paulo

Floresta com interferência humana

Floresta com araucária

*IBt/SP - Instituto de Botânica. **IB/USP - Instituto de Biociências da Universidade de São Paulo. 


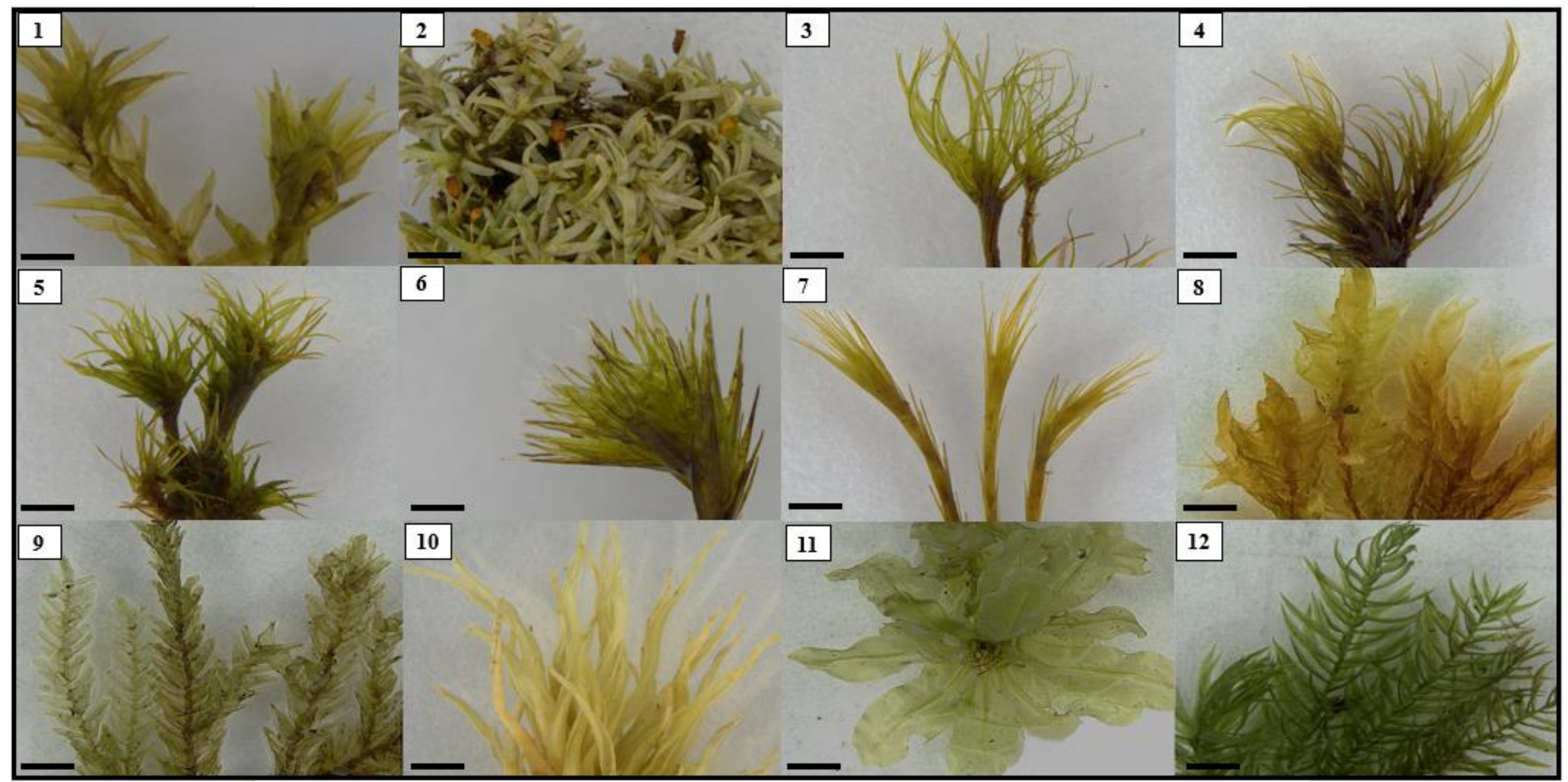

Figura 19. Detalhes dos gametófitos das espécies de musgos (Bryophyta) (Imagens 1 - 22) e hepáticas (Machantiophyta) (Imagens 23 - 34 ) coletadas no estado de São Paulo, Brasil. Os números correspondem às espécies listadas na tabela 2. Escala: 2 mm. Fotos: Tamara Matos (2019). 
Continuação.

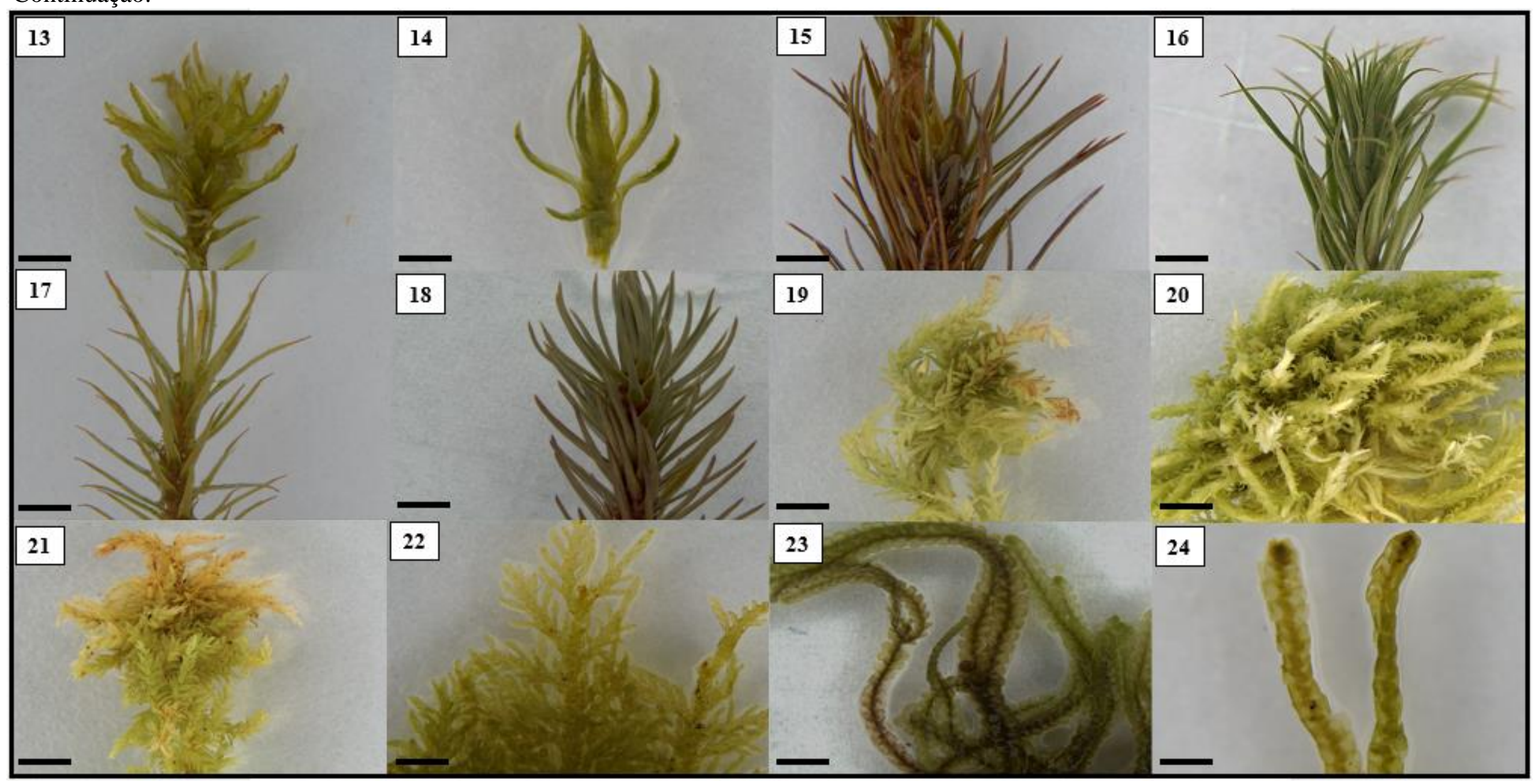


Continuação.

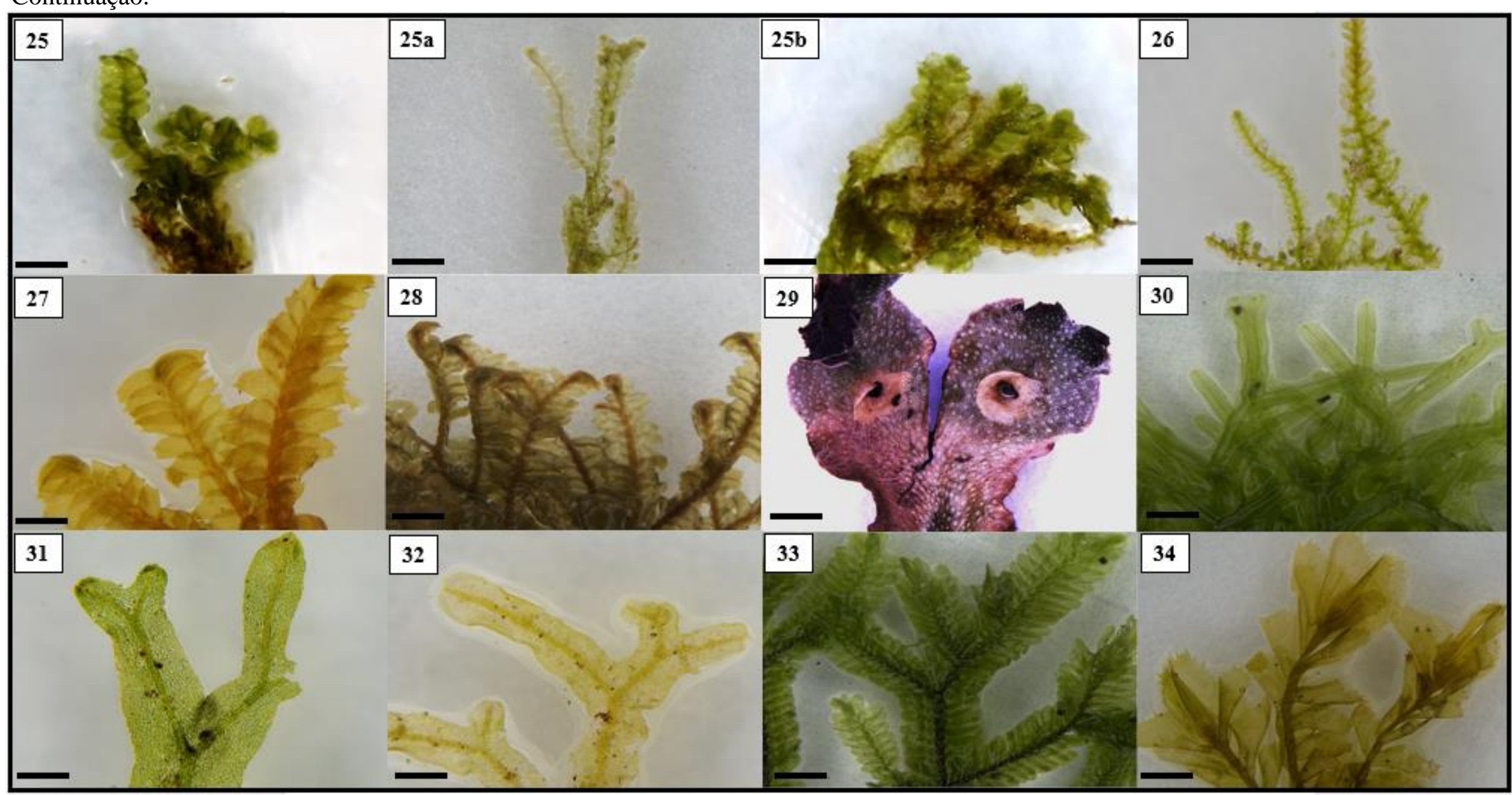




\subsection{Preparo do material para a extração de cera}

Após a coleta, foram realizadas a limpeza e a triagem das plantas. Inicialmente, através de diversas lavagens em água, os gametófitos foram limpos e os substratos (solo ou cascas de tronco de árvores) foram removidos. Em seguida, os gametófitos foram secos à temperatura ambiente (hepáticas: 300 mg a 4 g, musgos: 500 mg a 10 g de peso seco). Também os esporófitos, quando presentes, foram separados dos gametófitos e mantidos sob refrigeração.

Com os gametófitos e esporófitos secos foram realizadas as extrações das ceras cuticulares. A cera da caliptra e do esporófito (seta e cápsula), quando possível foi extraída separadamente. Para tanto, todas as vidrarias utilizadas foram previamente lavadas três vezes com diclorometano. As ceras cuticulares foram extraídas através de duas imersões consecutivas com diclorometano por 20 segundos (modificado de Fernandes, 1964). Os extratos obtidos foram reunidos, filtrados e concentrados em evaporador rotativo sob pressão reduzida (com banho-maria a $50^{\circ} \mathrm{C}$ ). A cera concentrada foi transferida para frascos de massa conhecida, que foram mantidos em banho-maria a $60^{\circ} \mathrm{C}$ até a completa evaporação do solvente. Em seguida, foram transferidos para dessecador até que atingissem massa constante.

\subsection{Cálculo do teor de cera cuticular}

Para o cálculo do teor, os filídios secos dos musgos e os gametófitos completos das hepáticas foram pesados e, posteriormente, três sub-amostras de massa conhecida foram separadas para mensuração da área. Os filídios menores que $10 \mathrm{~mm}$ foram prensados entre lâminas com água e as imagens capturadas através do microscópio de luz Leica DMLB acoplado com câmera digital Leica DFC 310FX. As imagens dos demais filídios e das amostras de hepáticas foram obtidas por meio de microscópio digital (800x com câmera HD 2.0mp). A partir dessas imagens as áreas superficiais das amostras foram calculadas através do software Photoshop CS6® (adaptado de Busta et al., 2016a). A área calculada $\left(\mathrm{cm}^{2}\right)$ de cada sub-amostra foi multiplicada por dois para a obtenção da área total, considerando a superfície adaxial e abaxial. As áreas das sub-amostras foram usadas para estabelecer a relação massa:área para cada amostra. Em seguida foi feito uma média e esse valor usado para estimar a área total das amostras (musgos ou hepáticas). A partir da diferença de massa entre o frasco com cera e vazio, obteve-se a massa total de cera 
extraída (em $\mu \mathrm{g}$ ) das espécies. O teor total de cera foi obtido pela razão entre a massa total de cera e a área total do gametófito e/ou filídio, expresso em $\mu \mathrm{g} / \mathrm{cm}^{2}$.

\subsection{Análise dos compostos de cera}

As amostras de cera total foram ressuspendidas em diclorometano. Alíquotas de massa conhecida foram transferidas para frascos apropriados, secas e derivatizadas com acréscimo de $50 \mu \mathrm{L}$ de N,O-Bis(trimetilsilil)trifluoroacetamida (BSTFA) $+50 \mu \mathrm{L}$ piridina, seguido de aquecimento a $70^{\circ} \mathrm{C}$ por 1 hora em banho seco (adaptado de Jetter et al., 2000). Em seguida, as amostras derivatizadas foram injetadas em cromatógrafo a gás acoplado a espectrômetro de massas (CG-EM). Foi empregado o conjunto Agilent 6850/Agilent 5975C, coluna Agilent HP5-MS (30 m x $250 \mu \mathrm{m}$ x $0.25 \mu \mathrm{m}$ ). A temperatura inicial da coluna foi ajustada para $100^{\circ} \mathrm{C}$ por 5 minutos seguida de aquecimento de $5^{\circ} \mathrm{C}$ por minuto até uma temperatura final de $320^{\circ} \mathrm{C}$, mantida por 8 minutos. O volume de injeção foi de $1 \mu \mathrm{L}$ com hélio como gás de arraste em fluxo constante de $1 \mathrm{~mL} / \mathrm{min}$. As temperaturas do injetor, fonte de íons e quadrupolo foram de $300^{\circ} \mathrm{C}, 230^{\circ} \mathrm{C}$ e $150^{\circ} \mathrm{C}$, respectivamente. A detecção dos espectros de massas foi realizada com ionização eletrônica (EI) a 70 eV no modo de aquisição de varredura completa variando entre 50$800 \mathrm{~m} / \mathrm{z}$ a 2,66 scans. $\mathrm{s}^{-1}$. O tempo total de análise foi de 57 minutos. Os parâmetros de integração selecionados, para grande parte dos indivíduos, foram threshold 18,0 (valor considerado para discriminar o início e o fim do pico em relação à linha de base do cromatograma) e initial peak width 0,04 (largura mínima considerada do pico). Para as identificações foram considerados os compostos que apresentaram porcentagem relativa igual ou maior que $1 \%$.

Ácidos graxos insaturados e esteroides, quando identificados, não foram considerados como componentes de cera. Huang et al. (2009) e Buda et al. (2013) apontam que essas substâncias provavelmente provêm de estruturas de reservas internas que, devido a fragilidade das amostras de briófitas, acabam sendo extraídas mesmo com rápidas imersões no solvente.

\subsection{Identificação dos compostos de cera}

A espectrometria de massas baseia-se na formação de íons na fase gasosa. $\mathrm{O}$ método de ionização por impacto eletrônico utiliza feixes de elétrons de alta energia, onde um fluxo de elétrons é formado a partir de um filamento metálico aquecido. Esses elétrons são eletricamente acelerados e dirigidos para colidir contra a amostra vaporizada, 
causando explosão eletrônica dos analitos e a subsequente formação de fragmentos cátions radicais positivamente carregados que são separados em função da razão $m / z$ e, posteriormente, detectados, resultando em um espectro de massas (Silverstein \& Webster, 2000; El-Aneed et al., 2009). Os espectros de massas de compostos orgânicos obtidos por impacto de elétrons podem ser analisados a partir de mecanismos de fragmentação característicos, como as clivagens homolítica e heterolítica e o rearranjo de McLafferty (figura 20) (Silverstein \& Webster, 2000). Na quebra homolítica de uma ligação química simples, cada elétron se desloca independentemente e os fragmentos formados são um cátion e um radical livre com um número par e ímpar de elétrons, respectivamente. Já na quebra heterolítica um par de elétrons desloca-se para o átomo mais eletronegativo da cadeia carbônica. Os fragmentos formados também são um cátion (com um número par de elétrons) e um radical, mas com a carga associada ao cátion alquila. No caso do rearranjo McLafferty ocorre a clivagem homolítica da ligação entre o carbono $\alpha$ e o carbono $\beta$, havendo a migração do átomo de hidrogênio $(\mathrm{H})$ do carbono $\gamma$ para $\mathrm{o}$ fragmento da molécula que contém o heteroátomo em posição apropriada.

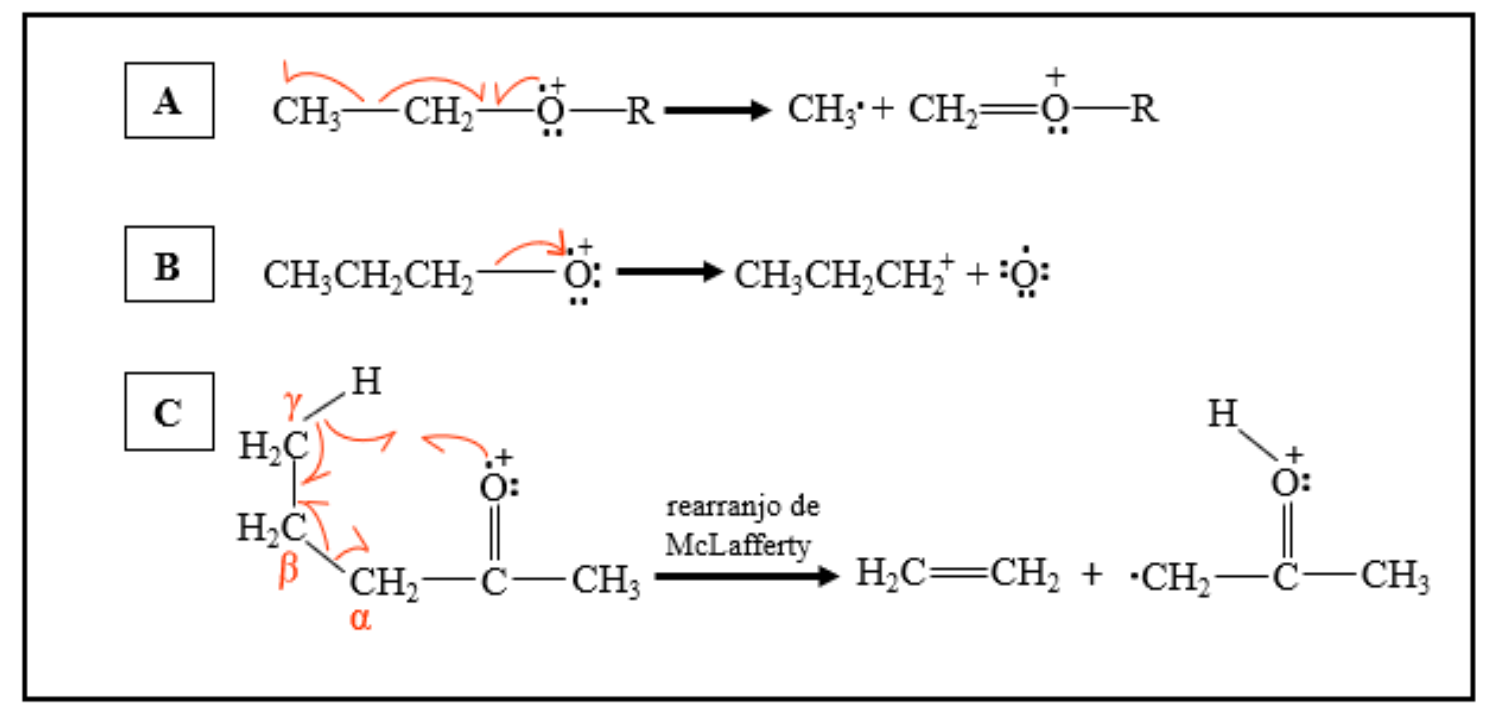

Figura 20. Mecanismos de fragmentação característicos de compostos orgânicos por impacto de elétrons. A: Clivagem homolítica. Setas vermelhas indicam o deslocamento independente dos elétrons. B: Clivagem heterolítica. Seta vermelha indica o deslocamento do par de elétrons para o átomo mais eletronegativo da cadeia carbônica. $\mathrm{C}$ : Rearranjo de McLafferty. $\mathrm{O}$ átomo de $\mathrm{H}$ do carbono $\gamma$ migra para a molécula que contém o oxigênio. Modificado de Silverstein \& Webster (2000). 
As classes de compostos de ceras cuticulares e seus homólogos foram identificados a partir da comparação com o tempo de retenção de substâncias padrão e da análise do padrão de fragmentação dos espectros de massas resultantes de cada cromatograma, comparando com aqueles disponíveis na literatura (p. ex. Taghizadeh, 2001; Jara, 2012; Pimentel, 2014; Roma, 2018) e com espectros de massas disponíveis na biblioteca digital NIST (versão 2.0, 2008). De acordo com Mikaia et al. (2008), os valores de comparação de Match e Reverse Match (R-Match) variam de 0 a 999 nas comparações com o banco de dados da biblioteca NIST. Valores acima de 900 são considerados excelentes, de 800 a 900 bons e de 700 a 800 razoáveis. Portanto, as sugestões da NIST foram consideradas para as identificações quando esses valores foram iguais ou superiores a 900 .

\subsection{Análise por microscopia eletrônica de varredura (MEV)}

Fragmentos secos com cerca de $1 \mathrm{~mm}^{2}$ dos filídios e/ou dos talos, caliptra e do esporófito (seta e cápsula), quando presentes, com e sem cera, removida a partir de uma lavagem com clorofórmio $\left(\mathrm{CHCl}_{3}\right)$ aquecido por 1 minuto (modificado de Brune \& Haas, 2011), foram prensados entre duas lâminas (com o auxílio de prendedores de papel de metal) para que essas estruturas permanecessem planas. Após secas em temperatura ambiente esses fragmentos foram transferidos e fixados em stubs com auxílio de fita adesiva dupla-face. Essa montagem foi realizada com o auxílio de lupa (40x Opton TIM30) para garantir a obtenção da imagem da região dorsal e ventral. Em seguida, esses stubs foram mantidos em dessecador com solução de ácido sulfúrico concentrado por aproximadamente uma semana a fim de retirar o máximo possível de umidade das estruturas preparadas (Barthlott \& Neinhuis, 1997).

Os stubs foram tratados com uma cobertura de solução de ouro por meio do metalizador Balzers SCD 050 sputter coater (Barthlott \& Neinhuis, 1997). Em seguida, os materiais foram observados através dos microscópios eletrônicos de varredura Sigma VP Electron Microscope, Zeiss, West Germany e pelo Digital Microscope DSM 940, Zeiss, West Germany, disponíveis no Instituto de Biociências da Universidade de São Paulo - IB/USP, de 5 a $10 \mathrm{KV}$ e ampliações variando de 250 a 5000 vezes.

A caracterização da morfologia das ceras epicuticulares foi realizada através de comparação com dados disponíveis na literatura (Proctor, 1979; Clayton-Greene et al., 
1985; Neinhuis \& Jetter, 1995; Barthlott et al., 1998; Heinrichs et al., 2000; Heinrichs \& Rycroft, 2001; Heinrichs \& Reiner-Drehwald, 2012).

\subsection{Análise dos dados}

A partir dos dados obtidos do teor das ceras cuticulares e das classes dos compostos de cera (porcentagem relativa total de cada classe), os gráficos foram construídos por meio do software Graphpad Prism® versão 7.01.

\section{REFERÊNCIAS}

Ambrose, B. A. \& Purugganan, M. (2013). The evolution of plant form. Annual Plant Review. volume 45. Wiley-Blackwell, Chichester, 382p.

Ando, H. \& Matsuo, A. (1984). Applied Bryology. 133-224. In W. Schultze-Motel (ed.), Advances in Bryology 2 Cramer, Vaduz.

Asakawa, Y.; Agnieszka, L. \& Fumihiro, N. (2013). Chemical Constituents of Bryophytes. Progress in the Chemistry of Organic Natural Products. 816p.

Báez-Sañudo, R.; Tafolla-Arellano, J. C.; González- León, A.; Tiznado-Hernández, M. E. \& García, L. Z. (2013). Composición, fisiologia y biosíntesis de la cutícula en plantas. Revista Fitotecnia Mexicana, 36(1), 3-12.

Bargel, H.; Koch, K.; Cerman, Z. \& Neinhuis, C. (2006). Structure - function relationships of the plant cuticle and cuticular waxes - a smart material? Functional Plant Biology, 33(10), 893-910.

Barthlott, W.; Mail, M.; Bhushan, B. \& Koch, K. (2017). Plant surfaces: structures and functions for biomimetic innovations. Nano-Micro Letters, 9(23).

Barthlott, W. \& Neinhuis, C. (1997). Purity of the sacred lotus or escape from contamination in biological surfaces. Planta, 202(1), 1-8.

Barthlott, W.; Neinhuis, C.; Cutler, D.; Ditsch, F.; Meusel, I.; Theisen, I. \& Wilhelmi, H. (1998). Classification and terminology of plant epicuticular waxes. Botanical Journal of the Linnean Society, 126(3), 237-260.

Benešová, V.; Streibl, M.; Châu, H. M.; Beneš, I. \& Konečný, K. (1972). Plant substances. On natural waxes. Higher alkanes and wax esters of some liverworts. Collection of Czechoslovak Chemical Communications, 37(9), 3090-3094. 
Bernard, A. \& Joubès, J. (2013). Arabidopsis cuticular waxes: advances in synthesis, export, and regulation. Progress in Lipid Research, 52(1), 110-129.

Bordin, J. (2009). Briófitas. Trabalho de estágio de docência. Núcleo de pesquisa em briologia. Instituto de Botânica, Ibt, São Paulo. 20p. Disponível em: < http://www.biodiversidade.pgibt.ibot.sp.gov.br/Web/pdf/Briofitas_Jucara_Bordi n.pdf > Acessado em março de 2019.

Bowman, J. L...\& Schmutz, J. (2017). Insights into land plants evolution garnered from the Marchantia polymorpha genome. The Plant Cell, 171(2), 287-304.

Brune, T. \& Haas, K. (2011). Equisetum species show uniform epicuticular wax structures but diverse composition patterns. AoB plants, Vol. 2011.

Buchanan, B. B.; Gruissem, W. \& Jones, R. L. (2000). Biochemistry \& molecular biology of plants. ( $2^{\circ}$ ed.). Rockville, Md. American Society of Plant Physiologists, 1367p.

Buch, H. (1945). Ueber die Wasser- und Mineralstoffversorgung der Moose. I. Commentat. Biologie der Moose. 9(16), 1-44.

Buda, G. J.; Barnes, W. J.; Fich, E. A.; Park, S.; Yeats, T. H.; Zhao, L.; Domozych, D. S. \& Rose, J. K. C. (2013). An ATP binding cassette transporter is required for cuticular wax deposition and desiccation tolerance in the moss Physcomitrella patens. The Plant Cell, 25(10), 4000-4013.

Budke, J. M.; Goffinet, B. \& Jones, C. S. (2011). A hundred-year-old question: is the moss calyptra covered by a cuticle? a case study of Funaria hygrometrica. Annals of Botany, 107(8), 1279-1286.

Budke, J. M.; Goffinet, B. \& Jones, C. S. (2012). The cuticle on the gametophyte calyptra matures before the sporophyte cuticle in the moss Funaria hygrometrica (Funariaceae). American Journal of Botany, 99(1), 14-22.

Budke, J. M.; Goffinet, B. \& Jones, C. S. (2013). Dehydration protection provided by a maternal cuticle improves offspring fitness in the moss Funaria hygrometrica. Annals of Botany, 111(5), 781-789.

Budke, J. M. \& Goffinet, B. (2016). Comparative cuticle development reveals taller sporophytes are covered by thicker calyptra cuticles in mosses. Frontiers in Plant Science, 7(832). 
Bush, R. T. \& McInerney, F. R. (2013). Leaf wax $n$-alkane distributions in and across modern plants: Implications for paleoecology and chemotaxonomy. Geochimica et Cosmochimica Acta, 117(15), 161-179.

Busta, L.; Budke, J. M. \& Jetter, R. (2016a). The moss Funaria hygrometrica has cuticular wax similar to vascular plants, with distinct composition on leafy gametophyte, calyptra, and sporophyte capsule surfaces. Annals of Botany, 118(3), 511-522.

Busta, L.; Budke, J. M. \& Jetter, R. (2016b). Identification of $\beta$-hydroxy fatty acid esters and primary, secondary-alkanediol esters in cuticular waxes of the moss Funaria hygrometrica. Phytochemistry, 121, 38-49.

Caldicott, A. B. \& Eglinton, G. (1976). Cutin acids from bryophytes: an $\omega$-1 hydroxy alkanoic acid in two liverwort species. Phytochemistry, 15(7), 1139-1143.

Clayton-Greene, K. A.; Collins, N. J.; Green, T. G. A. \& Proctor, M. C. F. (1985). Surface wax, structure, and function in leaves of Polytrichaceae. Journal of Bryology, 13(4), 549-562.

Cook, M. E. \& Graham L. E. (1998). Structural similarities between surface layers of selected charophycean algae and bryophytes and the cuticles of vascular. International Journal of Plant Sciences, 159(5), 780-787.

Costa, D. P. \& Almeida, J. S. S. (2010). Manual de Briologia. Editora Interciência, Rio de Janeiro. 207p.

Costa, D. P. \& Luizi-Ponzo, A. P. (2010). Introdução as briófitas do Brasil. In: Forzza et al. Catálogo de plantas e fungos do Brasil. Vol. 1. Instituto de pesquisa jardim botânico do Rio de Janeiro, Rio de Janeiro, 61-68.

Costa, D. P. \& Peralta, D. F. (2015). Bryophytes diversity in Brazil. Rodriguésia, 66(4).

Crandall-Stotler, B. (1986). Morphogenesis, developmental anatomy, and bryophyte phylogenetics: contraindications of monophyly. Journal of Bryology, 14(1), 1-23.

Crandall-Stotler, B. J.; Stotler, R. E. \& Long, D. G. (2009). Morphology and classification of the Marchantiophyta. In: Goffinet, B. \& Shaw, A.J. Bryophyte Biology. (2ºd.) Cambridge University Press, Cambridge, 1-54. 
Delgadillo, M., C. \& Cárdenas A. (1990). Manual de briófitas. (2ª ed.). México: Instituto de Biología de la Universidad Nacional Autónoma de México.

Dewick, P. M. (2009). Medicinal natural products: a biosynthetic approach. (3ºd.). New York: John Wiley \& Sons Ltda, London. 539p.

Edstam, M. M.; Laurila, M.; Höglund, A.; Raman, A.; Dahlström, K. M.; Salminen, T. A.; Edqvist, J. \& Blomqvist, K. (2014). Characterization of the GPI-anchored lipid transfer proteins in the moss Physcomitrella patens. Plant Physiology and Biochemistry, 75, 55-69.

El-Aneed, A.; Cohen, A. \& Banoub, J. (2009). Mass Spectrometry, review of the basics: electrospray, MALDI, and commonly used mass analyzers. Applied Spectroscopy Reviews, 44(3), 210-230.

Fernandes, A. M. S.; Baker, E. A. \& Martin, J. T. (1964). Studies on plant cuticle. VI. The isolation and fractionation of cuticular waxes. Annals of Applied Biology, 53(1), 43-58.

Fernandéz, E. G. \& Serrano, A. M. V. (2009). Atividades Biológicas das briófitas. Âmbito Cultural Edições Ltda. 190p.

Fich, E. A.; Segerson, N. A. \& Rose, J. K. C. (2016). The plant polyester cutin: biosynthesis, structure, and biolofical roles. Annual Review of Plant Biology, 67(1), 207-233.

Garbary, D. J.; Renzaglia, K. S. \& Duckett, J. G. (1993). The phylogeny of land plants: a cladistic analysis based on male gametogenesis. Plant Systematics and Evolution, 188(237), 69.

Gerrienne, P. \& Gonez, P. (2010). Early evolution of life cycles in embryophytes: A focus on the fossil evidence of gametophyte/sporophyte size and morphological complexity. Journal of Systematics and Evolution, 49(1), 1-16.

Glime, J. M. (2007). Economic and ethnic uses of bryophytes. In: Glime, J. M. Flora of North America North of Mexico. Oxford University Pressa, New York, Bryophyta, 27, 14-4. 
Goffinet, B. (2000). Origin and phylogenetic relationships or bryophytes. In: Goffinet, B. \& Shaw, A.J. Bryophyte Biology. ( $2^{\circ}$ ed.) Cambridge University Press, Cambridge, 124-149.

Goffinet, B.; Buck, W. R. \& Shaw, A. J. (2009). Morphology, anatomy, and classification of the bryophyta. In: Goffinet, B. \& Shaw, A.J. Bryophyte Biology. ( $2^{\circ}$ ed.) Cambridge University Press, Cambridge, 56-138.

Gradstein, S. R.; Churchill, S. P. \& Salazar-Allen, N. (2001). Guide to the bryophytes of tropical America. Memoirs of the New York Botanical Garden, 86, 1-301.

Green, T. G. A. \& Clayton-Greene, K. (1977). The growth of Dawsonia superba Grev. In J. G. Duckett (ed.) The annual meeting. Bryologist, 29, 5-6.

Haas, K. (1982). Surface wax of Andreaea and Pogonatum species. Phytochemistry, 21, 657-659.

Heinrichs, J.; Anton, H.; Gradstein, S. R.; Mues, R. \& Holz, I. (2000). Surface wax, a new taxonomic feature in Plagiochilaceae. Plant Systematics and Evolution, 225, $225-233$

Heinrichs, J. \& Rycroft, D. S. (2001). Leaf surface waxes and lipophilic secondary metabolites place the endemic European liverwort Plagiochila atlantica F. Rose in the Neotropical Plagiochila sect. Bursatae Carl. Cryptogamie Bryologie, 22(2), 95-103.

Heinrichs, J. \& Reiner-Drehwald, E. (2012). Surface wax in Dinckleria, Lejeunea and Mytilopsis (Jungermanniidae). Cryptogamie Bryologie, 33(1), 81-86.

Heredia, A. (2003). Biophysical and biochemical characteristics of cutin, a plant barrier biopolymer. Biochimica et Biophysica Acta (BBA)-General Subjects, 1620(1-3), $1-7$.

Huang, C. Y.; Chung, C. I.; Lin, Y. C.; Hsing, Y. I. \& Huang, A. H. C. (2009). Oil bodies and oleosins in Physcomitrella possess characteristics representative of early trends in evolution. Plant Physiology, 150, 1192-1203.

Huneck S. \& Vevle O. (1970). 16- $\alpha$-Hydroxykauran aus Anthelia julacea (L.) Dum. und Anthelia juratzkana (Limpr.) Zeitschrift für Naturforschung, 25, 227. 
Jara, C. P. (2012). Composição química dos grãos e da cera foliar da variedade Glycine $\max (\mathrm{L}$.) Merril cv. MG/BR-46 conquista cultivada sob atmosfera enriquecida de gás carbônico e temperatura elevada. Tese de mestrado. Universidade de São Paulo. 136p.

Jeffree, C. E.; Baker, E. A. \& Holloway, P. J. (1975). Ultrastructure and recrystallization of plant epicuticular waxes. New Phytologist, 75(3), 539-549.

Jeffree, C. E. (2006). The fine structure of the plant cuticle. In: M. Riederer \& C. Müller (Eds.), Annual Plant Reviews, volume 23: Biology of the Plant Cuticle. Blackwell publishing Ltd, 23, 11-110.

Jetter, R.; Schäffer, S. \& Riederer, M. (2000). Leaf cuticular waxes are arranged in chemically and mechanically distinct layers: evidence from Prunus laurocerasus L. Plant, Cell \& Environment, 23(6), 619-628.

Jetter, R.; Kunst, L. \& Samuels, A. L. (2006). Composition of plant cuticular waxes. In: M. Riederer \& C. Müller (Eds.), Annual Plant Reviews, volume 23: Biology of the Plant Cuticle. Blackwell publishing Ltd, 145-181.

Judd, W. S.; Campbell, C. S.; Kellogg, E. A.; Stevens, P. F. \& Donoghue, M. J. (2008). Sistemática vegetal: um enfoque filogenético ( $3^{\circ}$ ed.). ARTEMED Editora AS, $632 \mathrm{p}$.

Kerstiens, G. (2006). Water transport in plant cuticles: an update. Journal of Experimental Botany, 57(11), 2493-2499.

Koch, K. \& Ensikat, H. J. (2008). The hydrophobic coatings of plant surfaces: epicuticular wax crystals and their morphologies, crystallinity and molecular self-assembly. Micron, 39(7), 759-772.

Koch, K.; Bhushan, B. \& Barthlott, W. (2009a). Multifunctional surface structures of plants: an inspiration for biomimetics. Progress in Materials Science, 54(2), 137178.

Koch, K.; Frahm, J-P. \& Pollawatn, R. (2009b). The cuticle of the Buxbaumia viridis sporophyte. Flora, (204), 34-39.

Kolattukudy, P. E. (2001). Polyesters in higher plants. In Advances in Biochemical Engineering/Biotechnology. (Ed. T Scheper). 4-49. 
Kunst, L. \& Samuels, A. L. (2003). Biosynthesis and secretion of plant cuticular wax. Progress in Lipid Research, 42(1), 51-80.

Kunst, L. \& Samuels, A. L. (2009). Plant cuticles shine: advances in wax biosynthesis and export. Current Opinion in Plant Biology, 12(6), 721-727.

Leliaert, F.; Smith, D. R.; Moreau, H.; Herron, M. D.; Verbruggen, H.; Delwiche, C. F. \& De Clerck, O. (2012). Phylogeny and molecular evolution of the green algae. Critical Reviews in Plant Sciences, 31(1), 1-46.

Magallón, S. \& Hilu, K. W. (2009). Land plants (Embryophyta). In: Hedges S.B. \& Kumar, S. (eds.). The Timetree of Life. Oxford: Oxford University Press, 133-137.

Mikaia, A.; Neta, P. \& Yang, X. (2008). Nist Standard Reference Database 1A.

Mishler, B. D. \& Churchill, S. P. (1984). A cladistic approach to the phylogeny of the bryophytes. Brittonia, 36, 406-424.

Neinhuis, C. \& Jetter, R. (1995). Epicuticular wax of Polytrichales sporophytes. Journal of Bryology, 18, 399-406.

Oliveira, A. F. M.; Meirelles, S. T. \& Salatino, A. (2003). Epicuticular waxes from caatinga and cerrado species and their efficiency against water loss. Anais da Academia Brasileira de Ciências, 75(4), 431-439.

Peralta, D. F. (2009). Polytrichaceae (Polytrichales, Bryophyta) do Brasil. Tese de Doutorado. Instituto de Botânica de São Paulo. 176p.

Piironen, V.; Lindsay, D. G.; Miettinen, T. A.; Toivo, J. \& Lampi, A-M. (2000). Plant sterols: biosynthesis, biological and their importance to human nutrition. Journal of the Science of Food and Agriculture, 80(7), 939-966.

Pimentel, B. S. (2014). Constituintes de ceras cuticulares de espécies de Croton L. Tese de Mestrado. Universidade de São Paulo, Brasil, 96p.

Pócs, T. (1982). Tropical forest Bryophytes. In: Smith, A.J.E. (ed.). Bryophyte Ecology. New York: Chapman and Hall, 59-103.

Pócs, T. (2005). East African Bryophytes, XX. Observations on some Calypogeiaceae. Acta Academiae Paedagogicae Agriensis, 32(2), 20-35. 
Pressel, S.; P'ng, K. M. Y. \& Duckett, J. G. (2011). An ultrastructural study of the liverwort Mizutania riccardioides Furuki et Iwatsuki: new insights into its systematic affinities and unique surface ornamentation. The Bryologist, 144, 3851.

Proctor, M. C. F. (1979). Surface wax on the leaves of some mosses. Journal Bryology, 10(4), 531-538.

Puttick, M. N.; Morris, J. L.; Williams, T. A.; Cox, C. J.; Edwards, D.; Kenrick, P.; Pressel, S.; Wellman, C. H.; Schneider, H.; Pisani, D. \& Donoghue, P. C. J. (2018). The interrelationships of land plants and the nature of the ancestral embryophyte. Current Biology, 28 (5), 733-745.

Raven, P. H.; Evert, R. F. \& Eichhorn, S. E. (2014). Biologia vegetal (8 ed.). Guanabara Koogan Editora, 856p.

Reidel, M.; Eichner, A. \& Jetter, R. (2003). Slippery surfaces of carnivorous plants: composition of epicuticular wax crystals in Nepenthes alata Blanco pitchers. Planta, 218(1), 87-97.

Reina-Pinto, J. J. \& Yephremov, A. (2009). Surface lipids and plant defenses. Plant Physiology and Biochemistry, 47(6), 540-549.

Renault, H. \& Werck-Reichhart, D. (2017). A phenol-enriched cuticle is ancestral to lignin evolution in land plants. Nature Communications, 8(14713).

Resemann, H. C.; Lewandowsk, M.; Gömann, J. \& Feussner, I. (2019). Membrane lipids, waxes and oxylipins in the moss model organism Physcomitrella patens. Plant \& Cell Physiology, 60(6), 1166-1175.

Riederer, M. \& Schreiber, L. (2001). Protecting against water loss: analysis of the barrier properties of plant cuticles. Journal of Experimental Botany, 52(363), 2023-2032.

Roma, L. P. (2018). Composição química e morfologia das ceras cuticulares foliares de diferentes espécies de Simaba Aubl. Sensu stricto e Homalolepis Turcz. (Simaroubaceae). Tese de Mestrado. Universidade de São Paulo, Brasil, 177p.

Rowland, O. \& Domergue, F. (2012). Plant fatty acyl reductases: enzymes generating fatty alcohols for protective layers with potential for industrial applications. Plant Science, 193-194(1), 28-38. 
Salminen, T. A.; Eklund, D. M.; Joly, V.; Blomqvist, K.; Matton, D. P. \& Edqvist, J. (2018). Deciphering the evolution and development of the cuticle by studying lipid transfer proteins in mosses and liverworts. Plants, 7(1), 6.

Samuels, L.; Kunst, L. \& Jetter, R. (2008). Sealing plant surfaces: cuticular wax formation by epidermal cells. Annual Review of Plant Biology, 59(38), 683-707.

Santos, E. L. (2016). Briófitas em floresta nebular do parque estadual pico do Marumbi, Paraná, Brasil. Tese de Mestrado. Universidade Federal do Paraná. 159p.

Santos, E. L. \& Della, A. P. (2018). Morfologia e ecologia de briófitas. Apostila botânica no Inverno. Capítulo 7. Universidade de São Paulo, 67-75.

Schofield, W. B. (2001). Introdution to bryology. (2 ${ }^{\mathrm{a}}$ ed). New Jersey: The Blackburn Press.

Schonherr, J. \& Ziegler, H. (1975). Hydrophobic cuticular ledges prevent water entering the air pores of liverwort thalli. Planta, 124(1),51-60.

Shaw, J. \& Goffinet, B. (2000). Bryophyte biology. The Bryologist, 104, 644-646.

Shepherd, T. \& Wynne Griffiths, D. (2006). The effects of stress on plant cuticular waxes. New Phytologist, 171(3), 469-499.

Silverstein, R. M. \& Webster, F. X. (2000). Identificação espectrométrica de compostos orgânicos. (6 ${ }^{\mathrm{a}}$ ed.). LTC Editora S.A, 460p.

Taghizadeh, T. (2001). Identificação de substâncias voláteis de insetos através de cromatografia gasosa acoplada a espectrometria de massas. In: Ferreira, J. T. B., Corrêa, A. G., Vieira, P. C. Produtos Naturais no Controle de Insetos. UFSCar. $176 \mathrm{p}$.

Taiz, L. \& Zeiger, E. (2009). Metabólitos secundários e defesa vegetal. In: Fisiologia vegetal. ( $3^{\mathrm{a}}$ ed.) Artemed Editora AS, 343-372.

The Plant List. (2018). The bryophyts: mosses and liverworts. Disponível em: < http://www.theplantlist.org/1.1/browse/B/ > Acessado em março de 2019.

Timmappa, R.; Geisler, K.; Louveau, T.; O’Maille, P. \& Osbourn, A. (2014). Triterpene biosynthesis in plants. Annual Review of Plant Biology, 65(1), 225-257. 
Vanderpoorten, A. \& Goffinet, B. (2009). Introduction to Bryology. New York: Cambridge University Press, 1-329.

Vickery, M. L. \& Vickery, B. (1981). Secondary plant metabolism. Warwick Univ.UK. $335 \mathrm{p}$.

Vioque, J. \& Kolattukudy, P. E. (1997). Resolution and purification of an aldehydegenerating and an alcohol-generating fatty acyl-CoA reductase from pea leaves (Pisum sativum L.). Archives of Biochemistry and Biophysics, 340(1), 64-72.

Vranová, E.; Coman, D. \& Gruissem, W. (2013). Network analysis of the MVA and MEP pathaways for isoprenoid synthesis. Annual Review of Plant Biology, 64, 665-700.

Xue, D.; Zhang, X.; Lu, X.; Chen, G. \& Chen, Zhong-Hua. (2017). Molecular and evolutionary mechanisms of cuticular wax for plant drought tolerance. Frontiers in Plant Science, 8, 621.

Xu, S. J.; Jiang, P. A.; Wang, Z. W. \& Wang, Y. (2009). Crystal structures and chemical composition of leaf surface wax depositions on the desert moss Syntrichia caninervis. Biochemical Systematics and Ecology, 37, 723-730.

Yeats, T. H. \& Rose, J. K. C. (2013). The formation and function of plant cuticles. Plant Physiology, 163, 5-20. 


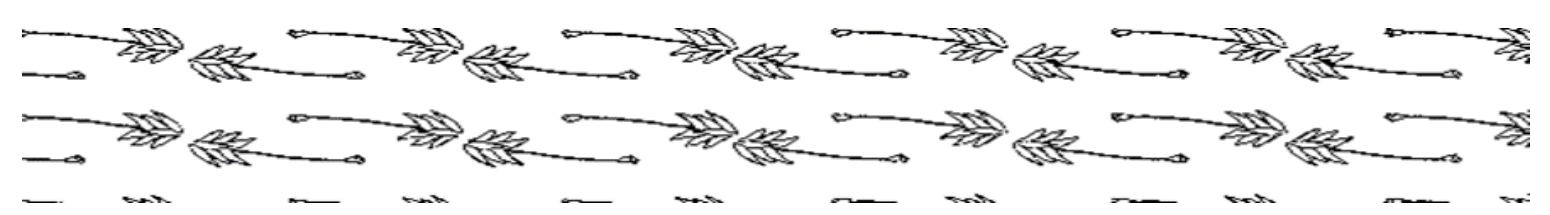

Capítulo 1: Caracterização geral da morfologia e da composição química das ceras cuticulares em espécies brasileiras de Bryophyta e Marchanthiophyta

Capítulo formatado para submissão a Journal of Bryology (Taylor \& Francis Group - IF $=1.361)$.

Colaboradores:

Denilson Fernandes Peralta*

Gladys Flávia de Albuquerque Melo de Pinna**

Lucas Paradizo Roma**

*Instituto de Botânica, Av. Miguel Estéfano 3687, 04301-902, São Paulo, SP, Brasil.

**Departamento de Botânica, Instituto de Biociências, Universidade de São Paulo, Rua do Matão, 277, 05508-090, São Paulo, SP, Brasil. 


\section{Resumo}

Introdução. As briófitas foram as primeiras plantas a se estabelecerem no ambiente terrestre. O surgimento da cutícula foi crucial no sucesso dessa transição, auxiliando principalmente na proteção contra a dessecação. Essa camada é formada por uma matriz de cutina embebida e recoberta pelas ceras cuticulares. No Brasil são encontradas mais de 1.500 espécies de briófitas. Neste estudo apresentamos uma caracterização geral das ceras cuticulares dos gametófitos de espécies nativas de Bryophyta e Marchantiophyta. Métodos. As ceras cuticulares de 34 espécies de diferentes localidades do estado de São Paulo/Brasil, foram analisadas por cromatografia a gás acoplada a espectrometria de massas. Os compostos foram identificados pelo padrão de fragmentação dos espectros de massas obtidos e a análise da morfologia das ceras epicuticulares foi realizada através de MEV. Principais resultados. O teor de cera nas hepáticas variou de $0,1 \mu \mathrm{g} / \mathrm{cm}^{2}$ a 4 $\mu \mathrm{g} / \mathrm{cm}^{2}$ e nos musgos de $0,02 \mu \mathrm{g} / \mathrm{cm}^{2}$ a $0,6 \mu \mathrm{g} / \mathrm{cm}^{2}$. As principais classes de componentes de cera foram os ácidos graxos, alcanos e álcoois primários. Alcenos, aldeídos, cetonas, ésteres, triterpenos, um diácido e um álcool secundário apresentaram distribuição mais restrita entre as espécies. Em ambas as divisões, a morfologia das ceras epicuticulares variou de amorfa à cristais de ceras, com predomínio das primeiras. Conclusão. Este é o primeiro estudo com foco na composição das ceras cuticulares em espécies brasileiras de briófitas, contribuindo para o desenvolvimento dos estudos em briologia, com foco na análise da diversidade química desse grupo. Várias substâncias e morfologias de cera foram detectadas pela primeira vez nesse grupo de plantas, ainda que já fossem bastante conhecidas em angiospermas. Acreditamos que nossos dados podem auxiliar no entendimento da evolução da cutícula e das vias biossintéticas nas embriófitas.

Palavras-chave: briófitas, evolução, hepáticas, lipídios de superfície, musgos, química de cera. 


\section{Abstract}

Introduction. Bryophytes were the first plants to conquest land environment. The cuticle appearance was crucial to the success of this transition, ensuring a protection against water loss. This layer is characterized by the cutin matrix embedded and covered with cuticular waxes. In Brazil, there are more than 1,500 species of bryophytes. In this study we present a general description of the cuticular waxes of gametophytes of native species of Bryophyta and Marchantiophyta. Methods. Cuticular waxes from 34 species from different locations of São Paulo/Brazil were analyzed by gas chromatography coupled with mass spectrometry. The compounds were identified based on mass spectra fragmentation. The morphology of the epicuticular waxes was analyzed using SEM. Main results. The wax content in the liverwort species varied from $0.1 \mu \mathrm{g} / \mathrm{cm}^{2}$ to 4 $\mu \mathrm{g} / \mathrm{cm}^{2}$, while in mosses the values ranged from $0.02 \mu \mathrm{g} / \mathrm{cm}^{2}$ to $0.6 \mu \mathrm{g} / \mathrm{cm}^{2}$. The main classes of wax compounds were fatty acids, alkanes, and primary alcohols. Aldehydes, alkenes, esters, ketones, triterpenes, a diacid and a secondary alcohol presented more restricted distribution among the species. The morphology of epicuticular waxes varied from amorphous to wax crystals, with a predominance of the first. Conclusion. This is the first study focusing on the composition of cuticular waxes in Brazilian species of bryophytes. Several compounds and wax morphologies were detected for the first time in this group of plants. We believe that our data can contribute to the development of studies in briology, emphasizing the chemical diversity of these plants, and help in understanding the cuticle evolution and the wax biosynthetic pathways in embryophytes.

Keywords: bryophytes, evolution, liverworts, mosses, surface lipids, wax chemistry. 


\section{Introdução}

O termo "briófitas" é utilizado para designar três linhagens evolutivas distintas de plantas terrestres que correspondem as divisões Anthocerotophyta (antóceros), Bryophyta sensu stricto (musgos) e Marchantiophyta (hepáticas) (Goffinet 2000; Vanderpoorten \& Goffinet 2009). Essas plantas foram as primeiras a se estabelecerem em ambiente terrestre, embora ainda dependam da água para a reprodução (Delgadillo \& Cárdenas 1990; Vanderpoorten \& Goffinet 2009). Nessa transição, um dos principais desafios enfrentados foi o da dessecação, sendo o surgimento da cutícula fundamental para o sucesso da colonização desse novo ambiente, auxiliando especialmente a reduzir a perda de água (Bargel et al. 2006; Busta et al. 2016a).

A cutícula é uma camada extracelular contínua altamente hidrofóbica formada por uma matriz de cutina embebida e recoberta pelas ceras, designadas como ceras intra e epicuticulares, respectivamente. Essa camada é encontrada revestindo as superfícies aéreas das plantas e desempenha um papel significativo na tolerância ao estresse biótico e abiótico (Dominguez et al. 2011; Yeats \& Rose 2013). As ceras cuticulares são uma mistura complexa de compostos lipofílicos de cadeia longa, entre eles, ácidos graxos, alcanos, álcoois primários e secundários, aldeídos, ésteres, cetonas etc. (Kunst \& Samuels 2003; 2009), podendo também serem encontrados alguns compostos cíclicos (BáezSañudo et al. 2013; Bernard \& Joubés 2013).

As briófitas são mundialmente reconhecidas pela sua ampla diversidade (aproximadamente 20.000 espécies) (The Plant List 2018), sendo considerado o segundo maior grupo de plantas terrestres depois das angiospermas (Gradstein et al. 2001; Goffinet et al. 2009), ocorrendo desde as florestas tropicais a habitats mais hostis, como desertos e ambientes congelados (Frahm 2003; Goffinet \& Shaw 2009). No Brasil, a brioflora foi 
recentemente reavaliada em 1.524 espécies, sendo as divisões Bryophyta e Marchantiophyta as mais diversas com 880 e 633 táxons, respectivamente, enquanto Anthocerotophyta apresenta 11 espécies (Costa \& Peralta 2015).

As briófitas, apesar de sua diversidade notável, têm sido negligenciadas como objeto de estudo há muito tempo, especialmente devido à dificuldade de identificação e ao tamanho geralmente pequeno (Klavina et al. 2015). Do ponto de vista fitoquímico, menos de 5\% das espécies de briófitas já foram investigadas (Asakawa et al. 2013). A presença da cutícula e suas propriedades têm sido comprovadas de forma convincente nesse grupo de plantas desde os anos de 1940, sendo descritas no gametófito e no esporófito (Buch 1945; Proctor 1979; Clayton-Greene et al. 1985; Heinrichs et al. 2000; Heinrichs \& Rycroft 2001; Koch et al. 2009; Budke et al. 2011; 2012; 2013; Busta et al. 2016a; 2016b), porém pouco mais de 180 espécies já foram investigadas. Grande parte dos estudos encontra-se limitado a divisão Bryophyta sensu stricto, havendo alguns com Marchantiophyta e apenas um com antócero (Notothylas orbicularis (Schwein.) Sull. Notothyladaceae) (Cook \& Graham 1998).

Bush (1945) observou a presença da cutícula como uma fina camada sobre a superfície dos gametófitos jovens de musgos e hepáticas. Mais tarde, Schonherr \& Ziegler (1975), através de microscopia eletrônica de transmissão (MET), descreveram a presença da cutícula recobrindo os poros aeríferos de Marchantia. A caracterização da morfologia das ceras epicuticulares utilizando microscopia eletrônica de varredura (MEV), variando do tipo amorfa até cristais, foi inicialmente descrita nos gametófitos de 43 espécies da divisão Bryophyta (Proctor 1979), posteriormente em 35 espécies de Polytrichaceae (Clayton-Greene 1985) e em 81 espécies de hepáticas de diferentes gêneros de Plagiochilaceae (Heinrichs et al. 2000). Cristais de cera também foram descritos na 
cápsula do esporófito de cinco espécies de Polytrichaceae (Neinhuis \& Jetter 1995) e do musgo Buxbaumia viridis (DC.) Moug. \& Nestl. (Buxbaumiaceae) (Koch et al. 2009).

Em relação a química das ceras cuticulares, para hepáticas Huneck \& Vevle (1970) descreveram um terpenoide como componente principal no gametófito de Anthelia julacea (L.) Dumort. (Antheliaceae), enquanto alcanos e ésteres foram detectados em Calypogeia meylanii H. Buch (Calypogeiaceae), Gymnocolea inflata (Huds.) Dumort. (Anastrophyllaceae), Jungermannia sphaerocarpa Hook. (Jungermanniaceae), Mylia taylorii (Hook.) Mitt. (Myliaceae) e Pellia fabbroniana Raddi (Pelliaceae) (Benešová et al. 1972). Já os ácidos graxos foram predominantes nos gametófitos de Plagiochila tabinensis Steph. (Heinrichs et al. 2000) e P. heterofolia Steph. (Plagiochilaceae) (Heinrichs \& Rycroft 2001). Nos gametófitos dos musgos Andreaea rupestris Hedw. (Andreaeaceae), Pogonatum aloides (Hedw.) P. Beauv. e Pogonatum urnigerum (Hedw.) P. Beauv. (Polytrichaceae), Haas (1982) identificou alcanos, ácidos graxos, álcoois e ésteres, enquanto Xu et al. (2009) verificaram a presença de ácidos graxos, alcanos e álcoois primários no gametófito de Syntrichia caninervis Mitt. (Pottiaceae). Em Polytrichaceae, nas ceras cuticulares da cápsula do esporófito de Pogonatum belangeri (Müll. Hal.) A. Jaeger e P. urnigerum foram detectados alcanos, álcoois primários, ésteres alquílicos e, majoritariamente, o álcool secundário nonacosan-10-ol (Neinhuis \& Jetter 1995). Recentemente, uma análise comparativa da cutícula do musgo Funaria hygrometrica Hedw. (Funariaceae) revelou a mesma morfologia do tipo filme das ceras epicuticulares no gametófito, caliptra e na cápsula do esporófito (Budke et al. 2011; 2012; 2013), porém uma variação na composição química dessas ceras, sendo os ésteres graxos $\beta$-hidroxilados limitados ao gametófito e a caliptra, enquanto os alcanos, os aldeídos e os ésteres graxos de alcano-diois foram restritos ao esporófito (Busta et al. 2016a; 2016b). 
Até onde sabemos, não há qualquer estudo sobre a cutícula em espécies brasileiras de briófitas. Nesse contexto, este estudo tem como principal objetivo fornecer uma caracterização geral da composição química e da morfologia das ceras cuticulares do gametófito de diferentes espécies pertencentes as divisões Bryophyta e Marchantiophyta. Desse modo, pretende-se contribuir com o conhecimento sobre esse grupo de plantas e ampliar nosso entendimento, com uma perspectiva evolutiva, sobre o papel da cutícula nas embriófitas.

\section{Material e métodos}

\section{Coleta do material vegetal}

Foram coletadas 12 espécies de hepáticas e 22 espécies de musgos provenientes de diferentes municípios do estado de São Paulo - Brasil (Tabela 1), entre os anos de 2018 e 2019. Devido ao pequeno porte das espécies, cada amostra foi formada por um conjunto de indivíduos da mesma localidade. Exemplares testemunhos foram depositados no Herbário de São Paulo - SP.

Tabela 1. Espécies de hepáticas (Machantiophyta) e musgos (Bryophyta) coletadas no estado de São Paulo, Brasil.

\begin{tabular}{|c|c|c|}
\hline \multicolumn{3}{|c|}{ Hepáticas (Marchantiophyta) } \\
\hline Espécie & Voucher & Local coleta \\
\hline Lejeuneaceae & & \\
\hline $\begin{array}{c}\text { Cheilolejeunea filiformis (Sw.) W. Ye, } \\
\text { R.L. Zhu \& Gradst. }\end{array}$ & 505383 & $\begin{array}{l}\text { Pico dos Marins - Piquete } \\
\left(22^{\circ} 30^{\prime} 57^{\prime \prime} \mathrm{S}, 45^{\circ} 09^{\prime} 02^{\prime \prime} \mathrm{O}\right)\end{array}$ \\
\hline Lejeunea isocalycina (Nees) Steph. & 486357 & $\begin{array}{l}\text { Horto Florestal - Campos do Jordão }\left(22^{\circ} 42^{\prime} 27^{\prime \prime} \mathrm{N},\right. \\
\left.\qquad 45^{\circ} 28^{\prime} 05^{\prime \prime} \mathrm{O}\right)\end{array}$ \\
\hline Lejeunea flava (Sw.) Nees & 493689 & $\begin{array}{l}\text { Universidade de São Paulo } \\
\left(23^{\circ} 33^{\prime} 60^{\prime \prime} \mathrm{S}, 46^{\circ} 43^{\prime} 45^{\prime \prime} \mathrm{O}\right)\end{array}$ \\
\hline Lejeunea laetevirens Ness \& Mont. & 505415 & $\begin{array}{c}\text { Paranapiacaba } \\
\left(23^{\circ} 46^{\prime} 09^{\prime \prime} \mathrm{S}, 46^{\circ} 22^{\prime} 52^{\prime \prime} \mathrm{O}\right)\end{array}$ \\
\hline $\begin{array}{c}\text { Lepidoziaceae } \\
\text { Bazzania gracilis (Hampe \& Gottsche) } \\
\text { Stephani }\end{array}$ & 502003 & $\begin{array}{l}\text { Parque Nacional da Serra da Bocâina - São José do Barreiro } \\
\qquad\left(22^{\circ} 45^{\prime} 34^{\prime \prime} \mathrm{S}, 44^{\circ} 36^{\prime} 46^{\prime \prime} \mathrm{O}\right)\end{array}$ \\
\hline Bazzania hookeri (Lindenb.) Trevis. & 486351 & $\begin{array}{l}\text { Horto Florestal - Campos do } \\
\text { Jordão }\left(22^{\circ} 42^{\prime} 27^{\prime \prime} \mathrm{N}, 45^{\circ} 28^{\prime} 05^{\prime \prime} \mathrm{O}\right)\end{array}$ \\
\hline
\end{tabular}




\section{Marchantiaceae}

Marchantia papillata Raddi

486356

\section{Metzgeriaceae}

Metzgeria albinea Spruce

505397

Metzgeria conjugata Lindb.

505371

Metzgeria furcata (L.) Dumort

505370

Plagiochilaceae

Plagiochila raddiana Lindenb.

505388

Plagiochila superba (Nees ex Spreng.) Mont. \& Nees

\section{Bryaceae}

Rosulabryum densifolium (Brid.) Ochyra

505379

\section{Calymperaceae}

Octoblepharum albidum Hedw.

485282

Dicranaceae

Campylopus arctocarpus (Hornsch.) Mitt.

486358

Campylopus filifolius (Hornsch.) Mitt.

486352

Campylopus gemmatus (Müll. Hal.) Paris

Campylopus pilifer Brid.

505373

505384

Pilopogon laevis (Taylor) Thér.

505374

\section{Hypnaceae}

Calliergonella cuspidata (Hedw.) Loeske

505377

Lembophyllaceae

Porotrichodendron superbum (Taylor) Broth.

Leucobryaceae

Leucobryum giganteum Müll. Hal.

Mniaceae

Plagiomnium rhynchophorum (Hook.) T.J.kop

Pyrrhobryum spiniforme (Hedw.) Mitt.

\section{Polytrichaceae}

Atrichum androgynum (Müll. Hal.) A. Jaeger

Pogonatum pensilvanicum (W. Bartram ex Hedw.) P. Beauv.

Polytrichadelphus pseudopolytrichum (Raddi) G.L. Sm.

Polytrichum angustifolium Mitt.

Polytrichum commune Hedw.

Polytrichum juniperinum Willd. ex Hedw

493688

505385

493690

502251

505376

505386
Horto Florestal - Campos do Jordão

(22॰42'27" N, 45²8'05" O)

Pico dos Marins - Piquete

(22³0'57" S, 4509'02" O)

Universidade de São Paulo

$\left(23^{\circ} 33^{\prime} 60^{\prime \prime} \mathrm{S}, 46^{\circ} 43^{\prime} 45^{\prime \prime} \mathrm{O}\right)$

Instituto de Botânica

(233'3'"S, 46³7'17"O)

Reserva Florestal do Instituto de Biociências (233'59" S, 4643'45" O)

Pico dos Marins - Piquete (22³0'57" S, 4509'02" O)

Musgos (Bryophyta)

Horto Florestal - Campos do Jordão $\left(22^{\circ} 43^{\prime} 0^{\prime \prime} \mathrm{S}, 45^{\circ} 27^{\prime} 41^{\prime \prime} \mathrm{O}\right)$

Parque Municipal São Marcelo - Mogi Guaçu (22²1'48" S, 4658'34" O)

Horto Florestal - Campos do Jordão $\left(22^{\circ} 42^{\prime} 27^{\prime \prime} \mathrm{N}, 45^{\circ} 28^{\prime} 05^{\prime \prime} \mathrm{O}\right)$

Horto Florestal - Campos do Jordão (22 42 '27" N, 45²8'05" O) Represa do Broa - Itirapina (22 $\left.{ }^{\circ} 10^{\prime} 37^{\prime \prime} \mathrm{S}, 47^{\circ} 54^{\prime} 39^{\prime \prime} \mathrm{O}\right)$ Pico dos Marins - Piquete (22³0'57" S, 4509'02" O) Represa do Broa - Itirapina (22 10'37" S, 4754'39" O)

Horto Florestal - Campos do Jordão $\left(22^{\circ} 43^{\prime} 0^{\prime \prime} \mathrm{S}, 45^{\circ} 27^{\prime} 41^{\prime \prime} \mathrm{O}\right)$

Pico dos Marins - Piquete (22³0'57" S, 4509'02" O)

Horto Florestal - Campos do Jordão $\left(22^{\circ} 42^{\prime} 27^{\prime \prime} \mathrm{N}, 45^{\circ} 28^{\prime} 05^{\prime \prime} \mathrm{O}\right)$

Pico dos Marins - Piquete (22॰30'57" S, 4509'02" O)

Reserva Florestal do Instituto de Biociências (233'ㄷ' S, 46²43'45" O)

Universidade de São Paulo (2333'55" S, 4643'51" O) Pico dos Marins - Piquete (2230'57" S, 4509'02" O)

Horto Florestal - Campos do Jordão (2242'27" N, 45²8'05" O) $\left(22^{\circ} 45^{\prime} 34^{\prime \prime} \mathrm{S}, 44^{\circ} 36^{\prime} 46^{\prime \prime} \mathrm{O}\right)$

Horto Florestal - Campos do Jordão $\left(22^{\circ} 42^{\prime} 27^{\prime \prime} \mathrm{N}, 45^{\circ} 28^{\prime} 05^{\prime \prime} \mathrm{O}\right)$ Pico dos Marins - Piquete (22 30 '57" S, 4509'02" O) 


\begin{tabular}{|c|c|c|}
\hline \multicolumn{3}{|l|}{ Sphagnaceae } \\
\hline $\begin{array}{l}\text { Sphagnum gracilescens Hampe ex Müll. } \\
\text { Hal. }\end{array}$ & 505375 & $\begin{array}{l}\text { Horto Florestal - Campos do Jordão } \\
\qquad\left(22^{\circ} 42^{\prime} 27^{\prime \prime} \mathrm{N}, 45^{\circ} 28^{\prime} 05^{\prime \prime} \mathrm{O}\right)\end{array}$ \\
\hline Sphagnum recurvum $\mathrm{P}$. Beauv. & 501994 & $\begin{array}{l}\text { Parque Nacional da Serra da Bocâina - São José do Barreiro } \\
\qquad\left(22^{\circ} 45^{\prime} 34^{\prime \prime} \mathrm{S}, 44^{\circ} 36^{\prime} 46^{\prime \prime} \mathrm{O}\right)\end{array}$ \\
\hline Sphagnum subsecundum Nees & 501994 & $\begin{array}{l}\text { Parque Nacional da Serra da Bocâina - São José do Barreiro } \\
\qquad\left(22^{\circ} 45^{\prime} 34^{\prime \prime} \mathrm{S}, 4^{\circ} 36^{\prime} 46^{\prime \prime} \mathrm{O}\right)\end{array}$ \\
\hline \multicolumn{3}{|l|}{ Thuidiaceae } \\
\hline Thuidium delicatulum (Hedw.) Schimp. & 486354 & $\begin{array}{l}\text { Horto Florestal - Campos do Jordão } \\
\qquad\left(22^{\circ} 42^{\prime} 27^{\prime \prime} \mathrm{N}, 45^{\circ} 28^{\prime} 05^{\prime \prime} \mathrm{O}\right)\end{array}$ \\
\hline
\end{tabular}

\section{Análise da cera cuticular}

As ceras foram obtidas dos gametófitos das hepáticas e musgos coletados e analisadas quanto a composição química e sua morfologia conforme metodologia descrita na Introdução geral (ver Material e Métodos - pag. 39-42). Os dados obtidos do teor das ceras cuticulares e das classes dos compostos de cera (porcentagem relativa total de cada classe) foram tabulados e os gráficos construídos utilizando o software Graphpad Prism ${ }^{\circledR}$ versão 7.01 .

\section{Resultados}

\section{Teor de cera cuticular}

O teor de cera cuticular obtido dos gametófitos foi maior para as espécies pertencentes a divisão Marchantiophyta (Figura 1A) em relação ao encontrado para as espécies da divisão Bryophyta (Figura 1B). O teor de cera encontrado nas espécies de hepáticas variou de $0,1 \mu \mathrm{g} / \mathrm{cm}^{2}$ em Cheilolejeunea filiformis (Lejeuneaceae) e Plagiochila superba (Plagiochilaceae) a $4 \mu \mathrm{g} / \mathrm{cm}^{2}$ em Bazzania hookeri (Lepidoziaceae) (Figura 1A). Para os musgos, o teor obtido para as espécies analisadas variou de $0,02 \mu \mathrm{g} / \mathrm{cm}^{2} \mathrm{em}$ Octoblepharum albidum (Calymperaceae) e Campylopus gemmatus (Dicranaceae) a 0,6 $\mu \mathrm{g} / \mathrm{cm}^{2}$ em Calliergonella cuspidata (Hypnaceae) (Figura 1B). Somente para Polytrichadelphus pseudopolytrichum foi possível avaliar a cera cuticular dos 
gametófitos femininos e masculinos, separadamente, sendo obtido igual valor $(0,2$ $\mu \mathrm{g} / \mathrm{cm}^{2}$ ) no teor de ceras (Figura 1B).

A

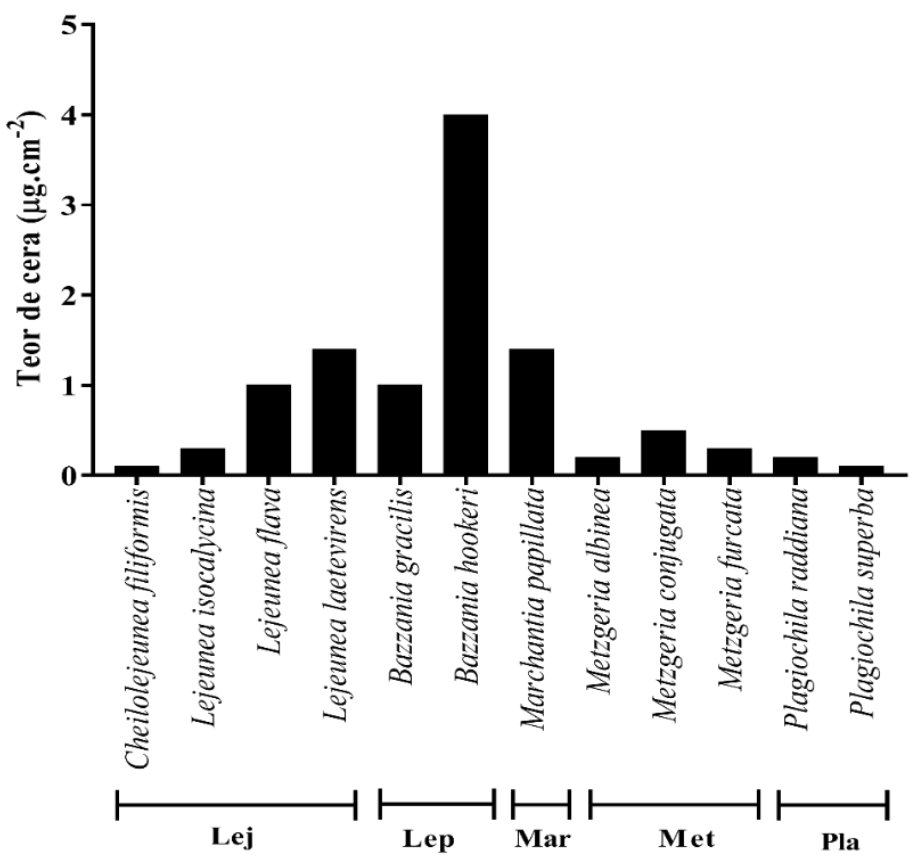

B

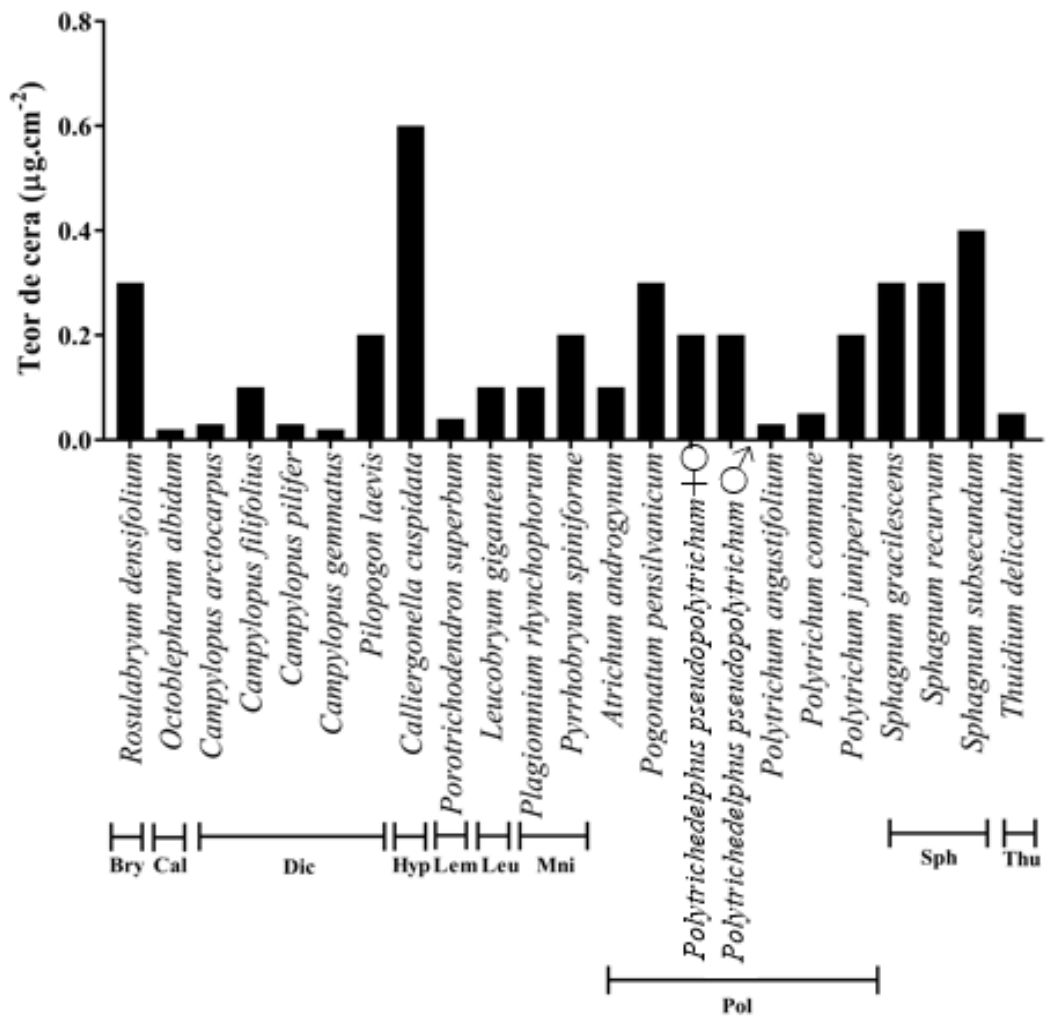


Figura 1. Teor de cera cuticular do gametófito de hepáticas (Marchantiophyta) (A) e musgos (Bryophyta) (B). As espécies estão listadas por ordem alfabética das famílias Marchantiophyta: Lej: Lejeuneaceae, Lep: Lepidoziaceae, Mar: Marchantiaceae, Met: Metzgeriaceae, Pla: Plagiochilaceae. Bryophyta: Bry: Bryaceae, Cal: Calymperaceae, Dic: Dicranaceae, Hyp: Hypnaceae, Lem: Lembophyllaceae, Leu: Leucobryaceae, Mni: Mniaceae, Pol: Polytrichaceae, Sph: Sphagnaceae, Thu: Thuidiaceae.

\section{Análise da composição química da cera cuticular}

A partir da análise química da cera cuticular dos gametófitos, foi detectada uma ampla diversidade de compostos nas espécies de ambas as divisões (Figura 2A e B).

Para divisão Marchantiophyta, foram identificadas nove classes de componentes de cera, entre elas, ácidos graxos, alcanos, alcenos, álcoois primários e secundários, aldeídos, cetonas, ésteres e triterpenos (Figura 2A). Os ácidos graxos formaram a principal classe de componentes de cera encontrada entre as hepáticas, exceto nas duas espécies de Plagiochilaceae (Plagiochila raddiana e $P$. superba), nas quais os alcanos foram majoritários (acima de 40\%) e em Cheilolejeunea filiformis (Lejeuneaceae) na qual triterpenos foram mais expressivos (Figura 2A). Marchantia papillata (Marchantiaceae) e as espécies pertencentes a Metzgeriaceae foram os indivíduos que apresentaram as maiores porcentagens de ácidos graxos, com mais de $80 \%$ da cera formada por essa classe. Em menor proporção, os álcoois primários foram verificados principalmente em Metzgeriaceae e em algumas espécies de Lejeuneaceae (Figura 2A). Os alcenos, aldeídos, ésteres, cetonas, triterpenos e um álcool secundário foram as classes menos diversas e de distribuição mais restrita entre as espécies dessa divisão (Figura 2A). 


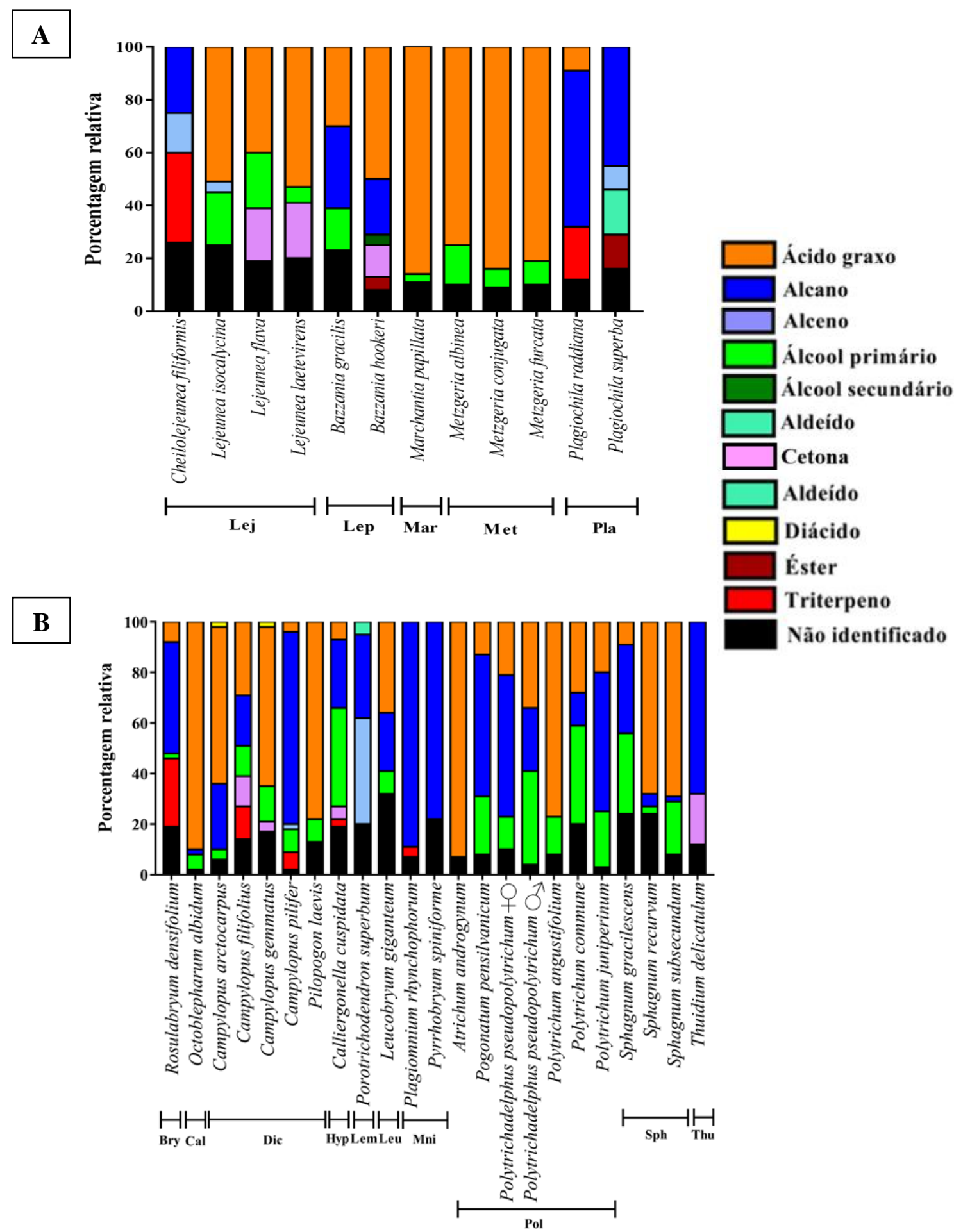

Figura 2. Caracterização química das ceras cuticulares dos gametófitos das espécies de hepáticas (Marchantiophyta) (A) e musgos (Bryophyta) (B). As espécies estão listadas por ordem alfabética das famílias - Marchantiophyta: Lej: Lejeuneaceae, Lep: Lepidoziaceae, Mar: Marchantiaceae, Met: Metzgeriaceae, Pla: Plagiochilaceae. 
Bryophyta: Bry: Bryaceae, Cal: Calymperaceae, Dic: Dicranaceae, Hyp: Hypnaceae, Lem: Lembophyllaceae, Leu: Leucobryaceae, Mni: Mniaceae, Pol: Polytrichaceae, Sph: Sphagnaceae, Thu: Thuidiaceae.

Em relação aos homólogos de ácidos graxos, foram encontrados homólogos variando entre C14 (ácido tetradecanoico) à C26 (ácido hexacosanoico). O ácido hexadecanoico (C16) foi o principal composto detectado entre as espécies, seguido do C18 (ácido octadecanoico). No caso do homólogo C16, esse composto representou 68\% da cera em M. conjugata (Metzgeriaceae) (Tabela 2). Os homólogos de alcanos identificados variaram entre C20 (eicosano) à C33 (tritriacontano). O nonacosano (C29) foi o alcano mais abundante presente na maioria das espécies, correspondendo a 11,4\% em Bazzania hookeri (Lepidoziaceae). Em Plagiochilaceae, para P. raddiana verificouse a ocorrência da série homóloga de C20 a C29, onde os homólogos C23 (tricosano) e C29 representaram $10,4 \%$ e $9,7 \%$ da cera. Já em $P$. superba foram identificados homólogos de alcanos variando de C20 à C33 com o homólogo C29 correspondendo a 9,6\% (Tabela 2). Entre os álcoois primários, foram identificados homólogos variando de C18 (octadecanol) à C28 (octacosanol). O composto C26 (hexacosanol) foi o principal homólogo detectado entre as hepáticas, sendo que esse álcool corresponde à 15\% da cera de M. albinea (Metzgeriaceae). Em Lejeunea flava (Lejeuneaceae) foi encontrada, em menor proporção, a série homóloga de C20 (eicosanol) à C27 (heptacosanol) (Tabela 2). Entre as classes de componentes com distribuição mais restrita, o alceno C18 (octadeceno) foi o principal homólogo dessa classe em $P$. superba (Plagiochilaceae) (6,4\%). Já em C. filiformes (Lejeuneaceae) o homólogo predominante foi o C20 (eicoseno) com 7,2\%. As cetonas nonadecan-2-ona (C19), heneicosan-2-ona (C21) e tricosan-2-ona (C23) foram detectadas restritamente em Lejeunea flava e L. laetevirens (Lejeuneaceae). Nessas, o homólogo C21 representou $14 \%$ e 13,6\% das ceras, 
respectivamente (Tabela 2). Além disso, verificou-se a presença da cetona pentacosan10-ona (C25) (12,2\%) e do álcool secundário nonacosan-10-ol (C29) $(4,4 \%)$ apenas em B. hookeri (Lepidoziaceae), bem como do éster C36 (octadecanoato de octadecila) com 4,6\% (Tabela 2). Em P. superba (Plagiochilaceae) foram detectados a presença dos ésteres C36 (7,4\%) e C38 (eicosanoato de octadecila) (5,6\%) e dos aldeídos C24 (tetracosanal) $(10,2 \%)$ e C26 (hexacosanal) $(6,4 \%)$ (Tabela 2).

Compostos cíclicos também foram identificados nas ceras das hepáticas (Tabela 2). Em C. filiformes foi identificado em maior proporção o triterpeno simiarenol $(33,6 \%)$. Em $P$. raddiana (Plagiochilaceae) foram identificados os triterpenos fridelina, $\beta$-amirina e $\alpha$-amirina com $10 \%, 3,7 \%$ e $6,2 \%$, respectivamente (Tabela 2). 
Tabela 2. Porcentagem relativa dos homólogos das classes de cera identificados nos gametófitos das espécies de hepáticas (Marchantiophyta).

\begin{tabular}{|c|c|c|c|c|c|c|c|c|c|c|c|c|c|c|c|c|c|c|c|c|c|c|c|c|c|c|c|c|c|c|c|c|}
\hline \multirow{2}{*}{ Espécie } & \multicolumn{6}{|c|}{ Ácido graxo } & \multicolumn{9}{|c|}{ Alcano } & \multicolumn{2}{|c|}{ Alceno } & \multicolumn{6}{|c|}{ Álcool primário } & \multirow{2}{*}{$\begin{array}{c}\text { *AS } \\
\text { ปิ }\end{array}$} & \multirow{2}{*}{$\begin{array}{l}\text { Aldeído } \\
\\
\text { ปั ठั }\end{array}$} & \multicolumn{3}{|c|}{ Cetona } & Éster & \multicolumn{3}{|c|}{ Triterpeno } \\
\hline & $\stackrel{\vec{U}}{ }$ & $\frac{n}{0}$ & Uี & $\stackrel{\infty}{U}$ ปิ & ปี ปี & లั & ठิ & ปี & $\tilde{\Xi}$ & ปै & فి రి & $\widehat{U}$ Uి & ठิ & $\overline{\tilde{v}}$ & $\tilde{U}$ & $\stackrel{\infty}{U}$ & ठิ & $\stackrel{\infty}{U}$ & ปิ ปี & తి & ปี & ठี & जิ & & & $\vec{\partial}$ & $\bar{U}$ กิ & ટี & లో & & 竞罢 & 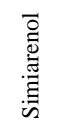 \\
\hline \multicolumn{33}{|l|}{$\overline{\text { Lejeuneaeae }}$} \\
\hline Cheilolejeunea filiformis & & & & & & & & 3,1 & 3 & &, 8 & 3,6 & 7,9 & 4 & & & $7,2 \quad 2,7$ & & & & & & & & & & & & & & & 33,6 \\
\hline Lejeunea isocalycina & 7,7 & & 22,5 & 11,9 & - & 8,7 & & & & & & & & & & 4,1 & & & & & 3,8 & 9,2 & 6,6 & & & & & & & & & \\
\hline Lejeunea flava & & & 4,3 & $2,6 \quad 12,21$ & $214,36,9$ & & & & & & & & & & & & & & $1,4 \mathbf{5}$ & 1,3 & $\begin{array}{lll}3 & 3,8 & 1,5\end{array}$ & $4 \quad 2,5$ & 2,5 & & & 31 & $14 \quad 3,3$ & & & & & \\
\hline Lejeunea laetevirens & & & 10,9 & $\begin{array}{lll}6,6 & 8,7 & 1\end{array}$ & $\mathbf{1 3 , 7} 13,2$ & & & & & & & & & & & & & & & & 5 & & & & & 4,51 & $13,63,5$ & & & & & \\
\hline \multicolumn{33}{|l|}{ Lepidoziaceae } \\
\hline Bazzania gracilis & & & 12,7 & $5,7 \quad 5,36$ & 6,4 & & & & 8,2 & 8 , & 5,9 & & & 7,9 & & & & & & & 11,7 & 4,4 & & & & & & & & & & \\
\hline Bazzania hookeri & 5,6 & - & 44,5 & & & & & & & & & 4,2 & 11,4 & 5,1 & & & & & & & & & & 4,4 & & & & 12,2 & 4,6 & & & \\
\hline \multicolumn{33}{|l|}{ Marchantiaceae } \\
\hline Marchantia papillata & 2,5 & 2,9 & 50,7 & $\begin{array}{lll}7,1 & 2 & 3\end{array}$ & $3,2 \quad 10,52,2$ & 5,7 & & & & & & & & & & & & - & & & & 2,6 & - & & & & & & & & & \\
\hline \multicolumn{33}{|l|}{ Metzgeriaceae } \\
\hline Metzgeria albinea & 4,3 & & 51,7 & $\begin{array}{lll}6 & 4,9 & 4\end{array}$ & $4 \quad 3,9$ & & & & & & & & & & & & & & & & & 15 & & & & & & & & & & \\
\hline Metzgeria conjugata & 3 & - & 68,32 & $\begin{array}{lll}5,9 & 2,1 & 2\end{array}$ & $2,6-$ & & & & & & & & & & & & & & -7 & & & & & & & & & & & & & \\
\hline Metzgeria furcata & 8,4 & 4,6 & 46,2 & 16,6 & & & & & & & & & & & & & & 2,3 & & & & 6,9 & & & & & & & & & & \\
\hline \multicolumn{33}{|l|}{ Plagiochilaceae } \\
\hline Plagiochila raddiana & & & 8,6 & & & & $4,6 \quad 6$ & 3 & 10,4 & 28 & 3,7 & $\begin{array}{ll}7 & 3,9\end{array}$ & 9,7 & & & & & & & & & & & & & & & & & 103, & $3,7 \quad 6,2$ & \\
\hline Plagiochila superba & & & & & & & $2,4 \quad 2,1$ & 12,6 & 34 & 4,2 & & 9 & 9,6 & 8,8 & 2,9 & 6,4 & 2,4 & & & & & & & & $\mathbf{1 0 , 2} 6,4$ & & & & $7,45,6$ & & & \\
\hline
\end{tabular}

*AS: Álcool secundário. (-) Refere-se aos compostos encontrados abaixo de 1\%. Espaço em branco significa que o homólogo não foi detectado. Valores em negrito correspondem às maiores porcentagens relativas dos componentes de uma mesma classe. 
Para a divisão Bryophyta foram encontradas oito classes de componentes de cera, ácidos graxos, alcanos, alcenos, álcoois primários, aldeídos, cetonas, diácidos e triterpenos (Figura 2B). Nos musgos, os ácidos graxos e alcanos também foram as principais classes detectadas entre as espécies. Pilopogon laevis (Dicranaceae), Octoblepharum albidum (Calymperaceae) e Atrichum androgynum (Polytrichaceae), por exemplo, foram os musgos com a maior porcentagem de ácidos graxos com 78\%, $90 \%$ e 93\%, respectivamente. Já as espécies Campylopus pilifer (Dicranaceae), Plagiomnium rhynchophorum e Pyrrhobryum spiniforme (Mniaceae) apresentaram valores expressivos de alcanos, com mais de $70 \%$ dessa classe (Figura 2B). Ainda que não tenha sido detectada diferença no teor de ceras entre os gametófitos feminino e masculino de Polytrichadelphus pseudopolytrichum (Polytrichaceae) (Figura 1B), o gametófito feminino apresenta maior proporção de alcanos, enquanto no gametófito masculino há maior proporção de álcoois primários (Figura 2B). Alcenos, aldeídos, cetonas e um diácido foram as classes de componentes de cera com distribuição mais restrita em determinadas espécies dessa divisão (Figura 2B).

Nos musgos, os homólogos de ácidos graxos variaram de C9 (ácido nonadioico) à C26 (ácido hexacosanoico), sendo o ácido hexadecanoico (C16) o principal composto encontrado entre os musgos, correspondendo a $49,5 \%$ em A. androgynum (Polytrichaceae), 44,8\% em O. albidum (Calymperaceae) e 40,9\% em Pilopogon laevis (Dicranaceae) (Tabela 3). Para os alcanos, foi identificada a série homóloga de C20 (eicosano) à C35 (pentatriacontano), a qual foi detectada completamente em Campylopus pilifer (Dicranaceae). Os homólogos C29 (nonacosano) e C27 (heptacosano) foram os compostos presentes na maioria das espécies (Tabela 3). Em Porotrichodendron superbum (Lembophyllaceae), Plagiomnium rhynchophorum e Pyrrhobryum spiniforme (Mniaceae) e Thuidium delicatulum (Thuidiaceae), por exemplo, foram observadas as 
maiores proporções desses homólogos de alcanos. Além disso, nas espécies de Mniaceae, Thuidiaceae e no Sphagnum gracilescens (Sphagnaceae) também foi verificada a presença expressiva dos homólogos C23 (tricosano) e C25 (pentacosano) (Tabela 3). Os álcoois primários variaram de C16 (hexadecanol) à C30 (triacontanol), sendo o homólogo C26 (hexacosanol) correspondente à 26,5\% em Calliergonella cuspidata (Hypnaceae) e o homólogo C28 (octacosanol) encontrado com 18,9\% em S. gracilescens (Sphagnaceae) (Tabela 3). Para Polytrichadelphus pseudopolytrichum (Polytrichaceae) foi observada diferença qualitativa entre os gametófitos feminino e masculino. No masculino o alcano majoritário foi C23, enquanto o feminino apresentou maior diversidade de homólogos, tendo o C25 como principal. Entre os álcoois primários, em ambos o C18 foi o majoritário, havendo, porém, maior diversidade no masculino (Tabela 3).

Novamente, entre as classes de distribuição mais restrita, os homólogos identificados de alcenos foram praticamente restritos a $P$. superbum (Lembophyllaceae), na qual também foi identificado o aldeído C20 (eicosanal) (Tabela 3). O diácido nonanodioico foi encontrado apenas nas espécies de Dicranaceae, Campylopus arctocarpus e C. gemmatus com $2 \%$ em cada, nessa última também foi detectada a cetona heneicosan-2-ona (C21) assim como em Campylopus filifolius (Tabela 3). Em C. filifolius (Dicranaceae) e T. delicatulum (Thuidiaceae) foi detectada a presença de nonacosan-10ona (C29) com 9,7\% e 20\%, respectivamente, enquanto em Calliergonella cuspidata (Hypnaceae) foi encontrada a cetona pentacosan-8-ona (C25) com 5\% (Tabela 3).

Em relação aos compostos cíclicos das ceras em musgos, os triterpenos foram restritos em algumas espécies, sendo a lupenona detectada em Rosulabryum densifolium (Bryaceae) e Campylopus pilifer (Dicranaceae) com 22,8\% e 7\%, respectivamente, enquanto a fridelina correspondeu a $6 \%$ na cera de $C$. filifolius (Dicranaceae) (Tabela 3). 
Tabela 3. Porcentagem relativa dos homólogos das classes de cera identificados nos gametófitos das espécies de musgos (Bryophyta).

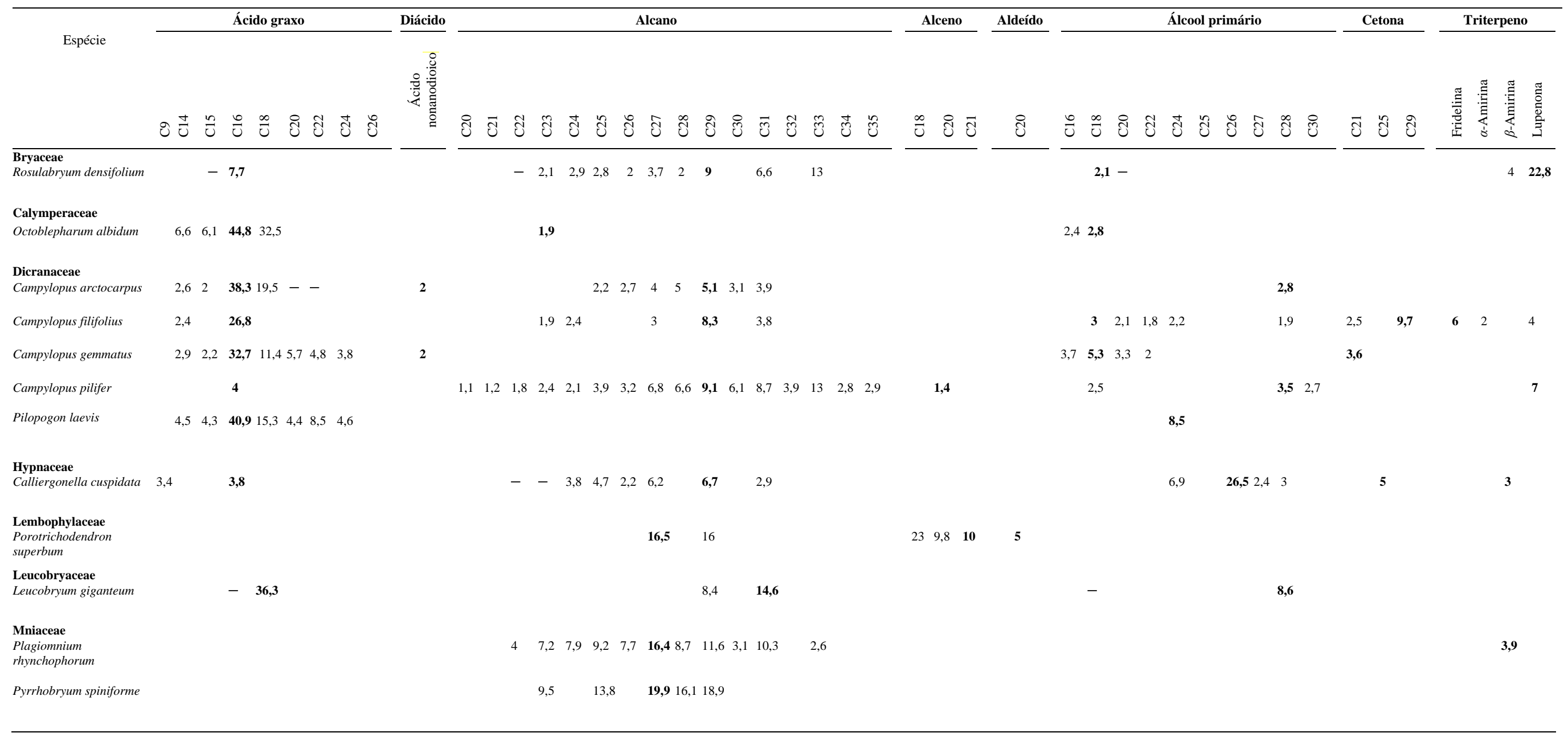

(-) Refere-se aos compostos encontrados abaixo de 1\%. Espaço em branco significa que o homólogo não foi detectado. Valores em negrito correspondem às maiores porcentagens relativas dos componentes de uma mesma classe. 
Tabela 3. Continuação.

\begin{tabular}{|c|c|c|c|c|c|c|c|c|c|c|c|c|c|c|c|c|c|c|c|c|c|c|c|c|c|c|c|c|c|c|c|c|c|c|c|c|c|c|c|c|}
\hline \multirow{2}{*}{ Espécie } & \multirow[b]{2}{*}{$8 \stackrel{0}{0}$} & \multirow[b]{2}{*}{$\stackrel{n}{u}$} & \multicolumn{6}{|c|}{ Ácido graxo } & \multicolumn{16}{|c|}{ Alcano } & \multicolumn{3}{|c|}{ Alceno } & \multicolumn{10}{|c|}{ Álcool primário } & \multicolumn{3}{|c|}{ Cetona } \\
\hline & & & $\stackrel{\circlearrowright}{U}$ & $\stackrel{\infty}{U}$ & రิ & ปี & ป̃ & రి & ర్రి & $\overrightarrow{\widetilde{U}}$ & ปี & $\tilde{\mho}$ & $\stackrel{\widetilde{U}}{\text { Un }}$ & ปิ & లั & $\widehat{\widehat{V}}$ & తి & ปิ & ర్ల & $\overline{\tilde{v}}$ & $\tilde{ల}$ & $\tilde{U}$ & 苅 & $\ddot{U}$ & $\stackrel{\infty}{U}$ & రิ & $\overline{\tilde{O}}$ & $\stackrel{0}{0}$ & $\stackrel{\infty}{U}$ & రి & ปี & đ্ & ปี & లి & $\hat{\tilde{U}}$ & లి & ల్ల & $\overrightarrow{\widetilde{N}}$ & ชี & తิ \\
\hline $\begin{array}{l}\text { Polytrichaceae } \\
\text { Atrichum androgynum }\end{array}$ & 6,4 & 3,6 & 49,5 & 20,2 & 4,8 & 4 & 2,9 & & & & & & & & & & & & & & & & & & & & & & & & & & & & & & & & & \\
\hline $\begin{array}{l}\text { Pogonatum } \\
\text { pensilvanicum }\end{array}$ & & & 8,3 & 4,4 & & & & & & & & 2,3 & 4,4 & 4,2 & 3,2 & 6,5 & 7,6 & 8,6 & 6,5 & 5,8 & 2,3 & 4,8 & & & - & & & - & 3,1 & 4,1 & 3,2 & & & 5,1 & & 4,7 & 2,9 & & & \\
\hline $\begin{array}{l}\text { Polytrichadelphus } \\
\text { pseudopolytrichum } \text { 우 }\end{array}$ & 7,6 & & 13,4 & & & & & & & & 2,5 & 8,7 & 4,3 & 11,4 & 4,4 & 7,5 & 4,1 & 6,8 & 3 & 2,6 & & & & & & & & 2,1 & 4,8 & & & 3,2 & & 3,5 & & & & & & \\
\hline $\begin{array}{l}\text { Polytrichadelphus } \\
\text { pseudopolytrichum } \widehat{ }\end{array}$ & 12,3 & & 21,3 & & & & & & & & & 9,5 & 3,8 & 6,7 & & & & 4,6 & & & & & & & & & & 4,3 & 11,6 & 5,9 & 4,5 & 3,9 & & 7,1 & & & & & & \\
\hline $\begin{array}{l}\text { Polytrichum } \\
\text { angustifolium }\end{array}$ & 7 & 3,8 & 5,6 & 21 & 18,4 & 4,8 & 13,2 & 3,4 & & & & & & & & & & & & & & & & & & & & & & 3 & & 8 & & 3 & & & & & & \\
\hline Polytrichum commune & 9,6 & & 18,4 & & & & & & & & & & & & & 3,3 & & 5,1 & & 4,4 & & & & & & & & & 4,4 & 6,5 & 5,4 & 12,9 & & 6 & & 4,3 & & & & \\
\hline Polytrichum juniperinum & 1,4 & & 10,9 & 5,8 & & & 1,3 & & & 1,3 & 2,1 & 6,3 & 3,3 & 6,6 & 5,6 & 7,6 & 4,1 & 7,2 & 2,5 & 4,2 & & 4,1 & & & & & & 6,7 & & & & & & 1,5 & 2,5 & 4,8 & 6,6 & & & \\
\hline Sphagnaceae & & & & & & & & & & & & & & & & & & & & & & & & & & & & & & & & & & & & & & & & \\
\hline Sphagnum gracilescens & & & 9,7 & & & & & & & & & 11,2 & & 12 & & 5,5 & & 5,9 & & & & - & & & & & & & - & & & & & 13,3 & & 18,9 & - & & & \\
\hline Sphagnum recurvum & 2,5 & 3,5 & 34,1 & 3,8 & 4,5 & 4,8 & 7,8 & 4,4 & & & & 3,6 & & & & 2,4 & & & & & & & & & & & & - & - & & & & & - & & 2,6 & & & & \\
\hline Sphagnum subsecundum & 4,7 & 3,2 & 39,2 & 4,6 & & 5,9 & 7,2 & 4,2 & & & & 2 & & & & & & & & & & & & & & & & & & & & & & & & & & & & \\
\hline Thuidiaceae & & & & & & & & & & & & & & & & & & & & & & & & & & & & & & & & & & & & & & & & \\
\hline Thuidium delicatulum & & & & & & & & & & & & 14,8 & 10,6 & 14,6 & & 13,1 & & 14,8 & & & & & & & & - & & & & & & & & & & & & & & 2 \\
\hline
\end{tabular}

(-) Refere-se aos compostos encontrados abaixo de 1\%. Espaço em branco significa que o homólogo não foi detectado. Valores em negrito correspondem às maiores porcentagens relativas dos componentes de uma mesma classe. 


\section{Análise da morfologia da cera epicuticular por meio de MEV}

As espécies de musgos e hepáticas possuem morfologia das ceras epicuticulares na superfície de seus gametófitos bastante variável, de amorfa à cristaloides (Figura 3AL). Contudo, na maioria das espécies analisadas é possível observar que a cera do tipo filme é predominante (Tabela 4). As imagens das ceras epicuticulares de todas as espécies podem ser vistas no Material Suplementar (Figura i).

Cristais de cera foram verificados em espécies de hepáticas (Figura 3C- G). Nos gametófitos das espécies de Lejeuneaceae, L. flava (Figura 3C) e L. laetevirens (Figura 3D), foram constatadas a presença de plaquetas. Essa mesma morfologia foi verificada ao redor das células do poro aerífero de Marchantia papillata (Marchantiaceae) (Figura 3E). Além disso, grânulos de cera foram encontrados nas espécies pertencentes a Lepidoziaceae, Bazzania gracilis (Figura 3F) e B. hookeri (Figura 3G).

Na divisão Bryophyta, a presença de grânulos de cera também foi observada no gametófito de Pyrrhobryum spiniforme (Mniaceae) (Figura 3H). Em Polytrichaceae, a morfologia das ceras epicuticulares da região dorsal dos filídios de $P$. pseudopolytrichum (Polytrichaceae) assim como a composição, também apresentou certa variação entre o gametófito feminino e masculino (Figura 3I - L). No primeiro há a formação de plaquetas de ceras na superfície das lamelas fotossintetizantes (Figura 3I), enquanto no segundo há a ornamentação do tipo crosta (Figura 3K). Na região ventral a cera é do tipo filme nos dois gametófitos (Figura 3J e 3L). Apenas para essa espécie foi possível detectar variação morfológica das ceras epicuticulares na região dorsal e ventral do gametófito. 


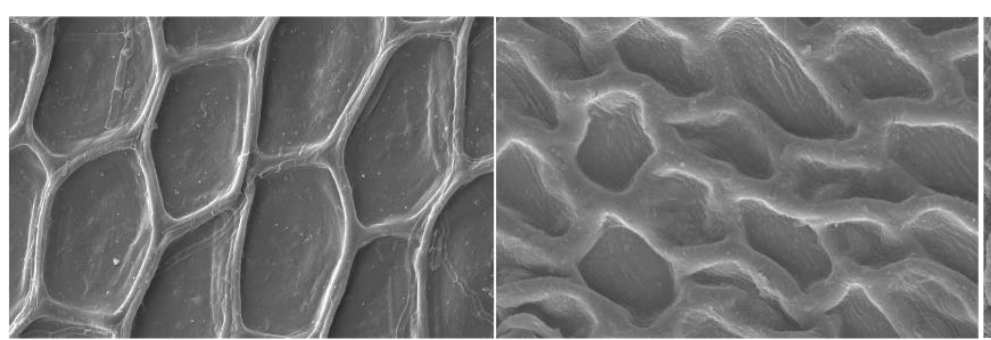

A

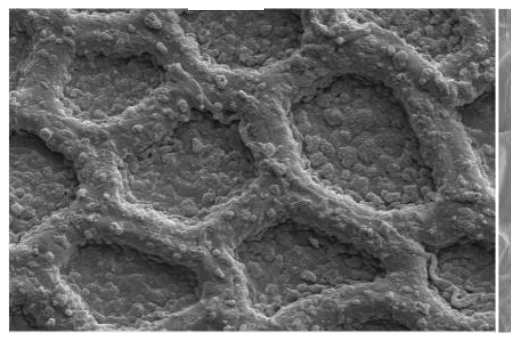

D

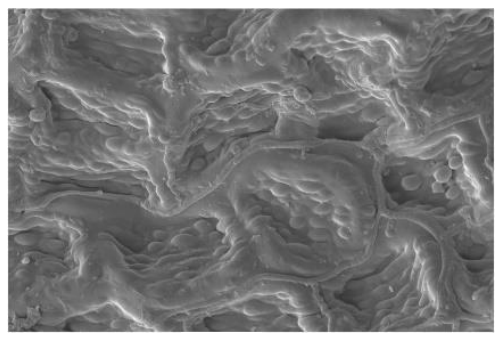

G

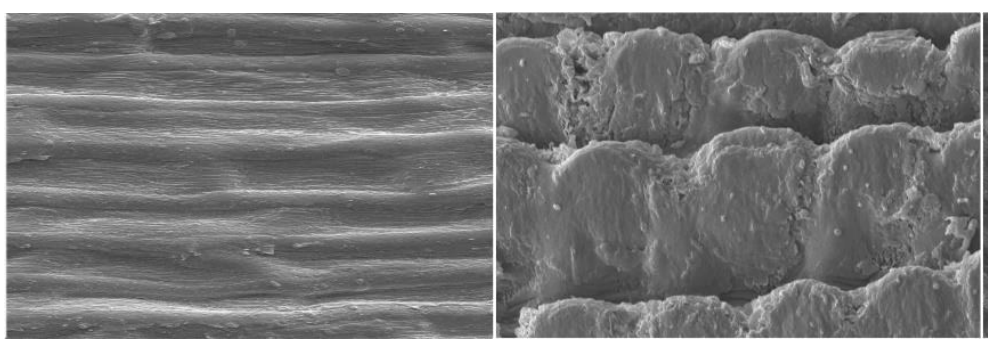

J
B

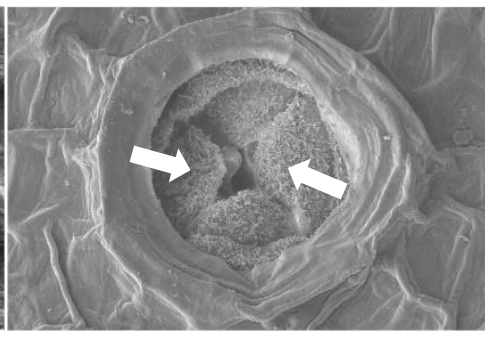

E

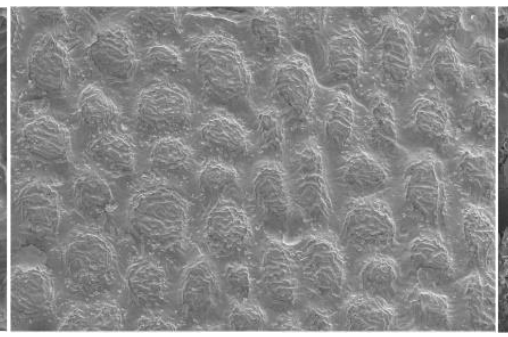

H

K

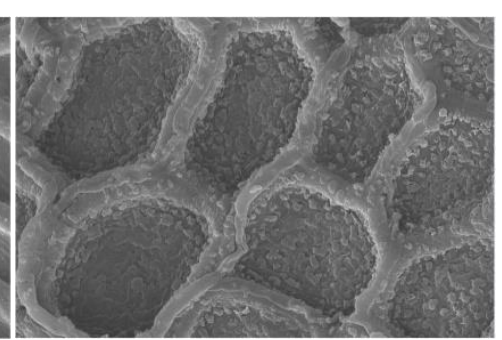

C

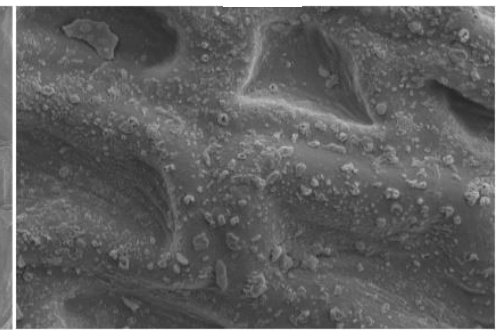

F

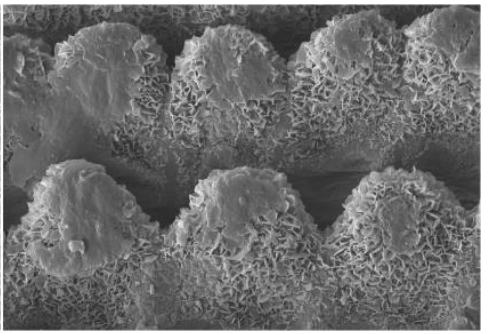

I

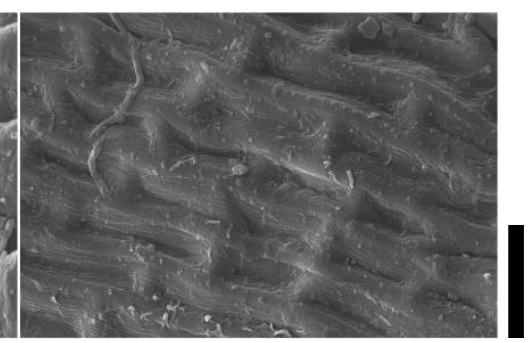

L

Figura 3. Microscopia eletrônica de varredura da superfície dos gametófitos em espécies de musgos (Bryophyta) e hepáticas (Marchantiophyta). Exemplos de morfologia amorfa do tipo filme A e B. A: hepática Metzgeria albinea (Metzgeriaceae), B: musgo Plagiomnium rhynchophorum (Mniaceae). Morfologia cristaloide C-H. C-E: Plaquetas de cera. C: Lejeunea flava e D: L. laetevirens (Lejeuneaceae), E: Marchantia papillata (Marchantiaceae). As setas indicam as plaquetas em torno da abertura do poro aerífero. F-H: Grânulos de cera. F: Bazzania gracilis e G: B. hookeri (Lepidoziaceae), H: Pyrrhobryum spiniforme (Mniaceae). I-J: Gametófito feminino de Polytrichadelphus 
pseudopolytrichum (Polytrichaceae). I: Plaquetas de cera na superfície dorsal. J: Morfologia do tipo filme na superfície ventral. K-L: Gametófito masculino de $P$. pseudopolytrichum. K: Crosta de cera na superfície dorsal. L: Morfologia do tipo filme na superfície ventral. Escala: $10 \mu \mathrm{m}$. 
Tabela 4. Caracterização das morfologias das ceras epicuticulares na superfície dos gametófitos de hepáticas (Marchantiophyta) e de musgos (Bryophyta).

\begin{tabular}{|c|c|c|c|}
\hline \multicolumn{2}{|c|}{ Hepáticas (Marchantiophyta) } & \multicolumn{2}{|l|}{ Musgos (Bryophyta) } \\
\hline Espécie & Morfologia & Espécie & Morfologia \\
\hline Lejeuneaceae & & Bryaceae & \\
\hline Cheilolejeunea filiformis & filme & Rosulabryum densifolium & filme \\
\hline Lejeunea isocalycina & filme & Calymperaceae & \\
\hline Lejeunea flava & plaqueta & Octoblepharum albidum & filme \\
\hline Lejeunea laetevirens. & plaqueta & Dicranaceae & \\
\hline Lepidoziaceae & & Campylopus arctocarpus & filme \\
\hline Bazzania gracilis & grânulo & Campylopus filifolius & filme \\
\hline Bazzania hookeri & grânulo & Campylopus gemmatus & filme \\
\hline Marchantiaceae & & Campylopus pilifer & filme \\
\hline Marchantia papillata & plaqueta & Pilopogon laevis & filme \\
\hline Metzgeriaceae & & Hypnaceae & \\
\hline Metzgeria albinea & filme & Calliergonella cuspidata & filme \\
\hline Metzgeria conjugata & filme & Lembophyllaceae & \\
\hline Metzgeria furcata & filme & Porotrichodendron superbum & filme \\
\hline Plagiochilaceae & & Leucobryaceae & \\
\hline Plagiochila raddiana & filme & Leucobryum giganteum & filme \\
\hline \multirow[t]{17}{*}{ Plagiochila superba } & filme & Mniaceae & \\
\hline & & Plagiomnium rhynchophorum & filme \\
\hline & & Pyrrhobryum spiniforme & grânulo \\
\hline & & Polytrichaceae & \\
\hline & & Atrichum androgynum & filme \\
\hline & & Pogonatum pensilvanicum & filme \\
\hline & & Polytrichadelphus pseudopolytrichum $\uparrow$ & Plaqueta/filme* \\
\hline & & Polytrichadelphus pseudopolytrichum $\widehat{\diamond}$ & Crosta/filme* \\
\hline & & Polytrichum angustifolium & filme \\
\hline & & Polytrichum commune & filme \\
\hline & & Polytrichum juniperinum & filme \\
\hline & & Sphagnaceae & \\
\hline & & Sphagnum gracilescens & filme \\
\hline & & Sphagnum recurvum & filme \\
\hline & & Sphagnum subsecundum & filme \\
\hline & & Thuidiaceae & \\
\hline & & Thuidium delicatulum & filme \\
\hline
\end{tabular}

* Variação morfológica da cera epicuticular na região dorsal e ventral do gametófito. 


\section{Discussão}

Conforme verificado na literatura, em briófitas há uma grande lacuna de dados químicos de cera. A grande maioria dos dados disponíveis está relacionada a angiospermas, para as quais o teor de cera pode ser muito variável. De acordo com Holloway \& Jeffree (2017) esse valor pode ser menor que de $1 \mu \mathrm{g} / \mathrm{cm}^{2}$ em algumas espécies vasculares, ou atingir valores acima de $60 \mu \mathrm{g} / \mathrm{cm}^{2}$ considerados muito altos por Baker (1982). Esses valores são característicos de cada espécie e podem variar de acordo com as condições ambientais as quais as plantas estão expostas. Em Pistacia lentiscus L. (Anacardiaceae) e em Olea europaea L. (Oleaceae), cultivadas em condições áridas, foram observadas quantidades de cera variando de $60 \mu \mathrm{g} / \mathrm{cm}^{2}$ à $300 \mu \mathrm{g} / \mathrm{cm}^{2}$ cada. Entretanto, em condições favoráveis, verificou-se nas hortaliças Spinacia oleracea L. (Chenopodiaceae) e Lactuca sativa L. (Asteraceae) valores de cera entre 5-10 $\mu \mathrm{g} / \mathrm{cm}^{2}$ (Baker 1982).

Para briófitas sensu lato, até onde sabemos, dados sobre o teor de cera foi investigado previamente somente no musgo Funaria hygrometrica Hedw. (Funariaceae), tendo sido obtido do gametófito folhoso o valor de $0,94 \mu \mathrm{g} / \mathrm{cm}^{2}$ (Busta et al. 2016a), maior do que aquele mais alto obtido com as espécies de musgo deste estudo (Calliergonella cuspidata - Hypnaceae - 0,6 $\mu \mathrm{g} / \mathrm{cm}^{2}$ ) (Figura 1B). Em relação ao teor de cera cuticular para espécies de hepáticas, os dados deste trabalho são os primeiros para esse grupo de plantas.

A hepática Bazzania hookeri (Lepidoziaceae) (Figura 1A) e o musgo C. cuspidata (Figura 1B), os quais apresentaram os maiores teores de cera, foram coletados na mesma localidade. Apesar de serem oriundas de uma área florestal (Tabela 1), as duas espécies foram coletadas em um barranco bastante exposto à luminosidade e em altitude elevada, 
podendo ter alguma influência nesses teores. Segundo Riederer \& Schreiber (2001), fatores abióticos, como luminosidade, temperatura, umidade, altitude etc., podem influenciar na quantidade de cera.

A composição química das ceras cuticulares encontradas nos gametófitos das espécies de musgos e hepáticas investigados é bastante diversificada (Figuras 2A e 2B). A presença de alcanos, ácidos graxos, álcoois primários, aldeídos e ésteres nas ceras de gametófitos de algumas espécies de musgos já foi descrita (Haas 1982; Xu et al. 2009 Buda et al. 2013; Busta et al. 2016a; 2016b), corroborando com o perfil químico obtido para as espécies dessa divisão neste estudo (Figura 2B). De acordo com Heinrichs e colaboradores (2000), pouco se sabe a respeito da composição química das ceras em hepáticas. Apenas a presença de ácidos graxos, alcanos, ésteres, e terpenoides já havia sido relatada como componentes de cera desse grupo (Huneck \& Vevle 1970; Benešová et al. 1972; Heinrichs et al. 2000; Heinrichs \& Rycroft 2001), além da caracterização das substâncias da cutina (Caldicott \& Eglinton 1976). A semelhança na composição das ceras cuticulares de musgos e hepáticas com aquela das ceras de gimnospermas e angiospermas sugere, segundo Jetter et al. (2006), que as vias de síntese envolvidas na produção desses componentes da cutícula tenham surgido nos estágios iniciais da história evolutiva das plantas terrestres. Além disso, a presença dessas classes de componentes de ceras comuns supõe que a biossíntese desses metabólitos em briófitas pode ser semelhante à das plantas vasculares (Kolattukudy 2001; Busta et al. 2016a).

Nas espécies de ambas as divisões foi verificado a presença marcante dos ácidos graxos livres nas ceras cuticulares (Figuras 2A e 2B). A presença desses homólogos em ceras é sempre bastante comum, visto serem os precursores das outras classes de componentes encontrados nessas ceras (Kunst \& Samuels 2003; 2009). A ocorrência dos alcanos nas ceras de plantas vasculares também é bastante comum, podendo ser a classe 
majoritária de alguns táxons (Kunst \& Samuels 2003; Barthlott et al. 2017). Curiosamente, em várias espécies de hepáticas e algumas poucas de musgos analisadas nesse trabalho os alcanos não foram detectados (Figuras 2A e 2B). No gametófito do musgo F. hygrometrica (Funariaceae), por exemplo, também não foi detectada a presença de alcanos, sendo esses encontrados no esporófito e em menor proporção na caliptra (Busta et al. 2016a).

Nos gametófitos das hepáticas Plagiochila tabinensis Steph. e P. heterofolia Steph. (Plagiochilaceae) foi constatada a ocorrência majoritária de ácidos graxos (Heinrichs et al. 2000; Heinrichs \& Rycroft 2001), diferente do observado no presente estudo em que Plagiochila raddiana e $P$. superba apresentaram alcanos como majoritários (Figura 2A). De acordo com Benešová et al. (1972), alcanos e ésteres foram as classes de cera predominantes em representantes de Anastrophyllaceae, Calypogeiaceae, Jungermanniaceae, Myliaceae e Pelliaceae.

Ácidos graxos, alcanos e álcoois primários foram descritos como componentes principais nos gametófitos dos musgos Pogonatum aloides (Hedw.) P. Beauv., Pogonatum urnigerum (Hedw.) P. Beauv. (Polytrichaceae) e de Syntrichia caninervis Mitt. (Pottiaceae) (Haas 1982; Xu et al. 2009). Essas três classes de componentes cera foram detectadas em grande parte das espécies de musgos analisadas no presente estudo, sendo os ácidos graxos e alcanos majoritários em algumas dessas plantas (Figura 2B), incluindo os representantes de Polytrichaceae. Em Atrichum androgynum e Polytrichum angustifolium, os ácidos graxos foram os componentes dominantes perfazendo mais de $70 \%$ da cera total (Figura 2B). Pogonatum pensilvanicum, Polytrichadelphus pseudopolytrichum (gametófito feminino) e Polytrichum juniperinum apresentaram os alcanos como majoritários (Figura 2B). Essas espécies foram amostradas em ambiente aberto sem cobertura florestal, onde a incidência da radiação solar geralmente é maior. 
Uma vez que os alcanos são os componentes de cera mais eficientes como barreira a passagem de água (Oliveira et al. 2003), talvez esse maior investimento em alcanos poderia ser considerado uma estratégia de proteção. De acordo com Shepherd \& Griffiths (2006), fatores ambientais como a luminosidade, temperatura, altitude etc., podem influenciar nas características de composição química das ceras cuticulares. Entretanto, a confirmação dessa ideia precisa de análises mais detalhadas.

O ácido hexadecanoico (C16) foi o principal homólogo encontrado na maioria das espécies de musgos e hepáticas neste estudo (Tabelas 2 e 3). Caldicott \& Eglinton (1976) já apontaram essa substância como o componente principal dos ácidos graxos em ceras de briófitas, semelhante ao que se tem descrito para plantas vasculares. Nas hepáticas Plagiochila tabinensis e P. heterofolia (Plagiochilaceae) a composição dos homólogos de ácidos graxos variaram de C14 à C26, sendo o C16 o composto majoritário com $10 \%$ na primeira espécie, enquanto na segunda o C18 foi o principal com 61\% (Heinrichs et al. 2000; Heinrichs \& Rycroft 2001). Em plantas vasculares, já é bem estabelecido a presença de homólogos pares de ácidos graxos com tamanhos entre 12 a 36 carbonos (Kunst \& Samuels 2003; 2009; Barthlott et al. 2017).

No gametófito do musgo Syntrichia caninervis (Pottiaceae), os ácidos graxos de cadeia curta $\mathrm{C} 16$ e $\mathrm{C} 18$ foram os compostos predominantes, tendo o $\mathrm{C} 16$ como componente principal com 35,7\%, sendo os ácidos graxos de cadeia longa (C20-C26) também detectados nos filídios de S. caninervis (Xu et al. 2009). Em Polytrichaceae, homólogos de ácidos graxos variando de C16-C30 foram detectados nos gametófitos de Pogonatum aloides e P. urnigerum, tendo o composto C22 como majoritário representando $23 \%$ e $32 \%$ das ceras, respectivamente. No presente estudo, as espécies de Polytrichaceae apresentaram perfil de homólogos semelhante, sendo que em Pogonatum pensilvanicum predominaram os compostos de cadeia curta (Tabela 3). 
A ocorrência de diácidos em ceras cuticulares não é comum. A presença dos diácidos octanodioico e nonanodioico foi recentemente descrita em espécies de Simaroubaceae (Roma 2018). Neste estudo, foi possível identificar o diácido nonanodioico com porcentagem igual nos musgos Campylopus arctocarpus e Campylopus gemmatus (2\%) (Dicranaceae) (Tabela 3).

Assim como nas ceras das plantas vasculares, nas de espécies de briófitas os homólogos de alcanos C27 e C29 são bastante comuns (Benešová et al. 1972; Caldicott \& Eglinton 1976; Kunst \& Samuels 2003; Samuels et al. 2008; Kunst \& Samuels 2009). No entanto, os homólogos C23 e C25 são bem característicos nesse grupo de plantas, apresentando porcentagens consideráveis já relatadas em espécies de Sphagnum (Bush \& McInerney 2013). Nas espécies de musgos e hepáticas analisadas, os homólogos C29 e C27 se destacam como majoritários. Nas hepáticas Calypogeia meylanii H. Buch (Calypogeiaceae), Jungermannia sphaerocarpa Hook. (Jungermanniaceae) e Pellia fabbroniana Raddi (Pelliaceae), o homólogo C27 também foi verificado como predominante nas ceras (Benešová et al. 1972). Homólogos de cadeia mais curta, sobretudo C23 e C25, também foram detectados em algumas espécies (Tabelas 2 e 3). De acordo com Benešová e colaboradores (1972), as ceras dos gametófitos das hepáticas Gymnocolea inflata (Huds.) Dumort. (Anastrophyllaceae) e Mylia taylorii (Hook.) Mitt. (Myliaceae) apresentam a mesma porcentagem do constituinte C25. Já para o gametófito dos musgos Sphagnum palustre L. e S. cuspidatum Ehrh. ex Hoffm. o alcano C23 correspondeu a 43,2\% e 52,9\%, respectivamente, enquanto o homólogo C25 equivaleu a 21,6\% e 25,4\%, em cada planta (Caldicott \& Eglinton 1976). Nas espécies de Sphagnum analisadas no presente estudo, o homólogo C23 foi identificado em menores porcentagens, com destaque para $S$. gracilescens que apresentou $11,2 \%$ desse componente e $12 \%$ do constituinte C25 (Tabela 3). Nos gametófitos dos musgos 
Andreaea rupestris Hedw. (Andreaeaceae), Pogonatum aloides e P. urnigerum (Polytrichaceae), o alcano C25 foi descrito como homólogo majoritário com 41\%, 23\% e 46\%, respectivamente (Haas 1982).

Vale ressaltar que homólogos de cadeia longa, C33 e C35, foram detectados na hepática Plagiochila superba e em alguns musgos (Rosulabryum densifolium, Campylopus pilifer, Plagiomnium rhynchophorum, Pogonatum pensilvanicum, Polytrichum juniperinum) (Tabelas 2 e 3). Homólogos de cadeias longas têm sido associados a espécies de locais mais áridos, considerando-se dados para plantas vasculares (Riederer \& Schreiber 2001; Kerstiens 2006). No caso das briófitas do presente estudo, todas espécies foram coletadas em regiões de mata, porém associadas a altas altitudes (Tabela 1). Em Juniperus communis L. (Crupessaceae, Gymnospermae) de altitudes elevadas, a presença de homólogos de cadeias longas foi sugerida como uma adaptação ao ambiente com temperaturas altas no verão e bastante baixas no inverno (Dodd \& Poveda 2003).

Nas hepáticas, os homólogos de álcoois primários detectados variaram de C18 a C28, com predomínio dos homólogos C26. Já nos musgos, o homólogo C30 foi detectado em algumas espécies, sendo os homólogos predominantes o C26 e o C28 (Tabelas 2 e 3). Perfis semelhantes de homólogos de álcoois primários já foram descritos para as ceras dos gametófitos dos musgos Physcomitrella patens (Hedw.) Bruch \& Schimp. com o homólogo C26 como principal (Buda et al. 2013). Em Andreaea rupestris (Andreaeaceae), Pogonatum aloides e P. urnigerum (Polytrichaceae) o homólogo C28 foi o composto abundante (Haas 1982). Nos representantes de Polytrichaceae deste estudo, com exceção de Atrichum androgynum, os álcoois primários encontrados variaram de C16-C30, em P. pensilvanicum o principal homólogo foi o C26 (Tabela 3). 
O álcool secundário nonacosan-10-ol, identificado na hepática Bazzania hookeri (Lepidoziaceae) (Tabela 2), já foi relatado como composto majoritário na cápsula do esporófito de espécies de Pogonatum (Neinhuis \& Jetter 1995), mas não em gametófitos.

Haas (1982) já descreveu aldeídos nas ceras de espécies de musgos. Homólogos de cadeia longa C22-C30 foram identificados no gametófito de Pogonatum urnigerum (Polytrichaceae), tendo C26 como o componente majoritário com 59\%. Entre as espécies analisadas, somente no musgo Porotrichodendron superbum (Lembophyllaceae) e na hepática Plagiochila superba (Plagiochilaceae) essa classe foi detectada, sendo somente o homólogo C20 detectado na primeira, enquanto na segunda os homólogos C24 e C26 estão presentes (Tabela 2 e 3). De acordo com Holloway \& Jeffree (2017), o composto hexacosanal (C26) é o aldeído mais comum detectado nas ceras vegetais.

Ésteres de cadeia longa variando de C42 à C52 já foram descritos nos gametófitos dos musgos Andreaea rupestris (Andreaeaceae), Pogonatum aloides e P. urnigerum (Polytrichaceae) (Haas 1982). Nas hepáticas, Calypogeia meylanii (Calypogeiaceae), Jungermannia sphaerocarpa (Jungermanniaceae), Pellia fabbroniana (Pelliaceae), Gymnocolea inflata (Anastrophyllaceae) e Mylia taylorii (Myliaceae), Benešová et al. (1972) constataram ésteres com série homóloga de C34-C54. Neste estudo, apenas nas hepáticas B. hookeri (Lepidoziaceae) e P. superba (Plagiochilaceae) foram verificados ésteres, porém com cadeias carbônicas menores (Tabela 2). De acordo com Barthlott e colaboradores (2017), é comum a presença de ésteres com 30 a 60 carbonos nas ceras vegetais.

As cetonas geralmente ocorrem restritamente nas ceras cuticulares de algumas espécies de plantas vasculares (Riederer \& Schreiber 2001; Shepherd \& Griffiths 2006) com homólogos variando de C21 a C35 (Holloway \& Jeffree 2017). Neste estudo cetonas 
também foram detectadas de forma restrita nas ceras de hepáticas e musgos (Tabelas 2 e $3)$.

Além disso, com base na literatura, até o momento não há dados da presença de alcenos, álcoois secundários, cetonas e diácidos nas ceras de gametófitos de briófitas. Dessa forma, todas as substâncias dessas classes identificadas neste trabalho são inéditas para essas plantas.

Em ceras de plantas vasculares também podem ser encontradas algumas classes de compostos cíclicos sintetizadas através de diferentes vias do metabolismo secundário, como triterpenos (Kunst \& Samuels 2003; 2009; Reina-Pinto \& Yephremov 2009; BáezSañudo et al. 2013). O diterpeno kaureno foi descrito como componente principal da cera do gametófito da hepática Anthelia julacea (Antheliaceae) (Huneck \& Vevle 1970). No presente estudo, triterpenos foram detectados tanto em hepáticas com em musgos, sendo que nos musgos esses compostos foram mais amplamente distribuídos (Tabelas 2 e 3). Entretanto, cabe ressaltar que o kaureno não foi detectado em qualquer uma das hepáticas analisadas (Tabela 2). Os triterpenos $\alpha$-amirina, $\beta$-amirina, fridelina e lupenona já foram descritos como componentes de ceras em várias espécies de plantas vasculares (Vickery \& Vickery 1981; Pimentel 2014; Thimmappa et al. 2014; Roma 2018), mas não há relatos em briófitas, sendo porém descritas pela primeira vez nesse grupo de plantas. Além disso, até onde vai o nosso conhecimento, o triterpeno simiarenol ainda não havia sido descrito como parte da composição química das ceras cuticulares, sendo verificado com porcentagem notável na hepática Cheilolejeunea filiformes (Lejeuneaceae) (Tabela 2).

Segundo Shepherd \& Griffiths (2006), ornamentações da cera do tipo cristais possuem propriedades ópticas importantes e desempenham funções ecológicas essenciais para as plantas, tais como de reflexão da radiação excessiva. Ceras epicuticulares de 
morfologia amorfa e cristaloide já foram descritas para diversas espécies de hepáticas de Plagiochilaceae e de musgos pertencentes a Polytrichaceae (Green \& Clayton-Greene 1977; Clayton-Greene et al. 1985; Neinhuis \& Jetter 1995; Heinrichs et al. 2000). No presente estudo, ceras epicuticulares do tipo filme foram as mais comuns, sendo também observados cristaloides do tipo grânulos e plaquetas (Figura 3, Tabela 4).

Proctor (1979) analisando gametófitos de 43 espécies de musgos, descreveu as morfologias do tipo filme, camadas crostosas e projeções cristaloides, semelhantes ao que já era conhecido para plantas vasculares. Morfologia do tipo plaquetas também já foram relatadas na superfície das lamelas de outras espécies pertencentes à Polytrichaceae (Green \& Clayton-Greene 1977; Clayton-Greene et al. 1985; Neinhuis \& Jetter 1995). Ornamentos de cristais de cera do tipo plaquetas e crostas foram observadas sobre a superfície das lamelas nos gametófitos femininos e masculinos de Polytrichadelphus pseudopolytrichum (Polytrichaceae), respectivamente (Figura 3I e 3K). Cristais de cera do tipo grânulos, encontrados na superfície do gametófito do musgo Pyrrhobryum spiniforme (Mniaceae) (Figura 3H), estão sendo relatados pela primeira vez para esse grupo.

As plaquetas de cera encontradas nas hepáticas Lejeunea flava e Lejeunea laetevirens (Lejeuneaceae) (Figura 3C, D), já haviam sido descritas por Heinrichs \& Reiner-Drehwald (2012). No caso da hepática Marchantia papillata (Marchantiaceae) esses ornamentos foram observados em torno do poro aerífero (Figura 3E), sugerindo alguma função de proteção extra para as ceras nessas plantas.

A morfologia das ceras pode, entretanto, ser bastante variável. Heinrichs et al. (2000) e Heinrichs \& Rycroft (2001) caracterizaram a morfologia das ceras dos gametófitos de algumas hepáticas Plagiochilaceae, descrevendo a presença de plaquetas, 
o que não foi observado para Plagiochila raddiana e $P$. superba, analisadas neste estudo, as quais apresentaram morfologia do tipo filme (Tabela 4). Da mesma forma, ceras epicuticulares do tipo filme foram relatadas em espécies de hepáticas de Lepidoziaceae (Heinrichs \& Reiner-Drehwald 2012), porém, neste estudo, as espécies dessa família, Bazzania gracilis e $B$. hookeri, apresentaram morfologia do tipo grânulos (Figura 3F e 3G, Tabela 4).

\section{Conclusões}

Os dados apresentados no presente estudo trazem grande contribuição ao conhecimento sobre a composição química das ceras cuticulares em briófitas. Esses dados podem auxiliar no entendimento da evolução da cutícula e das vias biossintéticas nas embriófitas. Várias substâncias e morfologias de cera foram detectadas pela primeira vez nesse grupo de plantas, ainda que já fossem bastante conhecidas em angiospermas. Além disso, este é o primeiro estudo com esta abordagem em espécies brasileiras que temos conhecimento, contribuindo para o desenvolvimento dos estudos em briologia, com foco na análise da diversidade química desse grupo.

\section{Financiamento}

Agrademos à Coordenação de Aperfeiçoamento de Pessoal de Nível Superior Brasil (CAPES) - Código Financeiro 001 pelo financiamento deste trabalho.

\section{Agradecimentos}

Agradecemos ao professor Dr. Denilson F. Peralta do Núcleo de Pesquisa em Briologia do Instituto de Botânica - IBt/SP pela colaboração nas coletas e identificações do material vegetal estudado, ao doutorando Lucas P. Roma pelo auxílio nas identificações das substâncias, às técnicas Mourisa Ferreira e Aline Bertinatto Cruz pela 
assistência durante as análises por CG-EM, ao técnico Irwandro Roberto Pires pela assistência na análise do material através de MEV.

\section{Referências}

Asakawa, Y., Agnieszka, L. \& Fumihiro, N. 2013. Chemical constituents of bryophytes. Progress in the chemistry of organic natural products. $816 \mathrm{p}$.

Báez-Sañudo, R., Tafolla-Arellano, J.C., González- León, A., Tiznado-Hernández, M.E. \& García, L.Z. 2013. Composición, fisiologia y biosíntesis de la cutícula en plantas. Revista Fitotecnia Mexicana, 36(1), 3-12.

Baker, E.A. 1982. Chemistry and morphology of plant epicuticular waxes. In the Plant Cuticle, Linnean Society Symposium Series (eds D.F. Cutler, K.L. Alvins \& C.E. Price). Academic Press, London. 10, 139-165.

Bargel, H., Koch, K., Cerman, Z. \& Neinhuis, C. 2006. Structure - function relationships of the plant cuticle and cuticular waxes - a smart material? functional Plant Biology, 33(10), 893-910.

Barthlott, W., Mail, M., Bhushan, B. \& Koch, K. 2017. Plant surfaces: structures and functions for biomimetic innovations. Nano-Micro Letters, 9(23).

Benešová, V., Streibl, M., Châu, H.M., Beneš, I. \& Konečný, K. 1972. Plant substances. On natural waxes. Higher alkanes and wax esters of some liverworts. Collection of Czechoslovak Chemical Communications, 37(9), 3090-3094.

Bernard, A. \& Joubès, J. 2013. Arabidopsis cuticular waxes: Advances in synthesis, export, and regulation. Progress in Lipid Research, 52(1), 110-129.

Buch, H. 1945. Ueber die wasser- und mineralstoffversorgung der moose. I. Commentat. Biologie der Moose. 9(16), 1-44. 
Buda, G.J., Barnes, W.J., Fich, E.A., Park, S., Yeats, T.H., Zhao, L., Domozych, D.S. \& Rose, J.K.C. 2013. An ATP binding cassette transporter is required for cuticular wax deposition and desiccation tolerance in the moss Physcomitrella patens. The Plant Cell, 25(10), 4000-4013.

Budke, J.M., Goffinet, B. \& Jones, C.S. 2011. A hundred-year-old question: Is the moss calyptra covered by a cuticle? A case ctudy of Funaria hygrometrica. Annals of Botany, 107(8), 1279-1286.

Budke, J.M., Goffinet, B. \& Jones, C.S. 2012. The cuticle on the gametophyte calyptra matures before the sporophyte cuticle in the moss Funaria hygrometrica (Funariaceae). American Journal of Botany, 99(1), 14-22.

Budke, J.M., Goffinet, B. \& Jones, C.S. 2013. Dehydration protection provided by a maternal cuticle improves offspring fitness in the Moss Funaria hygrometrica. Annals of Botany, 111(5), 781-789.

Bush, R.T. \& McInerney, F.R. 2013. Leaf was n-alkane distributions in and across modern plants: Implications for paleoecology and chemotaxonomy. Geochimica et Cosmochimica Acta, 117(15), 161-179.

Busta, L., Budke, J.M. \& Jetter, R. 2016a. The moss Funaria hygrometrica has cuticular wax similar to vascular plants, with distinct composition on leafy gametophyte, calyptra and sporophyte capsule surfaces. Annals of Botany, 118(3), 511-522.

Busta, L., Budke, J.M. \& Jetter, R. 2016b. Identification of $\beta$-hydroxy fatty acid esters and primary, secondary-alkanediol esters in cuticular waxes of the moss Funaria hygrometrica. Phytochemistry, 121, 38-49. 
Caldicott, A.B. \& Eglinton, G. 1976. Cutin acids from bryophytes: an $\omega-1$ hydroxy alkanoic acid in two liverwort species. Phytochemistry, 15(7), 1139-1143.

Clayton-Greene, K.A., Collins, N.J., Green, T.G.A. \& Proctor, M.C.F. 1985. Surface wax, structure, and function in leaves of Polytrichaceae. Journal of Bryology, 13(4), 549-562.

Cook, M.E. \& Graham L.E. 1998. Structural similarities between surface layers of selected charophycean algae and bryophytes and the cuticles of vascular. International Journal of Plant Sciences, 159(5), 780-787.

Costa, D.P. \& Peralta, D.F. 2015. Bryophytes diversity in Brazil. Rodriguésia, 66(4).

Delgadillo, M.C. \& Cárdenas A. 1990. Manual de briófitas. (2ª edição). México: Instituto de Biología de la Universidad Nacional Autónoma de México.

Dodd, R.S. \& Poveda, M.M. 2003. Environmental gradientes and population divergence contribute to variation in cuticular wax composition in Juniperus communis. Biochemical Systematics and Ecology, 31(11), 1257-1270.

Dominguez, E., Heredia-Guerrero, J.A. \& Heredia, A. 2011. The biophysical design of plant cuticles: an overview. New Phytologist. 189, 938-949.

Frahm, J-P. 2003. Manual of tropical bryology. Tropical Bryology, 23, 1-196.

Goffinet, B. 2000. Origin and phylogenetic relationships or bryophytes. In: Goffinet, B. \& Shaw, A.J. Bryophyte Biology. ( $2^{\circ}$ ed.) Cambridge University Press, Cambridge, 124-149.

Goffinet, B., Buck, W.R. \& Shaw, A.J. 2009. Morphology, anatomy, and classification of the bryophyta. In: Goffinet, B. \& Shaw, A.J. Bryophyte Biology. (2 ed.) Cambridge University Press, Cambridge, 56-138. 
Goffinet, B. \& Shaw, A.J. 2009. Bryophyte Biology. Cambridge University Press, 1, 132.

Gradstein, S.R., Churchill, S.P. \& Salazar-Allen, N. 2001. Guide to the bryophytes of tropical america. Memoirs of the New York Botanical Garden, 86, 1-301.

Green, T.G.A. \& Clayton-Greene, K. 1977. The growth of Dawsonia superba Grev. In J. G. Duckett (ed.) The annual meeting. Bryologist, 29,5-6.

Haas, K. 1982. Surface wax of Andreaea and Pogonatum species. Phytochemistry, 21, 657-659.

Heinrichs, J., Anton, H., Gradstein, S.R., Mues, R. \& Holz, I. 2000. Surface wax, a new taxonomic feature in Plagiochilaceae. Plant Systematics and Evolution, 225, 225233.

Heinrichs, J. \& Rycroft, D.S. 2001. Leaf surface waxes and lipophilic secondary metabolites place the endemic European liverwort Plagiochila atlantica F.Rose in the Neotropical Plagiochila sect. Bursatae Carl. Cryptogamie, Bryologie, 22(2), 95-103.

Heinrichs, J. \& Reiner-Drehwald, E. 2012. Surface wax in Dinckleria, Lejeunea and Mytilopsis (Jungermanniidae). Cryptogamie Bryologie, 33(1), 81-86.

Holloway, P.J. \& Jeffree, C.E. 2017. Epicuticular waxes. Encyclopedia of Applied Plant Sciences, 2, 374- 386.

Huneck S. \& Vevle O. 1970. 16- $\alpha$-Hydroxykauran aus Anthelia julacea (L.) Dum. und Anthelia juratzkana (Limpr.). Zeitschrift für Naturforschung, 25, 227. 
Jetter, R., Kunst, L. \& Samuels, A. L. 2006. Composition of plant cuticular waxes. In: M. Riederer \& C. Müller (Eds.), Annual Plant Reviews, volume 23: Biology of the Plant Cuticle. Blackwell publishing Ltd, 23, 11-110.

Kerstiens, G. 2006. Water transport in plant cuticles: an update. Journal of Experimental Botany. 57, 2493-2499.

Klavina, L., Springe, G., Nikolajeva, V., Martsinkevich, I., Nakurte, I., Dzabijeva, D. \& Steinberga, I. 2015. Chemical composition analysis, antimicrobial activity, and cytotoxicity screening of moss extracts (moss phytochemistry). Molecules, 20, $17221-17243$.

Koch, K., Bhushan, B. \& Barthlott, W. 2009. Multifunctional surface structures of plants: an inspiration for biomimetics. Progress in Materials Science, 54(2), 137-178.

Kolattukudy, P.E. 2001. Polyesters in higher plants. In Advances in Biochemical Engineering/Biotechnology. (Ed. T Scheper). 4-49.

Kunst, L. \& Samuels, A.L. 2003. Biosynthesis and secretion of plant cuticular wax. Progress in Lipid Research, 42(1), 51-80

Kunst, L. \& Samuels, A.L. 2009. Plant cuticles shine: advances in wax biosynthesis and export. Current Opinion in Plant Biology, 12(6), 721-727.

Neinhuis, C. \& Jetter, R. 1995. Epicuticular wax of Polytrichales sporophytes. Journal of Bryology, 18, 399-406.

Oliveira, A.F.M., Meirelles, S.T. \& Salatino, A. 2003. Epicuticular waxes from caatinga and cerrado species and their efficiency against water loss. Anais da Academia Brasileira de Ciências, 75(4), 431-439. 
Pimentel, B.S. 2014. Constituintes de ceras cuticulares de espécies de Croton L. Tese de Mestrado. Universidade de São Paulo, Brasil, 96p.

Proctor, M.C.F. 1979. Surface wax on the leaves of some mosses. Journal of Bryology, $10(4), 531-538$.

Reina-Pinto, J.J. \& Yephremov, A. 2009. Surface lipids and plant defenses. Plant Physiology and Biochemistry, 47(6),540-549.

Riederer, M. \& Schreiber, L. 2001. Protecting against water loss: analysis of the barrier properties of plant cuticles. Journal of Experimental Botany, 52(363), 2023-2032.

Roma, L.P. 2018. Composição química e morfologia das ceras cuticulares foliares de diferentes espécies de Simaba Aubl. Sensu stricto e Homalolepis Turcz. (Simaroubaceae). Tese de Mestrado. Universidade de São Paulo, Brasil, 177p.

Samuels, L., Kunst, L. \& Jetter, R. 2008. Sealing plant surfaces: Cuticular wax formation by epidermal cells. Annual Review of Plant Biology, 59(38), 683-707.

Schonherr, J. \& Ziegler, H. 1975. Hydrophobic cuticular ledges prevent water entering the air pores of liverwort thalli. Planta 124(1),51-60.

Shepherd, T. \& Griffiths, D.W. 2006. The effects of stress on plant cuticular waxes. New Phytology. 171(3), 469-499.

Timmappa, R., Geisler, K., Louveau, T., O’Maille, P. \& Osbourn, A. 2014. Triterpene biosynthesis in plants. Annual Review of Plant Biology, 65(1), 225-257.

The Plant List. 2018. The bryophyts: mosses and liverworts. Disponível em: < http://www.theplantlist.org/1.1/browse/B/ > Acessado em março de 2019. 
Vanderpoorten, A. \& Goffinet, B. 2009. Introduction to bryology. New York: Cambridge University Press, 1-329.

Vickery, M.L. \& Vickery, B. 1981. Secondary plant metabolism. Warwick Univ.UK. $335 \mathrm{p}$.

Xu, S.J., Jiang, P.A., Wang, Z.W. \& Wang, Y. 2009. Crystal structures and chemical composition of leaf surface wax depositions on the desert moss Syntrichia caninervis. Biochemical Systematics and Ecology, 37, 723-730.

Yeats, T.H. \& Rose, J.K.C. 2013. The formation and function of plant cuticles. Plant Physiology, 163, 5-20. 


\section{Material suplementar}

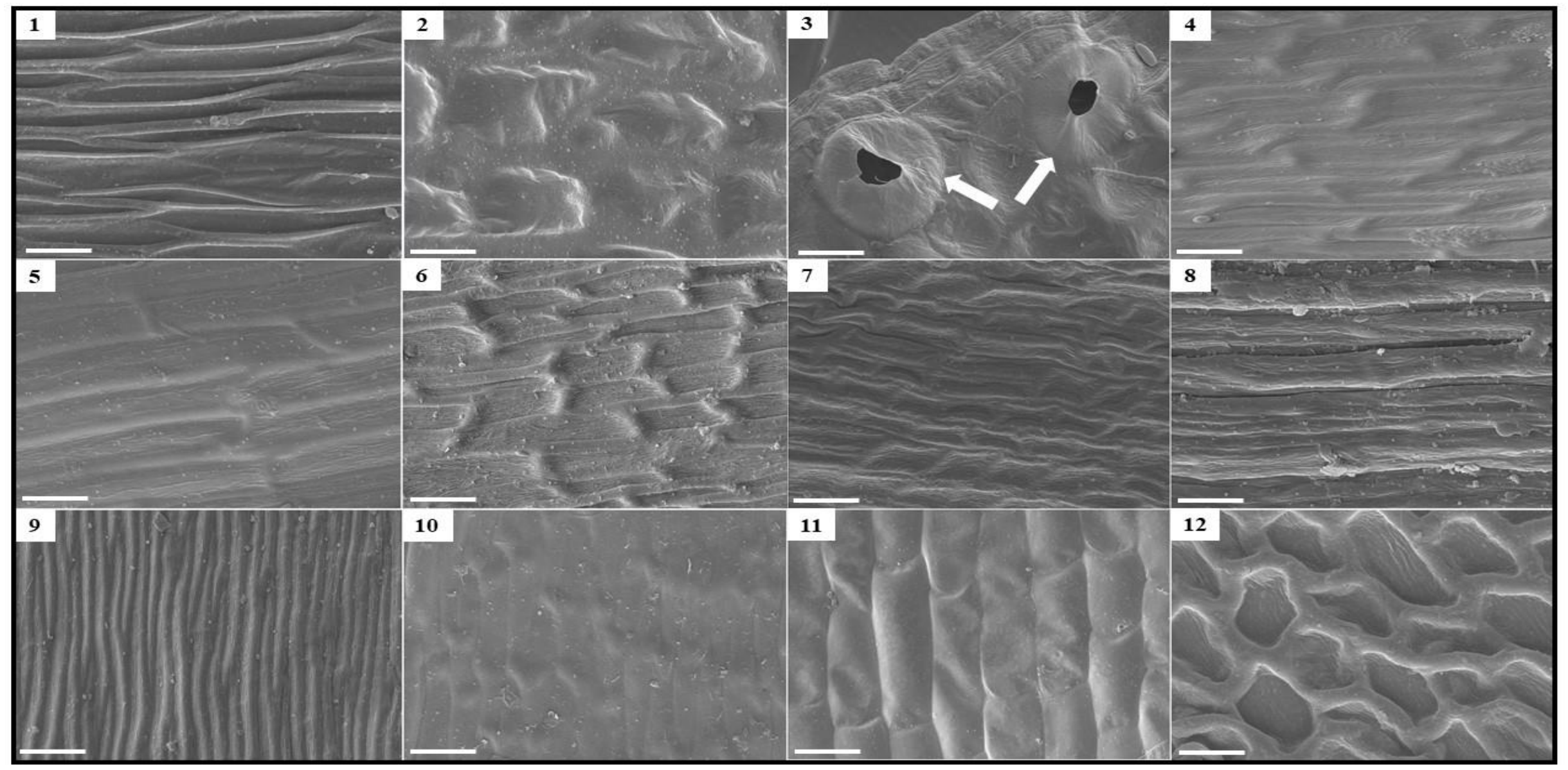

Figura i. Microscopia eletrônica de varredura da superfície dos gametófitos de espécies de musgos (Bryophyta) e hepáticas (Marchantiophyta). Imagens de 1-12: morfologia do tipo amorfa. 1: Rosulabryum densifolium. 2-3: Octoblepharum albidum. 3: as setas indicam os poros aeríferos na superfície dorsal do gametófito. 4: Campylopus arctocarpus. 5: Campylopus filifolius. 6: Campylopus gemmatus. 7: Campylopus pilifer. 8: Pilopogon laevis. 9: Calliergonella cuspidata. 10: Porotrichodendron superbum. 11: Leucobryum giganteum. 12: Plagiomnium rhynchophorum. Escala: $10 \mu \mathrm{m}$. 


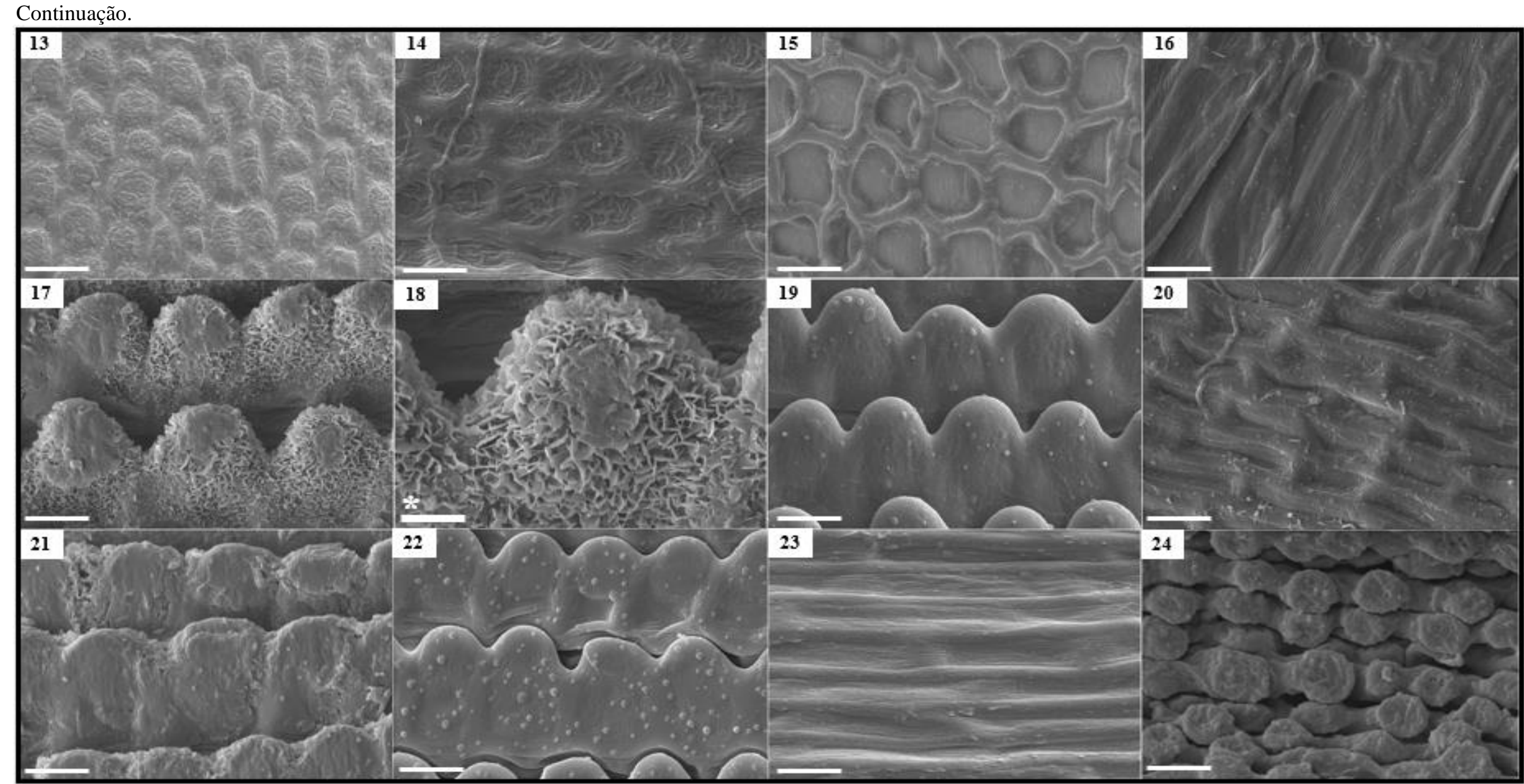

Imagens 13-14: Pyrrhobryum spiniforme. 13: morfologia do tipo grânulos. 14: superfície do gametófito sem cera. 15-16: morfologia do tipo amorfa. 15: Atrichum androgynum. 16: Pogonatum pensilvanicum. 17-23: Polytrichadelphus pseudopolytrichum. 17-20: gametófito feminino. 17-18: morfologia do tipo plaquetas nas lamelas da superfície dorsal. 19: superfície da lamela sem cera. 20: morfologia do tipo amorfa na superfície ventral. 21-23: gametófito masculino. 21: morfologia do tipo crosta nas lamelas da superfície dorsal. 22: superfície da lamela sem cera. 23: morfologia do tipo amorfa na superfície ventral. 24-25: morfologia do tipo amorfa em Polytrichum angustifolium. 24: lamelas da superfície dorsal. 18: $(*)$ refere-se a escala de $2 \mu \mathrm{m}$, demais imagens escala de $10 \mu \mathrm{m}$. A cera epicuticular foi removida com clorofórmio $\left(\mathrm{CHCl}_{3}\right)$. 


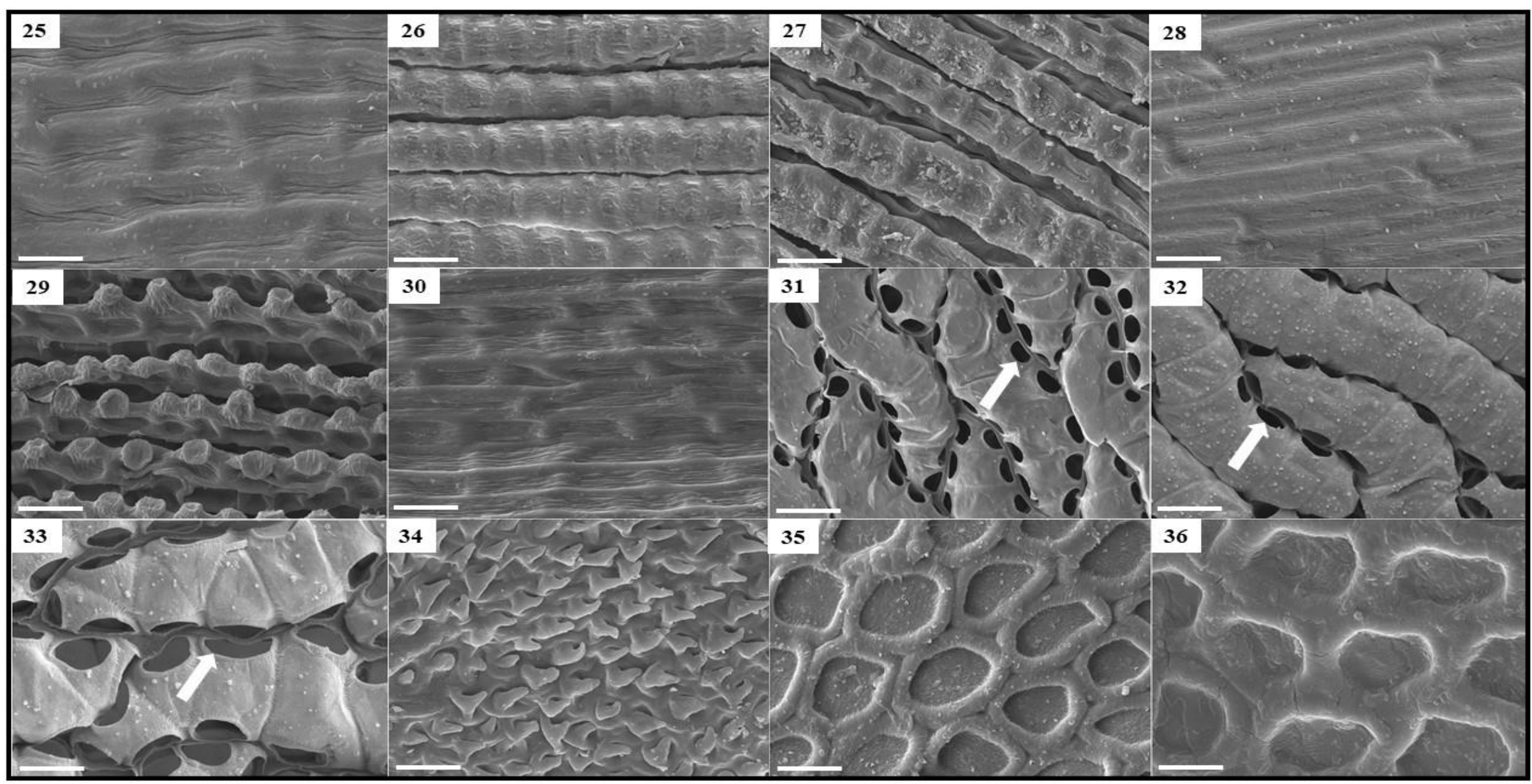

Imagem 25: superfície ventral em Polytrichum angustifolium. 26-28: Polytrichum commune. 26: morfologia do tipo crosta nas lamelas da superfície dorsal. 27: superfície da lamela sem cera. 28: morfologia do tipo amorfa na superfície ventral. 29-36: morfologia do tipo amorfa. 29-30: Polytrichum juniperinum. 29: lamelas da superfície dorsal. 30: superfície ventral. 31-33: as setas indicam os poros aeríferos na superfície do gametófito. 31: Sphagnum gracilescens. 32: Sphagnum recurvum. 33: Sphagnum subsecundum. 34: Thuidium delicatulum. 35: Cheilolejeunea filiformis. 36: Lejeunea isocalycina. Escala: $10 \mu \mathrm{m}$. A cera epicuticular foi removida com clorofórmio (CHCl 3 ). 


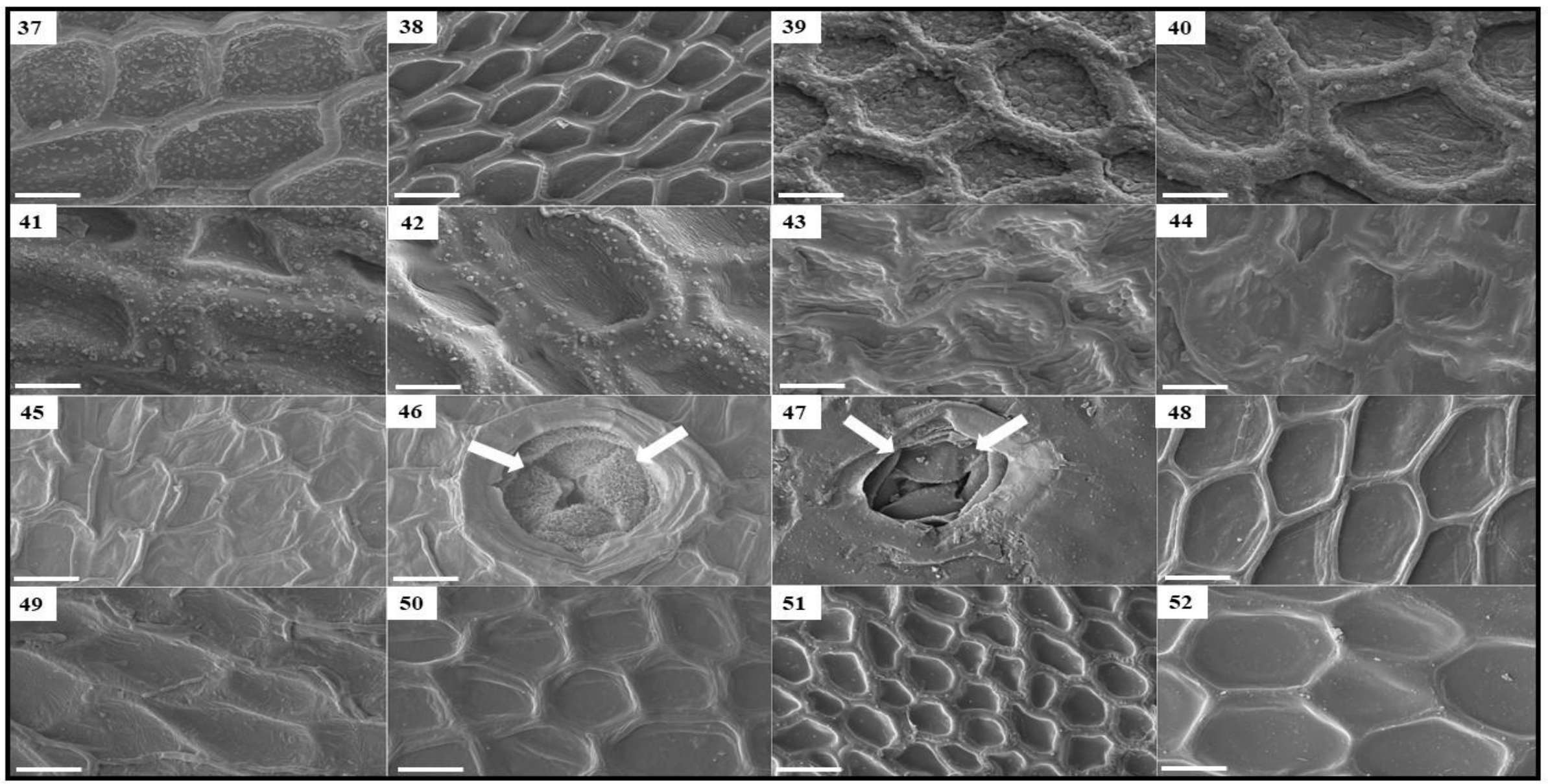

Imagens 37-38: Lejeunea flava. 37: morfologia do tipo plaquetas. 38: superfície sem cera. 39-40: Lejeunea laetevirens. 39: morfologia do tipo grânulos. 40: superfície sem cera. 41-42: Bazzania gracilis. 41: morfologia do tipo grânulos. 42: superfície sem cera. 43-44: Bazzania hookeri. 43: morfologia do tipo grânulos. 44: superfície sem cera. 45-47: Marchantia papillata. 45: morfologia do tipo amorfa na superfície dorsal. 46: as setas indicam morfologia do tipo plaquetas ao redor da abertura do poro aerífero. 47: superfície do poro aerífero sem cera. 48-52: morfologia do tipo amorfa. 48: Metzgeria albinea. 49: Metzgeria conjugata. 50: Metzgeria furcata. 51: Plagiochila raddiana. 52: Plagiochila superba. Escala: $10 \mu \mathrm{m}$. A cera epicuticular foi removida com clorofórmio $\left(\mathrm{CHCl}_{3}\right)$. 


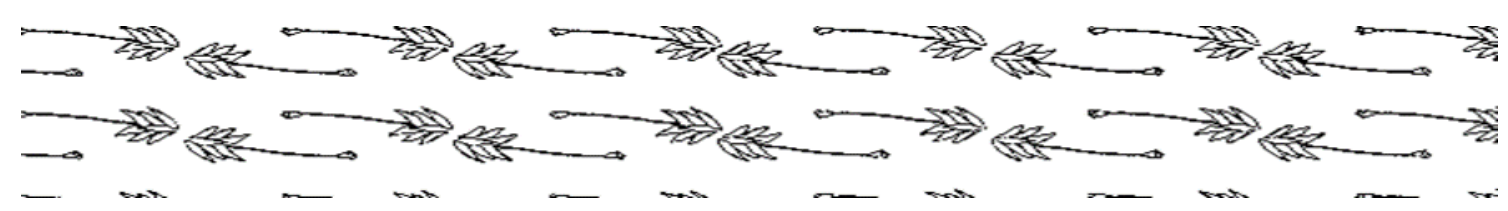

Capítulo 2: Análise comparativa das ceras cuticulares do gametófito e do esporófito de espécies de Polytrichaceae

Capítulo formatado para submissão a Annals of Botany (Oxford University Press - IF $=$ $3.454)$.

Colaboradores:

Denilson Fernandes Peralta*

Gladys Flávia de Albuquerque Melo de Pinna**

Lucas Paradizo Roma**

*Instituto de Botânica, Av. Miguel Estéfano 3687, 04301-902, São Paulo, SP, Brasil.

**Departamento de Botânica, Instituto de Biociências, Universidade de São Paulo, Rua do Matão, 277, 05508-090, São Paulo, SP, Brasil. 


\section{RESUMO}

- Contexto e objetivos Polytrichaceae é caracterizada por musgos com gametófitos e esporófitos robustos, ocorrendo em regiões de planalto e altitude elevada. No Brasil, os gêneros mais recorrentes são Polytrichum, Pogonatum e Polytrichadelphus, distribuídos em diferentes regiões do país. Assim como para musgos em geral, há poucos dados sobre a composição química das ceras em espécies dessa família, principalmente incluindo as fases do gametófito e esporófito. Este estudo tem como principal objetivo apresentar uma análise comparativa da composição química e da morfologia das ceras cuticulares do gametófito e do esporófito de Pogonatum pensilvanicum, Polytrichadelphus pseudopolytrichum e Polytrichum juniperinum.

- Métodos As ceras foram extraídas em diclorometano, derivatizadas e analisadas através de cromatografia a gás acoplada a espectrometria de massas. $\mathrm{O}$ teor total de ceras foi expresso em $\mu \mathrm{g} / \mathrm{cm}^{2}$ e os componentes foram identificados pelo padrão de fragmentação. A morfologia das ceras epicuticulares foi observada através de microscopia eletrônica de varredura.

- Principais resultados Para as três espécies, os teores de cera no gametófito e na caliptra variaram de 0,2 a $0,3 \mu \mathrm{g} / \mathrm{cm}^{2}$, na seta os valores foram de 0,01 a 0,04 $\mu \mathrm{g} / \mathrm{cm}^{2}$ e na cápsula os valores obtidos variaram entre 0,07 a $0,2 \mu \mathrm{g} / \mathrm{cm}^{2}$. Alcanos e ácidos graxos foram encontrados nas duas fases de vida. Álcoois primários foram detectados no gametófito das três espécies investigadas. Ésteres e aldeídos foram encontrados somente no esporófito. $\mathrm{Na}$ caliptra e na cápsula das três espécies de Polytrichaceae o álcool secundário nonacosan-10-ol foi encontrado em porcentagens expressivas. Ornamentos cristaloides de ceras foram observados 
somente no gametófito de $P$. pseudopolytrichum e na cápsula de $P$. juniperinum. Nas demais partes analisadas foi observada cera tipo filme.

- Conclusões A análise da composição química da cera cuticular em espécies de Polytrichaceae possibilitou a detecção de substâncias nunca descritas nesse grupo de embriófitas. O tamanho robusto das espécies foi essencial para a análise comparativa das gerações do ciclo de vida, possibilitando a detecção de diferenças quanti e qualitativas entre o gametófito e esporófito.

- Palavras-chave: Álcool secundário, aldeído, briófitas, ceras cuticulares, ceras epicuticulares, cristais de cera, esporófito, evolução, gametófito, musgos, Polytrichaceae. 
ABSTRACT

- Background and Aims Polytrichaceae is characterized by mosses with robust gametophytes and sporophytes, distributed in highland and high altitude regions. In Brazil, the most common genera are Polytrichum, Pogonatum and Polytrichadelphus, widely distributed in different regions. As well as for mosses in general, there are few data on chemical composition of waxes in species of Polytricaceae. The main goal of this study is to present a comparative analysis of the morphology and chemical composition of cuticular waxes of the gametophyte and the sporophyte of Pogonatum pensilvanicum, Polytrichadelphus pseudopolytrichum e Polytrichum juniperinum.

- Methods The waxes were extracted with dichloromethane, derivatized and analyzed using gas chromatography coupled with mass spectrometry. The total wax content was expressed in $\mu \mathrm{g} / \mathrm{cm}^{2}$ and the compounds were identified based on mass fragmentation pattern. The morphology of epicuticular waxes was analyzed through scanning electron microscopy.

- Key Results For the three species, the wax content of the gametophyte and the calyptra varied from 0.2 to $0.3 \mu \mathrm{g} / \mathrm{cm}^{2}$, in the seta the values ranged from 0.01 to $0.04 \mu \mathrm{g} / \mathrm{cm}^{2}$ and in the capsule the values varied from 0.07 to $0.2 \mu \mathrm{g} / \mathrm{cm}^{2}$. Alkanes and fatty acids were found in both phases of life. Primary alcohols were detected in the gametophyte of the three species. Aldehydes and esters were found only in the sporophyte. Nonacosan-10-ol presented high proportion in the calyptra and capsule of the three species. Film type of cuticular waxes was predominant. Crystalloid wax ornaments were observed only in the $P$. pseudopolytrichum gametophyte and in the $P$. juniperinum capsule. 
- Conclusions The analysis of the chemical composition of cuticular wax in Polytrichaceae species allowed the detection of compounds never described in this group of embryophytes. The robust size of these species was essential for the comparative analysis, enabling the detection of quanti and qualitative differences between the gametophyte and sporophyte.

- Keywords: Aldehyde, bryophytes, cuticular waxes, epicuticular waxes, evolution, gametophytes, mosses, Polytrichaceae, secondary alcohol, sporophytes, wax crystals. 


\section{INTRODUÇÃO}

Polytrichaceae é a única família de Polytrichales que, juntamente com Tetraphidales, formam a classe Polytrichopsida (Buck \& Goffinet, 2000). Os musgos pertencentes a essa classe são caracterizados por possuir gametófitos tipicamente robustos, com até $80 \mathrm{~cm}$ de altura, formando densos agrupamentos, dióicos ou autóicos, com a presença de hidroides e leptoides e, frequentemente, com lamela fotossintetizante dorsal sobre os filídios costados. A caliptra é reduzida (até $0,5 \mathrm{~cm}$ ) e apresenta morfologia variável entre as espécies. O esporófito apresenta seta lisa e alongada atingindo até 15 vezes o comprimento da cápsula. A forma e o tamanho da cápsula também são bastante variáveis, com peristômio dentado e com a presença de estômatos em grande parte das espécies (Peralta, 2009).

Essa família apresenta ampla distribuição, principalmente em regiões de clima temperado (Peralta, 2009). Atualmente são considerados 23 gêneros (Goffinet et al., 2009) e o número de espécies pode variar de 218 até 300 (Churchill \& Linares, 1995; Crosby et al., 1999). Para o Brasil, Peralta (2009) listou sete gêneros e 14 espécies, sendo Polytrichadelphus pseudopolytrichum (Raddi) G.L. Sm. endêmica. Dentre os gêneros mais recorrentes estão Pogonatum, Polytrichadelphus e Polytrichum, geralmente ocorrendo em regiões do país delimitadas pelo Bioma Mata Atlântica (Peralta, 2009).

Entre as várias novidades evolutivas essenciais para a conquista do ambiente terrestre pelas plantas, a cutícula certamente teve um papel muito importante (Bargel et al., 2006; Raven et al., 2014). Essa camada protetora contínua depositada sobre as paredes periclinais externas dos vegetais é formada pela cutina, que compreende uma matriz de poliésteres, e pelas ceras cuticulares, formadas por uma variedade de derivados graxos de cadeia longa, que desempenham um papel multifuncional nas plantas, especialmente reduzindo a perda de água e evitando a dessecação (Báez-Sañudo et al., 2013; Bernard \& 
Joubés, 2013). Entretanto, apesar desse papel crucial para todas as embriófitas, há poucos estudos sobre a estrutura e a química da cutícula em musgos (Busta et al., 2016).

Para musgos, a maior parte dos trabalhos analisa a morfologia das ceras epicuticulares (Green \& Clayton-Greene, 1977; Proctor, 1979; Clayton-Greene et al., 1985, Koch et al., 2009), existindo alguns dados relativos à análise dos componentes das ceras (Haas, 1982; Neinhuis \& Jetter, 1995; Xu et al., 2009; Busta et al., 2016). Ceras do tipo plaquetas e grânulos foram descritas para a cápsula do esporófito do musgo Buxbaumia viridis (DC.) Moug. \& Nestl. (Buxbaumiaceae) (Koch et. al, 2009). Em Funaria hygrometrica Hedw. (Funariaceae) foram observadas ceras do tipo filme tanto no gametófito como no esporófito (Busta et al., 2016). Nessa espécie, ésteres graxos $\beta$ hidroxilados foram detectados exclusivamente no gametófito e na caliptra, enquanto os alcanos, os aldeídos e os ésteres graxos de alcano-diois foram restritos ao esporófito, evidenciando a variabilidade química de acordo com a fase do ciclo de vida (Busta et al., 2016).

Em Polytrichaceae, a composição química das ceras cuticulares foi investigada no gametófito e/ou esporófito apenas em Pogonatum (Haas, 1982; Neinhuis \& Jetter, 1995). Nos gametófitos de Pogonatum aloides (Hedw.) P. Beauv. e Pogonatum urnigerum (Hedw.) P. Beauv. foram descritos alcanos, ácidos graxos, álcoois e ésteres, além de aldeídos restritos a P. urnigerum (Haas, 1982). Nos esporófitos de Pogonatum belangeri (Müll. Hal.) A. Jaeger e P. urnigerum foram encontrados ácidos graxos, alcanos, álcoois primários e secundários, ésteres alquílicos, além de aldeídos na primeira espécie e alcanodiois na segunda (Neinhuis \& Jetter, 1995). Espécies pertencentes à Polytrichaceae também tiveram a morfologia das ceras epicuticulares do gametófito e do esporófito descrita (Green \& Clayton-Greene, 1977; Clayton-Greene et al., 1985; Neinhuis \& Jetter, 1995). Em gametófitos de 35 representantes dessa família, Clayton-Greene et al. (1985) 
verificaram a presença de ceras do tipo amorfa e cristaloides do tipo plaquetas e grânulos. No gametófito de Polytrichum juniperinum Willd. ex Hedw. foram detectados grânulos de cera (Neinhuis \& Jetter, 1995), também descritos na cápsula do esporófito de $P$. urnigerum. Túbulos de cera foram observados na cápsula de Pogonatum rubenti-viride (Müll. Hal.) Paris, Dawsonia beccarii Broth. \& Geh. e Polytrichum juniperinum (Neinhuis \& Jetter, 1995).

Até onde sabemos, não há qualquer estudo sobre a química e a morfologia das ceras cuticulares em táxons brasileiros de Polytrichaceae. Nesse contexto, o objetivo deste estudo foi analisar comparativamente e caracterizar a composição química e a morfologia das ceras cuticulares do gametófito e do esporófito de três espécies brasileiras de Polytrichaceae: Pogonatum pensilvanicum (W. Bartram ex Hedw.) P. Beauv., Polytrichadelphus pseudopolytrichum (Raddi) G.L. Sm. e Polytrichum juniperinum Willd. ex Hedw.

\section{MATERIAIS E MÉTODOS}

Coleta do material vegetal

As espécies de Polytrichaceae foram coletadas em diferentes municípios do estado de São Paulo - Brasil (Tabela 1). Cada amostra foi composta por um conjunto de indivíduos da mesma localidade. Exemplares testemunhos foram depositados no Herbário de São Paulo - SP. 
Tabela 1. Espécies de Polytrichaceae analisadas.

Polytrichaceae (Bryophyta)

\begin{tabular}{ccc}
\hline Espécie & Voucher & Local de coleta \\
\hline Pogonatum pensilvanicum (W. Bartram & 505385 & Pico dos Marins - Piquete \\
ex Hedw.) P. Beauv. & & $\left(22^{\circ} 30^{\prime} 57^{\prime \prime} \mathrm{S}, 45^{\circ} 09^{\prime} 02^{\prime \prime} \mathrm{O}\right)$ \\
Polytrichadelphus pseudopolytrichum & 493690 & Horto Florestal - Campos do Jordão \\
(Raddi) G.L. Sm. & & $\left(22^{\circ} 42^{\prime} 27^{\prime \prime} \mathrm{N}, 45^{\circ} 28^{\prime} 05^{\prime \prime} \mathrm{O}\right)$ \\
Polytrichum juniperinum Willd. ex & 505386 & Pico dos Marins - Piquete \\
Hedw. & & $\left(22^{\circ} 30^{\prime} 57^{\prime \prime} \mathrm{S}, 45^{\circ} 09^{\prime} 02^{\prime \prime} \mathrm{O}\right)$ \\
\hline
\end{tabular}

Obtenção e análise da cera cuticular

Para a obtenção das ceras cuticulares, os gametófitos e esporófitos foram limpos, triados e secos à temperatura ambiente. As ceras cuticulares foram extraídas e analisadas como descrito na Introdução geral (ver Material e Métodos - pag. 39-41).

O teor total de cera das amostras foi expresso em $\mu \mathrm{g} / \mathrm{cm}^{2}$. As imagens dos filídios dos gametófitos, das caliptras, das setas e das cápsulas foram obtidas através do microscópio digital (800x com câmera HD 2.0mp) e a área calculada com auxílio software Photoshop CS6®. No caso das setas, cápsula e caliptra utilizou-se as fórmulas geométricas do cilindro (seta) e do cone (caliptra e cápsula) (adaptado de Busta et al., 2016a).

Análise por microscopia eletrônica de varredura (MEV)

Amostras dos filídios de ambas as superfícies e das porções do esporófito com e sem cera, foram preparadas e analisadas conforme descrito na Introdução geral (ver Material e Métodos - pag. 42). 
Análise dos dados

A partir dos dados obtidos do teor das ceras cuticulares e das classes dos compostos de cera (porcentagem relativa total de cada classe), os gráficos foram elaborados por meio do software Graphpad Prism® versão 7.01.

\section{RESULTADOS}

Teor de cera cuticular

O teor de cera cuticular do gametófito foi de $0,2 \mu \mathrm{g} / \mathrm{cm}^{2}$ para Polytrichadelphus pseudopolytrichum e Polytrichum juniperinum e de $0,3 \mu \mathrm{g} / \mathrm{cm}^{2}$ para Pogonatum pensilvanicum. Para caliptra, o teor de cera foi de $0,2 \mu \mathrm{g} / \mathrm{cm}^{2}$ em $P$. pensilvanicum e $P$. pseudopolytrichum e de $0,3 \mu \mathrm{g} / \mathrm{cm}^{2}$ em P. juniperinum. Entre as partes do esporófito houve diferença bastante pronunciada, sendo a seta com valores muito menores do que a cápsula (Fig. 1). O teor obtido da seta foi de $0,01 \mu \mathrm{g} / \mathrm{cm}^{2}$ para $P$. pseudopolytrichum, 0,02 $\mu \mathrm{g} / \mathrm{cm}^{2}$ para $P$. juniperinum e $0,04 \mu \mathrm{g} / \mathrm{cm}^{2}$ em $P$. pensilvanicum. Para a cápsula, os valores foram semelhantes ao da caliptra, exceto em $P$. pensilvanicum, para a qual o teor de cera foi de $0,07 \mu \mathrm{g} / \mathrm{cm}^{2}$. Em P. pseudopolytrichum e P. juniperinum o teor de cera na cápsula foi de $0,2 \mu \mathrm{g} / \mathrm{cm}^{2}$ (Fig. 1). 


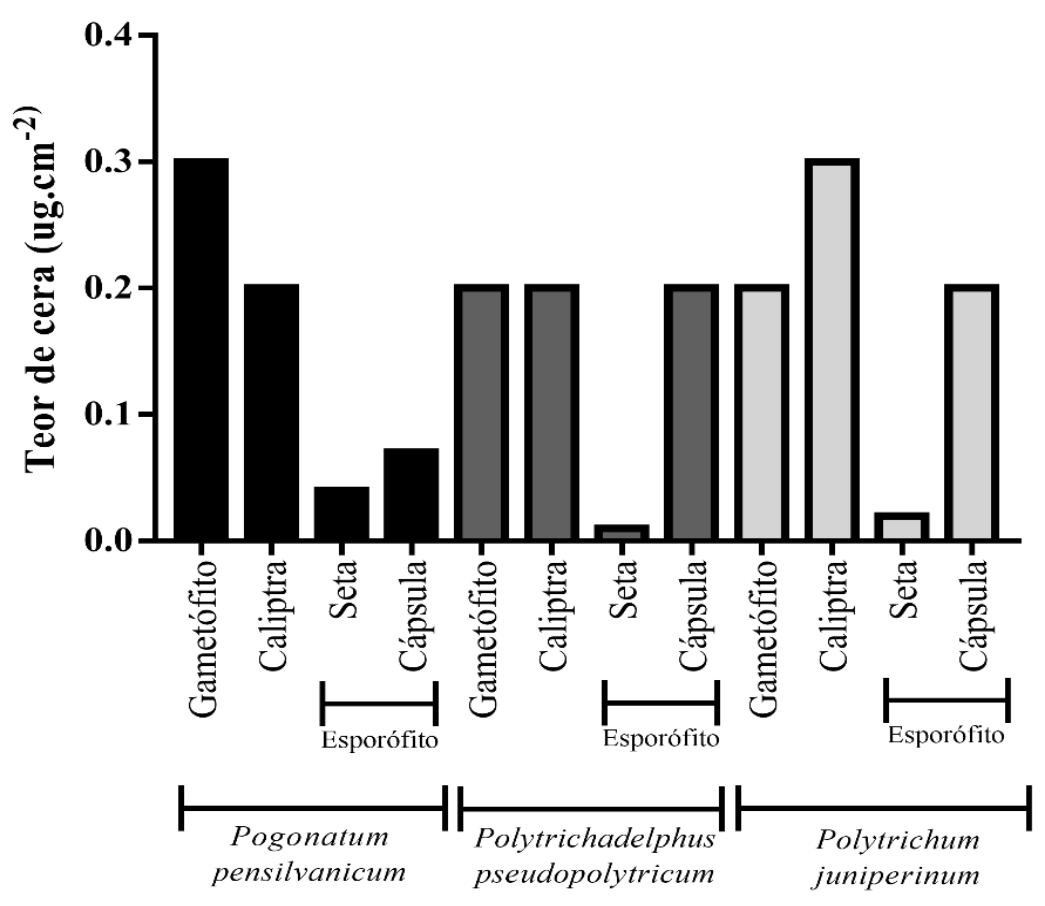

FIG. 1. Teor de cera cuticular do gametófito e esporófito das espécies de Polytrichaceae.

\section{Análise da composição química da cera cuticular}

A composição das ceras cuticulares foi bastante diferenciada entre as amostras analisadas. Alcanos e ácidos graxos foram as únicas classes detectadas em todas as espécies, tanto no gametófito como no esporófito (Fig. 2).

No gametófito das três espécies de Polytrichaceae, as principais classes de substâncias encontradas foram os alcanos, os ácidos graxos e os álcoois primários (Fig. 2). Os alcanos foram a classe majoritária correspondendo a $56 \%$ da cera cuticular em $P$. pensilvanicum e P. pseudopolytrichum (Fig. 2A e B) e 55\% em P. juniperinum (Fig. 2C).

Na caliptra, além dos alcanos e ácidos graxos, o único homólogo de álcool secundário identificado nessas plantas também foi detectado nas três espécies, sendo pouco abundante em P. pensilvanicum (Fig. 2). Aldeídos foram identificados na caliptra de $P$. pensilvanicum e $P$. juniperinum (Fig. 2A e C), enquanto álcool primário foi restrito à caliptra de $P$. pseudopolytrichum (Fig. 2B). 
Para o esporófito, a região da seta e da cápsula foram analisadas separadamente. Nesse caso, o álcool secundário foi detectado nas cápsulas das três espécies (Fig. 2). A presença de ésteres também foi observada nos esporófitos de $P$. pensilvanicum e $P$. juniperinum, sendo restritos à cápsula nesse último (Fig. 2A e C). Álcoois primários foram menos frequentes no esporófito, sendo detectados somente na seta de $P$. pensilvanicum e na cápsula de $P$. pseudopolytrichum. Na cápsula dessas duas espécies também foram detectados aldeídos (Fig. 2A e B). Os alcanos foram a classe majoritária na seta de $P$. pseudopolytrichum e $P$. juniperinum, perfazendo $83 \%$ e $56 \%$ da cera, respectivamente (Fig. 2B e C). Já em $P$. pensilvanicum, os ésteres foram majoritários tanto na seta (35\%) como na cápsula (47\%) (Fig. 2A). 


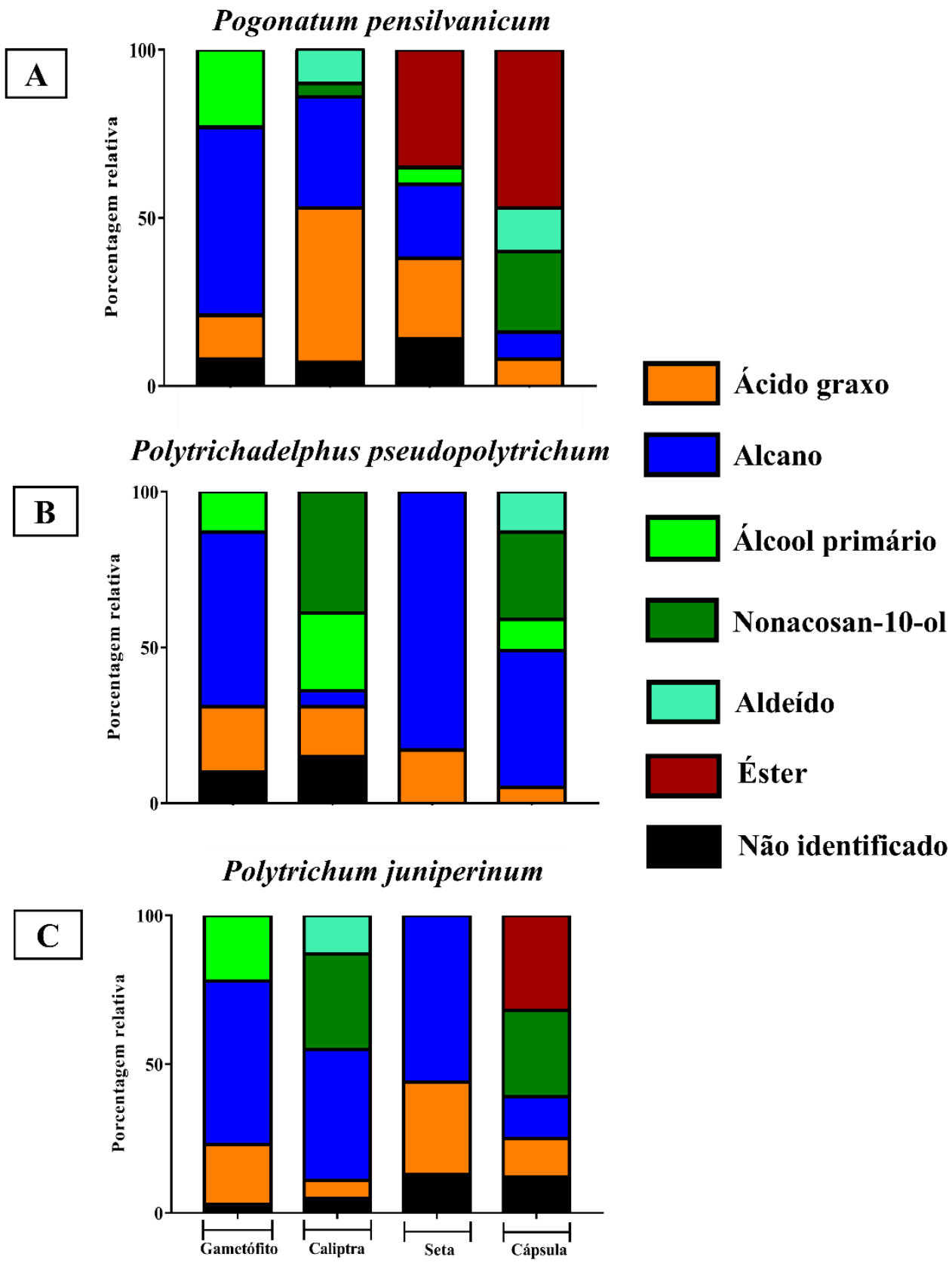

FIG. 2. Caracterização química das ceras cuticulares do gametófito e esporófito das espécies de Polytrichaceae.

Em relação aos homólogos de ácidos graxos foram identificados somente componentes com cadeias carbônicas pares. O ácido hexadecanoico (C16) foi o componente majoritário tanto no gametófito como no esporófito. A maior diversidade de homólogos foi observada na seta de $P$. pensilvanicum, variando de C14 (ácido 
tetradecanoico) a C28 (ácido octacosanoico) (Tabela 2). Alcanos variando de C21 (heneicosano) à C33 (tritriacontano) foram verificados especialmente no gametófito das três espécies analisadas. Os componentes C27 (heptacosano) e C29 (nonacosano) foram os principais homólogos detectados entre o gametófito e o esporófito (Tabela 2). Os álcoois primários foram identificados principalmente nos gametófitos das três espécies, variando de C16 (hexadecanol) à C30 (tritriacontanol) (Tabela 2).

O álcool secundário encontrado na caliptra e na cápsula das três espécies investigadas foi o nonacosan-10-ol (C29) (Tabela 2). Entre os aldeídos, os homólogos identificados foram o C28 (octacosanal), o C30 (tricontanal) e o C32 (dotriacontanal), não tendo sido detectados todos em uma mesma espécie ou estrutura (Tabela 2). Dois ésteres foram identificados, o C36 (octadecanoato de octadecila) e o C38 (eicosanoato de octadecila), sendo que no esporófito de $P$. pensilvanicum foram detectados esses dois componentes. Já na cápsula de P. juniperinum o constituinte C38 (32\%) foi o componente majoritário da cera (Tabela 2). 
Tabela 2. Porcentagens relativas dos homólogos de classes de cera identificados no gametófito e esporófito das espécies de Polytrichaceae.

\begin{tabular}{|c|c|c|c|c|c|c|c|c|c|c|c|c|c|c|c|c|c|c|c|c|c|c|c|c|c|c|c|c|c|c|c|c|c|c|c|}
\hline & \multicolumn{7}{|c|}{ Ácido graxo } & \multicolumn{13}{|c|}{ Alcano } & \multicolumn{9}{|c|}{ Álcool primário } & $\underline{\mathbf{A S} *}$ & \multicolumn{3}{|c|}{ Aldeído } & \multicolumn{2}{|c|}{ Éster } \\
\hline & $\stackrel{\Xi}{U}$ & $\stackrel{0}{0}$ & $\stackrel{\infty}{\circlearrowright}$ & లิ & ปี & ঠ̃ & లి & $\overline{\tilde{U}}$ & ปี & శึ่ & İ & జี่ & ชั & $\hat{\tilde{O}}$ & ల్రి & సิ & ซึ & $\overline{0}$ & $\tilde{ช ี ~}$ & $\tilde{3}$ & పొ & $\stackrel{\infty}{U}$ & ชิ & ปี & ঠ̃ & లั้ & సิ & జิి & ซิ & సิ & లి & లิ & $\tilde{ర}$ & $\tilde{ల}$ & 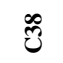 \\
\hline \multicolumn{36}{|c|}{$\begin{array}{c}\text { Pogonatum } \\
\text { pensilvanicum }\end{array}$} \\
\hline Gametófito & & 7,3 & 3,9 & & & & & & & 2 & 2,8 & 3,9 & 3,7 & 6,7 & 5,6 & 7,1 & 5,1 & 5,8 & 2,7 & 4,2 & - & 2,8 & 3,5 & 2,9 & 4,5 & 4,2 & & 2,6 & & & & & & & \\
\hline Caliptra & & 38 & 7,8 & & & & & & & 2,6 & & 18 & & 12 & & & & & & & & & & & & & & & & 4 & 6 & 4,6 & & & \\
\hline Seta & 4,1 & 4,7 & 3,3 & 4 & 2 & 3,6 & 2 & & & & & & & & & 22 & & & & & 4,6 & & & & & & & & & & & & & 18,4 & 16,5 \\
\hline Cápsula & 2 & 4 & 2 & & & & & & & & & & & & & 8 & & & & & & & & & & & & & & 24 & & 7 & 6 & 28 & 19 \\
\hline \multicolumn{36}{|c|}{$\begin{array}{l}\text { Polytrichadelphus } \\
\text { pseudopolytrichum }\end{array}$} \\
\hline Gametófito & 6,2 & 12,4 & & & & & & & 2,4 & 8,7 & 4,3 & 10,4 & 4,4 & 7 & 4,1 & 6,4 & 2,9 & 2,6 & & & 2,1 & 4,6 & & & 2,1 & 3,2 & & & & & & & & & \\
\hline Caliptra & & 15 & - & & & & & & & & & & & 5 & & & & & & & & & & & & 25 & & & & 38,6 & & & & & \\
\hline Seta & & 17 & & & & & & & & 11 & & 13 & 9 & 19 & 13 & 18 & & & & & & & & & & & & & & & & & & & \\
\hline Cápsula & & 4,3 & & & & & & & & & & & & 15,3 & & 28,9 & & & & & & & & & & & & 9,8 & & 28,4 & & 6,1 & 7 & & \\
\hline \multicolumn{36}{|l|}{$\begin{array}{l}\text { Polytrichum } \\
\text { juniperinum }\end{array}$} \\
\hline Gametófito & 1,4 & 10,9 & 5,8 & & 1,3 & & & 1,3 & 2,1 & 6,3 & 3,3 & 6,6 & 5,6 & 7,2 & 4,1 & 7,6 & 2,5 & 4,2 & & 4,1 & 6,7 & & & & & 1,5 & 2,5 & 4,8 & 6,6 & & & & & & \\
\hline Caliptra & & 6 & & & & & & & & 16 & & & & & & 28 & & & & & & & & & & & & & & 32 & 13 & & & & \\
\hline Seta & 17 & 14 & & & & & & & & & & & & & & 30 & & 26 & & & & & & & & & & & & & & & & & \\
\hline Cápsula & & 13 & & & & & & & & & & & & & & 14 & & & & & & & & & & & & & & 29 & & & - & & 32 \\
\hline
\end{tabular}

* AS: Álcool secundário. (-) Refere-se as substâncias presentes em quantidades abaixo de 1\%. Espaço em branco significa que o homólogo não foi detectado. Valor em negrito corresponde ao composto com a maior porcentagem relativa de cada classe. 
Análise por microscopia eletrônica de varredura (MEV)

Com algumas exceções, a morfologia do tipo filme foi predominante entre o gametófito e o esporófito das espécies investigadas de Polytrichaceae (Fig. 3). Ornamentos de cera do tipo plaquetas foram verificados recobrindo a superfície das lamelas fotossintetizantes na região dorsal do filídio de P. pseudopolytrichum (Fig. 3B). Cristais de cera do tipo placas e grânulos foram encontrados recobrindo a superfície da cápsula e os estômatos de $P$. juniperinum (Fig. 3C). Na caliptra de $P$. pensilvanicum e $P$. juniperinum foi possível observar muitos tricomas recobrindo a superfície (Fig. 3A e C), não sendo possível definir a morfologia epicuticular dessa região do esporófito. 
Filídio

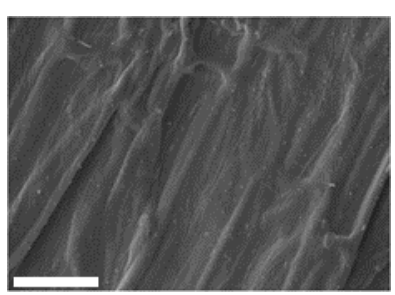

B) Polytrichadelphus pseudopolytrichum

C) Polytrichum juniperinum

A) Pogonatum pensilvanicum
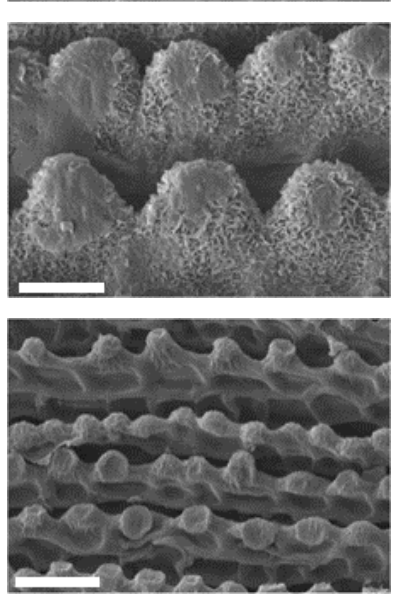

Caliptra
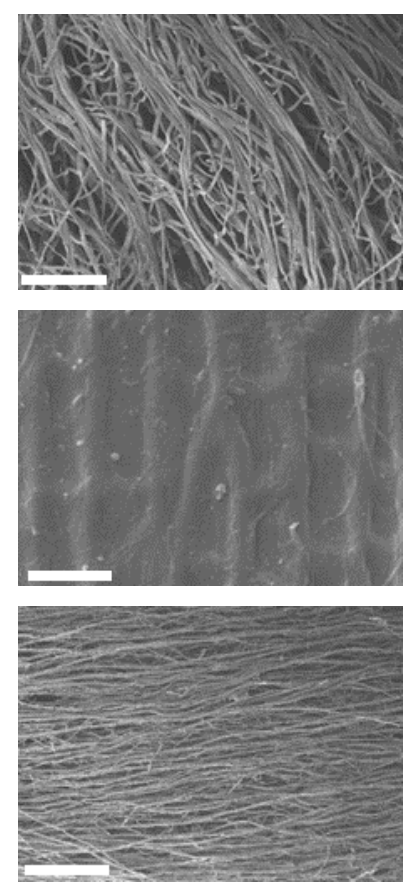

Seta
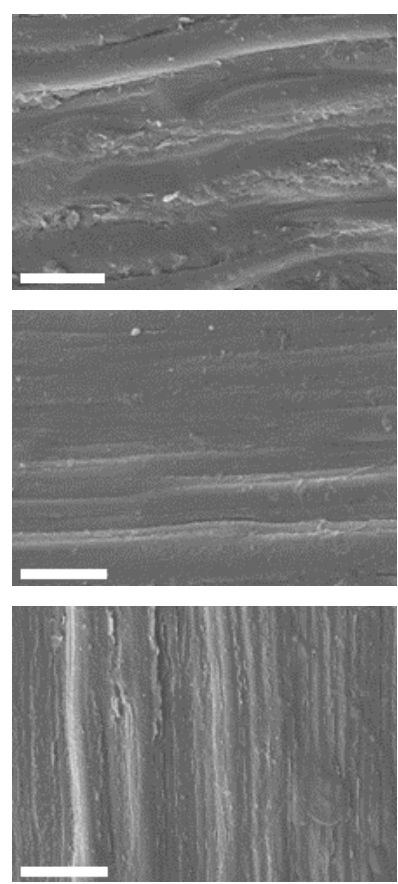

Cápsula
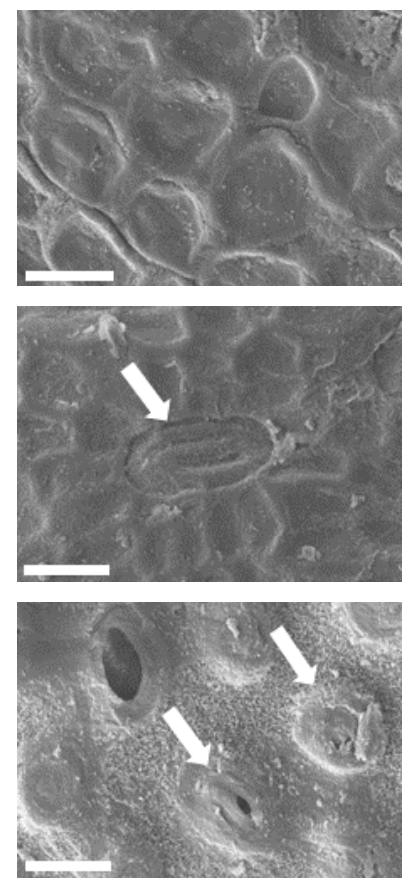

FIG. 3. Microscopia eletrônica de varredura da superfície dos gametófitos e esporófitos das espécies de Polytrichaceae. A morfologia dominante é do tipo filme. Nas lamelas do filídio de P. pseudopolytrichum a cera tem morfologia do tipo plaqueta. Na cápsula do esporófito em $P$. juniperinum a morfologia da cera é do tipo placas e grânulos. Na caliptra de $P$. pensilvanicum e $P$. juniperinum a grande quantidade de tricomas impediu a confirmação da morfologia da cera. As setas indicam os estômatos na superfície da cápsula. Escala MEV: $10 \mu \mathrm{m}$. 


\section{DISCUSSÃO}

Grande parte dos dados disponíveis de teores de ceras cuticulares se refere a cobertura foliar de plantas vasculares. Para briófitas, esses dados são escassos, ainda mais no que se refere às duas fases do ciclo de vida. No musgo Funaria hygrometrica Hedw. (Funariaceae), o teor de cera encontrado no gametófito folhoso, na caliptra e na cápsula do esporófito foi de $0,94 \mu \mathrm{g} / \mathrm{cm}^{2}, 2,0 \mu \mathrm{g} / \mathrm{cm}^{2}$ e $0,44 \mu \mathrm{g} / \mathrm{cm}^{2}$, respectivamente (Busta et al., 2016). Esses valores foram bem maiores em relação aos obtidos para as três espécies de Polytrichaceae (Fig. 1) em todas as partes, sendo cerca de 10 vezes maior na caliptra e duas vezes na cápsula. Analisando somente o gametófito, o teor descrito para Funaria hygrometrica é maior que várias outras espécies de musgos analisadas (ver Figura 1B Capítulo 1 - pag. 62). No caso de outras espécies de Polytrichaceae, Polytrichum angustifolium $\left(0,03 \mu \mathrm{g} / \mathrm{cm}^{2}\right)$, Polytrichum commune $\left(0,05 \mu \mathrm{g} / \mathrm{cm}^{2}\right)$ e Atrichum androgynum $\left(0,1 \mu \mathrm{g} / \mathrm{cm}^{2}\right)$ apresentaram valores ainda menores (Figura 1B - Capítulo 1 pag. 62) que as três espécies deste estudo. Até onde vai nosso conhecimento, nossos dados são os primeiros no que se refere ao teor de cera na seta. Com esses dados, detectamos uma distribuição das ceras cuticulares não homogênea no esporófito.

Exceto para o gametófito de Pogonatum pensilvanicum, o teor de cera detectado para a caliptra nas espécies deste estudo foi semelhante ou maior quando comparado com a cápsula, seta e gametófito (Fig. 1). Da mesma forma, Busta e colaboradores (2016) verificaram maior teor de cera na caliptra de Funaria hygrometrica quando comparado com a cápsula e o gametófito. A caliptra é originada de parte do gametófito, possui forma de “capuz" que envolve e protege a cápsula do esporófito até a liberação dos esporos (Schofield, 2001; Vanderpoorten \& Goffinet, 2009). Pensando no papel de barreira contra dessecação, o maior teor de cera na caliptra pode auxiliar na proteção da cápsula enquanto os esporos, essenciais para a continuidade do ciclo de vida, não estão maduros. 
Em briófitas ainda há uma grande lacuna de dados químicos de cera. No caso de Polytrichaceae, poucas espécies foram investigadas nesse aspecto (Haas, 1982; Neinhuis \& Jetter, 1995). Além disso, até onde sabemos, não há estudos de análise química das ceras para a caliptra ou mesmo para a seta de espécies de Polytrichaceae.

Os ácidos graxos e alcanos foram as únicas classes de cera encontradas em ambas as fases de vida das espécies analisadas (Fig. 2). A presença comum dessas duas classes é amplamente descrita em plantas vasculares (Kunst \& Samuels, 2003; 2009; Barthlott et al., 2017) e também são comuns em briófitas (Haas, 1982; Neinhuis \& Jetter, 1995; Xu et al., 2009).

Para os gametófitos dos musgos Pogonatum aloides (Hedw.) P. Beauv. e Pogonatum urnigerum (Hedw.) P. Beauv., por exemplo, já foram descritos ácidos graxos livres, alcanos, álcoois primários e ésteres nas ceras. Em P. urnigerum também foram encontrados aldeídos (Haas, 1982). Alcanos, álcoois primários e ácidos graxos também foram verificados no gametófito de Pogonatum pensilvanicum e das outras duas espécies caracterizadas neste estudo (Fig. 2).

Nas ceras cuticulares do esporófito de Polytrichaceae já foram descritas classes típicas de cera de plantas vasculares (Neinhuis \& Jetter, 1995). Na cápsula de Pogonatum belangeri (Müll. Hal.) A. Jaeger foram detectados ácidos graxos, alcanos, álcoois primários, álcoois secundários, aldeídos e alquil ésteres de ácidos graxos. Já Pogonatum urnigerum não apresentou aldeídos, porém foram identificados os alcano-diois (Neinhuis \& Jetter, 1995). Os alcanos, aldeídos, álcool secundário e ácidos graxos livres também foram verificados na cápsula de Pogonatum pensilvanicum no presente estudo, assim como ésteres. Esta é a primeira descrição de ésteres no esporófito de Pogonatum, presente também na cápsula de Polytrichum juniperinum (Fig. 2). Os ésteres são comumente descritos em ceras de plantas vasculares (Kunst \& Samuels, 2003; Barthlott et al., 2017), 
já aldeídos e álcoois secundários apresentam distribuição mais restrita (Barthlott et al., 2017). Na cápsula de $P$. pseudopolytrichum também foi identificado um álcool primário (Tabela 2), como constatado nas espécies de Pogonatum analisadas por Neinhuis \& Jetter (1995).

Assim como já observado anteriormente, a composição das ceras cuticulares é diferente no gametófito e no esporófito das espécies analisadas. Essa diferença já havia sido descrita para o musgo Funaria hygrometrica (Funariaceae), no qual alcanos, aldeídos e ésteres graxos de alcano-diois foram identificados somente no esporófito, enquanto ésteres graxos $\beta$-hidroxilados foram restritos ao gametófito e a caliptra (Busta et al., 2016).

De maneira geral, nas espécies de Polytrichaceae investigadas neste estudo, as ceras do esporófito parecem mais diversas (Fig. 2). Curiosamente, a composição das ceras da caliptra, estrutura de origem gametofítica, parece mais próxima a do esporófito (seta + cápsula). O nonacosan-10-ol foi detectado, exclusivamente, na cápsula e na caliptra das três espécies (Fig. 2, Tabela 2). Diferente do observado por Busta et al. (2016), não foram detectadas classes de componentes de cera compartilhadas exclusivamente entre o gametófito e a caliptra.

Em relação aos homólogos das classes dos componentes de cera, o composto C16 foi o ácido graxo majoritário detectado em ambas as fases de vida das espécies analisadas (Tabela 2). Essa substância já é reconhecida como o homólogo mais comum de ácidos graxos em briófitas sensu lato (Caldicott \& Eglinton, 1976). No gametófito de Pogonatum aloides, por exemplo, esse homólogo correspondeu à 22\% da cera (Haas, 1982). Além disso, no gametófito dessa espécie e de Pogonatum urnigerum foram encontrados homólogos de ácido graxo variando de C16 à C30, sendo o homólogo C22 majoritário nas duas espécies, representando $23 \%$ e $32 \%$, respectivamente (Haas, 1982). Neste 
estudo, o homólogo C22 foi detectado, em menores porcentagens, somente no gametófito de Polytrichum juniperinum e na seta de Pogonatum pensilvanicum (Tabela 2).

Nas ceras cuticulares de plantas vasculares, as séries homólogas de alcanos podem variar de C19 à C37, sendo predominantemente ímpares (Barthlott et al., 2017), com os homólogos C27 e C29 bastante comuns (Kunst \& Samuels, 2003; Samuels et al., 2008; Kunst \& Samuels, 2009; Bush \& McInerney, 2013). Alcanos de cadeia carbônica mais curtas, como por exemplo o homólogo C25, são apontados como característicos das ceras de gametófitos de briófitas sensu lato (Bush \& McInerney, 2013). Alcanos com séries homólogas de C21 à C31 foram encontrados nos gametófitos de Pogonatum aloides e Pogonatum urnigerum, com o C25 como majoritário (Haas, 1982). As três espécies de Polytrichaceae analisadas neste estudo apresentaram ampla série homóloga de alcanos nos gametófitos, variando de C21 a C33. Entretanto, somente em P. pseudopolytrichum o C25 apareceu como majoritário. Nas outras duas espécies o C29 foi o alcano principal (Tabela 2). No esporófito de Pogonatum belangeri e de $P$. urnigerum, os homólogos C27 e C29 foram os únicos alcanos identificados com porcentagens inferiores a 1\% (Neinhuis \& Jetter, 1995). Os dados obtidos neste estudo permitiram identificar a presença majoritária do alcano C29 no esporófito das três espécies investigadas em quantidades bem maiores, tanto na cápsula como na seta (Tabela 2).

Os álcoois primários foram encontrados quase exclusivamente nos gametófitos das espécies de Polytrichaceae investigadas, com séries homólogas variando entre C16 à C30, com predomínio do C24 em Pogonatum pensilvanicum, C18 em Polytrichadelphus pseudopolythrichum e C16 em Polytrichum juniperinum (Tabela 2). Geralmente, os homólogos de álcoois primários detectados nas ceras de plantas vasculares são homólogos de cadeia carbônica par variando de C12 à C36 (Bernard \& Joubès, 2013). No gametófito de Pogonatum aloides e Pogonatum urnigerum, os álcoois primários 
resultaram em uma série homóloga de C20 à C30, sendo o C26 o componente majoritário (Haas, 1982), diferente do observado nas espécies analisadas neste estudo em que os homólogos majoritários foram álcoois de cadeia carbônica mais curta. Neinhuis \& Jetter (1995) detectaram nas ceras dos esporófitos de Pogonatum belangeri e P. urnigerum álcoois primários variando de C24 à C30. Neste estudo, o homólogo C16 foi o único identificado na seta de Pogonatum pensilvanicum e o C28 na cápsula de Polytrichadelphus pseudopolytrichum (Tabela 2).

Segundo Neinhuis \& Jetter (1995), foi detectada a presença majoritária do álcool secundário nonacosan-10-ol nas ceras da cápsula em espécies de Polytrichaceae, incluindo Pogonatum belangeri e Pogonatum urnigerum. Esse componente também foi constatado na cápsula das espécies de Polytrichaceae investigadas neste estudo. Além disso, na caliptra de Polytrichadelphus pseudopolytrichum e de Polytrichum juniperinum, esse álcool secundário foi o constituinte majoritário das ceras (Tabela 2).

Aldeídos foram encontrados nas três espécies de Polytrichaceae, presentes na cápsula e/ou na caliptra, variando entre C28-C32 (Tabela 2). Em plantas vasculares, os homólogos de aldeídos podem variar de C14 à C34, sendo que os compostos C28 e C30 são predominantes nas ceras (Kunst \& Samuels, 2003; Barthlott et al., 2017; Holloway \& Jeffree, 2017). Em Pogonatum belangeri, aldeídos de C24-C30 foram verificados compondo as ceras na cápsula do esporófito (Neinhuis \& Jetter, 1995).

Este estudo, até onde sabemos, é a primeira descrição dos ésteres C36 e C38 em espécies de briófita sensu lato. De acordo com Barthlott e colaboradores (2017), ésteres de C30 à C60 são encontrados comumente nas ceras de plantas vasculares.

No que se refere a morfologia, Clayton-Greene et al. (1985) verificaram a presença de ceras do tipo amorfa e cristaloides do tipo plaquetas e grânulos recobrindo a superfície dos gametófitos de 35 representantes de Polytrichaceae, sendo alguns de 
Pogonatum e Polytrichum, assim como verificado para os gametófitos das espécies investigadas neste estudo (Fig. 3). Cristais de cera do tipo grânulos e placas também estão presentes na cápsula do esporófito do musgo Buxbaumia viridis (DC.) Moug. \& Nestl. (Buxbaumiaceae) (Koch et al., 2009). Segundo Neinhuis \& Jetter (1995), cristais de cera do tipo túbulos e grânulos foram detectados na cápsula do esporófito de Pogonatum rubenti-viride (Müll. Hal.) Paris e Pogonatum urnigerum, respectivamente, assim como os túbulos no gametófito de Polytrichum juniperinum. O mesmo não foi verificado para o gametófito dessa espécie analisada neste estudo, tendo sido observadas placas e grânulos na superfície da cápsula (Fig. 3C). Neinhuis \& Jetter (1995) sugerem que essa ornamentação em grânulos de cera na cápsula do esporófito de $P$. urnigerum está relacionada com a presença majoritária de nonacosan-10-ol. Entretanto, essa correspondência não foi observada no presente estudo. A presença majoritária dessa substância nas ceras da caliptra de Polytrichadelphus pseudopolytrichum e Polytrichum juniperinum não está associada a essa ornamentação. Por outro lado, verificamos ornamentos do tipo plaqueta no filídio de P. pseudopolytrichum (Fig. 3B). Da mesma forma, a presença de plaquetas também foi encontrada recobrindo a superfície da lamela no gametófito de outras espécies de Polytrichaceae (Green \& Clayton-Greene, 1977; Clayton-Greene et al., 1985; Neinhuis \& Jetter, 1995). A caracterização morfológica das ceras nas setas de espécies de Polytrichaceae é uma contribuição inédita, tendo sido possível identificar a morfologia do tipo filme (Fig. 3).

\section{CONCLUSÕES}

As espécies pertencentes à Polytrichaceae podem ser consideradas bastante viáveis para a investigação química e morfológica das ceras cuticulares em ambas as fases de vida. O fácil reconhecimento das espécies em campo e o tamanho geralmente robusto 
do gametófito e esporófito das espécies facilitam a coleta e também o processo de análise das ceras.

A possibilidade de investigar quimicamente não somente a fase de vida dominante (gametófito), como também o esporófito, possibilitou a detecção de substâncias nunca descritas nas briófitas sensu lato. Com isso, contribuímos para ampliar o nosso entendimento sobre a diversidade química nesse grupo de plantas ainda negligenciadas como objeto de investigação.

De acordo com Jetter et al. (2006), no geral, as classes de componentes de cera cuticular descritas para as briófitas sensu lato são bem semelhantes aos das plantas vasculares, sugerindo que as vias de síntese envolvidas na produção desses componentes da cutícula tenham surgido nos estágios iniciais da história evolutiva das plantas terrestres. Os dados encontrados neste trabalho corroboram essa ideia. Dessa forma, podese sugerir que a maquinaria biossintética para a síntese dos componentes das ceras já estava presente, tanto na fase de vida do gametófito como do esporófito, desde as linhagens basais de plantas terrestres.

FINANCIAMENTO

Agrademos à Coordenação de Aperfeiçoamento de Pessoal de Nível Superior Brasil (CAPES) - Código Financeiro 001 pelo financiamento deste trabalho.

\section{AGRADECIMENTOS}

Agradecemos ao professor Dr. Denilson F. Peralta do Núcleo de Pesquisa em Briologia do Instituto de Botânica - IBt/SP pela colaboração nas coletas e identificações do material vegetal estudado, ao doutorando Lucas P. Roma pelo auxílio nas identificações das substâncias, às técnicas Mourisa Ferreira e Aline Bertinatto Cruz pela assistência durante as análises por CG-EM, ao técnico Irwandro Roberto Pires pela assistência na análise do material através de MEV. 


\section{REFERÊNCIAS}

Báez-Sañudo, R., Tafolla-Arellano, J.C., González-León, A., Tiznado-Hernández, M.E. \& García, L.Z. 2013. Composición, fisiologia y biosíntesis de la cutícula en plantas. Revista Fitotecnia Mexicana, 36: 3-12.

Bargel, H., Koch, K., Cerman, Z. \& Neinhuis, C. 2006. Structure - function relationships of the plant cuticle and cuticular waxes - a smart material? Functional Plant Biology, 33: 893-910.

Barthlott, W., Mail, M., Bhushan, B. \& Koch, K. 2017. Plant surfaces: structures and functions for biomimetic innovations. Nano-Micro Letters, 9: 23.

Bernard, A. \& Joubès, J. 2013. Arabidopsis cuticular waxes: advances in synthesis, export and regulation. Progress in Lipid Research, 52: 110-129.

Buck, W.R. \& Goffinet, B. 2000. Morphology and classification of mosses. In: Goffinet, B. \& Shaw, A.J. Bryophyte Biology. (2 ed.) Cambridge University Press, Cambridge, 71-123.

Bush, R.T. \& McInerney, F.R. 2013. Leaf wax $n$-alkane distributions in and across modern plants: implications for paleoecology and chemotaxonomy. Geochimica et Cosmochimica Acta, 117: 161-179.

Busta, L., Budke, J.M. \& Jetter, R. 2016. The moss Funaria hygrometrica has cuticular wax similar to vascular plants, with distinct composition on leafy gametophyte, calyptra, and sporophyte capsule surfaces. Annals of Botany, 118: 511-522.

Caldicott, A.B. \& Eglinton, G. 1976. Cutin acids from Bryophytes: an $\omega-1$ hydroxy alkanoic acid in two liverwort species. Phytochemistry, 15: 1139-1143. 
Churchill, S.P. \& Linares, C.E. 1995. Prodromus Bryologiae Novo-Granatensis: Introduccion a la Flora de Musgos de Colombia. Biblioteca "Jose Jeronimo Triana", 1- 924.

Clayton-Greene, K.A., Collins, N.J., Green, T.G.A. \& Proctor, M.C.F. 1985. Surface wax, structure and function in leaves of Polytrichaceae. Journal of Bryology, 13: $549-562$.

Crosby, M.R., Magill, R.E., Allen, B. \& He, S. 1999. A checklist of the Mosses. Missouri Botanical Garden, St. Louis, 194.

Green, T.G.A. \& Clayton-Greene, K. 1977. The growth of Dawsonia superba Grev. In J. G. Duckett (ed.) the annual meeting. Bryologist, 29: 5-6.

Goffinet, B., Buck, W.R. \& Shaw, A.J. 2009. Morphology, anatomy, and classification of the bryophyta. In: Goffinet, B. \& Shaw, A.J. Bryophyte Biology. (2 ed.) Cambridge University Press, Cambridge, 56-138.

Haas, K. 1982. Surface wax of Andreaea and Pogonatum species. Phytochemistry, 21: 657-659.

Holloway, P.J. \& Jeffree, C.E. 2017. Epicuticular waxes. Encyclopedia of Applied Plant Sciences, 2: 374-386.

Jetter, R., Kunst, L. \& Samuels, A.L. 2006. Composition of plant cuticular waxes. In: M. Riederer \& C. Müller (Eds.), Annual Plant Reviews, volume 23: Biology of the Plant Cuticle. Blackwell publishing Ltd, 23: 145-181.

Koch, K., Frahm, J-P. \& Pollawatn, R. 2009. The cuticle of the Buxbaumia viridis sporophyte. Flora, 204: 34-39. 
Kunst, L. \& Samuels, A.L. 2003. Biosynthesis and secretion of plant cuticular wax. Progress in Lipid Research, 42: 51-80.

Kunst, L. \& Samuels, A.L. 2009. Plant cuticles shine: advances in wax biosynthesis and export. Current Opinion in Plant Biology, 12: 721-727.

Neinhuis, C. \& Jetter, R. 1995. Epicuticular wax of Polytrichales sporophytes. Journal of Bryology, 18: 399-406.

Peralta, D.F. 2009. Polytrichaceae (Polytrichales, Bryophyta) do Brasil. Tese de Doutorado. Instituto de Botânica de São Paulo. 176.

Proctor, M.C.F. 1979. Surface wax on the leaves of some mosses. Journal of Bryology, 10: $531-538$.

Raven, P.H., Evert, R.F. \& Eichhorn, S.E. 2014. Biologia vegetal ( $8^{\text {a }}$ ed.). Guanabara Koogan Editora, 856p.

Samuels, L., Kunst, L. \& Jetter, R. 2008. Sealing plant surfaces: cuticular wax formation by epidermal cells. Annual Review of Plant Biology, 59: 683-707.

Schofield, W. B. 2001. Introdution to Bryology, $2^{\mathrm{a}}$ ed. New Jersey: The Blackburn Press.

Vanderpoorten, A. \& Goffinet, B. 2009. Introduction to Bryology. New York: Cambridge University Press, 1-329.

Xu, S.J., Jiang, P.A., Wang, Z.W., Wang, Y. 2009. Crystal structures and chemical composition of leaf surface wax depositions on the desert moss Syntrichia caninervis. Biochemical Systematics and Ecology, 37: 723-730. 


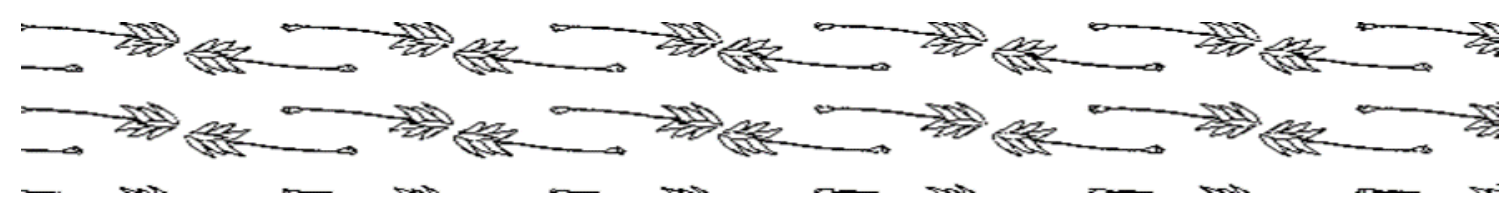

Capítulo 3: Variação intraespecífica da composição química das ceras cuticulares em Lejeunea flava (Sw.) Ness (Lejeuneaceae)

Capítulo formatado para submissão a Biochemical Systematics and Ecology (Elsevier $\mathrm{IF}=1.127)$.

\section{Colaboradores:}

Denilson Fernandes Peralta*

Gladys Flávia de Albuquerque Melo de Pinna**

Lucas Paradizo Roma**

*Instituto de Botânica, Av. Miguel Estéfano 3687, 04301-902, São Paulo, SP, Brasil.

**Departamento de Botânica, Instituto de Biociências, Universidade de São Paulo, Rua do Matão, 277, 05508-090, São Paulo, SP, Brasil. 


\section{Resumo}

Lejeuneaceae é a maior família da divisão Marchantiophyta com mais de 1.000 espécies. Para o Brasil são descritos 57 gêneros e 285 espécies, dentre as quais destaca-se Lejeunea flava, recorrente em levantamentos de brioflora devido a sua ampla adaptação a diferentes ambientes distribuídos pelo país. Com relação as ceras cuticulares, até o momento, apenas a micromorfologia já foi investigada em algumas espécies de Lejeunea, não havendo dados sobre a composição química. Nesse contexto, o objetivo deste estudo foi caracterizar a composição química e a morfologia das ceras cuticulares do gametófito de L. flava proveniente de diferentes localidades do estado de São Paulo. Para tanto, as ceras dos gametófitos foram analisadas através de cromatografia a gás acoplada a espectrometria de massas e os componentes identificados pelo padrão de fragmentação. As áreas superficiais do gametófito foram calculadas com auxílio do software Photoshop CS6 ${ }^{\circledR}$ e o teor das ceras expresso em $\mu \mathrm{g} / \mathrm{cm}^{2}$. Com base no teor e na composição química das ceras foi realizada a análise de agrupamento por UPGMA. A análise da morfologia das ceras epicuticulares foi realizada através de microscopia eletrônica de varredura. Os teores de cera em L. flava coletadas em São Paulo, Itirapina e Mogi Guaçu foram de 1 $\mu \mathrm{g} / \mathrm{cm}^{2}, 0,4 \mu \mathrm{g} / \mathrm{cm}^{2}$ e $0,2 \mu \mathrm{g} / \mathrm{cm}^{2}$, respectivamente. De modo geral, as ceras das três amostras foram caracterizadas principalmente por ácidos graxos, álcoois primários e cetonas. Alcanos e o ácido nonanodioico foram encontrados em menor proporção. Foram detectadas diferenças qualitativas nos homólogos principais entre as amostras. $\mathrm{O}$ ácido graxo docosanoico (C22) foi o homólogo majoritário em L. flava de São Paulo e Mogi Guaçu e o ácido hexadecanoico (C16) na amostra de Itirapina. Álcoois primários de cadeia longa foram verificados principalmente nos indivíduos de São Paulo e Mogi Guaçu, nos quais a cetona heneicosan-2-ona (C21) também foi abundante. Já a série homóloga de alcanos C26-C29 foi detectada apenas na amostra de Itirapina. A partir da análise de agrupamento preliminar, L. flava de São Paulo mostrou-se mais distinta com base no teor total e das classes de componentes da cera, em comparação as amostras de regiões menos antropizadas. Entretanto, essa distinção não foi observada considerandose a porcentagem relativa de cada homólogo, sendo, nesse caso, a amostra de Itirapina mais distinta em relação as das outras localidades. Diferente da composição química, a micromorfologia não apresentou variação, sendo observada presença cristaloides de cera do tipo plaquetas. Assim, sugerimos que a caracterização química das ceras cuticulares de L. flava pode auxiliar na compreensão da ampla diversidade e plasticidade fenotípica 
apresentada pelos representantes de Lejeuneaceae, além de possibilitar o estudo da influência de fatores abióticos nessas plantas.

Palavras-chave: cristais de cera, fatores abióticos, hepáticas, variação intraespecífica, lipídios de superfície. 


\section{Abstract}

Lejeuneaceae is the largest family of Marchantiophyta with more than 1,000 species. In Brazil there are 57 genera and 285 species, among which Lejeunea flava stands out. This species is quite common in bryophytes checklists due to its wide adaptation to different environments. Concerning cuticular waxes, the micromorphology of some species of Lejeunea has already been investigated. However, no chemical composition is available. In this context, the aim of this study was to characterize the chemical composition and morphology of cuticular waxes of the L. flava gametophyte from different locations of São Paulo. The waxes of the gametophytes were extracted with dichloromethane and analyzed through gas chromatography coupled with mass spectrometry. The surface areas of the gametophyte were measured with the software Photoshop CS6® and the wax content expressed in $\mu \mathrm{g} / \mathrm{cm}^{2}$. Cluster analysis by UPGMA was performed using total amount and chemical composition data. The epicuticular wax morphology was analyzed by scanning electron microscopy. The wax contents of $L$. flava collected in São Paulo, Itirapina and Mogi Guaçu were $1 \mu \mathrm{g} / \mathrm{cm}^{2}, 0.4 \mu \mathrm{g} / \mathrm{cm}^{2}$ and $0.2 \mu \mathrm{g} / \mathrm{cm}^{2}$, respectively. In general, the waxes of the three samples were mainly characterized by fatty acids, primary alcohols and ketones. Alkanes and the nonanodioic acid were also found. Qualitative differences were found in the main homologues among the samples. Docosanoic acid was the major fatty acid in L. flava from São Paulo and Mogi Guaçu, while hexadecanoic acid was in the Itirapina. Long chain primary alcohols were found in samples from São Paulo and Mogi Guaçu, as well as the heneicosan-2-one. The C26-C29 alkanes were detected only in the Itirapina sample. Using total wax content and relative percentages of classes, the UPGMA analysis unveil the higher distinction of sample from São Paulo comparing to the other two regions. However, this distinction was not observed when the relative percentage of each homologue was considered. Unlike the chemical composition, no variation on the wax micromorphology was observed, with the presence of platelet type wax crystalloids. Therefore, we suggest that the chemical study of cuticular waxes of $L$. flava can help explaining the wide diversity and phenotypic plasticity found in members of Lejeuneaceae. In addition, these data can enabling the study of the influence of abiotic factors in these plants.

Keywords: abiotic factors, intraspecific variation, liverworts, surface lipids, wax crystals. 


\section{Introdução}

Lejeuneaceae é a família de hepáticas folhosas da recente linhagem de Porellales com maior diversidade de espécies (1.000), distribuídas em aproximadamente 80 gêneros, sendo a maior família da divisão Marchantiophyta (Gradstein, 2013; Bechteler et al., 2016). Ocorre em regiões tropicais e subtropicais, com algumas ocorrências em regiões de clima temperado (Ilkiu-Borges \& Oliveira-da-Silva, 2018), crescendo sobre a casca de troncos e galhos, ou sobre folhas (Gradstein, 1997; Sonnleitner et al., 2009). No Brasil são reconhecidos 57 gêneros e 285 espécies, correspondendo a $45 \%$ de todas as espécies reconhecidas para Marchantiophyta no país (Gradstein \& Costa, 2003; Costa \& Peralta, 2015). Dentre essas, Lejeunea flava (Sw.) Ness apresenta ampla distribuição, sendo registrada em praticamente todos os estados do país (Ilkiu-Borges \& Lisboa, 2002). A plasticidade quanto a adaptação à diferentes ambientes como florestas tropicais, campos rochosos e áreas urbanas é sugerida como responsável por essa ampla ocorrência (Bordin, 2009; Carmo \& Peralta, 2017).

A cutícula, camada que constitui a interface entre a planta e o ambiente, é constituída por dois componentes principais: as ceras cuticulares e a cutina (Kolattukudy, 2001). As ceras cuticulares são caracterizadas por uma mistura complexa de substâncias lipofílicas alifáticas de cadeia longa. As ceras intracuticulares estão associadas à cutina, matriz de poliésteres que forma a cutícula, enquanto as ceras epicuticulares formam a camada mais externa da superfície cuticular (Heredia, 2003). Os componentes da cera que constituem a cutícula vegetal conferem hidrofobicidade a essa camada que reveste os órgãos aéreos das plantas, atuando principalmente como barreira na perda de água (Bargel et al., 2006). Além disso, a cutícula confere proteção contra radiação ultravioleta, poluentes, patógenos e etc. (Koch et al., 2009; Ahmad et al., 2015).

É bem conhecido que a variação no perfil químico das ceras cuticulares nas plantas está relacionada a fatores intrínsecos e extrínsecos. Essa variação pode se dar entre espécies, entre diferentes órgãos, entre plantas de idade ou fase de desenvolvimento diferentes, de acordo com a fitogeografia, com as condições atmosféricas, com a temperatura, a luminosidade e a precipitação, entre outros (Baker, 1982; Jetter \& Schäffer, 2001; Dodd \& Poveda, 2003; Oliveira et al., 2003; Reina-Pinto \& Yephremov, 2009). 
Estudos sobre a composição química das ceras em hepáticas são escassos. Em espécies de Plagiochilaceae, Plagiochila tabinensis Steph. e Plagiochila atlantida (= P. heterofolia Steph.), os ácidos graxos foram descritos como a principal classe de componentes da cera cuticular (Heinrichs et al., 2000; Heinrichs \& Rycroft, 2001). Entretanto, alcanos e ésteres foram identificados na cera do gametófito de Gymnocolea inflata (Huds.) Dumort. (Anastrophyllaceae), Calypogeia meylanii H. Buch (Calypogeiaceae), Jungermannia sphaerocarpa Hook. (Jungermanniaceae), Mylia taylorii (Hook.) Mitt. (Myliaceae) e Pellia fabbroniana Raddi (Pelliaceae) (Benešová et al., 1972). Até recentemente, somente dados relacionados a micromorfologia das ceras epicuticulares em algumas espécies de Lejeunea, incluindo L. flava, estavam disponíveis na literatura (Heinrichs \& Reiner-Drehwald, 2012). A composição geral da cera do gametófito de L. flava foi descrita pela primeira vez no Capítulo 1 do presente estudo.

A lacuna de dados químicos de cera aliada a notável diversidade de Lejeuneaceae tornam os táxons desse grupo interessantes para investigação. Nesse contexto, o principal objetivo deste trabalho foi iniciar um estudo, analisando comparativamente a composição química e a morfologia das ceras cuticulares dos gametófitos de Lejeunea flava provenientes de diferentes localidades do estado de São Paulo, a fim de verificar a possível ocorrência de variação intraespecífica desse caráter.

\section{Material e métodos}

\subsection{Coleta do material vegetal}

Amostras dos gametófitos de Lejeunea flava foram coletadas em três diferentes localidades do estado de São Paulo - Brasil (Tabela 1). Devido ao pequeno porte da espécie, cada amostra foi composta por um conjunto de indivíduos da mesma localidade. Exemplares testemunhos foram depositados no Herbário de São Paulo - SP. 
Tabela 1. Locais de coleta de Lejeunea flava no estado de São Paulo, Brasil.

\begin{tabular}{|c|c|c|c|}
\hline \multicolumn{4}{|c|}{ Lejeuneaceae (Marchantiophyta) } \\
\hline & Voucher & Município & Fitofisionomia \\
\hline \multirow{3}{*}{$\begin{array}{c}\text { Lejeunea flava } \\
\text { (Sw.) Nees }\end{array}$} & 493689 & $\begin{array}{l}\text { São Paulo - estacionamento } \\
\text { próximo ao IB* } \\
\left(23^{\circ} 33^{\prime} 60^{\prime \prime} \mathrm{S}, 46^{\circ} 43^{\prime} 45^{\prime \prime} \mathrm{O}\right)\end{array}$ & $\begin{array}{c}\text { Formação arbórea típica da } \\
\text { área urbana }\end{array}$ \\
\hline & 505372 & $\begin{array}{c}\text { Itirapina - Próximo à Represa } \\
\text { do Broa } \\
\left(22^{\circ} 10^{\prime} 01^{\prime \prime} \mathrm{S}, 47^{\circ} 54^{\prime} 49^{\prime \prime} \mathrm{O}\right)\end{array}$ & Matas de galerias \\
\hline & 485279 & $\begin{array}{c}\text { Mogi Guaçu - Parque } \\
\text { Municipal São Marcelo } \\
\left(22^{\circ} 21^{\prime} 48^{\prime \prime} \text { S, 46 } 58^{\circ} 34^{\prime \prime} \text { O) }\right.\end{array}$ & $\begin{array}{c}\text { Área de reflorestamento com } \\
\text { espécies nativas }\end{array}$ \\
\hline
\end{tabular}

* Instituto de Biociências da Universidade de São Paulo.

\subsection{Análise da cera cuticular}

A extração, análise do teor, da composição química e da morfologia das ceras epicuticulares foram realizadas como descrito na Introdução geral (ver Material e métodos - pag. 39-42). A partir dos dados obtidos do teor das ceras cuticulares e das classes dos compostos de cera (porcentagem relativa total de cada classe), os gráficos foram construídos por meio do software Graphpad Prism® versão 7.01.

\subsection{Análise de agrupamento}

Para verificar o quanto as amostras de L. flava são semelhantes entre si, os valores de teor total de cera, porcentagem relativa total de cada classe e porcentagem relativa de cada homólogo foram utilizados. Foram elaboradas três matrizes de dados: (a) uma utilizando os valores de teor total de cera e porcentagem relativa total de cada classe, (b) a segunda com os valores de teor total de cera e porcentagem relativa de cada homólogo e (c) a última, utilizando todas as variáveis, ou seja, teor total das ceras, porcentagem relativa total de cada classe e porcentagem relativa de cada homólogo. Para tanto, os valores das variáveis foram transformados em uma mesma unidade de medida de distância. Esses dados padronizados foram submetidos a uma análise quantitativa de similaridade, empregando-se o índice de Distância Euclidiana. A matriz de similaridade obtida foi submetida a análise de agrupamento empregando-se o método de UPGMA 
(unweighted pair-group method using arithmetic averages). Essas análises foram realizadas com auxílio do software FITOPAC ${ }^{\circledR}$ versão 2.1.

\section{Resultados}

\subsection{Teor de cera cuticular}

O conteúdo de cera obtido dos gametófitos de L. flava coletados em São Paulo, Itirapina e Mogi Guaçu correspondeu a $1 \mu \mathrm{g} / \mathrm{cm}^{2}, 0,4 \mu \mathrm{g} / \mathrm{cm}^{2}$ e $0,2 \mu \mathrm{g} / \mathrm{cm}^{2}$, respectivamente (Fig. 1).

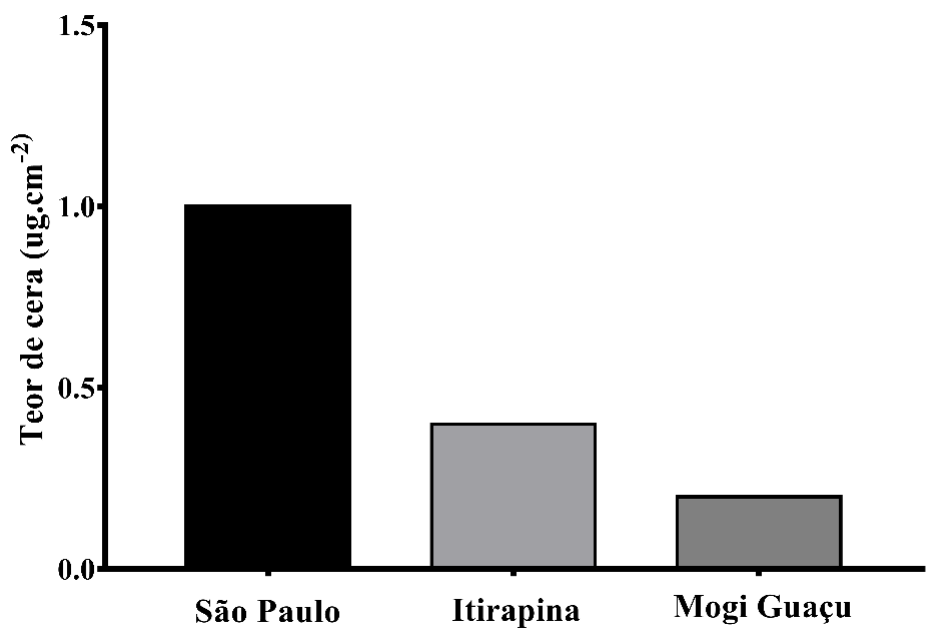

Fig. 1. Teor de cera cuticular dos gametófitos de Lejeunea flava (Lejeuneaceae) coletados em três regiões distintas do estado de São Paulo.

\subsection{Análise da composição química da cera cuticular}

As principais classes de cera cuticular encontradas no gametófito de L. flava foram os ácidos graxos, álcoois primários e cetonas. Nas três amostras de L. flava os ácidos graxos foram a classe majoritária, correspondendo a cerca de $40 \%$ das ceras. Os álcoois primários representaram 21\% na amostra de São Paulo, 23\% na de Mogi Guaçu e 26\% na de Itirapina. As cetonas foram identificadas em maior proporção na amostra de L. flava de São Paulo correspondendo a 20\%, seguida da amostra de Mogi Guaçu com 10\% e, em menor proporção, na amostra de Itirapina com 7\% (Fig. 2). Os alcanos foram detectados somente nas amostras de Itirapina (8\%) e Mogi Guaçu (3\%). Nessa última também foi verificado a presença de um diácido (ácido nonanodioico - 2\%) (Fig. 2). 


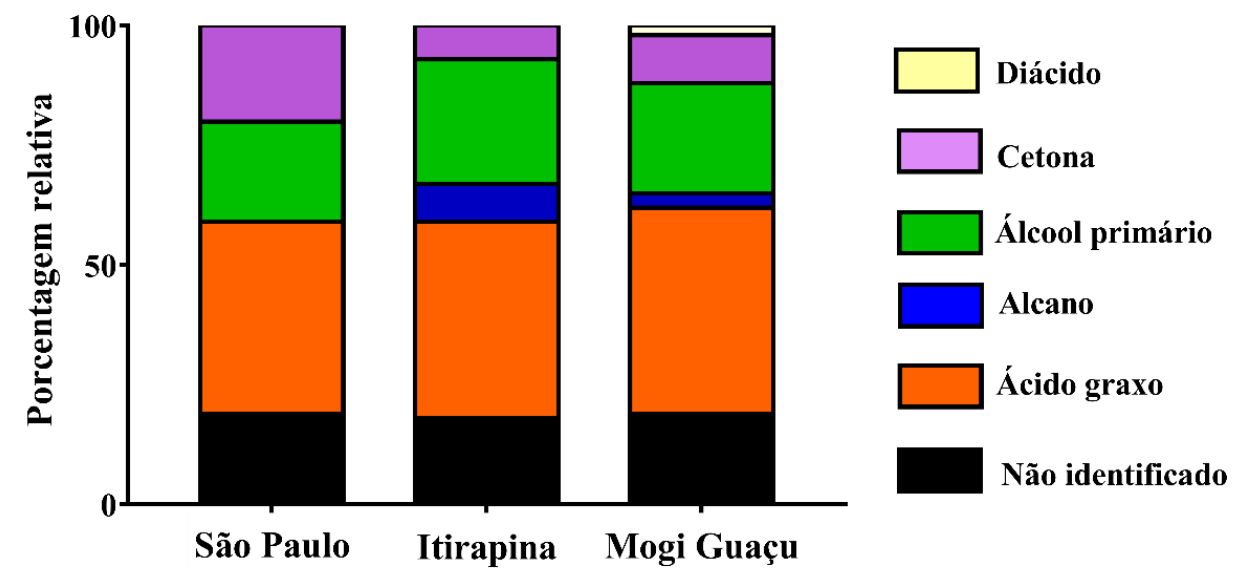

Fig. 2. Composição química da cera cuticular do gametófito de Lejeunea flava (Lejeuneaceae) coletados em três regiões distintas do estado de São Paulo.

A composição de homólogos das classes das ceras cuticulares dos gametófitos das amostras de L. flava pode ser vista na Tabela 2. Em relação aos homólogos de ácidos graxos, compostos variando de C14 (tetradecanoico) à C22 (docosanoico) foram encontrados no gametófito das diferentes localidades. Nas amostras de São Paulo e Mogi Guaçu o componente majoritário foi o C22 com $14 \%$ e 15,2\%, respectivamente, e na de Itirapina o constituinte dominante foi o C16 (ácido hexadecanoico) com 30\%. Álcoois primários de cadeia longa variando de C21 (heneicosanol) à C28 (octacosanol) foram verificados na amostra de L. flava de São Paulo, sendo o homólogo C24 (tetracosanol) predominante com 5,1\%. Na amostra de Itirapina foram observados os homólogos de álcoois primários de cadeia curta variando de C16 (hexadecanol) à C25 (pentacosanol), com o C18 (ocatadecanol) como componente principal com 6,7\%. Por outro lado, na amostra de Mogi Guaçu foram identificados os constituintes C20 (eicosanol) com 17,1\%, C23 (tricosanol) com 2,3\% e o álcool C26 (hexacosanol) com 3,4\%. As cetonas nonadecan-2-ona (C19), heneicosan-2-ona (C21) e tricosan-2-ona (C23) com 3,1\%, 14\% e 3,3\%, respectivamente, foram detectadas nas amostras de L. flava de São Paulo. Os homólogos C19 (5,2\%) e C23 (1,9\%) foram encontrados na amostra de Itirapina, enquanto apenas a cetona C21 com 9,8\% foi identificada na de Mogi Guaçu. Alcanos com série homóloga de C26 (hexacosano) à C29 (nonacosano) foram detectados na amostra de Itirapina, quase todos na mesma proporção. Na amostra de Mogi Guaçu somente o componente C29 foi identificado com 2,5\% (Tabela 2). 
Tabela 2. Porcentagens relativas dos homólogos de classes de cera identificados no gametófito de Lejeunea flava (Lejeuneaceae).

\begin{tabular}{|c|c|c|c|c|c|c|c|c|c|c|c|c|c|c|c|c|c|c|c|c|c|c|c|c|}
\hline \multirow{2}{*}{ Localidade } & \multicolumn{5}{|c|}{ Ácido graxo } & \multicolumn{4}{|c|}{ Alcano } & \multicolumn{11}{|c|}{ Álcool primário } & \multicolumn{3}{|c|}{ Cetona } & \multirow{2}{*}{ 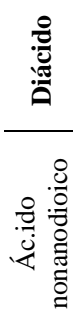 } \\
\hline & $\underset{U}{\Xi}$ & $\frac{0}{U}$ & $\stackrel{\infty}{U}$ & లి & ปี & ల̃ & $\widehat{\widetilde{U}}$ & లి & ঠे & $\stackrel{0}{u}$ & $\frac{\infty}{\widetilde{u}}$ & లి & $\overrightarrow{\mathrm{U}}$ & ปี & $\tilde{U}$ & $\stackrel{\Xi}{U}$ & $\stackrel{\tilde{U}}{\imath}$ & Uี & $\hat{\Xi}$ & $\stackrel{\sim}{ు}$ & $\stackrel{\vec{U}}{ }$ & $\overrightarrow{\widetilde{U}}$ & లి & \\
\hline São Paulo & & 4,3 & 2,6 & 12 & 14 & & & & & & & & 1,4 & & 1,3 & 5,1 & 1,5 & 3,8 & 2,5 & 4 & 3,1 & 14 & 3,3 & - \\
\hline Itirapina & 2,2 & 30 & 9,6 & & & 1,9 & 2 & 1,9 & 1,9 & 4,6 & 6,7 & 6,5 & & 3,6 & 2,4 & & 2 & & & & 5,2 & & 1,9 & \\
\hline Mogi Guaçu & 8,5 & 7,2 & 1,6 & 9,9 & 15,2 & & & & 2,5 & & & 17,1 & & & 2,3 & & & 3,4 & & & & 9,8 & & 2 \\
\hline
\end{tabular}

(-) Refere-se a substância presente em quantidades abaixo de 1\%. Espaço em branco significa que o homólogo não foi detectado. Valor em negrito corresponde ao composto com a maior porcentagem relativa de cada classe. 


\subsection{Análise de agrupamento}

Nos dendrogramas gerados a partir da análise de agrupamento (UPGMA) (Fig. 3), considerando somente os dados de teor total da cera e a porcentagem total de cada classe, há a formação de um grupo entre L. flava de Itirapina e Mogi Guaçu, ficando a amostra de São Paulo mais distinta (Fig. 3A). Porém, quando se considera a porcentagem relativa dos homólogos, independente do teor total e das classes, não temos a mesma relação, sendo o grupo formado entre as amostras de São Paulo e Mogi Guaçu, com a amostra de Itirapina mais distinta (Fig. 3B e 3C). De qualquer modo, cabe salientar que os valores de dissimilaridade entre as amostras são altos com qualquer conjunto de dados. 

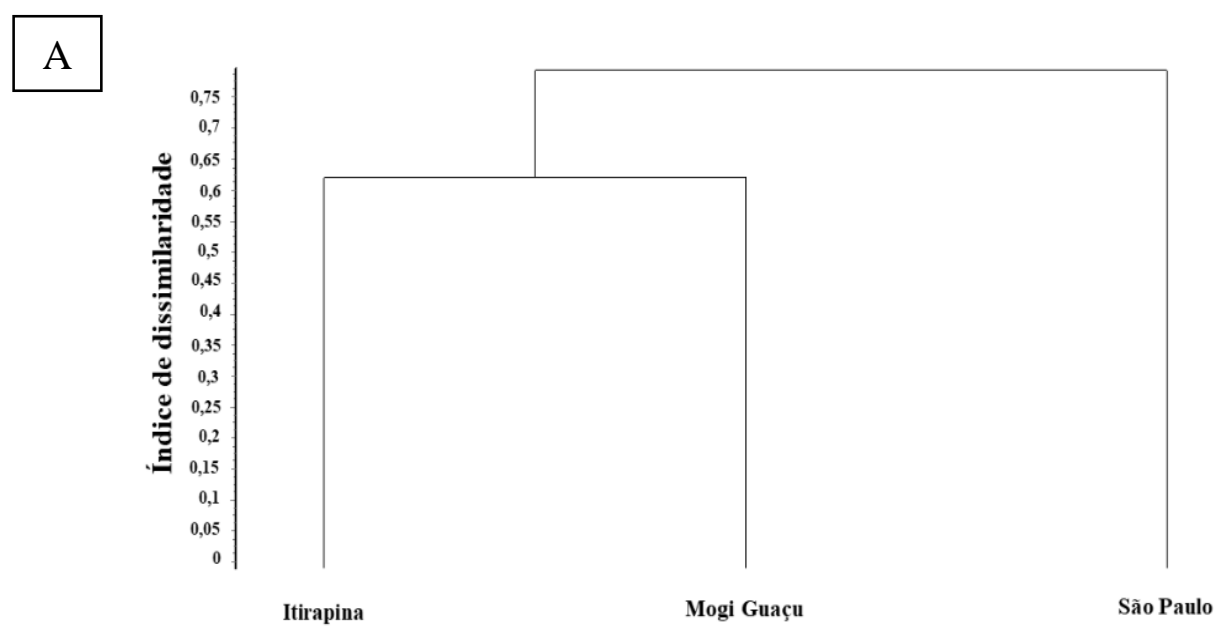

\section{$\mathrm{B}$}
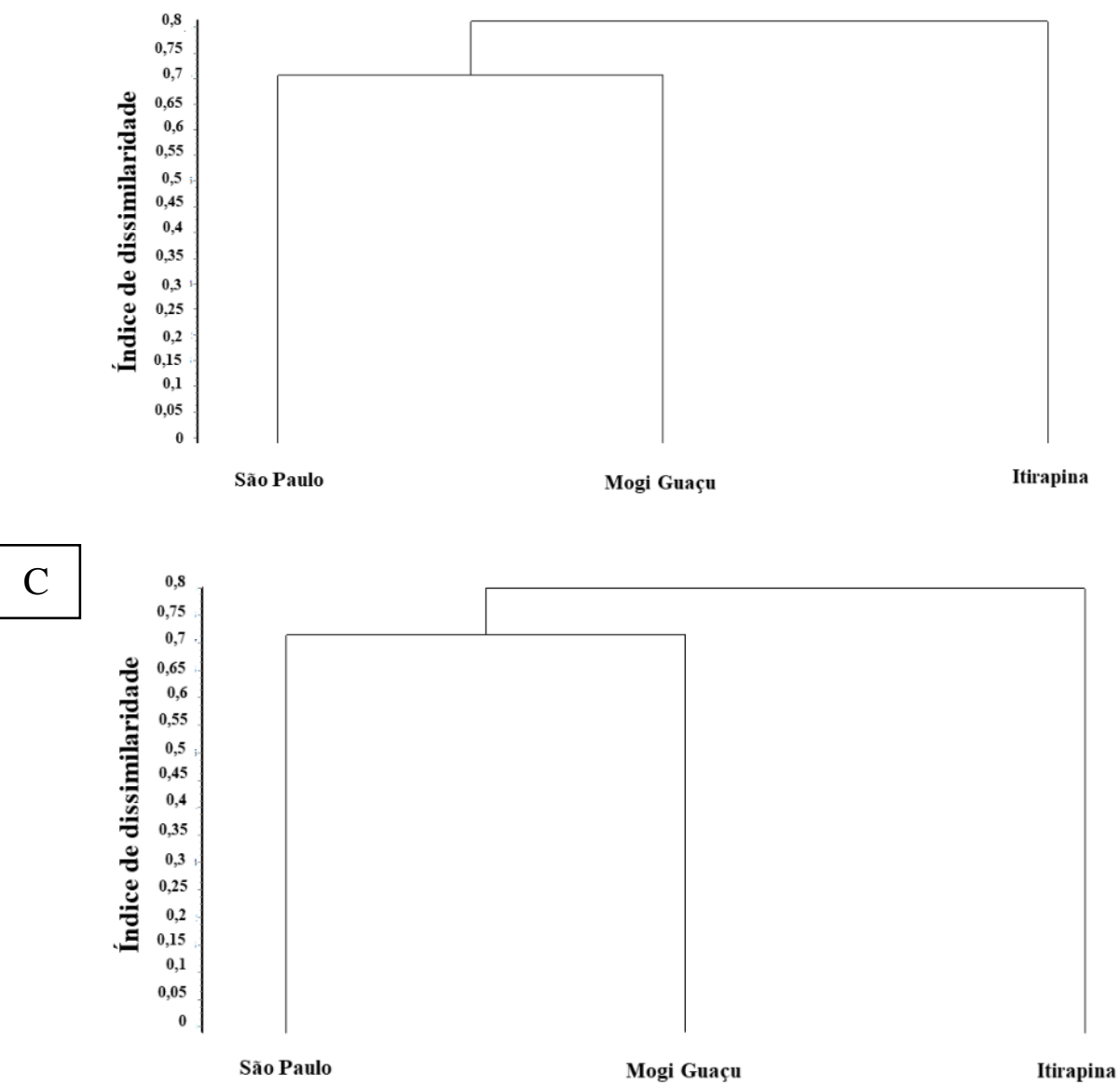

Fig. 3. Análise de similaridade entre as amostras de L. flava provenientes de três localidades do estado de São Paulo. Os dados foram submetidos a análise utilizando o índice de Distância Euclidiana e os dendrogramas gerados pelo método de agrupamento por UPGMA. A: Dendrograma gerado a partir do teor e da porcentagem relativa total das classes de cera. Índice de correlação cofenética = 0,9935. B: Dendrograma obtido a partir do teor e da porcentagem relativa dos homólogos das classes de cera. Índice de correlação 
cofenética $=0,7785 . \mathrm{C}$ : Dendrograma resultante da aplicação de todas as variáveis de cera das amostras (teor + porcentagem relativa total das classes + porcentagem relativa dos homólogos). Índice de correlação cofenética = 0,6926.

\subsection{Análise por microscopia eletrônica de varredura (MEV)}

A partir da análise por MEV não foi verificada diferença na morfologia das ceras das amostras de L. flava das três localidades. As ceras do gametófito apresentam ornamentos do tipo plaquetas em toda a superfície (Fig. 4).

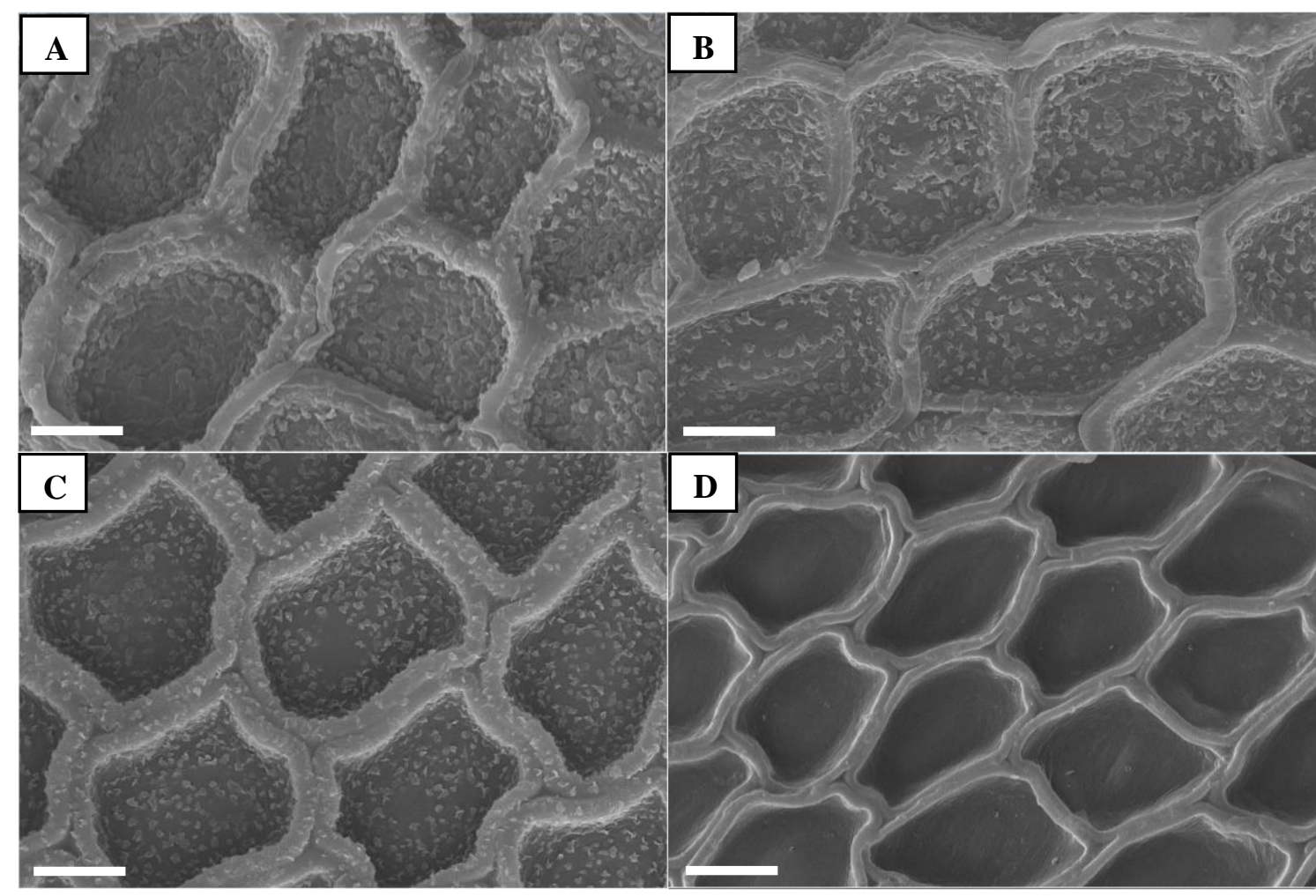

Fig. 4. Caracterização da micromorfologia das ceras epicuticulares por microscopia eletrônica de varredura (MEV) do gametófito de L. flava (Lejeuneaceae). A: São Paulo, B: Itirapina, C: Mogi Guaçu e D: Mogi Guaçu - sem cera. Escala fotos: $10 \mu \mathrm{m}$.

\section{Discussão}

De acordo com Baker (1982), o conteúdo de cera pode variar, entre outros pontos, conforme o grupo vegetal, de acordo com fatores genéticos inerentes aos táxons e em diferentes órgãos vegetais. Além disso, fatores bióticos e abióticos podem influenciar as ceras cuticulares, inclusive no teor (Bianchi \& Bianchi, 1990). O aumento na quantidade de cera foliar minimiza a deposição de água na superfície, reduzindo a retenção de poeira e poluentes do ar na planta (Kerstiens, 1996; Barthlott \& Neinhuis, 1997). Neste estudo, verificamos que o teor de cera da amostra de L. flava de São Paulo, coletada em área 
urbana, foi maior em relação as amostras oriundas das outras localidades (Fig. 1). Segundo Bordin (2009), L. flava é um táxon considerado bem adaptado a áreas urbanas, apresentando diversas estratégias morfológicas e reprodutivas que conferem maior proteção contra dessecação e injúrias mecânicas, além de rápida propagação, permitindo a sua sobrevivência em ambientes sob forte influência de atividades humanas. Dessa forma, o maior teor de ceras na amostra de São Paulo poderia refletir a plasticidade adaptativa desse táxon às condições ambientais onde foi encontrada. Entretanto, essa hipótese necessita de investigações mais aprofundadas para ser confirmada.

Em amostras foliares de Cryptomeria japonica (L. f.) D. Don (Cupressaceae) de áreas urbanas foram constatados o dobro de teor de ceras cuticulares em relação ao valor obtido de indivíduos coletados de regiões montanhosas, sendo esse maior teor de ceras sugerido como uma resposta adaptativa ao ambiente com poluentes atmosféricos (Sase et al., 1998). Segundo Riederer \& Schreiber (2001), fatores abióticos como luminosidade, temperatura, umidade, poluentes e altitude podem estar relacionados com aumento da quantidade de cera.

Como já mencionado anteriormente, há uma grande lacuna sobre dados de composição química das ceras cuticulares em briófitas. Ácidos graxos, álcoois primários, detectadas em todas as amostras de L. flava (Fig. 2) são reportadas como classes comuns de componentes presentes nas ceras cuticulares de plantas vasculares. Já as cetonas, também bastante comuns em L. flava, são menos comuns em plantas vasculares (Riederer \& Schreiber, 2001; Kunst \& Samuels, 2003; 2009; Koch et al., 2009). Nos gametófitos do "musgo do deserto" Syntrichia caninervis Mitt. (= Tortula desertorum Broth.) (Pottiaceae), os ácidos graxos também foram a classe predominante, correspondendo a $72 \%$ da composição das ceras (Xu et al., 2009). Nessa espécie, Xu et al. (2009) verificaram homólogos de ácidos graxos variando entre C16-C28. Os ácidos graxos também foram a principal classe encontrada no gametófito de espécies de hepáticas de Plagiochilaceae. Em Plagiochila tabinensis Steph. essa classe representou $25 \%$ da composição química das ceras, com homólogos variando de C14 à C24, sendo o composto C16 (10\%) o ácido graxo majoritário (Heinrichs et al., 2000). Já em Plagiochila atlantida (= P. heterofolia Steph) foram encontrados ácidos graxos variando entre C16-C26, com o componente C18 correspondendo a 61\% nessa fração (Heinrichs \& Rycroft, 2001). Características semelhantes de amplitude na composição química dos ácidos graxos 
foram verificadas entre as amostras de L. flava (Tabela 2). Entretanto, em duas amostras, São Paulo e Mogi-Guaçu, o homólogo C22 foi o majoritário.

Por outro lado, no musgo Physcomitrela patens (Hedw.) Bruch \& Schimp. (Funariaceae), os álcoois primários foram a classe mais abundante da cera do gametófito, apresentando série homologa de C21 à C34, com o álcool primário C26 como principal constituinte (Buda et al., 2013). Nos gametófitos dos musgos Pogonatum aloides (Hedw.) P. Beauv. e Pogonatum urnigerum (Hedw.) P. Beauv. (Polytrichaceae), o constituinte C26 também foi identificado como o principal homólogo, correspondendo à $37 \%$ da fração dos álcoois (Haas, 1982). No musgo Andreaea rupestris Hedw. (Andreaeaceae), o composto C28 representou 47\% dessa classe (Haas, 1982). Para as amostras de L. flava, os álcoois primários foram encontrados variando de C16-C28, sendo os homólogos de cadeia mais longa verificados principalmente na amostra de São Paulo. Além disso, cada amostra analisada no presente estudo apresentou um homólogo diferente como majoritário nessa classe (Tabela 2). Com base na literatura encontrada, o presente estudo, incluindo os dados apresentados no Capítulo 1 (Figura 2A - pag. 64), traz o primeiro relato de álcoois primários em ceras de hepáticas.

As cetonas, comuns nas amostras de L. flava, podem ocorrer de forma restrita em alguns táxons de plantas vasculares, sendo comumente encontradas com cadeia carbônica variando entre C21 à C35 (Riederer \& Schreiber, 2001; Shepherd \& Griffiths, 2006; Holloway \& Jeffree, 2017). Neste trabalho foram detectados três homólogos, sendo o heneicosan-2-ona (C21) a principal cetona nos gametófitos provenientes de São Paulo e Mogi Guaçu (Tabela 2). Nas poucas espécies de hepáticas quimicamente investigadas, cetonas também não haviam sido descritas como parte da composição das ceras cuticulares em Marchantiophyta, exceto para Lejeunea laetevirens e Bazzania hookeri (Lindenb.) Trevis (Lepidoziaceae) (Capítulo 1 - Figura 2A - pag. 64).

Os alcanos foram identificados em menor porcentagem entre as amostras de $L$. flava (Fig. 2). Essa classe é citada como predominante em diversas espécies de plantas vasculares (Jetter et al., 2000; Kunst \& Samuels, 2003; 2009), sobretudo aquelas de ambientes com altas temperaturas e restrição hídrica, devido ao seu comprovado papel no controle da transpiração foliar (Oliveira et al., 2003; Jetter et al., 2006). No entanto, de acordo com Barthlott et al. (2017), os alcanos também podem estar presentes em menores quantidades nas ceras vegetais. No gametófito do musgo Funaria hygrometrica Hedw. 
(Funariaceae), por exemplo, os alcanos foram observados em baixas porcentagens apenas na cera do esporófito (Busta et al., 2016).

Alcanos com cadeia carbônica longa variando de C22-C36 foram detectados nas ceras do gametófito do "musgo do deserto" S. caninervis (= Tortula desertorum) (Pottiaceae) (Xu et al., 2009). Perfil químico semelhante foi encontrado nos gametófitos das hepáticas Calypogeia meylanii H. Buch (Calypogeiaceae), Gymnocolea inflata (Huds.) Dumort. (Anastrophyllaceae) Jungermannia sphaerocarpa Hook. (Jungermanniaceae), Mylia taylorii (Hook.) Mitt. (Myliaceae) e Pellia fabbroniana Raddi (Pelliaceae), com alcanos variando de C15 à C35 (Benešová et al., 1972). Neste estudo, a série homóloga C26-C29 de alcanos foi detectada especialmente na amostra de L. flava oriunda de Itirapina, sendo o composto C27 o majoritário. Já na amostra de Mogi Guaçu o constituinte C29 foi o único homólogo de alcano identificado (Tabela 2). Assim como nas ceras das plantas vasculares, nas espécies de briófitas sensu lato os componentes C27 e C29 são bastante comuns na fração de alcanos (Benešová et al., 1972; Caldicott \& Eglinton, 1976; Samuels et al., 2008; Koch et al., 2009; Bush \& McInerney, 2013). Entretanto, Caldicott \& Eglinton (1976) e Bush \& McInerney (2013) apontam o homólogo C25 como sendo bastante comuns em briófitas, porém esse componente não foi detectado na fração de alcanos das amostras analisadas (Tabela 2).

$\mathrm{Na}$ amostra de L. flava de Itirapina foi verificado o ácido nonanodioico (diácido) em baixas proporções (Fig. 2) (Tabela 2). Até onde sabemos, este é o primeiro relato desse componente em briófitas. A presença de diácidos nas ceras vegetais não é comum e dados de sua ocorrência em plantas vasculares são limitados (Roma, 2018).

A análise de agrupamento realizada mostra uma discrepância entre as amostras mais similares, dependendo dos dados utilizados. De qualquer modo, como já mencionado, os valores de dissimilaridade obtidos são muito altos, sempre acima de $50 \%$ (Fig. 3). Ao se considerar somente os valores de teor total de ceras e das classes, a maior separação da amostra de São Paulo pode ser explicada devido ao teor de cera maior (Fig. 1) e completa ausência de alcanos (Fig. 2). Ao se aumentar o número de variáveis, considerando a porcentagem relativa dos homólogos, a amostra de Itirapina aparece como mais distinta das outras duas (Fig. 3B e C). A ocorrência exclusiva de alguns homólogos de alcanos e de álcoois primários (Tabela 2) pode ser parte da explicação para esse 
agrupamento. Entretanto, é necessário ressaltar que esses dados são bastante preliminares considerando a amostragem reduzida de cada localidade.

Diferentemente da composição química, a micromorfologia das ceras não apresentou variação entre as amostras de L. flava provenientes de diferentes localidades (Fig. 4). Os ornamentos cristaloides sobre a camada cuticular podem estar intimamente relacionados com os componentes das ceras cuticulares (Jeffree et al., 1975; Koch \& Ensikat, 2008; Barthlott et al., 2017). Barthlott e colaboradores (2017) descreveram que a presença de cristais de cera em traqueófitas encontra-se geralmente associada a aldeídos, cetonas, álcoois primários e secundários. A presença de mais de um desses compostos ou até mesmo a predominância de algum desses constituintes nas ceras podem determinar a aparência da superfície cuticular (Jeffree, 2006; Koch et al., 2006; Koch et al., 2009; Barthlott et al., 2017). Em L. flava os álcoois primários e cetonas encontrados nas ceras podem estar correlacionados com a micromorfologia do tipo plaqueta detectada sobre a superfície dos gametófitos analisados (Fig. 4A, B e C). Plaquetas de cera já haviam sido reportadas em representantes de Lejeuneaceae (Heinrichs \& Reiner-Drehwald, 2012) e nos gametófitos de várias espécies de Plagiochilaceae (Heinrichs et al., 2000; Heinrichs \& Rycroft, 2001).

De acordo com Shepherd \& Griffiths (2006), a microestrutura cristalina da cera pode modular a refletância da luz, e deste modo, auxiliar na regulação da temperatura reduzindo a transpiração não estomática na superfície das plantas. Ainda segundo Maarseveen \& Jetter (2009), a composição química e morfologia das ceras são essenciais para a o entendimento de como ocorre a interação da planta com o meio biótico e abiótico e, consecutivamente, sua fisiologia específica e função ecológica.

\section{Conclusões}

Como já apontado, esses são os primeiros dados sobre a composição química das ceras cuticulares para espécies de Lejeuneaceae. Assim, consideramos que os dados deste estudo ampliam nosso entendimento sobre a química da cera para a divisão Marchantiophyta, incluindo alguns aspectos preliminares relacionados a variação intraespecífica em L. flava. As características relacionadas ao teor, composição química e micromorfologia das ceras cuticulares descritas por este estudo podem, em conjunto com características morfológicas e reprodutivas inerentes à L. flava, já reforçadas por outros autores, contribuir para a adaptação dessa hepática à diferentes ambientes, com 
fitofisionomias peculiares e sobre a influência de diferentes fatores abióticos. Portanto, estes dados também podem auxiliar na compreensão da ampla diversidade de espécies com notória plasticidade fenotípica em Lejeuneaceae.

\section{Financiamento}

Agrademos à Coordenação de Aperfeiçoamento de Pessoal de Nível Superior Brasil (CAPES) - Código Financeiro 001 pelo financiamento deste trabalho.

\section{Agradecimentos}

Agradecemos ao professor Dr. Denilson F. Peralta do Núcleo de Pesquisa em Briologia do Instituto de Botânica de São Paulo - IBt/SP pela colaboração nas coletas e identificações do material vegetal estudado, ao doutorando Lucas P. Roma pelo auxílio nas identificações das substâncias, à doutoranda Juliana C. S. Carvalho pela ajuda com a análise de agrupamento, às técnicas Mourisa Ferreira e Aline Bertinatto Cruz pela assistência durante as análises por CG-EM, ao técnico Irwandro Roberto Pires pela assistência na análise do material através de MEV.

\section{Referências}

Ahamad, H.M., Mahmood-Ur-Rahman, Ali, Q. \& Awan, S.I. 2015. Plant cuticular waxes: a review on functions, composition, biosyntheses mechanism and transportation. Life Science Journal, 12, 60-67.

Baker, E.A. 1982. Chemistry and morphology of plant epicuticular waxes. In the Plant Cuticle, Linnean Society Symposium Series (eds D.F. Cutler, K.L. Alvins \& C.E. Price). Academic Press, London. 10, 139-165.

Bargel, H., Koch, K., Cerman, Z. \& Neinhuis, C. 2006. Structure - function relationships of the plant cuticle and cuticular waxes - a smart material? functional Plant Biology, 33, 893-910.

Barthlott, W. \& Neinhuis, C. 1997. Purity of the sacred lotus or escape from contamination in biological surfaces. Planta, 202, 1-8.

Barthlott, W., Mail, M., Bhushan, B. \& Koch, K. 2017. Plant surfaces: structures and functions for biomimetic innovations. Nano-Micro Letters, 9, 23. 
Bechteler, J., Lee, G.E., Schäfer-Verwimp, A., Pocs, T., Peralta, D.F., Renner, M.A.M., Schneider H. \& Heinrichs, J. 2016. Towards a monophyletic classification of Lejeuneaceae IV: reinstatement of Allorgella, transfer of Microlejeunea aphanella to Vitalianthus and refinements of the subtribal classification. Plant Systematics and Evolution, 302, 187-201.

Benešová, V., Streibl, M., Châu, H.M., Beneš, I. \& Konečný, K. 1972. Plant substances. On natural waxes. Higher alkanes and wax esters of some liverworts. Collection of Czechoslovak Chemical Communications, 37, 3090-3094.

Bianchi, A. \& Bianchi, G. 1990. Surface lipid composition of $\mathrm{C}_{3}$ and $\mathrm{C}_{4}$ plants. Biochemical Systematics Ecology, 18, 533-537.

Bordin, J. 2009. Briófitas. Trabalho de estágio de docência. Núcleo de pesquisa em briologia do Instituto de Botânica de São Paulo - IBt/SP. pp.20. http://www.biodiversidade.pgibt.ibot.sp.gov.br/Web/pdf/Briofitas_Jucara_Bordi n.pdf (Acessado em março 2019).

Buda, G.J., Barnes, W.J., Fich, E.A., Park, S., Yeats, T.H., Zhao, L., Domozych, D.S. \& Rose, J.K.C. 2013. An ATP binding cassette transporter is required for cuticular wax deposition and desiccation tolerance in the moss Physcomitrella patens. The Plant Cell, 25, 4000-4013.

Bush, R.T. \& McInerney, F.R. 2013. Leaf was n-alkane distributions in and across modern plants: Implications for paleoecology and chemotaxonomy. Geochimica et Cosmochimica Acta, 117, 161-179.

Busta, L., Budke, J. M. \& Jetter, R. 2016. The moss Funaria hygrometrica has cuticular wax similar to vascular plants, with distinct composition on leafy gametophyte, calyptra, and sporophyte capsule surfaces. Annals of Botany, 118, 511-522.

Caldicott, A.B. \& Eglinton, G. 1976. Cutin acids from bryophytes: an $\omega-1$ hydroxy alkanoic acid in two liverwort species. Phytochemistry, 15, 1139-1143.

Carmo, D.M. \& Peralta, D.F. 2017. Morpho-ecological characterization and composition of rocky fields bryophytes in Brazilian Cerrado. Boletim de La Sociedad Argentina de Botanica, 52, 265-276.

Costa, D.P. \& Peralta, D.F. 2015. Bryophytes diversity in Brazil. Rodriguésia, 66. 
Dodd, R.S. \& Poveda, M.M. 2003. Environmental gradientes and population divergence contribute to variation in cuticular wax composition in Juniperus communis. Biochemical Systematics and Ecology, 31, 1257-1270.

Fukuda, S., Satoh, A., Kasahara, H., Matsuyama, H. \& Takeuchi, Y. 2008. Effects of ultravioleta-B irradiation on the cuticular wax of cucumber (Cucumis sativus) cotyledons. Journal Plant Research, 121, 179-189.

Gradstein, S.R. 1997. The taxonomic diversity of epiphyllous bryophytes. Abstracta Botanica, 21, 15-19.

Gradstein, S.R. \& Costa, D.P. 2003. The hepaticae and anthocerotae of Brazil. Memoirs of The New York Botanical Garden, 87, 1-318.

Gradstein, S.R. 2013. A classification of Lejeuneaceae (Marchantiophyta) based on molecular and morphological evidence. Phytotaxa, 100, 6-20.

Haas, K. 1982. Surface wax of Andreaea and Pogonatum species. Phytochemistry, 21, 657-659.

Hair, J.F., Black, C.W., Babin, J.B., Anderson, E.R. \& Tatham, L.R. Análise multivariada de dados. 2005. Porto Alegre: Bookman (6º ed.). 600 p.

Heinrichs, J., Anton, H., Gradstein, S.R., Mues, R. \& Holz, I. 2000. Surface wax, a new taxonomic feature in Plagiochilaceae. Plant Systematics and Evolution, 225, 225233.

Heinrichs, J. \& Rycroft, D.S. 2001. Leaf surface waxes and lipophilic secondary metabolites place the endemic European liverwort Plagiochila atlantica F.Rose in the Neotropical Plagiochila sect. Bursatae Carl. Cryptogamie Bryologie, 22, 95-103.

Heinrichs, J. \& Reiner-Drehwald, E. 2012. Surface wax in Dinckleria, Lejeunea and Mytilopsis (Jungermanniidae). Cryptogamie Bryologie, 33, 81-86.

Heredia, A. 2003. Biophysical and biochemical characteristics of cutin, a plant barrier biopolymer. Biochimica et Biophysica Acta (BBA)-General Subjects, 1620, 1-7.

Holloway, P.J. \& Jeffree, C.E. 2017. Epicuticular waxes. Encyclopedia of Applied Plant Sciences, 2, 374- 386. 
Ilkiu-Borges, A.L. \& Lisboa, R.C.L. 2002. Os gêneros Lejeunea e Microlejeunea (Lejeuneaceae) na estação científica Ferreira Penna, estado do Pará, Brasil, e novas ocorrências. Acta Amazonica, 32, 541-553.

Ilkiu-Borges, A.L. \& Oliveira-da-Silva, F.R. 2018. Flora das cangas da Serra dos Carajás, Pará: Lejeuneaceae. Rodriguésia, 69, 989-1012.

Jeffree, C.E., Baker, E.A. \& Holloway, P.J. 1975. Ultrastructure and recrystallization of plant epicuticular waxes. New Phytologist, 75, 539-549.

Jeffree, C.E. 2006. The fine structure of the plant cuticle. In: M. Riederer \& C. Müller (Eds.), Annual Plant Reviews, volume 23: Biology of the Plant Cuticle. Blackwell publishing Ltd, 23, 11-110.

Jetter R., Schäffer S. \& Riederer M. 2000. Leaf cuticular waxes are arranged in chemically and mechanically distinct layers: evidence from Prunus laurocerasus L. Plant, Cell and Environment, 2000, 619-628.

Jetter, R. \& Schäffer, S. 2001. Chemical composition of the Prunus laurocerasus leaf surface. Dynamic changes of the epicuticular wax film during leaf development. Plant Physiology, 126, 1-13.

Jetter, R., Kunst, L. \& Samuels, A.L. 2006. Composition of plant cuticular waxes. In: M. Riederer \& C. Müller (Eds.), Annual Plant Reviews, volume 23: Biology of the Plant Cuticle. Blackwell publishing Ltd, 145-181.

Kerstiens, G. 1996. Cuticular water permeability and its physiological significance. Journal of Experimental Botany, 47, 1813-1832.

Koch, K., Hartmann, K.D, Schreiber, L., Barthlott, W. \& Neinhuis, C. 2006. Influences of air humidity during the cultivation of plants on wax chemical composition, morphology and leaf surface wettability, Environmental and Experimental Botany, 56, 1-9.

Koch, K., Bhushan, B. \& Barthlott, W. 2009. Multifunctional surface structures of plants: an inspiration for biomimetics. Progress in Materials Science, 54, 137-178.

Koch, K. \& Ensikat, H.J. 2008. The hydrophobic coatings of plant surfaces: epicuticular wax crystals and their morphologies, crystallinity and molecular self-assembly. Micron, 39, 759-772. 
Kolattukudy, P.E. 2001. Polyesters in higher plants. In Advances in Biochemical Engineering/Biotechnology. (Ed. T Scheper). 4-49.

Kunst, L. \& Samuels, A.L. 2003. Biosynthesis and secretion of plant cuticular wax. Progress in Lipid Research, 42, 51-80.

Kunst, L. \& Samuels, A.L. 2009. Plant cuticles shine: advances in wax biosynthesis and export. Current Opinion in Plant Biology, 12, 721-727.

Maarseveen, V.C. \& Jetter, R. 2009. Composition of the epicuticular and intracuticular wax layers on Kalanchoe daigremontiana (Hamet et Perr. de la Bathie) leaves. Phytochemistry, 70, 899-906.

Oliveira, A.F.M., Meirelles, S.T. \& Salatino, A. 2003. Epicuticular waxes from caatinga and cerrado species and their efficiency against water loss. Anais da Academia Brasileira de Ciências, 75, 431-439.

Reina-Pinto, J.J. \& Yephremov, A. 2009. Surface lipids and plant defenses. Plant Physiology and Biochemistry, 47, 540-549.

Riederer M. \& Schreiber L. 2001. Protecting against water loss: analysis of the barrier properties of plant cuticles. Journal of Experimental Botany 52, 2023-2032.

Roma, L.P. 2018. Composição química e morfologia das ceras cuticulares foliares de diferentes espécies de Simaba Aubl. Sensu stricto e Homalolepis Turcz. (Simaroubaceae). Tese de Mestrado. Universidade de São Paulo, Brasil, pp.177.

Samuels, L., Kunst, L. \& Jetter, R. 2008. Sealing plant surfaces: Cuticular wax formation by epidermal cells. Annual Review of Plant Biology, 59, 683-707.

Sase, H., Takamatsu, T., Yoshida, T. \& Inubushi, K. 1998. Changes in properties of epicuticular wax and the related water loss in Japanese cedar (Cryptomeria japonica) affected by anthropogenic environmental factors. Canadian Journal of Forest Research, 28, 546-556.

Shepherd, T., Robertson, G.W., Griffiths, D.W., Birch, A.N.E. \& Duncan, G. 1995. Effects of environment on the composition of epicuticular wax from kale and swede. Phytochemistry, 40, 407-417. 
Shepherd, T. \& Griffiths, D.W. 2006. The effects of stress on plant cuticular waxes. New Phytology, 171, 469-499.

Sonnleitner, M., Dullinger, S., Wanek, W. \& Zechmeister, H. 2009. Microclimatic patterns correlate with the distribution of epiphyllous bryophytes in a tropical lowland rain forest in Costa Rica. Journal of Tropical Ecology, 25, 321-330.

Valentim J. L. 2000. Ecologia numérica: uma introdução à análise multivariada de dados ecológicos. Rio de janeiro, Interciência, 154p.

Xu, S.J., Jiang, P.A., Wang, Z.W. \& Wang, Y. 2009. Crystal structures and chemical composition of leaf surface wax depositions on the desert moss Syntrichia caninervis. Biochemical Systematics and Ecology, 37, 723-730. 


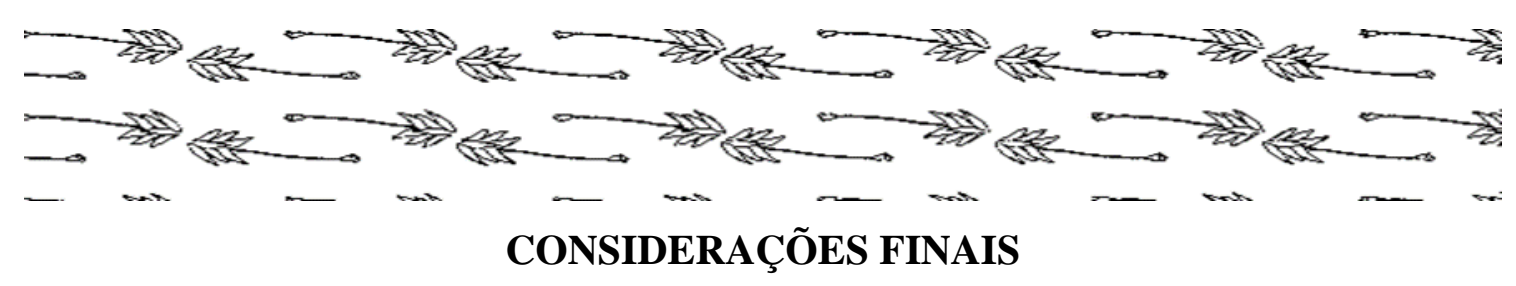

A cutícula é uma das principais características estruturais que foi essencial para o sucesso da colonização do ambiente terrestre pelas primeiras embriófitas. O conjunto dos seus principais componentes hidrofóbicos, cutina e ceras cuticulares, contribuiu para o estabelecimento, a evolução e a diversificação das plantas nesse novo ambiente.

A investigação das ceras cuticulares em espécies de musgos e hepáticas permitiu detectar uma notável diversidade morfológica e química. No geral, a morfologia do tipo filme foi a predominante. O conteúdo de cera foi maior para hepáticas. Em ambas as divisões foi possível detectar uma ampla diversidade de componentes de cera, sendo os ácidos graxos e alcanos as classes mais comuns em musgos e hepáticas. Diferenças quanti e qualitativas puderam ser observadas entre as fases do ciclo de vida das espécies de Polytrichaceae. O teor de cera obtido da caliptra foi igual ou maior quando comparado com os valores do gametófito e esporófito (seta e cápsula). Alcanos foram a classe majoritária no gametófito. Aldeídos e ésteres foram encontrados restritos ao esporófito. Já o nonacosan-10-ol foi o constituinte encontrado em maior proporção especialmente na caliptra. A morfologia do tipo filme também predominou entre as gerações de vida analisadas. Diferenças no perfil das ceras também foram verificadas em amostras de Lejeunea flava provenientes de diferentes localidades. Com base em uma análise preliminar, a hepática oriunda da área urbana mostrou maior diferença, quando considerado o conteúdo e as classes de cera, em relação as amostras de locais menos antropizados, supondo uma possível variação intraespecífica das ceras e influência de fatores ambientais. No entanto, não observou-se variação quanto a micromorfologia das ceras, sendo detectada a morfolofigia do tipo plaqueta em todas as amostras. Com isso, ampliamos o conhecimento sobre a química desse grupo de plantas e de diversas possibilidades de investigação afim de verificar plasticidade fenotípica, eficiência na colonização de ambientes hostis, resistência a diferentes fatores bióticos e abióticos, entre outros.

Apesar de não serem descritas substâncias novas associadas as ceras cuticulares, em geral, várias substâncias foram descritas pela primeira vez em briófitas sensu lato. Espera-se que os dados fornecidos por este estudo contribuam para um melhor 
entendimento da cutícula e de suas propriedades nas briófitas sensu lato ainda negligenciadas como objeto de investigação, sobretudo para a divisão Marchantiophyta. Além disso, ainda que comumente conhecidos em angiospermas, os dados de composição química deste estudo podem ampliar o nosso entendimento da evolução da cutícula e das vias biossintéticas nas embriófitas, presentes tanto no gametófito como no esporófito das linhagens basais de plantas terrestres. Acreditamos, também, que estudos com esta abordagem podem contribuir com a briologia de maneira geral, principalmente envolvendo espécies brasileiras. Por fim, esperamos que este estudo estimule mais trabalhos investigativos da diversidade química desse grupo. 


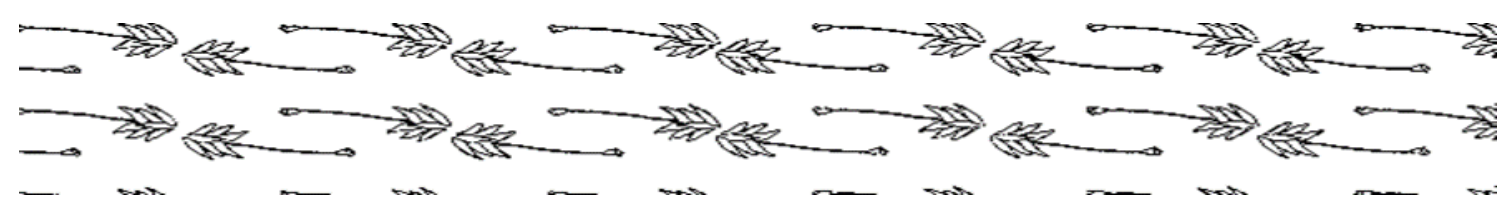

\section{RESUMO GERAL}

A transição das primeiras plantas para o ambiente terrestre ocorreu aproximadamente há 450 milhões de anos. O surgimento de uma camada extracelular lipofílica contínua recobrindo as partes aéreas das plantas, a cutícula vegetal, foi crucial para o sucesso evolutivo desse grupo, garantindo a relativa independência do habitat aquático. A cutícula é composta pela cutina a qual é envolvida pelas ceras cuticulares e desempenha um papel multifuncional nas plantas, sobretudo evitando a dessecação. As "briófitas" são consideradas as pioneiras na transição do ambiente aquático para o terrestre. Esse termo é utilizado para designar três divisões de plantas avasculares, criptógamas, com a geração gametofítica dominante: Marchantiophyta (hepáticas), Bryophyta (musgos) e Anthocerotophyta (antóceros). Elas compõem o segundo maior grupo de plantas terrestres com aproximadamente 20.000 espécies. No Brasil são listadas cerca de 1.524, sendo a Mata Atlântica do Sudeste o centro de diversidade dessas plantas. Embora vários trabalhos já tenham sido publicados desde os anos de 1940, ainda há controversas sobre a presença de uma camada cuticular nas briófitas. Neste estudo, foram analisadas um total de 34 espécies pertencentes às divisões Marchantiophyta e Bryophyta descrevendo a morfologia da cera epicuticular, o teor e a composição química da cera cuticular para os gametófitos, alguns esporófitos e também para a caliptra, quando disponíveis. A micromorfologia das ceras na superfície dessas estruturas é bastante variável, sendo possível verificar a presença de filmes e cristais de cera. Entre as espécies de musgos e hepáticas, o teor de cera dos gametófitos variou de $0,02 \mu \mathrm{g} / \mathrm{cm}^{2}$ à $0,6 \mu \mathrm{g} / \mathrm{cm}^{2}$ e $0,1 \mu \mathrm{g} / \mathrm{cm}^{2}$ à $0,4 \mu \mathrm{g} / \mathrm{cm}^{2}$, respectivamente. A composição química das ceras cuticulares foi bastante diversificada, sendo identificadas 10 classes de componentes de cera: ácidos graxos, alcanos, alcenos, álcoois primários e secundários, aldeídos, cetonas, diácidos, ésteres e triterpenos. No geral, ácidos graxos e alcanos foram as classes mais comuns tanto nas espécies de Bryophyta como nas de Marchantiophyta. Três espécies de Polytrichaceae tiveram a cera do gametófito, esporófito (cápsula e seta) e caliptra analisadas separadamente. No gametófito e na caliptra o teor de cera obtido foi semelhante, variando de $0,2 \mu \mathrm{g} / \mathrm{cm}^{2}$ à $0,3 \mu \mathrm{g} / \mathrm{cm}^{2}$. No esporófito, observou-se uma distribuição não homogênea no conteúdo de cera, sendo, no geral, cerca de duas vezes maior na cápsula em relação a 
seta. Ésteres e aldeídos foram detectados apenas no esporófito e o álcool secundário nonacosan-10-ol foi encontrado em maiores porcentagens na caliptra e na cápsula. Para Lejeunea flava (Lejeuneaceae - Marchantiophyta) foi iniciada uma investigação sobre possível variação intraespecífica das ceras. Ainda que seja necessário investigações mais detalhadas, a amostra coletada em região urbanizada apresentou a maior diferença, considerando o teor total de ceras e das classes, quando comparada as amostras de regiões menos antropizadas. Entretanto, essa diferença não foi observada considerando-se a composição dos homólogos. No geral, não foram detectadas substâncias nunca antes descritas como componentes de ceras em embriófitas. Entretanto, algumas das substâncias estão sendo relatadas pela primeira vez em briófitas. Com isso, acreditamos que os resultados deste trabalho podem ampliar o nosso entendimento sobre a evolução da estrutura e das vias biossintéticas dos componentes da cutícula nas embriófitas, já presentes tanto no gametófito como no esporófito das linhagens basais de plantas terrestres. Por fim, esperamos que este estudo estimule mais trabalhos investigativos de diversidade química desse grupo, especialmente envolvendo espécies brasileiras.

Palavras-chave: briófitas, cutícula vegetal, evolução, lipídios de superfície. 


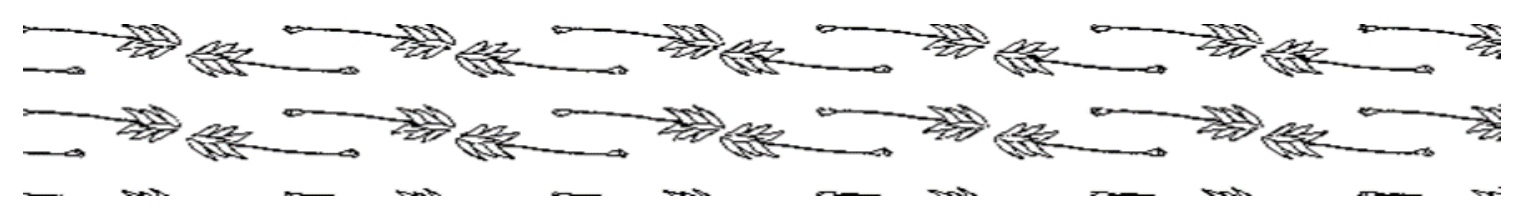

\section{ABSTRACT}

The transition of plants to the land environment took place approximately 450 million years ago. Among several evolutionary novelties, the emergence of a continuous lipophilic extracellular layer covering the aerial parts of plants, called plant cuticle, was crucial for the success of land plants, ensuring relative independence from the aquatic habitat. The cuticle is made up of the cutin which is surrounded by waxes and plays a multifunctional role in plants, mainly avoiding desiccation. "Bryophytes" are considered the pioneers in the transition from aquatic to land environment. This name is used to define three linages of avascular plants, cryptogams, with the gametophytic generation as dominant: Marchantiophyta (liverworts), Bryophyta (mosses) and Anthocerotophyta (hornworts). Bryophytes is the second largest group of land plants with approximately 20,000 species worldwide. In the Brazil, 1,524 have been described, with the southeast Atlantic Forest as the Brazilian center of diversity for these plants. Although several papers have already been published since the 1940's, there still have some controversy concerning the presence of a cuticular layer in the bryophytes. In this study, we described the morphology of the epicuticular wax, the total content, and the wax composition of the gametophytes of 34 species of Marchantiophyta and Bryophyta. Some sporophytes as well as the calyptra were also investigated when available. The micromorphology of the waxes was mainly detected as films, but some wax crystals were observed. The total amount of wax in under the gametophytes of mosses and liverworts varied from 0.02 $\mu \mathrm{g} / \mathrm{cm}^{2}$ to $0.6 \mu \mathrm{g} / \mathrm{cm}^{2}$ and $0.1 \mu \mathrm{g} / \mathrm{cm}^{2}$ to $0.4 \mu \mathrm{g} / \mathrm{cm}^{2}$, respectively. Ten classes of wax compounds were identified: aldehydes, alkanes, alkenes, diacids, esters, fatty acids, ketones, primary and secondary alcohols, and triterpenes. In general, fatty acids and alkanes were the most common classes in both Bryophyta and Marchantiophyta species. Three species of Polytrichaceae had the waxes from gametophyte, sporophyte (capsule and seta) and calyptra analyzed separately. The wax contents of the gametophyte and calyptra were similar, varying from $0.2 \mu \mathrm{g} / \mathrm{cm}^{2}$ to $0.3 \mu \mathrm{g} / \mathrm{cm}^{2}$. For the sporophyte, a nonhomogeneous wax layer was observed. The capsule content was twice higher than the seta one. Wax esters and aldehydes were detected only in the sporophyte, while the nonacosan-10-ol was found in higher percentages in the calyptra and capsule. For 
Lejeunea flava (Lejeuneaceae - Marchantiophyta) a preliminary study concerning wax intraspecific variation was initiated. Although more data are needed, considering total wax and classes amounts, the sample from urban region presented less similarity when compared to samples from less anthropized regions. However, this pattern was not observed when homologues composition was considered. In general, all compounds identified have already been described as wax component. Notwithstanding, some of these compounds were described for the first time in bryophytes. Therefore, we believe that the results of this work can expand our knowledge of the cuticle structure, found in both gametophyte and sporophyte of the basal lineages of terrestrial plants. Finally, we hope that this study encourage new research on the chemical diversity of bryophytes, especially involving Brazilian species.

Keywords: bryophytes, cuticle, evolution, surface lipids. 